\title{
IntechOpen
}

\section{Concepts of Semiconductor Photocatalysis}

Edited by Mohammed Rahman, Anish Khan, Abdullah Asiri and Inamuddin Inamuddin 



\section{Concepts of Semiconductor Photocatalysis}

Edited by Mohammed Rahman, Anish Khan, Abdullah Asiri and Inamuddin Inamuddin 

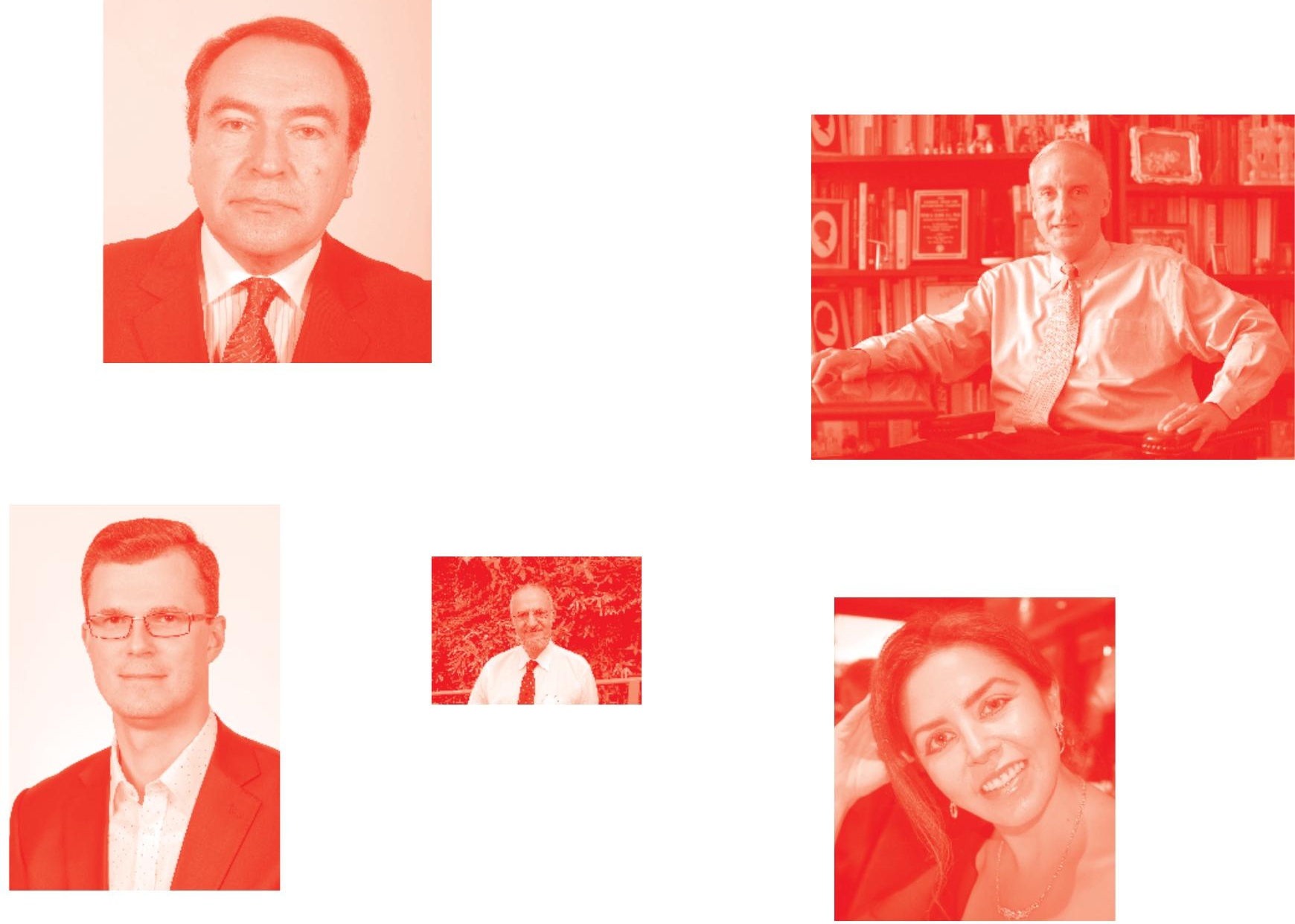

Supporting open minds since 2005
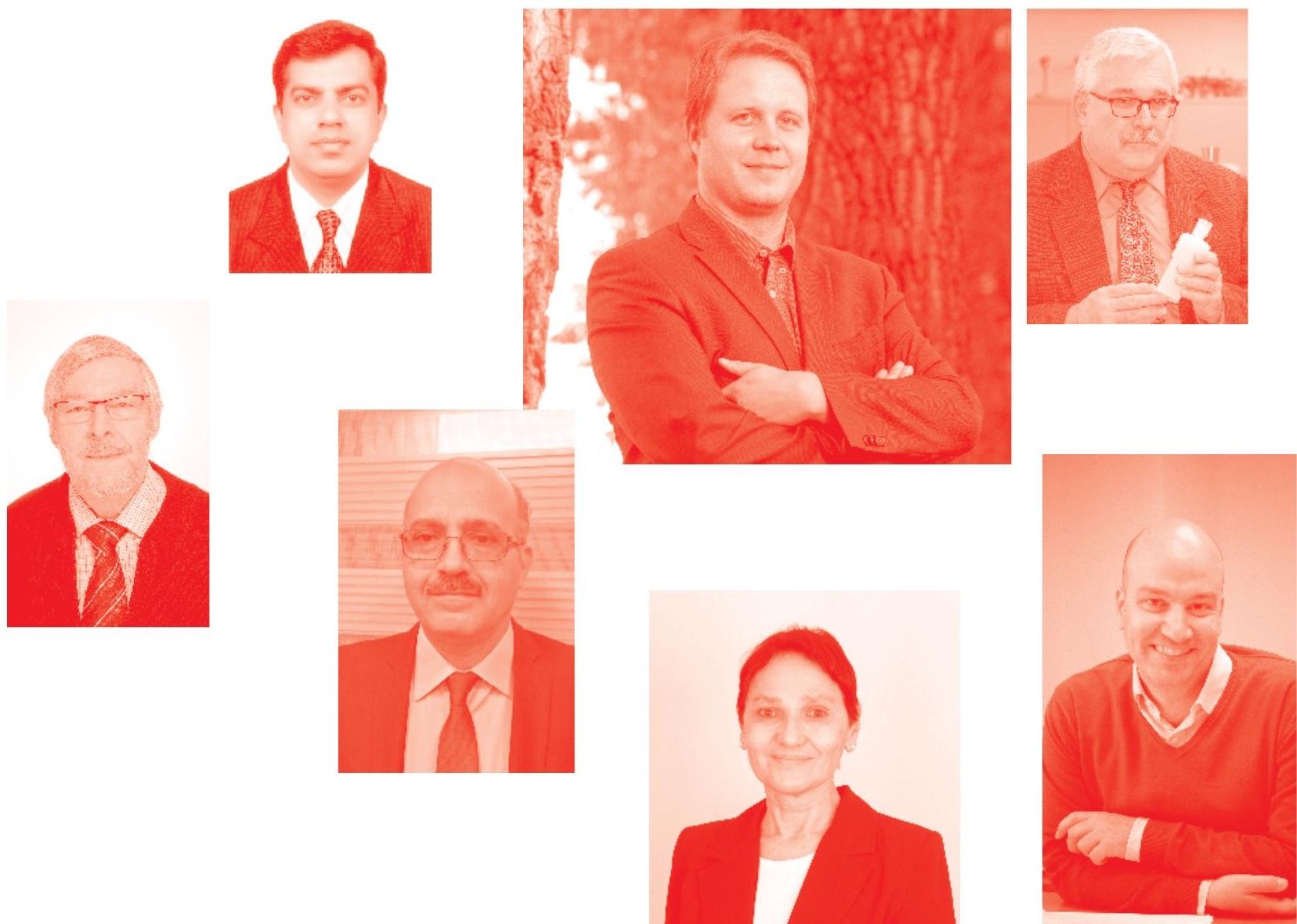
Concepts of Semiconductor Photocatalysis

http : //dx . doi . org/10.5772/intechopen. 77477

Edited by Mohammed Rahman, Anish Khan, Abdullah Asiri and Inamuddin Inamuddin

\section{Contributors}

Naorem Khelchand Singh, Rajshree Rajkumari, Keyla M. Fuentes, Sara Aldabe Bilmes, Margarita SanchezDominguez, Sahar Zinatloo_Ajabshir, Zahra Sayyar, Jamshaid Rashid, Fatima Imtiaz, Ming Xu, Yuichi Negishi, Wataru Kurashige, Sakiat Hossain, Marika Aoki, Seiichiro Watanabe, Manuel Alberto FloresHidalgo, Diana Barraza-Jimenez, Sandra Iliana Torres-Herrera, Elva Marcela Coria-Quiñones, Raúl Armando Olvera-Corral, David José Romero-Soto, Adolfo Ruiz Soto, Mohammed Muzibur Rahman

๑) The Editor(s) and the Author(s) 2019

The rights of the editor(s) and the author(s) have been asserted in accordance with the Copyright, Designs and Patents Act 1988. All rights to the book as a whole are reserved by INTECHOPEN LIMITED . The book as a whole (compilation) cannot be reproduced, distributed or used for commercial or non-commercial purposes without INTECHOPEN LIMITED's written permission. Enquiries concerning the use of the book should be directed to INTECHOPEN LIMITED rights and permissions department (permissions@intechopen.com).

Violations are liable to prosecution under the governing Copyright Law .

\section{(cc) BY}

Individual chapters of this publication are distributed under the terms of the Creative Commons Attribution 3.0 Unported License which permits commercial use, distribution and reproduction of the individual chapters, provided the original author(s) and source publication are appropriately acknowledged. If so indicated, certain images may not be included under the Creative Commons license. In such cases users will need to obtain permission from the license holder to reproduce the material. More details and guidelines concerning content reuse and adaptation can be found at http : //www . intechopen . com/copyright-policy . html.

\section{Notice}

Statements and opinions expressed in the chapters are these of the individual contributors and not necessarily those of the editors or publisher. No responsibility is accepted for the accuracy of information contained in the published chapters. The publisher assumes no responsibility for any damage or injury to persons or property arising out of the use of any materials, instructions, methods or ideas contained in the book.

First published in London, United Kingdom, 2019 by IntechOpen IntechOpen is the global imprint of INTECHOPEN LIMITED, registered in England and Wales, registration number: 11086078, 7th floor, 10 Lower Thames Street, London, EC3R 6AF, United Kingdom

Printed in Croatia

British Library Cataloguing-in-Publication Data

A catalogue record for this book is available from the British Library

Additional hard and PDF copies can be obtained from orders@intechopen.com

Concepts of Semiconductor Photocatalysis

Edited by Mohammed Rahman, Anish Khan, Abdullah Asiri and Inamuddin Inamuddin

p. cm.

Print ISBN 978-1-78985- $087-1$

Online ISBN 978-1-78985- $088-8$

eBook (PDF) ISBN 978-1-83968-245-2 


\section{We are IntechOpen, \\ the world's leading publisher of Open Access books}

\section{Built by scientists, for scientists}

\section{$4,500+$}

Open access books available

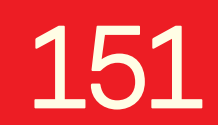

Countries delivered to

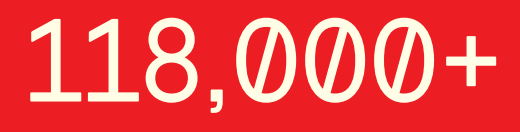

International authors and editors
$130 \mathrm{M}+$

Downloads

Our authors are among the

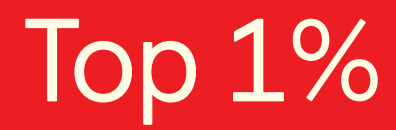

most cited scientists

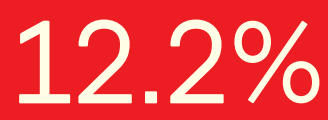

Contributors from top 500 universities

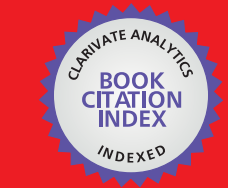

WEB OF SCIENCE ${ }^{\text {MM }}$

Selection of our books indexed in the Book Citation Index in Web of Science ${ }^{\mathrm{TM}}$ Core Collection (BKCI)

\section{Interested in publishing with us? \\ Contact book.department@intechopen.com}

Numbers displayed above are based on latest data collected.

For more information visit www.intechopen.com 



\section{Meet the editors}

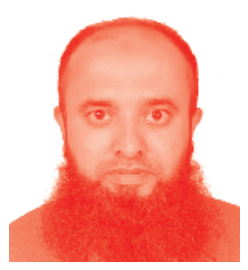

Mohammed Muzibur Rahman: He received his B.Sc. and M.Sc. from Shahjalal University of Science \& Technology, Sylhet, Bangladesh in 1999 and 2001 respectively. He received his Ph.D. from the Chonbuk National University, South Korea, in 2007. After his Ph.D., he worked in a postdoctoral fellowship and as an Assistant Professor in pioneer research centers and universities located in South Korea, Japan, and Saudi Arabia (2007 to 2011). Presently, he is working as an Associate Professor in the Center of Excellence for Advanced Materials Research (CEAMR) and the Chemistry Department at King Abdulaziz University, Saudi Arabia since 2011. He has published more than 250 papers for international and domestic conferences, published several book chapters, and edited ten books. His research work has been largely in the area of photocatalysis, semiconductor, nanoparticles, carbon nanotubes, nanotechnology, electrocatalysis, sensors, ionic liquid, surface chemistry, gold nanoparticles, electrochemistry, instrumental science, nanomaterials, self-assembled monolayers, photochemistry, m-chips, and devices etc.

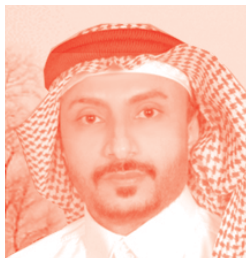

Abdullah Mohamed Asiri: He received his $\mathrm{PhD}$ from the University of Wales, College of Cardiff, UK in 1995. He has been the Head of the Chemistry Department at King Abdulaziz University since October 2009 and he is the founder and the Director of the Center of Excellence for Advanced Materials Research (CEAMR). He is a Professor of Organic Photochemistry. His research interests cover color chemistry, synthesis of novel photochromic and thermochromic systems, synthesis of novel coloring matters and dyeing of textiles, materials chemistry, nanochemistry, nanotechnology, polymers, and plastics. He is the Editor-in-Chief of King Abdul Aziz University Journal of Science. He is also a member of the Editorial Board of Pigments and Resin Technology (UK), Organic Chemistry in Sight (New Zealand), and Recent Patents on Materials Science (USA). He is the Vice-President of the Saudi Chemical Society (Western Province Branch).

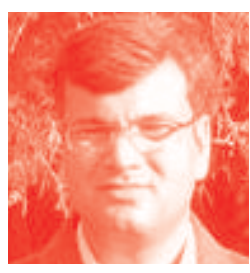

Dr. Inamuddin: He is currently working as an Assistant Professor in the Chemistry Department, Faculty of Science, King Abdulaziz University, Jeddah, Saudi Arabia. He has extensive research experience in the multidisciplinary fields of analytical chemistry, materials chemistry, and electrochemistry and, more specifically, renewable energy and the environment. He has published 127 research articles in international journals of repute and eighteen book chapters in knowledge-based book editions published by renowned international publishers. He has published thirty-nine edited books with Springer, United Kingdom, Elsevier, Nova Science Publishers, Inc. U.S.A., CRC Press Taylor \& Francis Asia Pacific, Trans Tech Publications Ltd., Switzerland, 
and Materials Science Forum, U.S.A. He is a member of various editorial boards of journals and serves as an associate editor for journals such as Environmental Chemistry Letter, Applied Water Science, Euro-Mediterranean Journal for Environmental Integration, Springer-Nature, editorial board member for Scientific Reports-Nature and editor for Eurasian Journal of Analytical Chemistry.

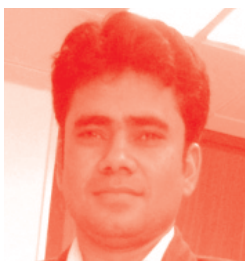

Dr. Anish Khan : He is currently working as an Assistant Professor, Chemistry Department, Centre of Excellence for Advanced Materials Research (CEAMR), Faculty of Science, King Abdulaziz University, Jeddah, Saudi Arabia. He received his Ph.D. from Aligarh Muslim University, India in 2010. He has research experience in the field of synthetic polymers and organic-inorganic electrically conducting nano-composites. He completed his postdoctoral studies from the School of Chemical Sciences, University Sains Malaysia (USM) in electroanalytical chemistry in 2010-2011. He has research and teaching experience and has published more than 127 research papers in international journals. He has attended more than 20 international conferences and workshops and has published 5 books with 14 books currently in progress and 14 book chapters. Preparation and characterization of hybrid nano composite materials and their applications, Polymeric inorganic cation -exchange materials, Electrically conducting polymeric, materials, Composite material use as Sensors, Green chemistry by remediation of pollution, Heavy metal ion selective membrane electrode, Biosensor on neurotransmitter. 


\section{Contents}

Preface

Chapter 1

Introductory Chapter: Fundamentals of Semiconductor Photocatalysis

by Mohammed Muzibur Rahman

Chapter 2

Semiconductor Nanocomposites for Visible Light Photocatalysis of Water Pollutants

by Fatima Imtiaz, Jamshaid Rashid and Ming Xu

Chapter 3

$\mathrm{TiO}_{2}$ Nanoparticles Supported on Hierarchical Meso/Macroporous $\mathrm{SiO}_{2}$

Spheres for Photocatalytic Applications

by Keyla M. Fuentes, Margarita Sánchez-Dominguez and Sara A. Bilmes

Chapter 4

Toward the Creation of Highly Active Photocatalysts That Convert Methane into Methanol

by Yuichi Negishi, Seiichiro Watanabe, Marika Aoki, Sakiat Hossain and Wataru Kurashige

Chapter 5

Rare-Earth-Based Materials for Heterogeneous Photocatalysis

by Sahar Zinatloo-Ajabshir and Zahra Sayyar

Chapter 6

Radiative Transference Equation Algorithm as an ANSYS® User-Defined Function for Solar Technology Applications

by Diana Barraza-Jiménez, Adolfo Ruiz-Soto, Sandra Iliana Torres-Herrera, Elva Marcela Coria-Quiñones, Raúl Armando Olvera-Corral,

David José Romero-Soto and Manuel Alberto Flores-Hidalgo

Chapter 7

Effect of Annealing on Metal-Oxide Nanocluster

by Naorem Khelchand Singh and Rajshree Rajkumari 



\section{Preface}

This book "Concepts of Semiconductor Photocatalysis" contains recent research on the preparation, characterization, and potential applications of the photocatalyst. The book includes information on solar exposure of the photocatalyst to ultraviolet light, which affects redox reactions, degradation, molecular transformations, as well as colored material mineralization. The development of new and efficient technology is pointing researchers toward the safe, facile, non-toxic, and eco-friendly route of synthesis-to-applications, which can be used for manufacture at a large scale. This is a simple, cost-effective, stable for a long time, and reproducible aqueous room temperature synthesis method to obtain an efficient semiconductor photocatalyst. This potentially unique work offers various approaches on R\&D with semiconductor photocatalyst materials in an aqueous or non-aqueous phase through fully modified or unmodified states. We know, recently the nanotechnology offer the regulating of semiconductor substances at the nano-scale and nano-dimensional substances in few nano-meters, which exclusive phenomenon facilitates us to control the novel catalytic applications with photocatalysts. Photocatalysis reactions performed in the presence of a low-dimensional semiconductor and light are rapidly becoming one of the most dynamic areas of catalysis research, with potential applications in areas such as environmental, solar, renewable energy, medicine, and nanomaterials. This was investigated in this book using the techniques of photocatalyst preparation, various types of characterization, and possible industrial applications related to solar photocatalyst research.

Mohammed Muzibur Rahman

Center of Excellence for Advanced Materials Research (CEAMR) and Chemistry Department, Faculty of Science, King Abdulaziz University, Jeddah, Saudi Arabia 



\title{
Introductory Chapter: Fundamentals of Semiconductor Photocatalysis
}

\author{
Mohammed Muzibur Rahman
}

\section{Introduction}

In semiconductor photo-catalysis, generally it is used to design, characterize, and potential photocatalytical applications with doped or undoped nanostructural materials especially considering their particle sizes as well as shapes.

Nanostructured materials, for example, porous metal oxides, metal nanoparticles, porous carbons, and their composites are widely studied for their potential applications in energy conversion/storage devices, gas storage, photocatalysis as well as in electrocatalysis. Photocatalysis is the phenomena, which occurs in catalysis by influence of photons. An efficient photocatalyst is a conductive nanomaterial, which directly absorbs incident light to bring up to higher energy states, which provides such energy to a reacting substance to make a chemical reaction occur. The mechanism of photocatalytic water splitting over semiconductor photocatalysts is also discussed in this chapter. Thermodynamically, the reaction of complete water splitting under normal conditions is a highly endothermic process because the change in the standard Gibbs energy is very large.

\section{Literature review}

For photocatalytic applications, the location of the $\mathrm{TiO}_{2}$ nanoparticle plays an important role in the photoactivity, since various nanoparticles should be accessible for both photons and reactive molecules. The advantages of using these materials as support for $\mathrm{TiO}_{2}$ in relation to photocatalytic processes are addressed by comparing the photocatalytic activity of $\mathrm{TiO}_{2}$ nanoparticles deposited by different routes with $\mathrm{TiO}_{2}$ nanoparticles on mesoporous materials [1-3]. Three-dimensional nanostructures have interconnected networks of bulk materials and larger accessible surface areas with respect to their lower dimensional counterparts. The surface functionalities, controllable host-guest interactions, and size-selective sensing properties are enabled due to the spatial arrangement of particles within three-dimensional framework [4-15].

Here, catalysts based on Ti-containing mesoporous silica have been developed from different synthetic pathways for selective oxidation of bulky organic compounds and photoreduction of greenhouse gases [16-18]. To support particles of $\mathrm{TiO}_{2}$ on mesoporous silica, maintaining or improving its photocatalytic activity is not an easy task as, in addition to be strongly attached to the substrate for avoiding leakage, nanoparticles' size, location, and agglomeration should be controlled to have accessibility for adsorbates and incident photons [19-22]. Nanostructure of 
rare earth material is appropriate for these applications that can be synthesized with different methods, for example co-precipitation, hydrothermal, sol-gel, combustion, stearic acid route, pechini, cathode plasma, electrolysis, co-ions complexation, molten salt, and other approaches [13]. Rare-earth-based materials were used in different fields. In this section, we study a brief review of rare-earth-doped materials, rare-earth-based oxide-oxide composites, metal-modified semiconductors, and mixed-oxide materials in the fields of photocatalytic application as solar energy generation. When a photon is absorbed by rare-earth-based material using the energy gap of the materials, electron-hole pairs are generated in the photocatalysis mechanism [23-27]. Semiconductor photocatalysis can be of two types, homogenous photocatalysis and heterogeneous photocatalysis, depending on the phase differences of reactants and catalysts, which triggered the concept of advanced oxidation processes at the end of twentieth century. $\mathrm{TiO}_{2}$ is the semiconductor, which can act as both the hetero- and homogenous photocatalyst photoreactions. There are numerous semiconductors, which can be coupled with other semiconductors and can be incorporated into heterostructures or composites. So, another example of inorganic heterostructure is the template-free simple synthesis of CdS- $\mathrm{ZnO}$ nanocomposites. This self-assembled flower-like structure resulted from coupling of two semiconductors, which increased the charge separation and demonstrated greater photocatalytic activity [28, 29].

Negheshi et al. attempted to improve the activity of mesoporous tungsten trioxide, and titanium dioxide $\left(\mathrm{m}-\mathrm{WO}_{3}\right.$ and $\left.\mathrm{m}-\mathrm{TiO}_{2}\right)$ photocatalysts, which convert methane into methanol, by loading the ultrafine metal clusters as co-catalyst on the photocatalysts. They have succeeded in loading ultrafine metal-cluster co-catalysts onto $\mathrm{m}-\mathrm{WO}_{3}$ and $\mathrm{m}-\mathrm{TiO}_{2}$, and thereby improving their photocatalytic activity in presence of mesoporous nanomaterials. The photocatalytic activity measurements clearly demonstrated that the loading of such co-catalysts is effective in improving the activity for both types of photocatalysts. It is important to appropriately select the element of the co-catalyst according to the photocatalyst to improve the photocatalytic activity. In this approach, the particle diameter of the co-catalyst was reduced to approximately $1.0 \mathrm{~nm}$ to increase the reactive surface area [29-32]. Textile dyes and other industrial dyestuffs constitute one of the largest groups of organic compounds that signify enhancing environmental pollution.

Contaminated water means undesirable substances; it adversely affects the quality and makes it inappropriate for use. Various sources such as residential, commercial, industrial practices, etc. contaminate the water and its sources as well. Wastewater parameters vary widely and depend on the source it is produced form. They are usually pathogenic, nonpathogenic microorganisms, organic, or inorganic $[33,34]$. The toxic and carcinogenic nature of these dyes and their manufacturing precursors represent a danger to human beings and perturbation in aquatic life. The enlarged public concern about these environmental pollutants and the creation of international environmental standards have prompted the need for the development of novel treatment methods for converting organic pollutants (such as dye effluents) to harmless compounds. Reductive cleavage via anaerobic biological treatment generates potentially carcinogenic intermediates or end products, especially aromatic amines. Physical processes are like reverse osmosis, flocculation, absorption, air-stripping, combustion, and aerobic biological oxidation, which are nondestructive, and these processes only shift the pollutants from one medium to others, thus creating secondary pollution [35-38]. For the past two decades, a lot of research is going on for advanced oxidation processes, pointing out its potential vital role in the wastewater purification, in which the high oxidizing potential species like hydroxyl radicals are utilized as an alternative way of treating undesirable organic pollutants. Advanced oxidation processes shows great effort in solving the 
bio-recalcitrant water-pollutant issues at near-ambient temperature and pressure [39-41]. Heterogeneous photocatalysis is a method wherein a blend of photochemistry and catalysis is operable and suggests that light and catalyst are necessary to bring out a chemical reaction. Lately, there has been a developing enthusiasm in usage of semiconductors as photosensitizers for the complete oxidative mineralization of pollutants by oxygen $[42,43]$. Heterogeneously scattered semiconductor surfaces give both a fixed situation to impact the chemical reactivity of a wide scope of adsorbates and a means to initiate light-induced redox reactivity in these feebly related molecules.

When a semiconductor is intact with an aqueous solution, thermodynamic equilibration takes place at the interface. This may result in the development of a space-charge layer inside a slight surface area of the semiconductor, in which the electronic vitality bands are commonly twisted downward or upward, respectively, in the instances of $\mathrm{p}$ - and $\mathrm{n}$-type semiconductors. The space-charge layer thickness is typically in the range of $1-10^{3} \mathrm{~nm}$, contingent upon the dielectric constant and carrier density of the semiconductor. If this semiconductor perceives photons with energies that are more noteworthy than that of the respective material's band gap energy, electron-hole pairs are produced and parted in the space-charge layer. The development of new and noble nanotechnology is urgently required for introducing the eco-friendly, safe, facile, non-toxic routes in synthesis-to-applications, which can be used by industrial sectors in broad scale.

Recently, the nanotechnology offers the control growth of semiconductor substances at the nanoscale, which exclusively facilitates the novel photocatalytic applications with transition doped semiconductor catalysts. Photocatalysis, reactions supported out in the presence of a low-dimensional semiconductor and light, is rapidly becoming one of the most dynamic areas of catalysis research, with potential applications in areas such as environmental, solar, renewable energy, medicine, and sensors [44-47]. Here, in this book, it presents an overview of current photocatalyst fundamental, substantial applications, and enactment of the research in worldwide. This investigated the techniques of photocatalyst preparation, various types of characterization, and possible industrial applications related to solar photocatalyst researches.

\title{
Author details
}

\author{
Mohammed Muzibur Rahman \\ Center of Excellence for Advanced Materials Research (CEAMR) and Chemistry \\ Department, Faculty of Science, King Abdulaziz University, Jeddah, Saudi Arabia
}

*Address all correspondence to: mmrahmanh@gmail.com

\section{IntechOpen}

(C) 2019 The Author(s). Licensee IntechOpen. This chapter is distributed under the terms of the Creative Commons Attribution License (http://creativecommons.org/licenses/ by/3.0), which permits unrestricted use, distribution, and reproduction in any medium, provided the original work is properly cited. (cc) BY 


\section{References}

[1] Gustafsson H, Isaksson S, Altskär A, Holmberg K. Mesoporous silica nanoparticles with controllable morphology prepared from oil-in-water emulsions. Journal of Colloid and Interface Science. 2016;467:253-260

[2] Subhan MA, Jhuma SS, Saha PC, Alam MM, Asiri AM, Al-Mamun M, et al. Efficient selective 4-aminophenol sensing and antibacterial activity of ternary $\mathrm{Ag}_{2} \mathrm{O}_{3} \cdot \mathrm{SnO}_{2} \cdot \mathrm{Cr}_{2} \mathrm{O}_{3}$ nanoparticles. New Journal of Chemistry. 2019;43:10352-10365

[3] Wahid A, Asiri AM, Rahman MM. One-step facile synthesis of $\mathrm{Nd}_{2} \mathrm{O}_{3}$ / $\mathrm{ZnO}$ nanorods for an efficient selective 2,4-dinitrophenol sensor probe. Applied Surface Science. 2019;487:1253-1261

[4] Rahman MM, Sheikh TA, Asiri AM, Awual MR. Development of 3-methoxyanaline sensor probe based on thin $\mathrm{Ag}_{2} \mathrm{O} @ \mathrm{La}_{2} \mathrm{O}_{3}$ nanosheets for environmental safety. New Journal of Chemistry. 2019;43:4620-4632

[5] Rahman MM, Wahid A, Alam MM, Asiri AM. Efficient 4-Nitrophenol sensor development based on facile $\mathrm{Ag} @ \mathrm{Nd}_{2} \mathrm{O}_{3}$ nanoparticles. Materials Today Communications. 2018;16:307-313

[6] Rahman MM, Alam MM, Asiri AM. Sensitive 1,2-dichlorobenzene chemisensor development based on solvothermally prepared $\mathrm{FeO} / \mathrm{CdO}$ nanocubes for environmental safety. Journal of Industrial and Engineering Chemistry. 2018;62:392-400

[7] Rahman MM. A label-free kanamycin sensor development based on CuO-NiO hollow-spheres: Food samples analyses. Sensors \& Actuators: B Chemical. 2018;264:84-91

[8] Rahman MM, Alam MM, Asiri AM. 2-Nitrophenol sensor-based wet-chemically prepared binary doped $\mathrm{Co}_{3} \mathrm{O}_{4} / \mathrm{Al}_{2} \mathrm{O}_{3}$ nanosheets by an electrochemical approach. RSC Advances. 2018;8:960-970

[9] Rahman MM, Ahmed J, Asiri AM. Thiourea sensor development based on hydrothermally prepared CMO nanoparticles for environmental safety. Biosensors and Bioelectronics. 2018;99:586-592

[10] Ahmed J, Rahman MM, Siddiquey IA, Asiri AM, Hasnat MA. Efficient hydroquinone sensor based on zinc, strontium and nickel based ternary metal oxide (TMO) composites by differential pulse voltammetry. Sensors and Actuators B: Chemical. 2018;256:383-392

[11] Hu Y, Martra G, Zhang J, Higashimoto S, Coluccia S, Anpo M. Characterization of the local structures of Ti-MCM-41 and their photocatalytic reactivity for the decomposition of $\mathrm{NO}$ into $\mathrm{N}_{2}$ and $\mathrm{O}_{2}$. The Journal of Physical Chemistry. B. 2006;110:1680-1685

[12] Li J, Zhou C, Xie H, Ge Z, Yuan L, Li X. Titanium-containing mesoporous materials: Synthesis and application in selective catalytic oxidation. Journal of Natural Gas Chemistry. 2006;15:164-177

[13] Hossain MA, Elias M, Sarker DR, Diba ZR, Mithun JM, Azad MAK, et al. Synthesis of $\mathrm{Fe}$ - or $\mathrm{Ag}$-doped $\mathrm{TiO}_{2-}$ MWCNT nanocomposite thin films and their visible-light-induced catalysis of dye degradation and antibacterial activity. Research on Chemical Intermediates. 2018;44:2667-2683

[14] Rahman MM, Asiri AM, YoussefTE, Marwani HM. Photocatalytic degradation of Remazol Brilliant Orange 3R using wet-chemically prepared $\mathrm{CdO}-\mathrm{ZnO}$ nanofibers for environmental remediation. Material Express. 2016;6:137-148 
[15] Zinatloo-Ajabshir S,

Salavati-Niasari M, Sobhani A, Zinatloo-Ajabshir Z. Rare earth zirconate nanostructures: Recent development on preparation and photocatalytic applications. Journal of Alloys and Compounds. 2018;767:1164-1185

[16] Liu Y, Deng Y, Sun Z, Wei J, Zheng G, Asiri AM, et al. Hierarchical $\mathrm{Cu}_{2} \mathrm{~S}$ microsponges constructed from nanosheets for efficient photocatalysis. Small. 2013;9:2702-2708

[17] Jamal A, Rahman MM, Khan SB, Faisal M, Asiri AM, Khan AAP, et al. Hydrothermally preparation and characterization of un-doped manganese oxide nanostructures: Efficient photocatalysis and chemical sensing applications. Micro and Nanosystems. 2013;5:22-28

[18] Ahmed J, Rahman MM, Siddiquey IA, Asiri AM, Hasnat MA. Efficient bisphenol-A detection based on the ternary metal oxide (TMO) composites by electrochemical approaches. Electrochimica Acta. 2017;246:597-605

[19] Rahman MM, Ahmed J. Cd-doped $\mathrm{Sb}_{2} \mathrm{O}_{4}$ nanostructures modified glassy carbon electrode for efficient detection of melamine by electrochemical approach. Biosensors and Bioelectronics. 2018;102:631-636

[20] Subhan MA, Saha PC, Rahman MM, Ahmed J, Asiri AM, Al-Mamun M. Fabrication of a 2,4-dinitrophenol sensor based on $\mathrm{Fe}_{3} \mathrm{O}_{4} @ \mathrm{Ag} @ \mathrm{Ni}$ nanomaterials and studies of their antibacterial properties. New Journal of Chemistry. 2018;42:872-881

[21] Alam MM, Asiri AM, Uddin MT, Inamuddin MAI, Awual MR, Rahman MM. One-step wet-chemical synthesis of ternary $\mathrm{ZnO} / \mathrm{CuO} /$ $\mathrm{Co}_{3} \mathrm{O}_{4}$ nanoparticles for sensitive and selective melamine sensor development.
New Journal of Chemistry. 2019;43:4849-4858

[22] Rahman MM, Alam MM, Asiri AM. Efficient phenolic sensor development based on facile $\mathrm{Ag}_{2} \mathrm{O} /$ $\mathrm{Sb}_{2} \mathrm{O}_{3}$ nanoparticles for environmental safety. Nanoscale Advances. 2019;1:696-705

[23] Hussein MA, Alam MM, Alenazi NA, Alamry KA, Asiri AM, Rahman MM. Nanocomposite based functionalized polyethersulfone and conjugated ternary $\mathrm{ZnYCdO}$ nanomaterials for the fabrication of selective $\mathrm{Cd}^{2+}$ sensor probe. Journal of Polymer Research. 2018;25:262

[24] Sheikh TA, Rahman MM, Asiri AM, Marwani HM, Awual MR. 4-Hexylresorcinol sensor development based on wet-chemically prepared $\mathrm{Co}_{3} \mathrm{O}_{4} @ \mathrm{Er}_{2} \mathrm{O}_{3}$ nanorods: A practical approach. Journal of Industrial \& Engineering Chemistry. 2018;66:446-455

[25] Rahman MM, Alam MM, Asiri AM. Selective hydrazine sensor fabrication with facile low-dimensional $\mathrm{Fe}_{2} \mathrm{O}_{3} / \mathrm{CeO}_{2}$ nanocubes. New Journal of Chemistry. 2018;42:10263-10270

[26] Awual MR, Hasan MM, Islam A, Rahman MM, Asiri AM, Khaleque MA, et al. Offering an innovative composited material for effective lead(II) monitoring and removal from polluted water. Journal of Cleaner Production. 2019;231:214-223

[27] Awual MR, Hasan MM, Asiri AM, Rahman MM. Cleaning the arsenic(V) contaminated water for safe-guarding the public health using novel composite material. Composites Part B: Engineering. 2019;171:294-301

[28] Awual MR, Hasan MM, Islam A, Rahman MM, Asiri AM, Khaleque MA, et al. Introducing an amine functionalized novel conjugate 
material for toxic nitrite detection and adsorption from wastewater. Journal of Cleaner Production. 2019;228:778-785

[29] Awual MR, Islam A, Hasan MM, Rahman MM, Asiri AM, Khaleque MA, et al. Introducing an alternate conjugated material for enhanced lead(II) capturing from wastewater. Journal of Cleaner Production. 2019;224:920-929

[30] Awual MR, Hasan MM, Rahman MM, Asiri AM. Novel composite material for selective copper(II) detection and removal from aqueous media. Journal of Molecular Liquids. 2019;283:772-780

[31] Awual MR, Hasan MM, Asiri AM, Rahman MM. Novel optical composite material for efficient vanadium(III) capturing from wastewater. Journal of Molecular Liquids. 2019;283:704-712

[32] Rao GV, Sree GS, Mohan BS, Anjaneyulu RB. A simple and green synthesis of Zinc oxide nanoparticles using Gloriosa superba leaves extract. International Journal of Green and Herbal Chemistry. 2018;7(2):373-378

[33] Robertson P. Semiconductor photocatalysis: An environmentally acceptable alternative production technique and effluent treatment process. Journal of Cleaner Production. 1996;1996(4):203

[34] Turchi CS, Ollis DF. Photocatalytic degradation of organic water contaminants: Mechanisms involving hydroxyl radical attack. Journal of Catalysis. 1990;122:178

[35] Awual MR, Khraisheh M, Alharthi NH, Luqman M, Islam A, Karim MR, et al. Efficient detection and adsorption of cadmium(II) ions using innovative nano-composite materials. Chemical Engineering Journal. 2018;343:118-127
[36] Awual MR, Alharthi NH, Hasan MM, Karim MR, Islam A, $\mathrm{Znad} \mathrm{H}$, et al. Inorganic-organic based novel nano-conjugate material for effective cobalt(II) ions capturing from wastewater. Chemical Engineering Journal. 2017;324:130-139

[37] Awual MR, Hasan MM, Eldesoky GE, Khaleque MA, Rahman MM, Naushad M. Facile mercury detection and removal from aqueous media involving ligand impregnated conjugate nanomaterials. Chemical Engineering Journal. 2016;290:243-251

[38] Katowah DF, Rahman MM, Hussein MA, Sobahi TR, Gabal MA, Alam MM, et al. Ternary Nanocomposite based poly (pyrroleco-O-toluidine), cobalt ferrite and decorated chitosan as a selective $\mathrm{Co}^{2+}$ cationic sensor. Composites Part B: Engineering. 2019;175:107175

[39] Rahman MM, Alam MM, Alamry KA. Sensitive and selective m-Tolylhydrazine sensor development based on $\mathrm{CdO}$ nanoparticles decorated multi-walled carbon nanotubes. Journal of Industrial and Engineering Chemistry. 2019;77:309-316

[40] Rahman MM, Hussain MM, Arshad MN, Awual MR, Asiri AM. Arsenic sensor development based on modified with (E)- $\mathrm{N}^{\prime}$-(2-nitrobenzylidine)benzenesulfonohydrazide: A real sample analysis. New Journal of Chemistry. 2019;43:9066-9075

[41] Abdu-Zied BM, Alam MM, Asiri AM, Schwieger W, Rahman MM. Fabrication of 1,2-dichlorobenzene sensor based on mesoporous MCM-41 material. Colloids and Surfaces A: Physicochemical and Engineering Aspects. 2019;562:161-169

[42] Karim MR, Alam MM, Aijaz MO, Asiri AM, Dar MA, Rahman MM. Fabrication of 1,4-dioxane sensor 
based on microwave assisted PAni$\mathrm{SiO}_{2}$ nanocomposites. Talanta. 2019;193:64-69

[43] Alam MK, Rahman MM, Rahman MM, Kim D, Asiri AM, Khan FA. In-situ synthesis of gold nanocrystals anchored graphene oxide and its application in biosensor and chemical sensor. Journal of Electroanalytical Chemistry. 2019;835:329-337

[44] Rahman MM, Alam MM, Asiri AM. Carbon black co-adsorbed $\mathrm{ZnO}$ nanocomposites for selective benzaldehyde sensor development by electrochemical approach for environmental safety. Journal of Industrial and Engineering Chemistry. 2018;65:300-308

[45] El-Shishtawy RM, Al-Ghamdi HA, Alam MM, Al-Amshany ZM, Asiri AM, Rahman MM. Development of $\mathrm{Cd}^{2+}$ sensor based on BZNA/nafion/glassy carbon electrode by electrochemical approach. Chemical Engineering Journal. 2018;352:225-231

[46] Hussain MM, Asiri AM, Arshad MN, Rahman MM. Fabrication of $\mathrm{a} \mathrm{Ga}^{3+}$ sensor probe based on methoxy benzylidene benzene sulfo no hydrazine (MBBSH) by an electrochemical approach. New Journal of Chemistry. 2018;42:1169-1180

[47] Rahman MM, Alam MM, Asiri AM, Islam MA. 3,4-Diaminotoluene sensor development based on hydrothermally prepared $\mathrm{MnCo}_{\mathrm{x}} \mathrm{O}_{\mathrm{y}}$ nanoparticles. Talanta. 2018;176:17-25 



\title{
Semiconductor Nanocomposites for Visible Light Photocatalysis of Water Pollutants
}

\author{
Fatima Imtiaz, Jamshaid Rashid and Ming Xu
}

\begin{abstract}
Semiconductor photocatalysis gained reputation in the early 1970s when Fujishima and Honda revealed the potential of $\mathrm{TiO}_{2}$ to split water in to hydrogen and oxygen in a photoelectrochemical cell. Their work provided the base for the development of semiconductor photocatalysis for the environmental remediation and energy applications. Photoactivity of some semiconductors was found to be low due to larger band gap energy and higher electron-hole pair recombination rate. To avoid these problems, the development of visible light responsive photocatalytic materials by different approaches, such as metal and/or non-metal doping, codoping, coupling of semiconductors, composites and heterojunctions materials synthesis has been widely investigated and explored in systematic manner. This chapter emphasizes on the different type of tailored photocatalyst materials having the enhanced visible light absorption properties, lower band gap energy and recombination rate of electron-hole pairs and production of reactive radical species. Visible light active semiconductors for the environmental remediation purposes, particularly for water treatment and disinfection are also discussed in detail. Studies on the photocatalytic degradation of emerging organic compounds like cyanotoxins, VOCs, phenols, pharmaceuticals, etc., by employing variety of modified semiconductors, are summarized, and a mechanistic aspects of the photocatalysis has been discussed.
\end{abstract}

Keywords: visible light photocatalysis, semiconductor composites, organic pollutants, mechanism, wastewater treatment

\section{Introduction to photocatalysis}

Catalysis refers to a phenomenon in which a substance (the catalyst) speed up a kinetically slow reaction and the catalyst is fully restored at the end of each catalytic cycle and the "Photocatalysis" is defined as a specific process for the acceleration of the "photoreaction" in the presence of a catalyst [1]. Photocatalysis can also be regarded as the catalysis of photochemical reaction on a solid substrate, mostly a semiconductor [2]. The term "Photocatalysis" is still an arguable subject due to controversies, according to some researchers the "light" acts as a catalyst, while it always acts as a "reactant" where it is spent in the chemical process [3].

The word "photoreaction" is sometimes explained as a "Photoinduced" or "Photoactivated," process, whereas in the field of photocatalysis, "catalytic 
activity" is the ability of a catalyst to show performance under light depending upon the reaction sites/active sites at the catalyst. The performance of a catalyst can be determined by its "turnover frequency" which is "number of turnovers per unit time of reaction, it is used to show how many times one active site produces a reaction product(s) within unit time." In case of photocatalysis, the reaction rate depends on the frequency of irradiated light which acts as the initiator of photoreaction. The term photocatalysis indicates the relation of light and some substance; (say a catalyst) so in the absence of light, the process of photocatalytic activities on active sites is not possible [1,4].

\subsection{Brief history of semiconductor photocatalysis}

In 1839 , the production of voltage and an electric current were reported when silver chloride electrode, immersed in electrolyte solution (connected to counter electrode) exhibited illumination under sunlight, which lately was known as "Becquerel effect" led to the beginning of existing era of photo electrochemistry [3]. In 1921, the Renz published first article on the degradation of carbon compounds by using titanium dioxide. In 1924 the photocatalytic deposition of silver on zinc oxide was observed for the production of metallic silver [2]. In 1929, the "chalking" (fading of paints) effect of titanium white $\left(\mathrm{TiO}_{2}\right)$, under the strong sunlight was observed, which in 1938 became the basis for self-cleaning property and modification in the concept of photo-induced reduction [5].

During 1950s, the insights of photocatalysis were shifted to ZnO. In 1953, two studies for the production of $\mathrm{H}_{2} \mathrm{O}_{2}$ on $\mathrm{ZnO}$ under the UV irradiation started a series of follow-up studies in the upcoming years which explained that an organic compound is oxidized when atmospheric oxygen is reduced. Till 1955, the photocatalytic behaviour of $\mathrm{ZnO}, \mathrm{Sb}_{2} \mathrm{O}_{3}$ and $\mathrm{TiO}_{2}$ including photoconductivity and fluorescence were well known. In 1958, the adsorption of reduced $\mathrm{O}_{2}$ on the $\mathrm{TiO}_{2}$ surface, as a result of photoexcitation, having the ability to degrade a dye was studied. During 1960s and 1970s, the processes and concepts of photo-oxidation of $\mathrm{CN}^{-}$and photodeposition of $\mathrm{Pt}, \mathrm{Cu}, \mathrm{Pd}$, and other metals on $\mathrm{TiO}_{2}, \mathrm{WO}_{3}, \mathrm{Al}_{2} \mathrm{O}_{3}$, and $\mathrm{SnO}_{2}$ to be used as co-catalysts, had been evolved. In 1972 the field of photo-electrochemical got more attention when Fujishima and Honda reported the ability of an illuminated $\mathrm{TiO}_{2}$ and $\mathrm{Pt}$ electrode to generate the $\mathrm{H}_{2}$ gas by a publication in Nature, which opened the doors for the close associations between photo electrochemistry and photocatalysis. By the end of that decade and by the mid of 1980s many other semiconductors, the ideas for nano-sized $\mathrm{TiO}_{2}$ particles and coupled semiconductors had been evolved. The decades of 1980-2000 were important for the field of photoelectrochemistry as major breakthroughs during this era led to the discovery of large number of applications varying from self-cleaning surfaces to disinfection of water $[2,6,7]$.

\subsection{Semiconductor photocatalysis}

The phenomenon gained importance during late 1970s and mid 1980s after the evolution of $\mathrm{H}_{2}$ by illuminated $\mathrm{TiO}_{2}$ (pristine semiconductor) in the presence of noble metal electrode, after that great concern was shown in water splitting followed by emergence of new era of photo electrochemistry at a single semiconductor crystal. The processes of semiconductor photocatalysis for environmental concerns have gained fame during the last 3 decades $[8,9]$.

Semiconductor photocatalysis can be of two types (i) homogenous photocatalysis, (ii) heterogeneous photocatalysis, depending on the phase differences of reactants and catalysts, triggered the concept of advanced oxidation 
processes (AOPs) at the end of twentieth century. $\mathrm{TiO}_{2}$ is the semiconductor which can act as both the hetero and homogenous photocatalyst photoreactions [10]

(Figure 1).

Heterogeneous photocatalysis is a process which includes a large variety of reactions: reductions oxidations, dehydrogenation, transfer of charge carriers, bacterial inactivation, organic pollutant degradation, water detoxification, etc. under both UV and visible light irradiation $[1,11]$. Having $\mathrm{TiO}_{2}$ as a semiconductor, the general mechanism is illustrated in Figure 2.

The chemistry behind the process is explained as [6]:

$$
\begin{gathered}
\mathrm{e}^{-} \mathrm{CB}+\mathrm{h}^{+} \mathrm{VB} \rightarrow \text { energy } \\
\mathrm{H}_{2} \mathrm{O}+\mathrm{h}^{+} \mathrm{VB} \rightarrow \cdot \bullet \mathrm{OH}+\mathrm{H}^{+} \\
\mathrm{O}_{2}+\mathrm{e}^{-} \mathrm{CB} \rightarrow \mathrm{O}_{2}^{\cdot-} \\
\cdot \mathrm{OH}+\text { pollutant } \rightarrow \rightarrow \rightarrow \mathrm{H}_{2} \mathrm{O}+\mathrm{CO}_{2} \\
\mathrm{O}_{2}^{\cdot-}+\mathrm{H}^{+} \rightarrow \cdot \mathrm{OOH}^{-} \\
\cdot \mathrm{OOH}+\cdot \mathrm{OOH} \rightarrow \mathrm{H}_{2} \mathrm{O}_{2}+\mathrm{O}_{2} \\
\mathrm{O}_{2}^{\cdot-}+\text { pollutant } \rightarrow \rightarrow \rightarrow \mathrm{CO}_{2}+\mathrm{H}_{2} \mathrm{O} \\
\cdot \mathrm{OOH}+\text { pollutant } \rightarrow \mathrm{CO}_{2}+\mathrm{H}_{2} \mathrm{O}
\end{gathered}
$$

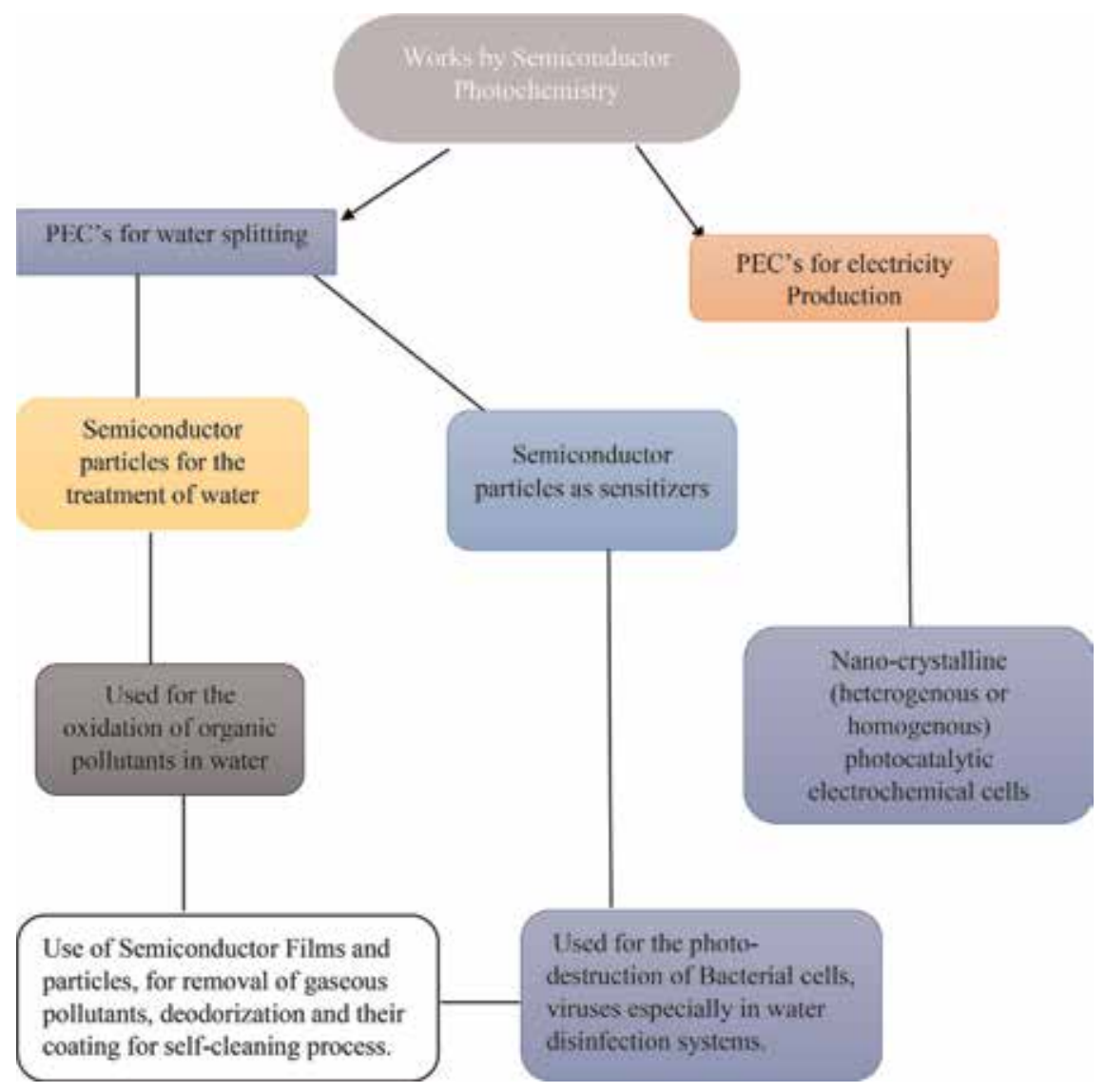

Figure 1.

Fields using semiconductors as photocatalysts from early ages to date [3]. 


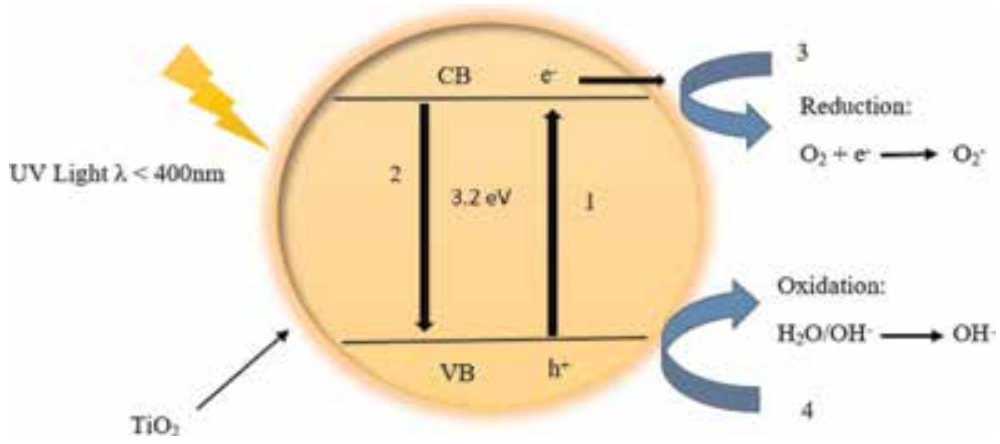

Figure 2.

Primary mechanism of photocatalysis of pristine semiconductor sphere illustrating different steps: (1)

Formation of $e^{-} / h^{+}$as a result of photoexcitation; (2) $e^{-}$recombination in absence of no electron acceptor; (3) photo induced electron transportation and reduction of oxygen; (4) oxidation due to hole in VB, while $3.2 \mathrm{eV}$ is $E_{g}$ between $V B$ and $C B$.

\subsection{Recombination}

In Figure 2, process "2" is "recombination." When it occurs, the excited electron return to valence band and recombines with hole (by dispersing the absorbed energy as heat) in the absence of electron acceptor in the conduction band.

Recombination of photoexcited electron is the major drawback of semiconductors as it lessens the efficiency of overall process. The chances of recombination can be reduced by modifications in the crystalline structure either by doping with metals, non-metals, ions or by the formation of heterostructures [12].

\subsection{Basics of heterojunctions}

In the internal structure of semiconductors (SCs), there are some band alignments which act as basis for the formation of heterojunctions/heterostructures; prepared for the enhanced activity of SCs' under sunlight. "Heterojunction is the junction in single crystal, formed by the combination of two dissimilar SCs." These heterostructures are formed on the basis of band gap, electron affinity and bands position thus leading to the formation of new energy levels. By the formation of HSs/HJs, the movement of charge carriers in a reaction can be controlled. There are three types of heterostructures depending on the energy band alignments. (i) Type I band alignment; the "Straddling" band Pattern. (ii) Type II band alignment; the "Staggered" band Pattern; (iii) Type III band alignment; the "Broken gap" Pattern. Agrawal [13] Type I, the most common band alignment in which the SC with smaller band gap relies under the SC with larger band gap; means band gaps are (not entirely but) overlapped. The charge carriers stay confined in the heterojunction due to the presence of potential barrier. Type II, the position of Valence and Conduction band of first SC is higher than that of second SC, the direction of steps in both SCs is same. The potential difference between two SCs causes the band bending at junction site due to this the electron and hole move in opposite directions, thus leading to good separation of charge carriers in heterojunction structure. When the band gaps stops to overlap then the case is known as "zero gap or broken gap" this is Type III band alignment, which is formed by the combination of semimetal having non-overlapping bandgap with a semiconductor $[14,15]$. The illustration of band gap alignment is given Figure 3. 
(a)

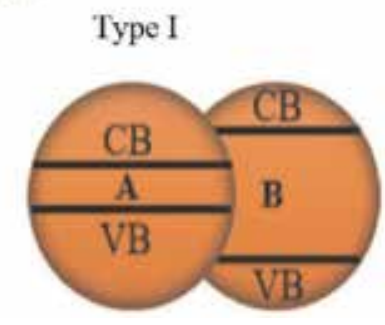

(b)

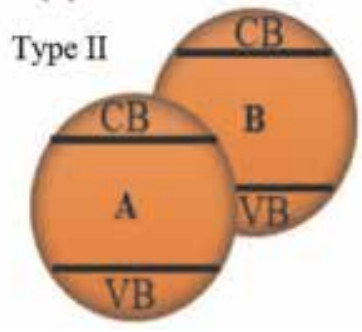

(c)

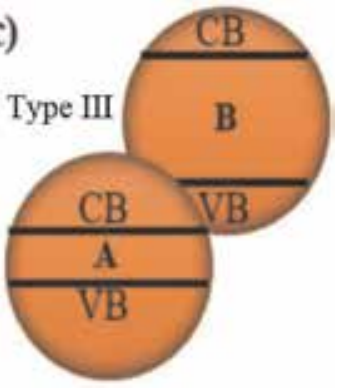

Figure 3 .

Schematic illustration of different types of semiconductors heterojunctions [16].

The formation of Type II heterojunctions are good candidates in the field of photocatalysis as it has capability to enhance the charge separation to improve the photoreactions, photocatalytic degradation and water splitting [17].

\subsection{General mechanism of water splitting by semiconductors for wastewater treatment}

Globally, 1 billion people do not have access to safe drinking water and approximately 2.6 billion people are suffering from safe sanitation, this is particularly an issue in Asia, Africa, South and central America [18], so there is no ambiguity in saying that water management has become an emerging issue for the twenty-first century. Number of anthropogenic activities like industrial activities, discharge of effluents in the water bodies, oil spills and leaching of compounds to groundwater, etc. are interfering the quality of water, thus making it unfit for drinking and domestic purposes and also threatening the natural water resources. It has been estimated that the water quality will be a worst in upcoming decades. In this regard, there is a need for advancement in the fields of water and wastewater treatment because the conventional treatment plants are not capable to remove some persistent pollutants from water [19].

In this perspective the concept of photocatalytic water splitting has been emerged in last decade which are a favorable method for attaining green and renewable energy. For effective water splitting the $\mathrm{CB}$ of a SC should be more negative than the redox potential of $\mathrm{H}^{+} / \mathrm{H}_{2}(0 \mathrm{~V}$ vs. NHE) and the top of the valence band should be more positive than the redox potential of $\mathrm{O}_{2} / \mathrm{H}_{2} \mathrm{O}(1.23 \mathrm{~V}$ vs. NHE). In splitting process water breaks in oxygen and hydrogen by the photoexcitation of electron leaving a hole behind. Semiconductor absorbs the energy equal to or greater than its band gap, the photogenerated electrons and holes starts the redox reactions. Three key stages of water splitting mechanism are; (i) energy absorbance and generation of $\mathrm{e}^{-} / \mathrm{h}^{+}$as result of photoexcitation; (ii) the charges remain separated at the opposite sides of SC crystal as a result of minimal recombination; (iii) charge carriers trigger the oxidation and reduction at valance and conduction band or vice versa. By production of reactive species as result of reduction of oxygen and oxidation of water or hydroxyl ion, like $\mathrm{H}^{+}, \mathrm{OH}^{*}$ and $\mathrm{O}_{2}{ }^{--}$the wide variety of organic pollutants in water are mineralized in to $\mathrm{CO}_{2}$ and $\mathrm{H}_{2} \mathrm{O}$ [20]. The water splitting mechanism is given in Figure 4.

\subsection{Roles of reactive species in pollutant degradation}

General reactive or oxidizing species formed during the photocatalytic degradation of pollutants are $\mathrm{H}^{+}, \mathrm{OH}, \mathrm{HO}_{2}, \mathrm{H}_{2} \mathrm{O}_{2}$ and $\mathrm{O}_{2}{ }^{--}$. These photo-oxidants are formed by the steps as described in Eqs. (2)-(7). 
Hole and hydroxyl radical: A hole generates when an electron moves to $\mathrm{CB}$ as a result of photo excitation, and hydroxyl radical generates when the hole oxidizes the hydroxyl ion or the water molecule. There is a debate on the reactiveness of hole and a hydroxyl radical, as they both are important for photocatalytic degradation, because it is still uncertain whether the hole or hydroxyl radical is core oxidant, or is there any dependence on the type of substrate. Minero et al. [21] has investigated that $\mathrm{OH}^{\bullet}$ has higher oxidizing power as compared to other oxidizing agents as it has the oxidation potential of $+2.80 \mathrm{eV}$ slightly less than that of Fluorine $+2.87 \mathrm{eV}$. There are many studies which support the reactivity of $\mathrm{OH}^{\bullet}$ as an oxidant [22]. Turchi and Ollis [23] have proposed the four ways by which the $\mathrm{OH}^{\bullet}$ oxidizes the pollutant, Figure 5.

Draper et al. [8] has investigated the direct oxidation by the hole, it can be said that the oxidation process in the valence band is started by the hole, by the oxidation of $\mathrm{H}_{2} \mathrm{O}$ molecule and hydroxyl ion. It would be rational to say that both the hole and $\mathrm{OH}^{\circ}$ deal with different classes of compounds; like the production of hydroxylated rings from the oxidation of aromatic compounds and the degradation of paracetamol (acetaminophen) on the $\mathrm{TiO}_{2}$ is caused by $\mathrm{OH}^{\bullet}$ [24].

Superoxide radical: This specie has been reported to play an important for the degradation/oxidation of many pollutants under both, the visible and ultra violet

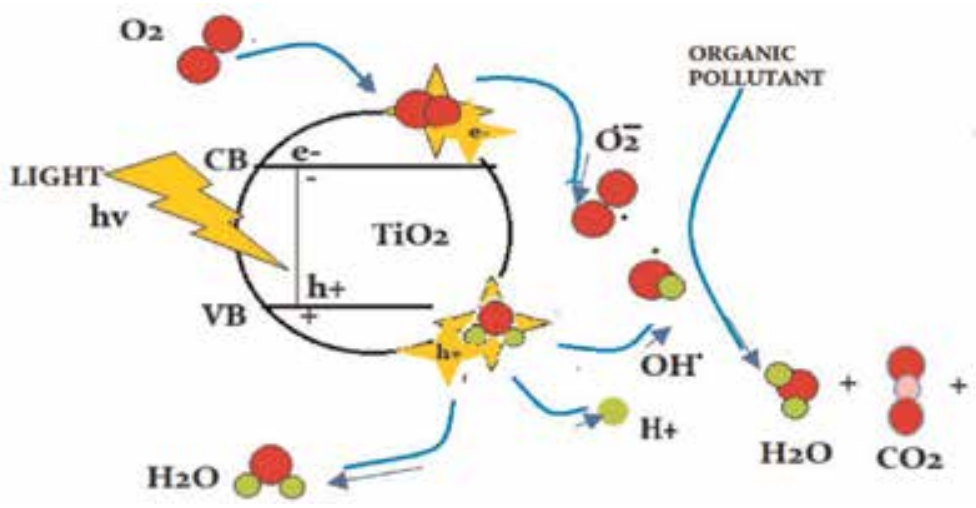

Figure 4 .

Water splitting mechanism illustration and mineralization of organic pollutant.

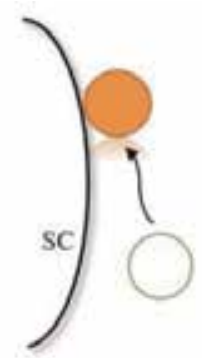

(a)

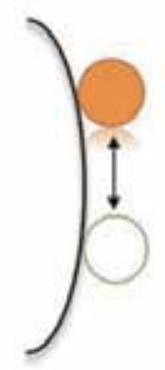

(b)

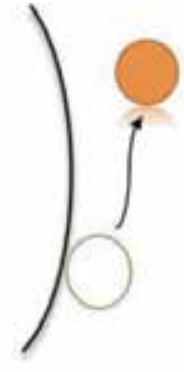

(c)

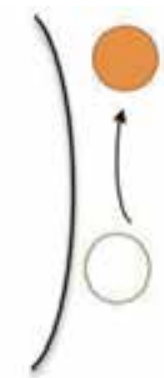

(d)

Figure 5 .

Scheme of oxidant and pollutant molecule interaction in the presence of a semiconductor. (a) $\mathrm{OH}^{*}$ is close to the pollutant molecule, when the latter is adsorbed. (b) Oxidation reaction, when $\mathrm{OH}^{*}$ and substrate both are adsorbed. (c) Pollutant is in the vicinity of $\mathrm{OH}^{*}$, when latter is adsorbed on SC surface. (d) Pollutant degradation by oxidation, when both are in solution; where $\bigcirc$ is the target molecule/substrate and $\bigcirc$ is the hydroxyl radical. 
light irradiations. In addition to direct participation in oxidation the formation of superoxides confirms the decreased recombination rate, as it is formed by the reduction of oxygen molecule. Therefore, superoxide formation is a vital process which controls the reaction rate by accepting the excited electron ([25]).

Hydrogen peroxide: Hydrogen peroxide is formed in the solution by the combination of two hydroperoxyl radicals (HOO-) or by the two electron reduction of $\mathrm{O}_{2}$ in the conduction band as shown in Eqs. (6), (7) and (10). It can affect the photocatalytic reaction by acting as electron acceptor directly from organic or inorganic pollutant or by its dissociation into $\mathrm{OH}^{*}$ due to "homolytic scission" [8]. Reactivity depends on rate of its production and the substrate concentration on the semiconductor. $\mathrm{H}_{2} \mathrm{O}_{2}$ mostly in the $\mathrm{TiO}_{2}$ solutions cannot be readily detected due to its high unstable nature. $\mathrm{H}_{2} \mathrm{O}_{2}$ is dissipated as it is produced into $\mathrm{OH}^{\bullet}$ by reduction [21].

$$
\begin{gathered}
\mathrm{O}_{2}+2 \mathrm{e}^{-}{ }_{c b}+\mathrm{H}^{+} \rightarrow \mathrm{H}_{2} \mathrm{O}_{2} \\
2 \mathrm{H}_{2} \mathrm{O}+2 \mathrm{~h}_{\mathrm{vb}}{ }^{+} \rightarrow \mathrm{H}_{2} \mathrm{O}_{2}+2 \mathrm{H}^{+}
\end{gathered}
$$

Photoproduced reactive species on the photocatalysts undergo oxidation that have been extensively studied during the last decades for environmental remediation including water disinfection, wastewater treatment, air decontamination, selfcleaning glass/surfaces degradation of organic compounds, etc. The reason to attraction towards this process lies in the end products of any type of pollutant which are $\mathrm{CO}_{2}$ and $\mathrm{H}_{2} \mathrm{O}$. Actually, the mineralisation of compounds having high carbon hydrogen content, occurs via the formation of many intermediates which also undergo oxidation. In short, the significance of photocatalytic process and photo-oxidation cannot be underestimated because of its emerging demand for the decomposition of refractory organics or recalcitrant compounds.

\section{Development of visible light active photocatalysts}

Among the several advanced oxidation processes, semiconductor assisted photoreactions are gaining importance in recent years due to their higher mineralization potential of organic pollutants in environment. The main limitation for the pure SC photocatalysts is their large band gap which means there is a need for shorter wavelength of light and high energy photons $(\lambda<380 \mathrm{~nm})$ to excite the electron from VB to CB. For this purpose, the photons falling in ultra violet region are required. Under the UV irradiation, the electrons in the VB of SCs are excited and $\mathrm{e}^{-} / \mathrm{h}^{+}$pair is formed. The problem is, the UV light makes only $4-5 \%$ of the solar spectrum while about $40-45 \%$ of the solar light falls in visible spectra. The need of UV light limits the photocatalytic activity due to its less availability [12, 20].

In recent years, Yongquan Quab [26] has pointed some critical requirements for a stable SC catalyst to yield the solar energy which are; firstly, the SC must have an appropriate band gap to produce robust electrons $\left(\mathrm{E}_{\mathrm{g}}>1.3 \mathrm{eV}\right.$ commonly $>2 \mathrm{eV}$ but $<3 \mathrm{eV}$ ) and sufficient band gap to allow effective absorption of light under visible region. Secondly, there should be less chances for recombination, i.e., should have an efficient charge separation system; lastly there should be a process to protect the semiconductors from the direct electrochemical reactions to confirm the photoelectrochemical strength of the system.

A single pure semiconductor photocatalyst is unable to fulfill the all above mentioned requirements. Therefore, in order to enhance the photocatalytic activity 
of the SC, there is a need to enhance their visible light activity, which can either be done by enhancing the surface modifications, i.e., by increasing the surface area and porosity, or by chemicals modifications like doping of metals, non-metals, ions, non-metal co-doping, dye sensitization or by the formation of junctions unitary, binary and tertiary, i.e., semiconductor/semiconductor, semiconductor/metal, semiconductor/metal oxides or the semiconductors/nano-composites [20].

\subsection{Doping/grafting of semiconductor photocatalysts}

Among all semiconductors $\mathrm{TiO}_{2}$ is considered as pristine, first-generation oldest one with many physical and structural properties. In addition to $\mathrm{TiO}_{2}$ other $d$ orbital metal oxides like $\mathrm{WO}_{3}, \mathrm{ZnO}, \mathrm{Fe}_{2} \mathrm{O}_{3}$ are regarded as $n$-type semiconductors while the semiconductors other than metal oxides are CdS, ZnS, CdSe, ZnSe, CdTe, $\mathrm{MoS}, \mathrm{Sb}_{2} \mathrm{~S}_{3}$ among them some have smaller band gaps like CdS and some have higher band gap like $\mathrm{ZnS}$. $\mathrm{TiO}_{2}$ is found in the three crystalline forms named as anatase, rutile and brookite, being the anatase and rutile are more active with band gaps or 3.2 and $3.0 \mathrm{eV}$. $\mathrm{TiO}_{2}$ has been extensively used and widely investigated due to its high photo activity, biodegradability, less-toxicity, low cost and high structural and chemical stability against photocorrosion process [6, 12].

In order to understand, doping can be defined as "when impurities are added to semiconconductors, the band structure is modified; this process is known as doping." During the doping process, the doped atoms can present the interstitial, substitution or defect factor in structure of SC. When a semiconductor is doped with an acceptor atom, it is converted into $p$-type SC, because the acceptor atom is reduced by accepting electrons from VB and increases the production of holes and vice versa. Once SC is doped with any specie, it is supposed to increase the absorption of light in the visible spectrum and the doping material will not disturb the structural or chemical integrity of the SC [22]. The doping positions of dopants are given in Figure 6.

\subsection{Non-metal-doped semiconductors}

For this type of doping to SCs the non-metals like N, C, S and F have been used. The production of visible light active photocatalysts starts with the doping of $\mathrm{N}$ to $\mathrm{TiO}_{2}$ or $\mathrm{ZnO}$ lattice, due to its small size, low ionization energy, and high stability. Livraghi et al. [28] proposed that contrary to the concept that nitrogen species are reason for formation of VLA photocatalyst the nitrogen precursor during the doping process induces the oxygen vacancies which renders the SCs able to absorb visible light and to increase phocatalytic activity. In 1986, Sato discovered the addition of $\mathrm{NH}_{4} \mathrm{OH}$ in the titania sol followed by the calcination of obtained product, the resulting products was visible light active [29]. After that Asahi et al. [30] first time explored the VL activity of $\mathrm{N}$-doped $\mathrm{TiO}_{2}$ by the sputter method of $\mathrm{TiO}_{2}$

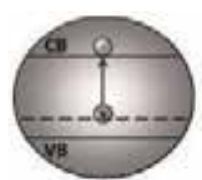

(A)

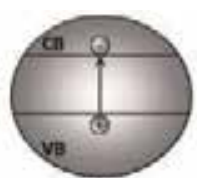

(B)

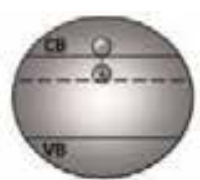

(C)

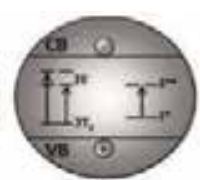

(D)

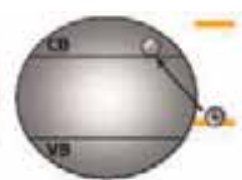

(E)

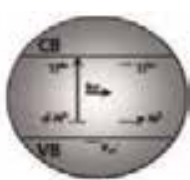

(F)

Figure 6.

Six schemes illustrating the different sites for dopants; $(A)$ the localized states above VB; $(B)$ lessened $E_{g} d u e$ to non-metal doping; (C) localized states below CB; (D) formation of colored centers between $E_{g}$; $(E)$ surface modification by addition of $N$-containing compounds; $(F)$ interstitial $N$ species and oxygen vacancies [27]. 
under N-Ar atmosphere. They also proposed that nitrogen doping creates a delocalized mixing/hybridization of $\mathrm{O} 2 \mathrm{p}$ and $\mathrm{N} 2 \mathrm{p}$ orbitals causing the rise in valence band position. Later on, for the efficient doping of $\mathrm{N}$ to $\mathrm{TiO}_{2}$ either in bulk or at surface both types the dry or wet methods have been adopted. Techniques, like sputtering $[31,32]$ and ion implementation are based on the direct treatment of $\mathrm{TiO}_{2}$ with nitrogen ions $[32,33]$.

The most used method of $\mathrm{N}$ doping in $\mathrm{TiO}_{2}$ is sol-gel method, in this method the titanium precursors are combined with the nitrogen containing surfactants, for example, the $\mathrm{N}$-doped $\mathrm{TiO}_{2}$ have been prepared by using dodecylammonium chloride (DDCA) as surfactant acting as nitrogen source which provided it damaging capability for microcystins-LR under visible irradiation [34] Figure 7. Degradation of MC-LR and mineralization of $78 \%$ of carbon has also been reported by using Bi-doped $\mathrm{TiO}_{2}$ under visible light irradiation having $\mathrm{OH}^{\bullet}$ as a reactive oxidation specie [35].

Several processes have been proposed to prepare the nanobelts by doping the $1 \mathrm{D}$ titania nanostructure with nitrogen following hydrothermal method having the anatase $\mathrm{TiO}_{2}$ particles and $\mathrm{NaOH}$ as precursors and heating treatment with $\mathrm{NH}_{3}$ ([25]). Production of $\mathrm{N}$-doped $\mathrm{TiO}_{2}$ nanotubes by the anodization of $\mathrm{Ti}$ in $\mathrm{HF} / \mathrm{H}_{2} \mathrm{SO}_{4}$ electrolyte have been reported [36].

In addition to the $\mathrm{N}$-doped $\mathrm{TiO}_{2}, \mathrm{ZnO}$ can also be doped which is one of the most studied $\mathrm{SC}$ other than $\mathrm{TiO}_{2}$ due to its applications in disinfection process and diversity of shapes but it has low stability. $\mathrm{ZnO}$ has also three crystalline forms, named as Zinc blend, Rocksalt and Wurtzite, having third one as most stable and active. The example of $\mathrm{N}$-doped $\mathrm{ZnO}$ is preparation of zinc nanobundles by thermal treatment of (already prepared) $\mathrm{ZnOHF}$ nanobundles with $\mathrm{NH}_{3}$ at different temperatures, as the temperature was increased the $\mathrm{ZnOHF}$ nanobundles were converted to $\mathrm{N}-\mathrm{ZnO}$ nanobundles (Figure 8). These $\mathrm{N}-\mathrm{ZnO}$ nanobundles gave dramatic increase absorption of light in visible region at $\lambda>420 \mathrm{~nm}$ [37].

Formation of the $\mathrm{N}$-doped $\mathrm{ZnO}$ mesoporous nanospheres is an example of use of solvothermal treatment of $\mathrm{Zn}\left(\mathrm{NO}_{3}\right)_{2} \cdot 6 \mathrm{H}_{2} \mathrm{O}$ which is the source of both $\mathrm{Zn}$ and nitrogen, in the presence of oleic acid, oleylamine, and octadecene. Mixture was heated at $260^{\circ} \mathrm{C}$ for $20 \mathrm{~min}$ and cooled at room temperature for $2 \mathrm{~h}$ followed by centrifugation, washing of precipitate and calcination at $400^{\circ} \mathrm{C}$ for $2 \mathrm{~h}$ led to the production of mesoporous nanospheres having size between 100-300 nm.

This structure had the higher photoactivity as compared to pristine $\mathrm{ZnO}$ ([38]).
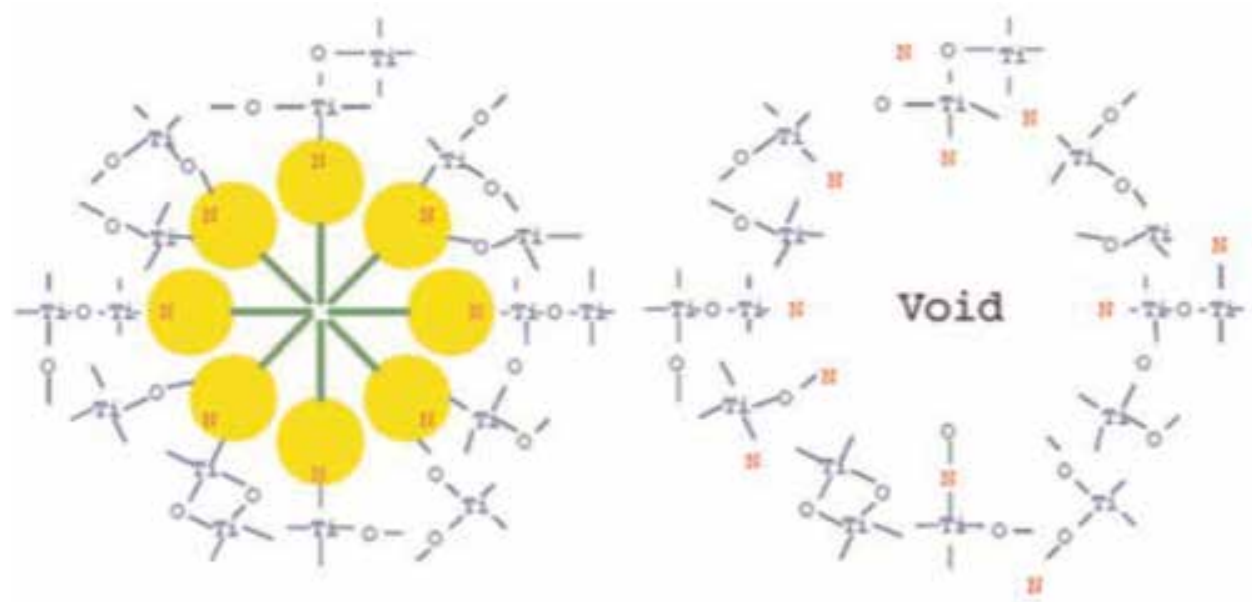

Figure 7.

$N$-doped $\mathrm{TiO}_{2}$ using the titanium precursor and nitrogen containing surfactant as $\mathrm{N}$ source and pore template. 
The nitrogen doped silver deposited $\mathrm{ZnO}$ thin films have been successfully prepared on a glass substrate by Kumar et al. via Radio frequency (RF) magnetron sputtering for the degradation of 2-CP under the visible light irradiation $\lambda 390-700 \mathrm{~nm}$ and resulted in production of mineralized products as in Figures 9 and 10 [39].

Nitrogen doped $\mathrm{ZnO}$ films were prepared by chemical vapour deposition (CVD) process using metallic zinc, $\mathrm{NO}_{2}$ and $\mathrm{NH}_{3}$ as precursors. The nitrogen concentration was varied while the temperature was kept constant at $350^{\circ} \mathrm{C}$. The gradual addition of dopant to $\mathrm{ZnO}$ films led to the formation of stable nitrogen vacancies clusters and n-type defects, the stability of vacancies is the beauty of this process because the vacancies formed by addition of other impurities are easily removable [40]. Other techniques for the production of $\mathrm{N}-\mathrm{ZnO}$ films on glass substrate, like high vacuum plasma-assisted chemical vapour deposition (HVP-CVD) [41] and pulsed-filtered cathodic vacuum arc deposition (PFCVAD) [42] have been reported. In both techniques, $\mathrm{N}_{2}$ or $\mathrm{N}_{2} \mathrm{O}$ was used as doping agents and as the dopant quantity was

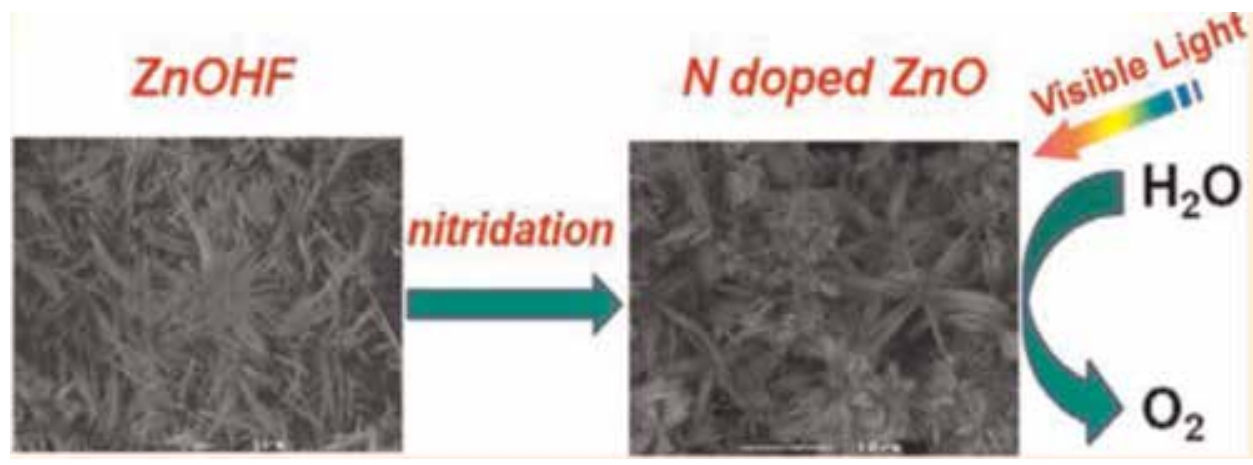

Figure 8.

Nitridation of $\mathrm{ZnOHF}$ nanobundles resulting in the formation of $\mathrm{N}$-doped $\mathrm{ZnO}$ with similar morphology, showing high absorption to visible region.

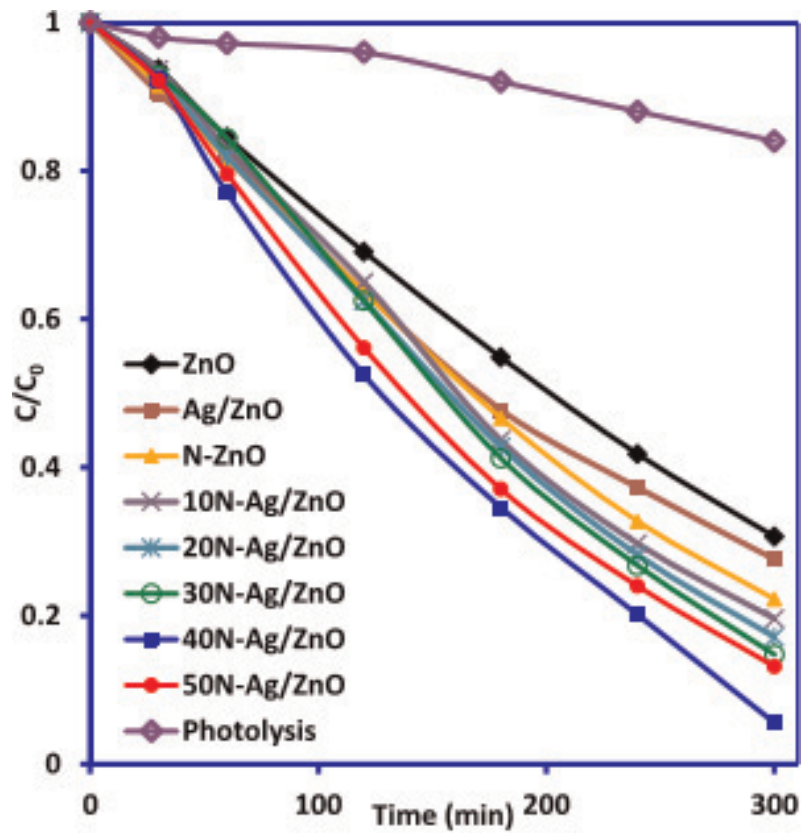

Figure 9.

Photocatalytic degradation of 2-CP on ZnO-based thin films under visible light irradiation [39]. 


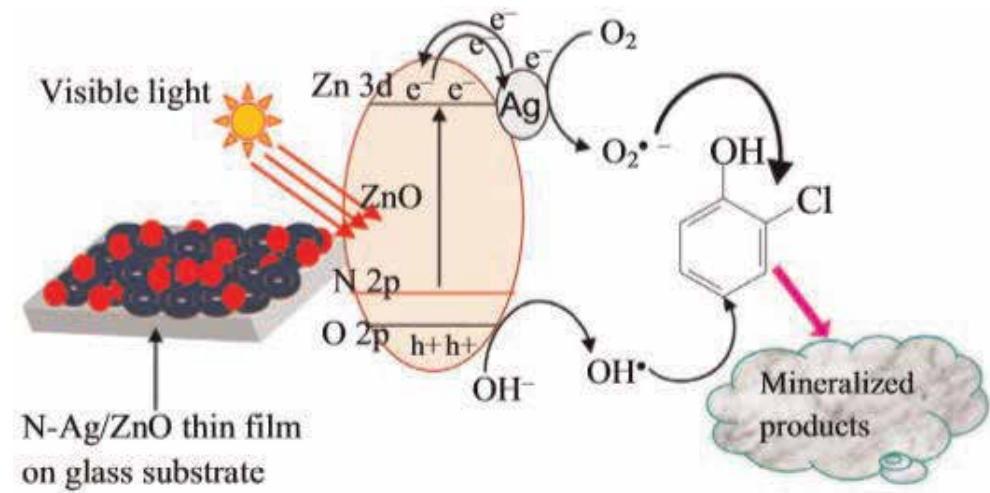

$\mathrm{Ag}$

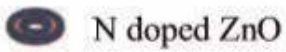

Figure 10.

Illustration of formation of $e^{-} / h^{+}$pair and degradation of 2-CP by the $\mathrm{N}-\mathrm{Ag} / \mathrm{ZnO}$ thin films [39].

increased the semiconductor changed from $n$-type to $p$-type while the stability of $p$ type was dependent upon the synthesis process. Surprisingly the films synthesized by the PFCVAD process maintained their $p$-type doping for 12 months.

In literature, in addition to the doping of $\mathrm{TiO}_{2}$ with nitrogen, there are studies which have reported the carbon doped $\mathrm{TiO}_{2}$ as visible light photocatalyst. In contrast to the nitrogen doped $\mathrm{TiO}_{2}$ which is commonly present in substitutional form, the carbon is doped to $\mathrm{TiO}_{2}$ in different ways depending on the doping process, the three possible ways for carbon addition to lattice are (i) replacement of lattice oxygen with carbon; (ii) replacement of $\mathrm{Ti}$ atom with carbon atom; (iii) addition of carbon at interstitial position. Due to relatively smaller size of C atom, third one can occur without creating too much strain in structure [43]. The green synthesis for the C-doped $\mathrm{TiO}_{2}$ has been described by using $\mathrm{Ti}\left(\mathrm{SO}_{4}\right)_{2}$ and sucrose as the precursors for $\mathrm{Ti}$ and carbon. This hydrothermal method is adoptable due to its low cost, nontoxic and easiness to perform, the $\mathrm{C}-\mathrm{TiO}_{2}$ was prepared by hydrothermal method and post-thermal treatment was applied at different temperatures and this was found to be effective to promote the visible light activity of $\mathrm{C}-\mathrm{TiO}_{2}$ for the degradation of toluene [44]. C-doped $\mathrm{TiO}_{2}$ material have been prepared by the oxidation of titanium carbide ( $\mathrm{TiC}$ ) coated multiwalled carbon nanotubes (MWCNTs). The MWCNTs were used as a reaction template and carbon source, and titanium powder as the titanium source. XPS results indicated that chemical structure of $\mathrm{Ti}$ in $\mathrm{TiO}_{2}$ coated-MWCNTs was different from that of pristine anatase due to the formation of Ti-O-C strong bond and interaction between $\mathrm{TiO}_{2}-\mathrm{MWCNT}$ (Figure 11). The photocatalytic activity of this material was tested for the degradation of methylene blue under visible light [45].

Carbon doped $\mathrm{TiO}_{2}$ has been reported to improve its VL response and photocatalytic activity and has been shown to be more effective than nitrogen doping. C-doped $\mathrm{TiO}_{2}$ nanomaterials were prepared by the oxidative annealing of titanium (IV) carbide, used as a precursor. XPS analysis revealed that the carbon in the sample was present as carbonate species. The nanopowders were used for the degradation of methylene blue in the aqueous solution and for anti-bactericidal activity of E. coli k-12 and 80\% inactivation in 30 min was observed [46].

Sulfur can also be used as a promising dopant to enhance the visible light activity despite of its difficulty to doping due to its large ionic radius. Sulfur-doped $\mathrm{TiO}_{2}$ was prepared by using thiourea and titanium (IV) isopropoxide as precursors 


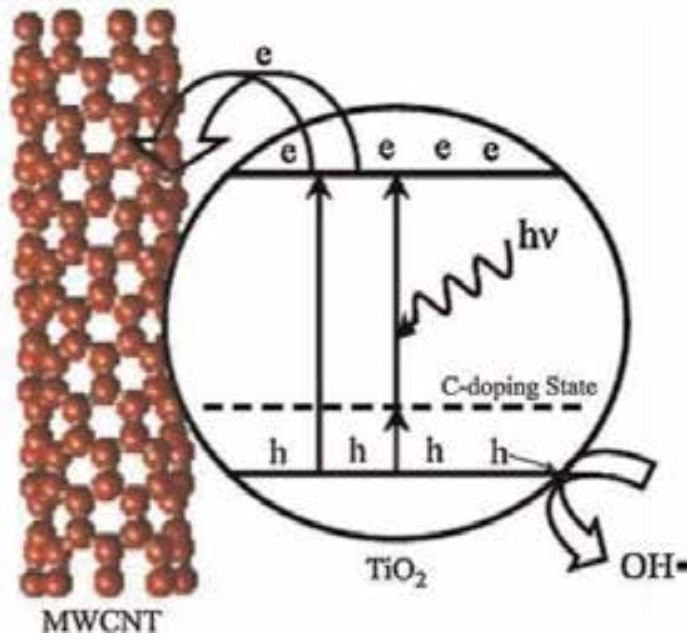

Figure 11.

Proposed mechanism of enhanced physical light activity of $M W C N T s-\mathrm{TiO}_{2}$ material [45].

followed by mixing and vigorous stirring in ethanol resulted in the production of white powder annealed at $450^{\circ} \mathrm{C}$ for $4 \mathrm{~h}$, the resulting material was S-doped $\mathrm{TiO}_{2}$. These powders gave degradation of quinoline at $\lambda=495 \mathrm{~nm}$ [47]. S-doped material can be produced by the oxidation heating of $\mathrm{TiS}_{2}$ powder followed by the annealing at $300^{\circ} \mathrm{C}$, the XRD and XPS patterns gave the results which confirmed that the $\mathrm{S}$ atoms doped into the substitutional site of $\mathrm{TiO}_{2}$ (e.g., the substitution of $\mathrm{S}$ for $\mathrm{O}$ ) are effective for the band gap narrowing. Moreover, band calculations showed that the band gap narrowing due to the $\mathrm{S}$ doping originates from mixing the $\mathrm{S} 3 \mathrm{p}$ states with VB, leading to an increase in the VB width [48].

Incorporation of $\mathrm{S}$ to $\mathrm{ZnO}$ is little difficult due to its low solubility in $\mathrm{ZnO}$ and separation of $\mathrm{ZnS}$ particles at high temperatures. To overcome this problem, homogenously mixed precursors should be treated at low temperature. Formation of sulfur-doped $\mathrm{ZnO}$ films have been reported by pulse laser deposition [49], reactive sputtering ([50]) and chemical spray pyrolysis [51]. S-ZnO films are more appropriate for the uses in electronics, sensors and photoelectrochemical cells. But for the photocatalytic processes, $\mathrm{S}-\mathrm{ZnO}$ powders give better results than films. Patil et al. [52] has proposed a method to make S-ZnO by a novel two steps process.

First was the formation of bis-thiourea zinc oxalate (BTZO) powders by a mechanochemical method followed by its thermal decomposition/annealing at different temperatures to produce $\mathrm{S}-\mathrm{ZnO}$. At lower temperatures the resulting product was $\mathrm{ZnS}$ but as the temperature rose to $600^{\circ} \mathrm{C}$ the product was $\mathrm{S}-\mathrm{ZnO}$. The prepared powder was used to degrade the resorcinol under visible light and complete photocatalytic degradation (PCD) of $150 \mathrm{ppm}$ resorcinol was observed in $7 \mathrm{~h}$ of light exposure at $\mathrm{pH} 7$ [52]. $\mathrm{ZnO}$ has also been reported to be doped with iodine by following a solvothermal method using zinc salts and iodic acids in polyol medium as precursors with heating at $160^{\circ} \mathrm{C}$. XRD and EDX analysis proved the presence of I in $\mathrm{ZnO}$ lattice. I doping increased the visible light absorbance, i.e., $\lambda>510 \mathrm{~nm}$. In addition to the change in absorption spectra, it was proposed that doped I could act as the electron trapping sites thus reducing the chances for recombination [53].

To enhance the absorption in visible spectrum, $\mathrm{P}$ doping to $\mathrm{TiO}_{2}$ has been reported using titanium isopropoxide and phosphide and $\mathrm{H}_{3} \mathrm{PO}_{4}$ as precursors. The content of $\mathrm{P}_{-}-\mathrm{TiO}_{2}$ had different properties prepared from two different precursors (Phosphide and $\mathrm{H}_{3} \mathrm{PO}_{4}$ ). A clear red shift in the absorption was observed due to the substitutional position of $\mathrm{P}^{3-}$ for oxygen in lattice. The presence of $\mathrm{P}^{3-}$ was 
confirmed by XPS analysis, the ion-doped product gave 4-CP and acetaldehyde degradation under pure visible light at $\lambda 410-440 \mathrm{~nm}$ [54].

Graphitic carbon nitride $\left(\mathrm{g}-\mathrm{C}_{3} \mathrm{~N}_{4}\right)$ is a polymeric semiconductor, in order to increase its visible light activity and to reduce band gap it is doping with phosphorous has been reported. Ligang et al. prepared P-doped g- $\mathrm{C}_{3} \mathrm{~N}_{4}$ by one pot green synthesis approach using dicyandiamide and phosphorous containing ionic liquid as precursors. The prepared particles were characterized and analysed and were used for the degradation of organic dyes like Rhodamine B and Methyle Orange under visible light. The photoactivity of particles was dependent on the post annealing temperature, doped particles gave higher photocatalytic activity as compared to pure $\mathrm{g}-\mathrm{C}_{3} \mathrm{~N}_{4}$, and degraded $95 \%$ of pollutants for the irradiation time of $180 \mathrm{~min}$ [55]. Chai et al. has also reported the degradation of dye by using P-doped gCN under visible light, synthesized by co-pyrolsis method, analysis like XRD, SEM, FESEM, XPS and FTIR were performed to check crystalline, morphological, structural and optical properties of catalyst. Prepared catalyst gave greater photocatalytic activity by substituting $\mathrm{P}$ atoms with $\mathrm{C}$ resulted in enhanced light harvesting phenomenon as it degraded $95 \%$ of dye in $30 \mathrm{~min}$, additionally radical scavenging test unveiled that holes and superoxide radicals were dominant reactive species [56]. Sulfur-doped gCN porous rods were prepared in one pot by a simple pyrolysis method of melamine-trithiocyanuric acid at different temperatures, analysis confirmed the formation of porous rods with high surface area than that of pure gCN, surface area increased with increasing temperature, as prepared catalyst gave higher photocatalytic activity and increased absorption of light in visible region and gave $92 \%$ of rhB degradation within $50 \mathrm{~min}$ [57]. $\mathrm{g}-\mathrm{C}_{3} \mathrm{~N}_{4}$ has also been reported to be doped with boron [58] and carbon atoms [59], to enhance the photocatalytic activity under visible light.

Some other non-metals like fluorine, bromine, and oxygen have also been reported to dope SCs to enhance the photocatalytic property. Doping of different type of dopant into the lattice structure of some other semiconductors like $\mathrm{Ta}_{2} \mathrm{O}_{5}$, $\mathrm{Nb}_{2} \mathrm{O}_{5}, \mathrm{BiVO}_{4}, \mathrm{InVO}_{4}, \mathrm{Bi}_{2} \mathrm{WO}_{6}, \mathrm{La}_{2} \mathrm{Ti}_{2} \mathrm{O}_{7}, \mathrm{H}_{2} \mathrm{Ti}_{4} \mathrm{O}_{9}, \mathrm{NaTaO}_{3}, \mathrm{Nb}_{2} \mathrm{O}_{5}, \mathrm{~V}_{2} \mathrm{O}_{5}, \mathrm{Sb}_{2} \mathrm{O}_{3}$, $\mathrm{Bi}_{2} \mathrm{O}_{3}, \mathrm{Fe}_{2} \mathrm{O}_{3}, \mathrm{NiO}, \mathrm{ZrO}_{2}, \mathrm{CeO}_{2}, \mathrm{Ga}_{2} \mathrm{O}_{3}, \mathrm{CuO}, \mathrm{Cu}_{2} \mathrm{O}, \mathrm{HNb}_{3} \mathrm{O}_{8}, \mathrm{WO}_{3}, \mathrm{ZnO}$, $\mathrm{K}_{2} \mathrm{La}_{2} \mathrm{Ti}_{3} \mathrm{O}_{10}, \mathrm{~K}_{2} \mathrm{Ti}_{4} \mathrm{O}_{9}, \mathrm{BiMoO}_{6}$ and $\mathrm{TiO}_{2}$ have been reported. Some doped SCs with their water treating abilities is given in Table 1. Among the above mentioned semiconductors some have the large band gaps and show excitation under the UV irradiation only, like $\mathrm{ZrO}_{2}$ has the band gap of $5 \mathrm{eV}$ and $\mathrm{Ga}_{2} \mathrm{O}_{3}$ have band gap of $4.8 \mathrm{eV}$ needs the excitation energy of 248-265 nm, while some $\mathrm{SCs}$ like $\mathrm{WO}_{3}$ and venedates have small band gaps but they are doped in order to enhance the quantum efficiency of the process. However, dependant on their synthetic approaches and crystalline structures some metal oxides have shown the degradation activity of organic and inorganic compounds under visible light [95].

\subsection{Grafting of semiconductors by co-doping}

\subsubsection{Non-metal co-doping}

Photocatalysts are not only doped with single non-metal, they can also be doped with more than one or two non-metals resulting to co-doping. A lot of work has been reported on this phenomenon in order to enhance the photocatalytic behaviour of SC. For example, N-C co-doped $\mathrm{TiO}_{2}$ has been reported, being P25 as titanium dioxide source, ammonia as a nitrogen source and different types of alcohols as carbon precursors by using one step hydrothermal method. The mixture was placed at $100^{\circ} \mathrm{C}$ for $4 \mathrm{~h}$. After thermal treatment, powder was cooled and dried for $24 \mathrm{~h}$ at $105^{\circ} \mathrm{C}$, the obtained product was $\mathrm{N}-\mathrm{C}$ doped $\mathrm{TiO}_{2}$. The physicochemical 


\begin{tabular}{|c|c|c|c|c|}
\hline $\begin{array}{l}\text { Pristine } \\
\text { photocatalyst }\end{array}$ & $\begin{array}{l}\text { Non-metal } \\
\text { dopant }\end{array}$ & Doping process & $\begin{array}{l}\text { Target pollutant for visible } \\
\text { light induced degradation }\end{array}$ & References \\
\hline \multirow[t]{13}{*}{$\mathrm{TiO}_{2}$} & Nitrogen & $\begin{array}{l}\text { Colloidal solution } \\
\text { hydrolysis }\end{array}$ & Methylene blue & {$[60]$} \\
\hline & & $\begin{array}{l}\text { DC sputtering and } \\
\text { oxidation }\end{array}$ & Rhodamine B & {$[61]$} \\
\hline & & $\begin{array}{l}\text { Hydrothermal } \\
\text { treatment }\end{array}$ & 2-propanol & {$[62]$} \\
\hline & & $\begin{array}{l}\text { Sol-gel, hydrothermal } \\
\text { and pyrolysis }\end{array}$ & Microcystin-LR & {$[63]$} \\
\hline & & $\begin{array}{l}\text { Thermal } \\
\text { decomposition, one- } \\
\text { step synthesis }\end{array}$ & MO degradation & {$[64]$} \\
\hline & & $\begin{array}{l}\text { Microemulsion- } \\
\text { hydrothermal method }\end{array}$ & 2,4-dichlorophenol & {$[65]$} \\
\hline & $\mathrm{N}-\mathrm{P}$ & Sol-gel method & 4-Chlorophenol & {$[66]$} \\
\hline & $\begin{array}{l}\text { Boron (F-B- } \\
\text { S tri-doped) }\end{array}$ & $\begin{array}{l}\text { Solvation/ } \\
\text { evaporation/sol-gel } \\
\text { synthesis }\end{array}$ & Acid napthol red (ANR) & {$[67]$} \\
\hline & Boron & & Trichlorophenol & {$[68]$} \\
\hline & C-S & Solvation/evaporation & $\begin{array}{l}\text { Toluene, 2-methlypyridine } \\
\text { and MO, E. coli sterilization }\end{array}$ & [69-71] \\
\hline & F-N & $\begin{array}{l}\text { Hydrothermal/sol-gel/ } \\
\text { Impregnation }\end{array}$ & $\begin{array}{l}\text { MC-LR } \\
4-\mathrm{CP} \\
\mathrm{MB}\end{array}$ & {$[72-74]$} \\
\hline & $\mathrm{C}-\mathrm{N}-\mathrm{S}$ & $\begin{array}{l}\mathrm{Ti}_{2} \mathrm{CN} \text { calcination/sol- } \\
\text { gel }\end{array}$ & $\begin{array}{l}\text { Reactive brilliant red X-3B, } \\
\text { Tetracycline }\end{array}$ & {$[75,76]$} \\
\hline & S-C & Mechanochemistry & 2-Propanol & {$[77]$} \\
\hline $\mathrm{SrTiO}_{3}$ & $\mathrm{~N}$ & Solvothermal/Sol-gel & $\mathrm{MO}, \mathrm{MB}, \mathrm{RhB}$ & {$[78]$} \\
\hline \multirow[t]{2}{*}{$\mathrm{NaTaO}_{3}$} & I & Hydrothermal & MB & {$[79]$} \\
\hline & $\mathrm{N}$ & Hydrothermal & Formaldehyde & {$[80]$} \\
\hline \multirow[t]{2}{*}{$\mathrm{ZrW}_{2} \mathrm{O}_{8}$} & $\mathrm{~S}$ & $\begin{array}{l}\text { Hydrothermal/ } \\
\text { Calcination }\end{array}$ & $\mathrm{O}_{2}$ Evolution & {$[81]$} \\
\hline & I & Hydrothermal & $\mathrm{RhB}$ & {$[82,83]$} \\
\hline $\mathrm{Bi}_{2} \mathrm{WO}_{6}$ & $\mathrm{~F}$ & Hydrothermal HF & MB & {$[84]$} \\
\hline $\mathrm{ZnO}$ & $\mathrm{N}$ & $\begin{array}{l}\text { Decomposition } \\
\text { reaction of } \mathrm{Zn} \text { nitrate }\end{array}$ & MO & {$[85]$} \\
\hline $\mathrm{HNb}_{3} \mathrm{O}_{8}-\mathrm{SiO}_{2}$ & $\mathrm{~N}$ & SSR urea & RhB & {$[86]$} \\
\hline \multirow[t]{2}{*}{$\mathrm{WO}_{3}$} & $\mathrm{~N}$ & $\begin{array}{l}\text { Thermal } \\
\text { decomposition in } \mathrm{NH}_{3}\end{array}$ & $\begin{array}{l}\text { MeOH Oxidation, } \mathrm{MO} \\
\text { oxidation }\end{array}$ & {$[87,88]$} \\
\hline & $\mathrm{F}$ & Hydrothermal & rhB degradation Phenol & {$[89,90]$} \\
\hline $\mathrm{BiVO}_{4}$ & $\mathrm{~S}$ & Aqueous thiourea & MB & [91] \\
\hline $\mathrm{LaCoO}_{3}$ & $\mathrm{C}$ & Sol-gel process & $\mathrm{CO}_{2}$ reduction & {$[92]$} \\
\hline $\mathrm{In}_{2} \mathrm{Ga}_{2} \mathrm{ZnO}_{7}$ & $\mathrm{~N}$ & SSR & $\mathrm{H}_{2}$ Production & {$[93]$} \\
\hline $\mathrm{Ce}_{3} \mathrm{O}_{4}$ & $\mathrm{~F}$ & PE-CVD & $\mathrm{H}_{2}$ production & {$[94]$} \\
\hline
\end{tabular}

Table 1.

Visible light active non-metal doped photocatalysts. 
properties and photocatalytic activity of catalyst was tested by using phenol as a model contaminant, phenol decomposition by different prepared materials confirmed that activity of catalyst was increased with the chain length of the alcohol precursor, and photoactivity of material was also evaluated [96]. A unique structured photocatalyst, C-S doped $\mathrm{TiO}_{2}$ (TCS) was prepared by the hydrolysis of tetrabutyl titanate in a mixed aqueous solution of thiourea and urea followed by the stirring of solution at $12-24 \mathrm{~h}$ and water in mixture was dried at $80^{\circ} \mathrm{C}$. Obtained precipitate was calcined at different temperatures, the obtained product was TCS. XPS analysis was performed which demonstrated $\mathrm{Ti}^{4+}$ ions were replaced by $\mathrm{S}^{4+}$ and carbonate ions. As prepared catalyst was used for the photodegradation of 4-chlororphenol under visible light $(\lambda=470 \mathrm{~nm})$ [97]. Another example of C-S doped $\mathrm{TiO}_{2}$ which is nanoporous highly reactive catalyst as $\mathrm{TiO}_{2}\left(\mathrm{C}-\mathrm{TiO}_{2}\right)$ and $\mathrm{TiO}_{2}$ $\left(\mathrm{S}-\mathrm{TiO}_{2}\right)$ was prepared at room temperature without heat treatment by using sol-gel method. Under visible light irradiation doped material showed high degradation of dye about $99 \%$ in $70 \mathrm{~min}$. The catalyst also showed the antibacterial activity about $95 \%$ of $E$. coli was killed within 180 min even after 10 cycles for use of $\mathrm{S}^{-\mathrm{TiO}_{2}}$ [98].

In addition to above mentioned non-metals, some halogens have also been reported for doping of $\mathrm{TiO}_{2}[99,100]$. An example for halogens doping is preparation of $\mathrm{Cl}-\mathrm{B}$ co-doped nanocrystalline titanium dioxide by a hydrothermal method using $\mathrm{TiCl}_{4}$ as a titanium source and mixed hydrobromic acid ( $\left.\mathrm{HBr}\right)$ with ethanol as a bromine source, the doping of $\mathrm{Cl}^{-}$and $\mathrm{Br}^{-}$indicated narrowing of band gap and enhanced the photocatalytic activity for the overall water splitting process under visible light [101].

Microcystins (MCs) are the effective toxins which are produced and released by algae in the fresh and brackish waters upon cell rapture. Among dozens of congeners MC-LR is becoming a cause for disturbance to water quality and environment due to its concentration in water and high solubility and stability in water. Among many practices, $\mathrm{N}-\mathrm{F}$ co-doped $\mathrm{TiO}_{2}$ has been reported to degrade it by the attack of $\mathrm{OH}^{\circ}$ on the toxic ADDA (3-Amino-9-methoxy-2,6,8-trimethyl-10-phenyldeca-4,6dienoic acid) chain under the visible light, normally the destruction of ADDA chain eliminates the associated toxicity but this breakage requires UV light $<280 \mathrm{~nm}$, but in case of $\mathrm{N}-\mathrm{F}$ co-doped $\mathrm{TiO}_{2}$ the production of free radicals due to photoexcitation, reductions and oxidations have reported to attack the ADDA and Mdha (Methyldehydroalanine group) chains and have resulted in the degradation of toxin and production of non-toxic intermediates and products [102].

Among titanates, co-doped $\mathrm{K}_{2} \mathrm{TiO}_{4}, \mathrm{SrTiO}_{3}, \mathrm{La}_{2} \mathrm{Ti}_{2} \mathrm{O}_{7}, \mathrm{~K}_{2} \mathrm{Ti}_{4} \mathrm{O}_{9}$ have been reported. The Co-doping of $\mathrm{SrTiO}_{3}$ with carbon and sulfur has been reported. Codoped product was produced by the calcination of mixture of thiourea and $\mathrm{SrTiO}_{3}$ powders in lidded crucible at different temperatures. The addition of $\mathrm{C}$ and Si were confirmed by FTIR, XRD, XPS analysis, the obtained powder had the enhanced absorption shift from 400 to $700 \mathrm{~nm}$. Cationic sulfur and tetravalent carbon doping increased the oxidative degradation of 2-propanol under visible light at $\lambda 440 \mathrm{~nm}[77]$.

Nisar et al. [103] investigated the increased efficiency of $\mathrm{BiTaO}_{4}$ by non-metal mono and co-doping in order to enhance its visible light activity. This SC has the band gap of $2.75 \mathrm{eV}$ but it has ability to absorb only $19 \%$ of the visible light.

Nitrogen doping to lattice created an electron acceptor state just above the VB in order to increase VBM. The lattice was co-doped with carbon and sulfur and after doping it was compared with the bulk. It was analysed that C-S doping led to the notable band gap reduction about $39 \%$ which was very close to the required band gap for a good photocatalytic material. The doped material had good overall water splitting ability [103]. Recently, co-doping of $\mathrm{CeO}_{2}$ with Carbon and nitrogen has been reported to enhance its visible light photocatalytic activity. Analysis and 
calculations revealed the addition of non-metals in the lattice. C-N co-doping shifts the fermi level at the bottom of conduction band by creating impurities in the lattice followed by the increased absorption of light under visible region. The surprising fact about this catalyst was its absorption intensity between 400 and $600 \mathrm{~nm}$ was very high as compared to other co-doped and $\mathrm{N}$-doped $\mathrm{CeO}_{2}$ and $\mathrm{C}$-doped $\mathrm{CeO}_{2}[104]$.

\subsubsection{Non-metal-metal co-doping}

To enhance the photocatalytic activity of semiconductors, co-doping with metal and non-metals has also been reported. In case of $\mathrm{TiO}_{2}$, Bagwasi et al. has reported the synthesis, characterization and application of $\mathrm{Bi}-\mathrm{B}-\mathrm{TiO}_{2}$ nanoparticles. The codoped nanoparticles were prepared by sol-gel method. Results indicated the bismuth and boron were doped in $\mathrm{TiO}_{2}$ lattice, as $\mathrm{Bi}$ substituted $\mathrm{Ti}$ as $\mathrm{Bi}^{3+}$ which reduced the rate of recombination and $\mathrm{B}$ was present as interstitial and substitutional B which enhanced the visible light absorption. Bi-B co-doped samples showed better activities for degradation of acid orange 7 (AO7) and 2,4-dichlorophenol under visible light $(\lambda=700 \mathrm{~nm})$ irradiation [105].

$\mathrm{TiO}_{2}$ is also co-doped with boron and nickel in the form of its oxide. As mentioned in Figure 12. The addition of boron at substitutional or interstitial position increases the response to visible spectra while the loading of $\mathrm{Ni}_{2} \mathrm{O}_{3}$ further enhanced its photocatalytic activity. TCP, 2,4-DCP and sodium benzoate were chosen as target pollutants. TCP was not only efficiently degraded under the visible light but also its was mineralized, moreover the degradation of other two pollutants was also same as of TCP [68].

Doping of $\mathrm{NaNbO}_{3}$ powders with $\mathrm{Cr}-\mathrm{N}$ and Mo-N has been studied by using hybrid density functional theory. Co-doping with two pairs of metal/non-metal was tested separately to check the enhanced visible light activity of doped $\mathrm{NaNbO}_{3}$. Metal atoms (Mo or $\mathrm{Cr}$ ) replaced the $\mathrm{Nb}$ from the lattice while the $\mathrm{O}$ was replaced by nearest Nitrogen atom. Analysis and calculations revealed that monodoping of different dopants and co doping of $\mathrm{Cr}-\mathrm{N}$ are inappropriate for photocatalytic decomposition of water under visible light because the defects formed due to dopants are above the fermi level so they cannot act as charge trapping sites thus resulting to increased rate of recombination. While, the co-doping of Mo-N proved to be an appropriate dopant as it reduced the band gap by creating different energy levels. Whereas the band gap reduction is dependent on the concentration of dopant material. Mo- $\mathrm{N}$ doped $\mathrm{NaNbO}_{3}$ have overall enhanced water splitting ability and a promising photocatalyst for pollutant degradation ([107]).

\subsection{Metal doping}

Doping in the semiconductors mostly become a reason to point defects which introduces the levels or states near, above or below the valence and conduction bands which are identified and calculated by different analysis. When the metal is incorporated in a lattice, it is doped in the form of metal ion which produces a band or energy level in the forbidden energy area thus rendering the photocatalyst able to absorb visible light irradiation. Additionally, doped metal in the form of metal ion can change the equilibrium concentration of charge carriers by acting as an electron acceptor. Thus, increasing the overall quantum efficiency of the photocatalytic process [108]. The doping of semiconductors with metals/metallic ions has also been investigated in recent decades using many procedures including sol-gel, hydrothermal, solvothermal processes, etc. (as discussed earlier). Photocatalysts can be doped with transition metals like $\mathrm{Fe}, \mathrm{Cr}, \mathrm{Mn}, \mathrm{W}, \mathrm{Ru}, \mathrm{Rh}$, low cost, non-noble 

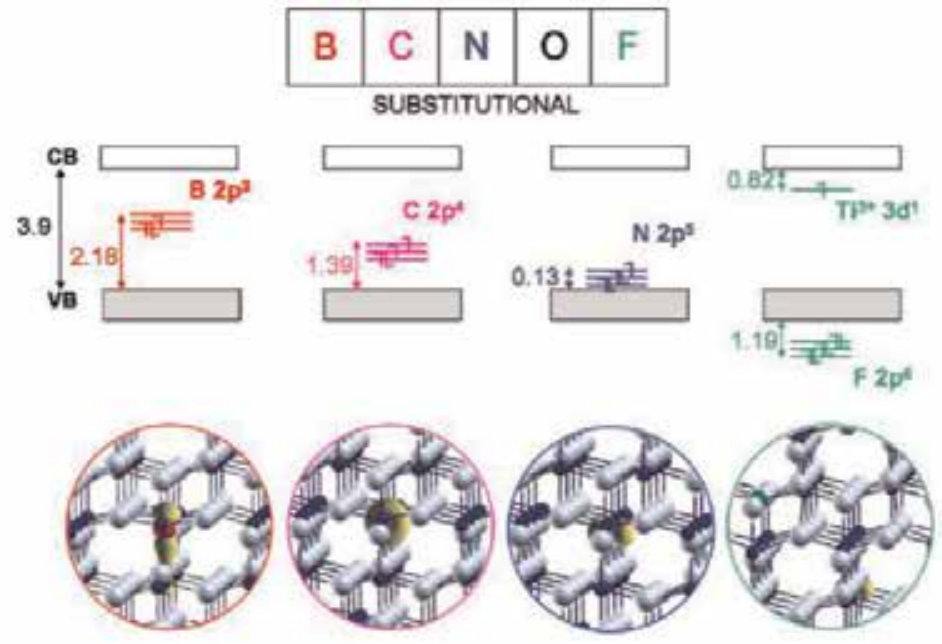

(a)
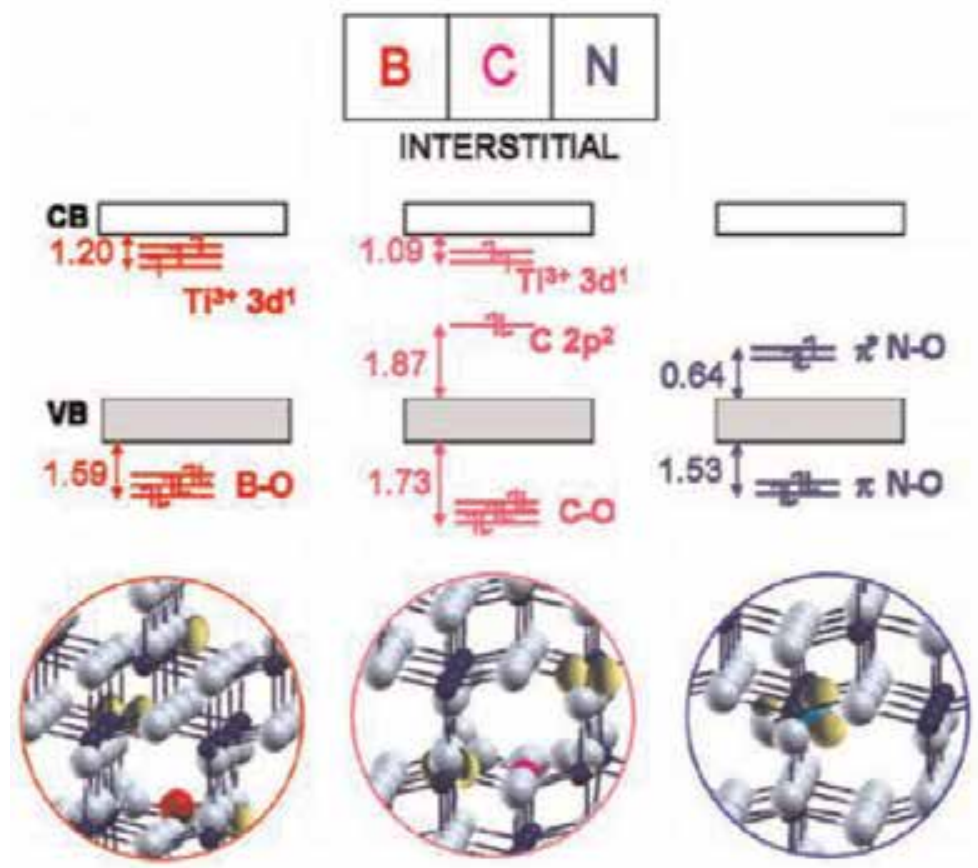

(b)

Figure 12.

Schematic illustration of positions of non-metals as dopants in the $\mathrm{TiO}_{2}$ lattice. The effect of electronic structure of replacing $O$ with $B, C, N$ and $F$ at substitutional and interstitial positions is considered; (a) doping of $B, C$ and $N$ atoms at substitutional positions results in magnetic impurities whose energy levels fall in the mid of energy gap. B sits high in the bandgap and $N$ produces a state just above the VB while F being very electronegative occupies the state below $\mathrm{O}_{2} P$ of $\mathrm{VB}$ resulting the formation of $\mathrm{TiO}^{3+}$ ions; $(b)$ at interstitial position, $B$ behaves as a donor with the formation of $\mathrm{B}^{3+}$ and $\mathrm{Ti}^{3+}$, carbon donates only two electrons and forma $C^{2+}$, nitrogen forms bond with $O$ in lattice and does not donate electrons to host atom [106].

transition and earth abundant metals like $\mathrm{Co}, \mathrm{Cu}, \mathrm{Ni}$ and the noble metals like $\mathrm{Pt}$, $\mathrm{Au}$ and Ag.

Preparation of iron doped $\mathrm{TiO}_{2}$ thin films for the photocatalytic degradation of Rhodamine $B$ has been reported by using reactive magnetron sputtering method having microscope slide as substrate and $99.99 \%$ pure $\mathrm{TiO}_{2}$ as target and thin film 
was prepared by fixing pressure and flow rate. During the preparation of $\mathrm{TiO}_{2}$ thin films, 99.9\% iron pieces was placed on $\mathrm{TiO}_{2}$ target to produce the doped plate the color of titanium dioxide film changed from light white to dark yellowish indicating the increasing concentration of iron. Analysis depicted as the concentration of $\mathrm{Fe}$ was increased, the wavelength of $\mathrm{Fe}$-doped $\mathrm{TiO}_{2}$ shifted to red due to excitation of $\mathrm{Fe}^{3+}$ electron to the conduction band. As prepared doped film was tested for the photocatalytic activity in comparison with undoped thin film and the degradation of rhB was observed under visible light on the doped thin film. The photocatalytic degradation rates of $\mathrm{rhB}$ was decreased surprisingly on the highly Fe-doped $\mathrm{TiO}_{2}$ plates ([109]). Vanadium doped $\mathrm{TiO}_{2}$ was prepared by sol-gel method with the objective to increase visible light response of $\mathrm{TiO}_{2}$ having $\mathrm{V}^{4+}$ substituted at $\mathrm{Ti}^{4+}$ place in the lattice using vanadyl acetylacetonate, acetic acid and titanium butoxide as precursors followed by hydrolysis and calcination at $400^{\circ} \mathrm{C}$. Analysis revealed that vanadium was highly dispersed inside the lattice and presented the red-shift, as prepared catalyst was used to degrade crystal violet (CV) and methylene blue (MB) under visible light irradiation which was higher than those of undoped powders [110].

Co-doping of $\mathrm{N}$-doped $\mathrm{TiO}_{2}$ with metals like $\mathrm{Sn}$ and $\mathrm{Zn}$ for enhanced activity under visible has been investigated and it is emerging as a promising approach to increase the photocatalytic ability of semiconductors because of synergistic effects in visible light absorption. $\mathrm{Zn}$ and $\mathrm{Sn}$ was compared for photocatalytic activity by doping with $\mathrm{N}(\mathrm{N}+\mathrm{Zn}$ and $\mathrm{N}+\mathrm{Sn})$, having tetracycline as a target pollutant. Different analysis (XRPD, HRTEM, XPS, EDX, and BET) for different calculations revealed that $\mathrm{Sn}$ and $\mathrm{Zn}$ modification directed to morphological, structural and surface changes, Sn was substituted at Ti site while Zn changed the lattice morphology. It was also determined that catalysts shown different performances in terms of light absorption, as Sn modified sample gave slight red shift by formation of intra-gap states and shown the absorption of light in range of 400-600 nm while Zn modification reduced the band gap by showing detrimental effect to crystallinity and creating surface defects [111].

Radio frequency (RF) sputtering technique was used to deposit $\mathbf{A g}$ and $\mathrm{ZnO}$ nanoparticle on a substrate at different temperatures on a fixed pressure. Ag and $\mathrm{ZnO}$ having high purity of $99.999 \%$ targets were used as depositing materials and three different thin films were prepared depending on the substrate temperatures as shown in Figure 13. Characterization and analysis revealed the equal distribution of Ag nanoparticles within $\mathrm{ZnO}$ matrix, the band gap of the prepared nanoparticles was ranging between 2.7 and $3.1 \mathrm{eV}$ while the pure $\mathrm{ZnO}$ has band gap of $3.37 \mathrm{eV}$. Photocatalytic degradation of 2-CP was tested by using prepared thin films by varying experimental parameters, results determined the enhanced photocatalytic activity of $\mathrm{Ag} / \mathrm{ZnO}$ as compared to pure $\mathrm{ZnO}$, reason for enhanced photocatalytic activity was the presence of Ag at the surface of film which acted as scavenger for an excited electron. The film prepared at substrate having highest temperature presented stability even after 4 cycles with only $8.7 \%$ efficiency loss [112]. Yayapao et al. prepared the undoped and $\mathrm{Nd}$-doped $\mathrm{ZnO}$ nanoneedles using ultrasonic assisted solution method by varying the percentages of doped metal. $\mathrm{Nd}-\mathrm{ZnO}$ nanoneedles gave the best results for the concentration of $1 \% \mathrm{Nd}$ which was $50 \mathrm{~nm}$ in diameter and 3-4 $\mu \mathrm{m}$ long, gave performance about 2.5 times more as compared to the undoped $\mathrm{ZnO}$. Analysis determined the presence of doped $\mathrm{Nd}^{3+}$ ions in lattice, which during photocatalysis acted as an electron scavenger and inhibited the process of recombination and promoted the photocatalytic activity by production of $\mathrm{O}_{2}{ }^{--}$[113].

Undoped and Ho-doped $\mathrm{ZnO} 3 \mathrm{D}$ microstructures were prepared using a sonochemical method having zinc nitrate hexahydrate $\left(\mathrm{Zn}\left(\mathrm{NO}_{3}\right)_{2} \cdot 6 \mathrm{H}_{2} \mathrm{O}\right)$, holmium 


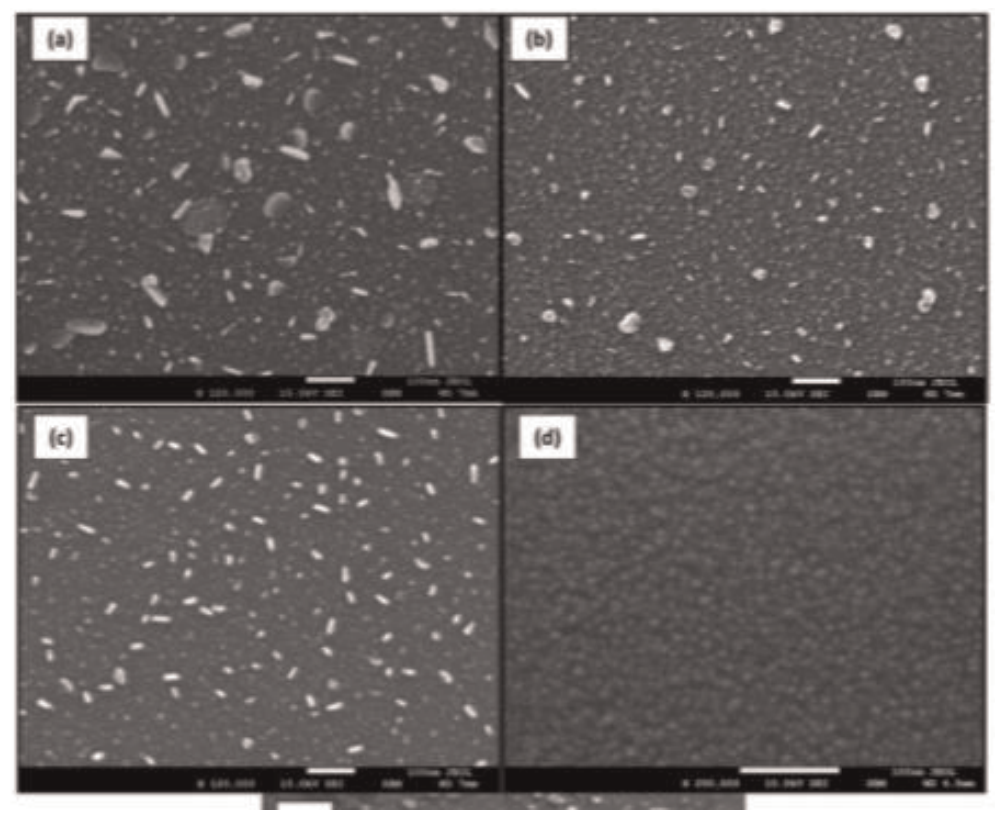

Figure 13.

SEM images of $\mathrm{Ag} / \mathrm{ZnO}$ thin film co-sputtered at different temperatures (a) Room temperature, $(b) 50 \mathrm{C}$, (c) $100 \mathrm{C}$ and (d) Pure $\mathrm{ZnO}$ [112].

nitrate hexahydrate $\left(\mathrm{Ho}\left(\mathrm{NO}_{3}\right)_{3} \cdot 6 \mathrm{H}_{2} \mathrm{O}\right)$ as precursors. The dopant concentration was varied from 0 to $3 \%$ after the sonication of $5 \mathrm{~h}$ the precipitate was washed and characterized. The flower like structure (Figure 14) gave the improved photocatalytic activity for the degradation of methylene blue (due to the production of non-selective oxidants) at $\lambda 664 \mathrm{~nm}$. The formation of $\mathrm{Ho}^{3+}$ ions at the dopant concentration of $3 \%$, which acted as electron scavenger [114]. Similar positive results were reported by doping of $\mathrm{La}^{3+}$ and $\mathrm{Sm}^{3+}$ into $\mathrm{ZnO}$ lattice for the degradation of 4-nitrophenol in wastewater [115].

For Copper doped $\mathrm{BiVO}_{4}$, the monoclinic crystal lattice $\left(\mathrm{mBiVO}_{4}\right)$ shown the efficient charge carrying capacity due to its smaller effective mass as compared to $\mathrm{Ag}$ and $\mathrm{Au}$, which is promising for higher mobility of electrons and holes. In this system the substitution of $\mathrm{Cu} 3 \mathrm{~d}$ states at the $\mathrm{Bi}$ sites reduces the band gap and also act as an electron acceptor produced by photoexcitation. This doped catalyst has shown the red shift which meant it enhanced the solar light absorbance and utilization, the system has overall great water splitting capacity [116].

Besides $\mathrm{TiO}_{2}$ and $\mathrm{ZnO}, \mathrm{WO}_{3}$ is also a promising semiconductor found to degrade the pollutants in water due to its photocatalytic activity with the band gap of $2.8 \mathrm{eV}$. Despite of short band gap, it can absorb only small portion of visible light. The photocatalytic activity of $\mathrm{WO}_{3}$ was found to be amplified in the occurrence of dopant. $\mathrm{WO}_{3}$ was doped with different metal ions using different precursors, each precursor was mixed vigorously with $\mathrm{WO}_{3}$ to ensure the homogenous mixing followed by the drying and calcination for $4 \mathrm{~h}$ at $550^{\circ} \mathrm{C}$, the final product was prepared after cooling and grounding of powder. Analysis confirmed the presence of different ions like $\mathrm{Mg}^{2+}, \mathrm{Al}^{3+}, \mathrm{In}^{3+}, \mathrm{Fe}^{3+}$, and $\mathrm{Zr}^{4+}$ on the interstitial positions in the $\mathrm{WO}_{3}$ lattice. Doped SC gave significance change in the photocatalytic property in comparison to pristine $\mathrm{WO}_{3}$ [117]. Palladium doped $\mathrm{WO}_{3}$ was used to remove Geosmin (GSM) from the wastewater. Nanocatalyst was prepared by mechanical mixing in a ceramic mortar having $\mathrm{Pd}$ and $\mathrm{WO}_{3}$ powder as a precursor, analysis revealed the size of $\mathrm{Pd}$ nanoparticles of about $10 \mathrm{~nm}$ which was dispersed evenly on 
the surface of $\mathrm{WO}_{3}$, the photocatalytic degradation was done by spiking of GSM and catalyst in a solution with water (Figure 15). Oxidative species analysis depicted that $\mathrm{OH}^{*}$ was dominant oxidative specie. Degradation rate in initial $5 \mathrm{~min}$ was $75 \%$ indicating higher degradation rate. While in next 20 min the degradation rate was more than $99 \%$, as the amount was catalyst increased gradually. The degradation rate decreased mainly due to the accumulation/agglomeration of catalyst and turbid environment caused hindrance to light penetration. The stability of $\mathrm{Pd}-\mathrm{WO}_{3}$ nanocatalyst was tested which retained $94 \%$ stability even after the fourth cycle which suggested its reusability for the GSM degradation [118].
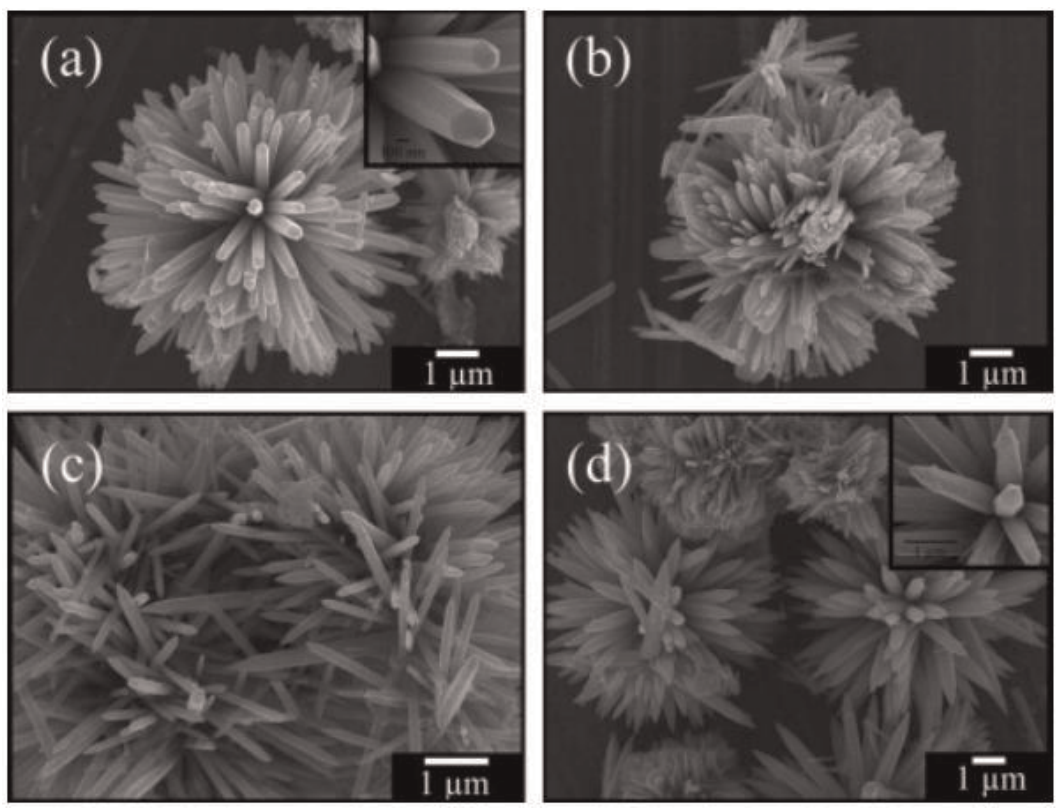

Figure 14.

SEM image of holmium doped $\mathrm{ZnO}$ microstructures with (a) $0 \%$, (b) $1 \%$, (c) $2 \%$ and (d) $3 \%$ of $\mathrm{HO}$ having100-400 $\mathrm{nm}$ diameter and length of several micrometers [114].

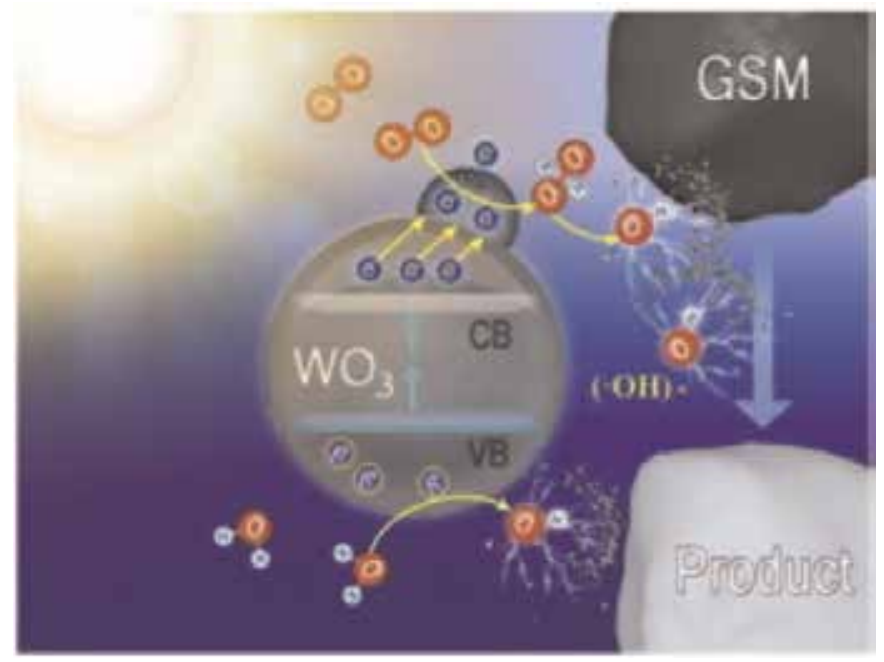

Figure 15.

Photocatalytic degradation of GSM under VL using novel catalyst [118]. 
Electronic, geometric and optical properties of chromium doped $\mathrm{SrTiO}_{3}$ has been studied by Wei et al. by using DFT with GGA scheme. Results revealed that in Cr-doped $\mathrm{SrTiO}_{3}$ structure the VBs did not suffer from any change while the bottom of $\mathrm{CB}$ shown a little rise. Cr substituted in lattice at the site of $\mathrm{Sr}$. as $\mathrm{Cr}^{3+}$ while band structure and DOS analysis shown that there were also some $\mathrm{Cr} 3 \mathrm{~d}$ gap states appeared near the bottom of CB. While Cr substituted at the site of $\mathrm{Ti}^{4+}$ was doped as $\mathrm{Cr}^{6+}$. So the results indicated that doped chromium partially take up Sr. and partially $\mathrm{Ti}, \mathrm{Cr}$ dopants at $\mathrm{Cr}$-Sr site has higher photocatalytic activity as compared to the photoactivity at $\mathrm{Cr}$-Ti dopants sites. Similarly the $\mathrm{SrTiO}_{3}$ doped with less concentrate on of dopant shown less photocatalytic activity and less absorption of visible light and vice versa [119].

Dysprosium doped $\mathrm{WO}_{3}$ nanopowders were prepared using $\mathrm{Na}_{2} \mathrm{WO}_{4} \cdot 2 \mathrm{H}_{2} \mathrm{O}$ and $\mathrm{CTAB}$ as precursors followed by a hydrothermal treatment at $80^{\circ} \mathrm{C}$ for 1 week. The resulting precipitate was centrifuged and calcined to obtain Dy-doped material. Analysis revealed that metal was doped as $\mathrm{Dy}^{3+}$ which acted as an electron donor to the adsorbed $\mathrm{O}_{2}$ to make superoxide radical and $\mathrm{Dy}^{4+}$, dopant ion also reduced recombination rate by accepting the exciting electron and formed $\mathrm{Dy}^{3+}$, nanopowders showed high photocatalytic activity for the degradation of rohdamine B (rhB) which was used as target pollutant [120]. Gallium, a post transition metal has been shown to dope semiconductors. Li et al. have reported the increased charge separation and photocatalytic activity by Ga-doped $\mathrm{SnO}_{2}$ in different molar ratios varying from 1 to $4 \%$, using $\mathrm{SnCl}_{4}, \mathrm{Ga}\left(\mathrm{NO}_{3}\right)_{3}$ and $\mathrm{HNO}_{3}$ as precursors followed by drying and baking at $573 \mathrm{~K}$ for $2 \mathrm{~h}$. The resulting product was $\mathrm{Ga}$-doped $\mathrm{SnO}_{2}$, analysis confirmed the presence of $\mathrm{Ga}$ as $\mathrm{Ga}^{3+}$ and shifted the absorption spectra towards blue region. To understand the charge separation, production of reactive species and photocatalytic efficiency methyl orange (MO) was used as a target pollutant, mainly due to the formation of $\mathrm{OH}^{\bullet} \mathrm{MO}$ was photocatalytically decolorized $[121,122]$.

$\mathrm{Hu}$ et al. reported the band gap-tunable K-doped $\mathrm{g}-\mathrm{C}_{3} \mathrm{~N}_{4}$ which had enhanced mineralization capacity, using dicyandiamide monomer and potassium hydrate as precursors followed by mixing, heating and annealing. SEM, TEM, FTIR, XRD and XPS analysis were used for the characterization and catalyst was used for the degradation of organic rhB under visible light and showed 6.5 times greater photocatalytic activity as compared to pristine gCN as it gave $70 \%$ decomposition during the irradiation time of $120 \mathrm{~min}$ [123]. Tungsten doped porous $\mathrm{g}-\mathrm{C}_{3} \mathrm{~N}_{4}$ was synthesized by hydrothermal method using urea, dicyandiamide and $\mathrm{Na}_{2} \mathrm{WO}_{4} \cdot 2 \mathrm{H}_{2} \mathrm{O}$ as precursors and catalysts with varying molar ratios of precursors were prepared and the catalyst W5/PGCN ( $\mathrm{P}$ stands for porous) gave the highest photocatalytic activity due to separation of charges and shown $99.6 \%$ degradation of MO under visible light $(\lambda=400-420 \mathrm{~nm})$ for the irradiation time of $60 \mathrm{~min}$ and $100 \%$ in 70 min [124]. Beside W, other transition metals like Yttrium ([125]), Iron [126], Eu, Zr [17], etc. doped gCN for the increased photocatalytic activity has also been reported in literature.

\section{Dye sensitized VLA semiconductors}

Dye photosensitizations have been reported by different scientists being a most operative mode to increase the response of semiconductors for visible light. Sensitization has been used for different approaches, from development of solar cells to degradation of pollutants in water. Many dyes like erythrosine B, eosin, rose bengal, rhodamine B, cresyl violet, thionine, chlorophyllin, anthracene-9-carboxylic acid, porphyrins, phthalocyanines and carbocyanines have been reported for their work 
as sensitizers, in addition to these organic dyes some inorganic dyes and coordination metal complexes are also reported. Inorganic sensitizers are basically the semiconductors with smaller band gap which are highly stable to photodegradation or photocorrosion. Their smaller band gap gives the light absorption at the wider wavelength region and examples are $\mathrm{Mn}, \mathrm{Fe}, \mathrm{Ni}, \mathrm{V}$, and $\mathrm{Cr}$ [127]. The principle of sensitization for photodegradation of pollutants is "an electron in a sensitizer molecule under visible light (as dyes have conjugate system that absorbs visible light) is excited (from HOMO to LUMO) to its conduction band from where it jumps quickly to the conduction band of attached semiconductor oxide and dye itself changed into its cationic radical and SC's CB act as an electron mediator where it is accepted by oxygen, thus starting the oxidations reactions by forming superoxide and $\mathrm{OOH}^{\circ}$, which are then converted to $\mathrm{OH}^{\bullet}$ for the degradation of pollutants"[12]. A main limitation/drawback of sensitization with an organic dye is its steady decomposition because of photocatalytic degradation due to its natural capacity to undergo redox reactions by donating its electrons, to dodge this limitation the addition of sacrificial electron donor is possible like the incorporation of EDTA and TEOA (triethanolamine) will improve the stability of dye. In a dye sensitized process the dye can be used as both a sensitizer or a substrate to be degraded in order to decolorize water [128]. The general mechanism for dye sensitized process for example $\mathrm{rhB}$ is given as:

$$
\begin{gathered}
r h B(a d s)+h v(554 n m) r h B *(\text { excitation of dye electron) } \\
r h B *+S C r h B^{++}+S C\left(e^{-} c b\right) \text { (electron } 3 \text { transfer to SC) } \\
S C\left(e^{-} c b\right)+\mathrm{O}_{2} \mathrm{O}_{2}^{\cdot-}+\mathrm{SC}\left(e^{-}{ }_{c b}\right) \text { (electron acceptance) } \\
\mathrm{rhB}^{+}+\mathrm{O}_{2}^{-{ }^{-}} \mathrm{CO}_{2}+\mathrm{H}_{2} \mathrm{O} \text { (mineralization process) }
\end{gathered}
$$

Many organic dyes have been tested for their excellent sensitizing ability to semiconductors like $\mathrm{TiO}_{2}$. Degradation of phenylurea herbicide monuron has been reported by using riboflavin-assisted photosensitization, an enhanced photodegradation effect was observed as compared to direct photolysis [129], degradation of micosporine like amino acids (small secondary metabolites produced by organisms that live in environments with high volumes of sunlight, usually marine environments by some type of algae) was observed by using rose bengal and riboflavin sensitizers [130]. Degradation of dye named reactive red 198 has been reported under visible light irradiation by using dye sensitized $\mathrm{TiO}_{2}$ activated by ultrasound, degradation rates were analysed by varying experimental parameters like initial concentration, $\mathrm{pH}$ and catalyst loading, the singlet oxygen and superoxide radical were found as dominant oxidative species which also degraded the produced intermediates like phenols. The results determined that a conventional dye can be used as a photosensitizer of $\mathrm{TiO}_{2}$ functioning under visible light [131]. A study investigated the application of $\mathrm{TiO}_{2}$ sensitized by tris $\left(4,4^{\prime}\right.$-dicarboxy-2,2'bipyridyl) ruthenium(II) complex for $\mathrm{CCl}_{4}$ deprivation under visible light irradiation. The transferred electrons to the $\mathrm{CB}$ of $\mathrm{TiO}_{2}$ from the excited complex molecule decomposed $\mathrm{CCl}_{4}$ at $\lambda>420 \mathrm{~nm}$, experiment in the absence of $\mathrm{TiO}_{2}$ revealed that there was no direct transfer between excited sensitizer complex molecule and pollutant, results also determined that sensitizing complex undergo redox reaction and photodegradation decreased in the absence of sacrificial electron donor which restore the $\mathrm{Ru}^{\mathrm{II}}$ complex which undergo continuous oxidations by electron transfer, to avoid this problem different types of alcohols can be used but 2-propanol was used for $\mathrm{Ru}^{\mathrm{II}} \mathrm{L} 3 / \mathrm{TiO}_{2} / \mathrm{CCl}_{4}$, in this process $\mathrm{CCl}_{4}$ was decomposed in $\mathrm{CCl}_{3}$ and $\mathrm{Cl}^{-}[132]$. 


\section{Heterostructures/heterojunctions/nano-composites}

Construction of heterojunctions or nanocomposites is a method to increase the charge separation and to increase the absorption towards visible light region in the solar spectrum. As discussed above, the increased charge separation will reduce recombination resulting in increased production of reactive oxidizing species leading to enhanced degradation of contaminants in water and wastewater treatment. The crystal lattice structure at the point of interface or junction plays an important role in tailoring the photocatalytic properties or quantum efficiency of the photocatalyst. A difference in the lattice spacing of two SC crystals cause the lattice mismatch at junction point which is the reason for defects formation which act as excited electron sink and lessens the electron hole fusion [133]. Careful selection of semiconductor material is required with respect to band edge positions. The band edge positions of widely used semiconductors are given in Figure 16. The traits for ideal nano-heterostructures which have to be used for photocatalytic processes are; (i) it should have large surface area and contain enough active sites; (ii) it should have high light absorption capacity to make efficient use of solar spectrum; (iii) there should be an effective separation of charge carriers in order to produce active radicals for pollutant degradation; while a co-catalyst in heterostructure should have ability to enhance the reaction rate, provide active sites and should act as electron scavengers [134]. Due to their increasing demand for the degradation of pollutants controllable fabrication of heterostructures/ nano-composites is possible, the different techniques which are being used over decades are chemical vapor deposition, chemical deposition, electrodeposition, etc. By using these techniques different types of heterostructures (capped and coupled) such as nano-composites, nano-rods, nano-sheets, nano-wires and core-shells (capped) structures have been reported. In comparison to single/alone SC the heterojunctions like $\mathrm{CdS} / \mathrm{TiO}_{2}, \mathrm{CdS} / \mathrm{ZnO}, \mathrm{ZnSe} / \mathrm{ZnO}, \mathrm{ZnS} / \mathrm{ZnO}, \mathrm{SnO}_{2} / \mathrm{CdS}$, $\mathrm{Bi}_{2} \mathrm{~S}_{3} / \mathrm{TiO}_{2}$ and some ternary composites like $\mathrm{Fe}_{3} \mathrm{O}_{4} / \mathrm{SiO}_{2} / \mathrm{TiO}_{2}, \mathrm{ZnO} / \mathrm{TiO}_{2} / \mathrm{CuO}$, etc. have been reported.

The heterojunction which are made by the combination of two or more nanocystalline semiconductors are very fruitful for photocatalysis regarding pollutant degradation and water splitting and being very famous as the Z-scheme process. Two main benefits of linking two or more semiconductors are (i) coupling of semiconductor having larger band gap with the semiconductor having smaller one, amplifies the photo response acting as a sensitizer; (ii) recombination is avoided by the transfer of excited electron in the low lying CB of SC bearing larger band gap [135]. So, it is crucial to find a suitable sensitizer for a semiconductor having larger band gap to get enhanced photocatalytic activity under visible light.

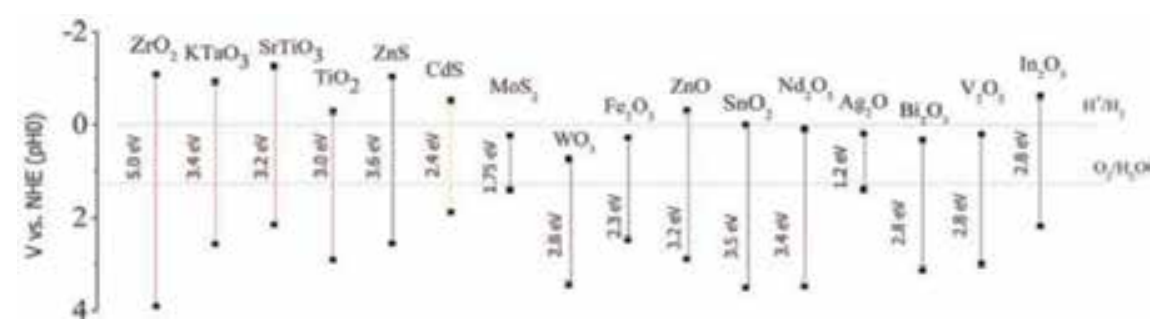

Figure 16.

Band gaps of different semiconductors with respect to NHE [17]. 


\subsection{Some $\mathrm{TiO}_{2}$-based heterostructures/nanocomposites}

$\mathrm{CdS}$ is an attractive semiconductor with a smaller band gap of $2.4 \mathrm{eV}$, which means it can be activated under visible irradiation. The drawback to this and some other semiconductors having smaller band gaps is their unstability against photocorrosion. To avoid this problem, this type of semiconductors are coupled with those which have larger band gap like $\mathrm{ZnO}, \mathrm{ZrO}_{2}, \mathrm{TiO}_{2}$, etc. and play a vital role in improving charge separation. As mentioned above there are many strategies to prepare the heterostructures and one is micro-emulsion method. CdS nanoparticles were coupled with $\mathrm{TiO}_{2}$ via micro-emulsion method under ultrasonic irradiation for the formation of core-shell type of nanostructure with uniformed coating of $\mathrm{TiO}_{2}$ nanoparticles on CdS, the depth of $\mathrm{TiO}_{2}$ shell was in range from 1.4 to $2.3 \mathrm{~nm}$ which could be controlled by varying the preparation temperature and precursors concentration. The nanostructure gave the red-shift in spectra which is typical trait of core-shell heterojunction [136]. Another $\mathrm{TiO}_{2} / \mathrm{CdS}$ core-shell nanorod heterostructure was obtained by chemical bath deposition method, $\mathrm{TiO}_{2}$ core was prepared firstly by the hydrothermal method and was converted to substrate for the deposition of CdS nanoparticles by dipping it an aqueous bath having $10 \mathrm{ml}$ $0.02 \mathrm{M} \mathrm{CdCl}_{2} .2 .5 \mathrm{H}_{2} \mathrm{O}, 10 \mathrm{ml} 0.2 \mathrm{M} \mathrm{CH}_{4} \mathrm{~N}_{2} \mathrm{~S}, 10 \mathrm{ml}$ of $1.5 \mathrm{M} \mathrm{NH}_{4} \mathrm{NO}_{3}$ and $10 \mathrm{ml}$ $0.5 \mathrm{M} \mathrm{KOH}$ to adsorb CdS nanoparticles on $\mathrm{TiO}_{2}$ rod at $85^{\circ} \mathrm{C}$. The resulting structure gave the highest charge separation (Figure 17) efficiency at incident wavelength of $500 \mathrm{~nm}$ [137].

A thin film heterostructure of copper zinc tin sulfide $\left(\mathrm{Cu}_{2} \mathrm{ZnSnS} 4\right)-\mathrm{TiO}_{2}$ was prepared by combining an $n$-type $\left(\mathrm{TiO}_{2}\right)$ and $p$-type (CZTS) heterostructure. To confirm the formation of visible light active photocatalyst it is suggested that the highly stable semiconductor with higher band gap like $\mathrm{TiO}_{2}$ should be present at most upper/outer layer in the heterostructure which will protect the

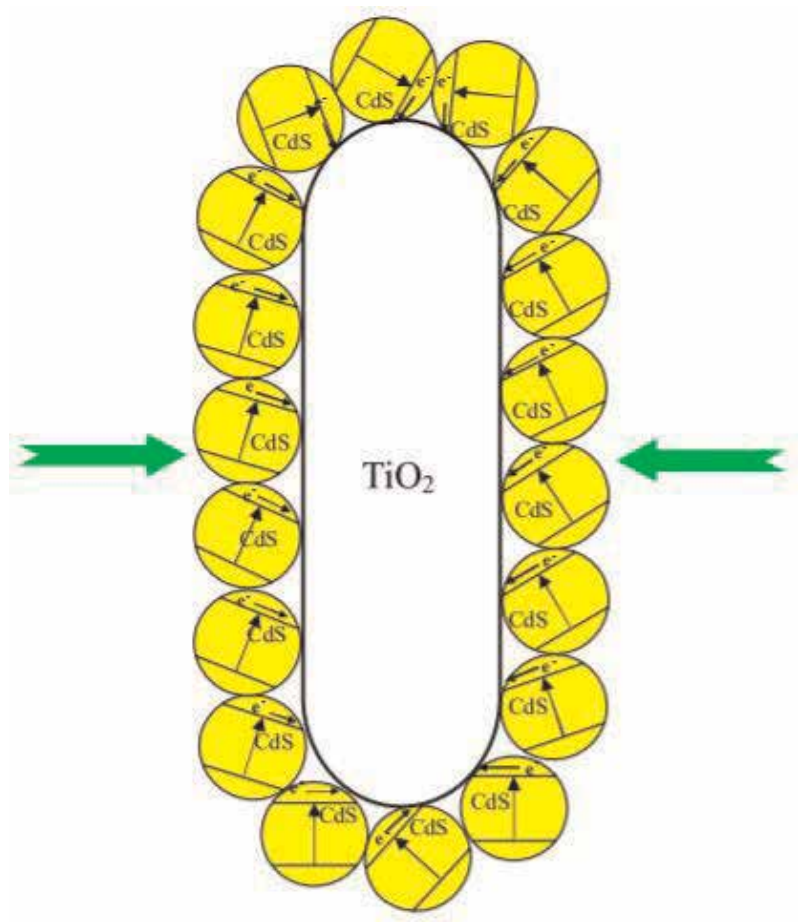

Figure 17.

Scheme illustrating charge injection from excited CdS nanoparticles to $\mathrm{TiO}_{2} \operatorname{rod}[137]$. 
semiconductors having smaller band gap to come in direct contact with wastewater/ water in order to avoid physical or chemical reactions and to absorb penetrated light. In the present study the thickness of outer layers of $\mathrm{TiO}_{2}$ was varied by changing the concentration of precursor $\left(\mathrm{TiCl}_{4} 0.1\right.$ and $\left.0.05 \mathrm{M}\right)$ and two types of catalysts also tested for photoactivity, uniform crystallinity depended on the thickness of the $\mathrm{TiO}_{2}$ film. The schematic illustration of photodegradation mechanism is given in Figure 18. Analysis like TEM, SEM and EDX discovered the presence of multiple $\mathrm{TiO}_{2}$ aggregates on the surface of CZTS thin films which have band gap of $1.46 \mathrm{eV}$. The catalyst prepared from $0.05 \mathrm{M}$ solution exhibited poor $\mathrm{Cu}$ and enhanced $\mathrm{Zn}$ deposition which led to enhanced charge separation in the composite. Methylene blue dye was degraded under visible light by $0.1 \mathrm{M}$ sample and shown efficiency of $43.50 \%$ while $0.05 \mathrm{M}$ sample gave $35.7 \%$ removal under wavelength of $400-700 \mathrm{~nm}$. In dark conditions $\mathrm{TiO}_{2}$-CZTS of $0.05 \mathrm{M}$ gave efficiency of $29.81 \%$ after $8 \mathrm{~h}$ [138].

Recently, the preparation of magnetic core-shell-shell heterostructure nanocomposite of $\mathrm{Fe}_{3} \mathrm{O}_{4} / \mathrm{SiO}_{2} / \mathrm{TiO}_{2}$ has been reported for the degradation of 2-CP in unreal wastewater under UV irradiation. Catalyst was prepared by three steps-facile synthesis process. Analysis was performed for surface morphology, chemical properties and for crystal structure. The size of NPs of magnetic core was $24.0 \mathrm{~nm}$ and that of magnetic shell-shell was $70.2 \mathrm{~nm}$. Experiments were performed by varying the experimental parameters like $\mathrm{pH}$, catalyst loading and pollutant concentration; results determined that effective degradation was $\mathrm{pH}$ dependant. Catalyst was regenerated after use by placing magnet under reaction container and retained its efficiency about $60 \%$ even after 3 cycles of use [139].

Another example of heterojunction is coupling of $\mathrm{Ag}_{3} \mathrm{PO}_{4}$ with $\mathrm{TiO}_{2}$ to degrade the organic pollutants under visible light irradiation using silver nitrate, sodium phosphate and $\mathrm{TiO}_{2}$ Degussa (P25) as precursors followed by in-situ precipitation method, by coupling the semiconductors the band gap reduced to $2.3-2.5 \mathrm{eV}$ and shown a notable shift from UV region to visible spectra. Analysis confirmed the size of particles and uniform crystallinity 2-CP was selected as the target pollutant because this parent compounds and derivatives are being an emerging pollutant and

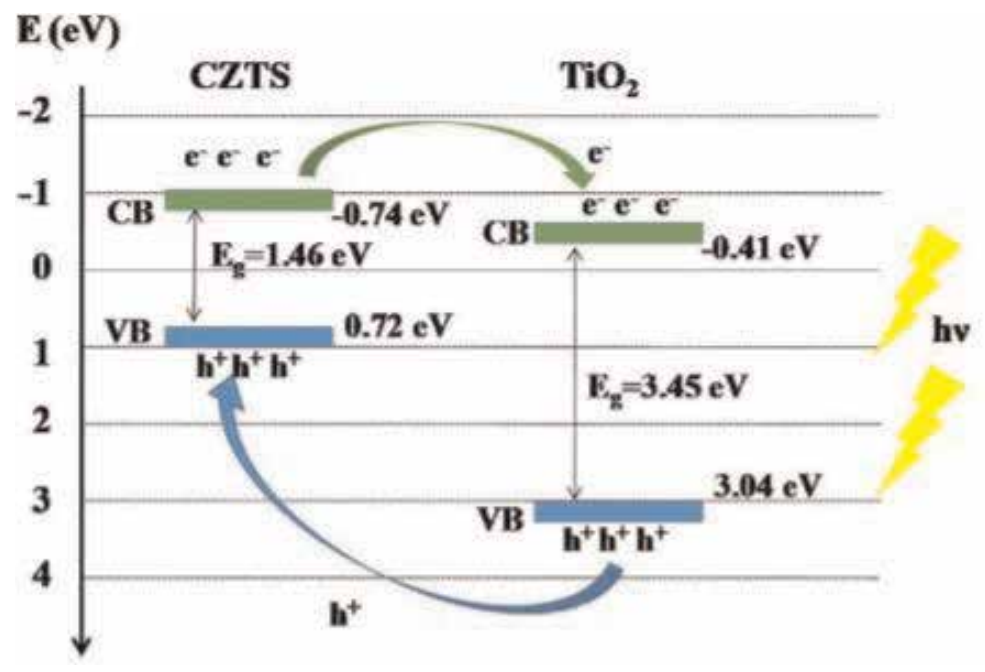

Figure 18.

Schematic illustration of charge separation in thin-film heterostructure; visible light passes through the upper layer of $\mathrm{TiO}_{2}$ and penetrated in lower CZTS thin film electrons gets excited and transferred to the $\mathrm{CB}$ of $\mathrm{TiO}_{2}$ creating and leaving the hole behind; electron in the $\mathrm{VB}$ of $\mathrm{TiO}_{2}$ gets excited after exposure to UV light and hole produced diffuses to the VB of CZTS thus completing the circuit, while the holes at the VBs act as oxidants and electrons in CBs act as reductants to produce oxidizing species [138]. 
already in the POPs. Experiments were performed by changing the parameters like $\mathrm{pH}$, catalyst loading and pollutant concentration. At low $\mathrm{pH}$ of 3 greater adsorption of pollutant was observed and maximum degradation was reported. The structure maintained its stability to $100 \%$ (Figure 19) even after 3 cycles of use with fresh 2-CP [112].

Pan et al. has reported a novel structure of $\mathrm{TiO}_{2}-\mathrm{ZnO}$ nanocomposite spheres decorated with $\mathrm{ZnO}$, this structure was prepared in order to increase the photocatalytic activity by improving charge separation in heterostructure. The composite was prepared by one-pot solvothermal method using tributyl titanate and zinc acetate as precursors and heating the mixed solution at $150^{\circ} \mathrm{C}$ for $24 \mathrm{~h}$ followed by calcination in air, as-prepared product was characterized. Surprisingly, by increasing to amount of $\mathrm{Zn}$ precursor the clusters of $\mathrm{ZnO}$ were produced on the surface of spheres (Figure 20). Analysis determined that prepared $\mathrm{ZnO}$ and $\mathrm{TiO}_{2}$ had the particle size in spheres was about $4 \mathrm{~nm}$ and spheres' surface thickness was about $5 \mathrm{~nm}$. It was also discovered that the clusters which decorated the spheres

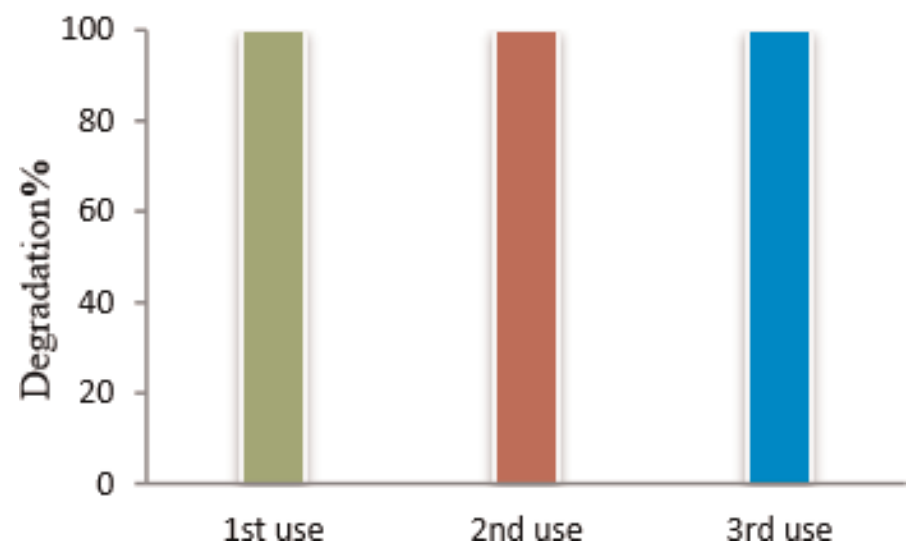

Figure 19.

Retained catalytic stability even after 3 cycles of use with fresh 2-CP [112].

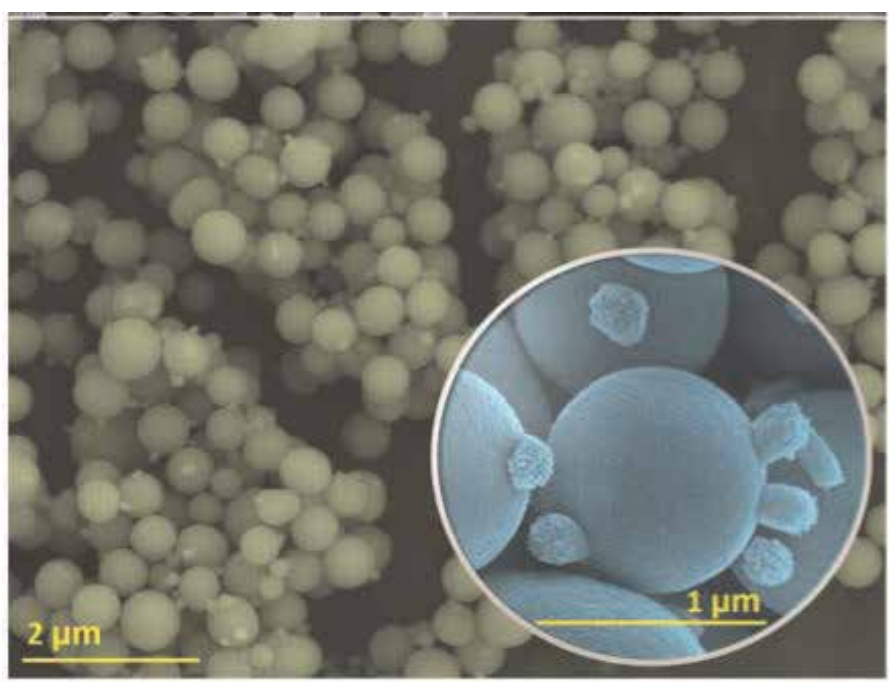

Figure 20.

SEM image of $\mathrm{TiO}_{2}-\mathrm{ZnO}-\mathrm{SC}$, showing the decorated clusters of $\mathrm{ZnO}$ on the $\mathrm{TiO}_{2}-\mathrm{ZnO}$ nanocomposite [140]. 
only had $\mathrm{Zn}$ and $\mathrm{O}$ and did not have Ti atoms. PL spectra for composite indicated the increased charge transfer and separation as compared to pristine $\mathrm{ZnO}$ and $\mathrm{TiO}_{2}$ due to presence of $\mathrm{ZnO}$ clusters acting as electron scavengers. To investigate the photocatalytic performance of $\mathrm{ZnO}-\mathrm{TiO}_{2}-\mathrm{SC}$ rohdamine $\mathrm{B}(\mathrm{rhB})$ degradation was tested, $\mathrm{OH}^{\circ}$ were reported to be the reactive specie, the activity of $\mathrm{ZnO}-\mathrm{TiO}_{2}$-SC for photodegradation was 2.3-2.8 times higher than that of pristine nanoparticles [140].

Stable preparation of core/shell nanocomposite of $\mathrm{TiO}_{2} / \mathrm{FeS}_{2}$ by solvothermal method has been reported for the photocatalytic production of hydrogen [141]. The benefits for incorporating different metal oxides/sulfides led to the structural and chemical modifications which render them better than that of parent materials. Rashid et al. has reported the formation of stable spherical nanocrystals of anatase$\mathrm{TiO}_{2} / \mathrm{FeS}_{2}$ by following wet chemical process, for the degradation of organic pollutants under visible light using $\mathrm{FeSO}_{4} .7 \mathrm{H}_{2} \mathrm{O}, \mathrm{Na}_{2} \mathrm{~S}_{2} \mathrm{O}_{3}$ and $\mathrm{TiCl}_{4}$ as precursors. Micrographs and other analysis determined the morphology, chemical properties, crystal structure, oxidation states and band gap positions which was $2.67 \mathrm{eV}$ for the composite and gave the red shift in spectra. The photocatalytic activity of $\mathrm{FeS}_{2}$ and $\mathrm{TiO}_{2}$ was tested alone and also for composite but the photoactivity of nanocrystal composite for the degradation of methylene blue, was much higher than that of pristine compounds. Experiments were performed by varying the parameters like $\mathrm{pH}$, catalyst dose and pollutant concentration. Composite was found to be much stable as it shown only 9\% loss in photocatalytic activity after 3 cycles of use [142].

Among venedates, bismuth vanadate and indium vanadate have gained much respect mainly due to stability, nontoxicity and photocatalytic activity under visible light $(\lambda>420 \mathrm{~nm})$ in coupled or single conditions. For coupled semiconductor heterostructure of $\mathrm{TiO}_{2} / \mathrm{InVO}_{4}, \mathrm{InVO}_{4}$ was prepared using organic precursor method and was incorporated with $\mathrm{TiO}_{2}$ by grinding, the catalyst shown higher photocatalytic degradation of 2-CP under visible light as compared to $\mathrm{TiO}_{2}$ alone. Among different conditions the best condition for degradation were found at $5 \mathrm{pH}$ in $1 \mathrm{~g} / \mathrm{L}$ of catalyst and $50 \mathrm{mg} / \mathrm{L}$ of pollutant with irradiation time of $180 \mathrm{~min}$ $[143,144]$. Li et al. has reported the unique structure of $\mathrm{TiO}_{2}$ incorporated on the polymethyl methacrylate (PMMA) nanofibers for the degradation of pollutants under the UV irradiation. The $\mathrm{TiO}_{2}$ nanoparticles were supported on fibers by the hydrothermal treatment at $135^{\circ} \mathrm{C}$ for $8 \mathrm{~h}$ using titanium n-butoxide and PMMA nanofibers as precursors. Analysis indicated that about $42 \%$ of tetragonal anatase $\mathrm{TiO}_{2}$ particles were adsorbed on the surface of fibers (Figure 21). Methylene orange was used as model pollutant and its complete degradation was observed after $50 \mathrm{~min}$ using $0.1 \mathrm{~g}$ of catalyst for $10 \mathrm{mg} / \mathrm{L}$ of pollutant. This good photocatalytic activity could be attributed to the (i) decoration of $\mathrm{TiO}_{2}$ nanoparticles on the PMMA fibers which assisted the adsorption of pollutants and helped them to come in contact with photocatalyst; (ii) high quantity of adsorbed $\mathrm{TiO}_{2}$ provides numerous action sites for the degradation of pollutants. Catalyst revealed the efficiency of about $94.4 \%$ even at the end of fifth cycle for the degradation of fresh MO which determined the stability and reusability of catalyst [145].

A novel nanocomposite of $\mathrm{BiOBr} / \mathrm{TiO}_{2}$ has been reported and prepared for the first time with facile acid assisted precipitation method by using TTIP, $\mathrm{KBr}$ and $\left(\left(\mathrm{BiNO}_{3}\right)_{3} .5 \mathrm{H}_{2} \mathrm{O}\right)$ as precursors. Catalysts of different percentages were prepared by using different molar ratios of $\mathrm{TiO}_{2}$ as a base material and $15 \% \mathrm{BiOBr} / \mathrm{TiO}$ behaved as an active catalyst. Analysis and characterization revealed the perfect structural integrity, increased surface area and increased absorption of light because of the formation of nanoscale layered butterfly like clustal structures with each flake having the broad absorption spectrum of about $500-800 \mathrm{~nm}$ with $<50 \mathrm{~nm}$ thickness (Figure 22). PL spectral analysis determined the band gap of $2.81 \mathrm{eV}$ and wavelength was observed from 480 to $570 \mathrm{~nm}$ for $15 \% \mathrm{BiOBr} / \mathrm{TiO}_{2}$ and it gave the 


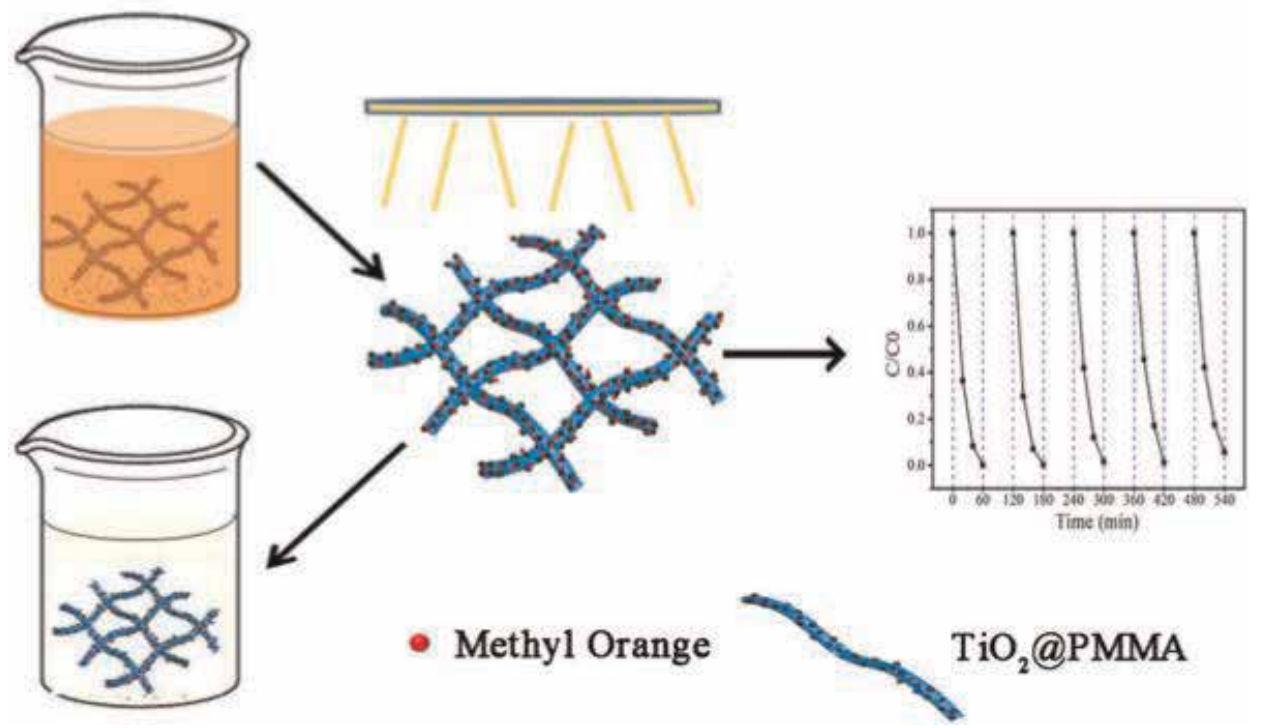

Figure 21.

Schematic illustration of formation of PMMA fibers and their photoactivity [145].

degradation of aqueous ciprofloxacin (target pollutant) under visible light at $\lambda>420 \mathrm{~nm}$ about $92.5 \%$ and under direct sunlight it gave $100 \%$ degradation utilizing reaction time of $2.5 \mathrm{~h}$. Radical scavenging study indicated that besides superoxide radicals and holes the $\mathrm{OH}^{*}$ had dominant effect on net photodegradation process. Results also suggested that the catalyst was 9.4 and 5.2 times active in degradation than pristine $\mathrm{BiOBr}$ and $\mathrm{TiO}_{2}$, reusability experiments determined the high stability of catalyst as it suffered loss of only $12 \%$ even after 5 cycles of fresh CIP degradation [146].
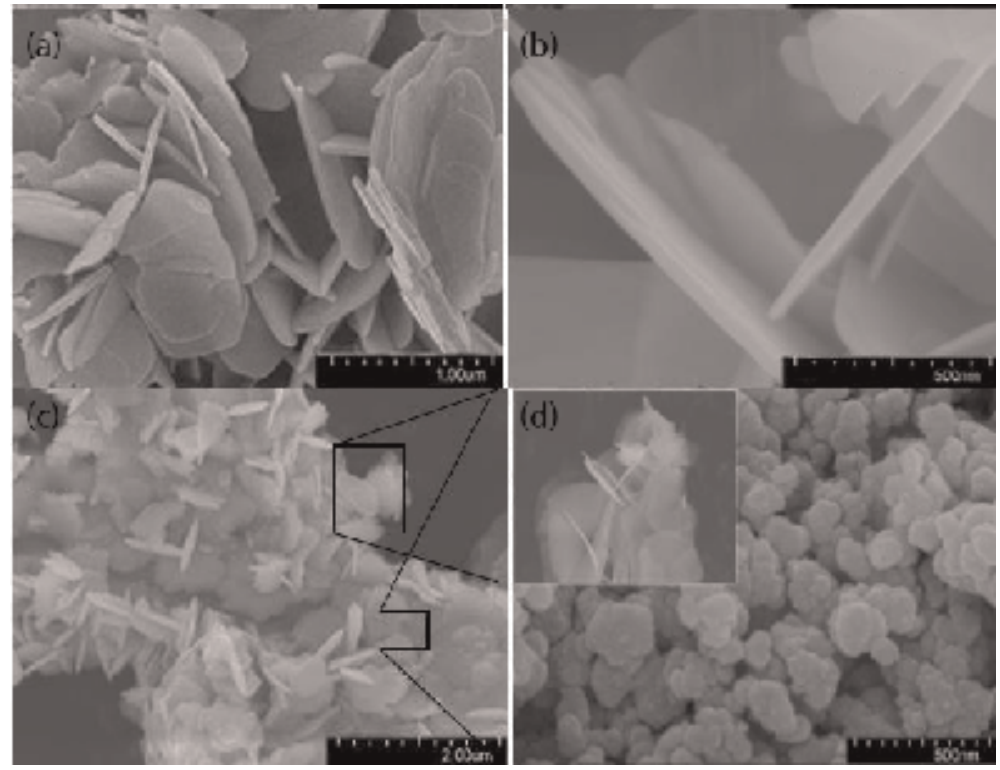

Figure 22.

SEM images of $(a, b)$ pristine $\mathrm{BiOBr}$; and $(c, d) 15 \% \mathrm{BiOBr} / \mathrm{TiO}_{2}$ nanocomposite. 


\subsection{Heterostructures/nanocomposites of different SCs}

In addition to $\mathrm{TiO}_{2}$ there are numerous semiconductors which can be coupled with other $\mathrm{SC}$ and can be incorporated into heterostructures or composites like $\mathrm{WO}_{3}, \mathrm{ZnO}, \mathrm{BiVO}_{4}, \mathrm{ZnSe}, \mathrm{C}_{3} \mathrm{~N}_{4}, \mathrm{In}_{2} \mathrm{O}_{3}, \mathrm{CuS}, \mathrm{MoS}, \mathrm{Cu}_{2} \mathrm{O}$ and many more. So another example of inorganic heterostructure is the template free simple synthesis of CdS$\mathrm{ZnO}$ nanocomposites. This self-assembled flower like structure resulted from coupling of two SCs which increased the charge separation and demonstrated greater photocatalytic activity. The average size of flower was $400 \mathrm{~nm}$ with the petal size of 100-150 nm and the rod among petals had the size of $10 \mathrm{~nm}$, band gap of composite was analyzed to be $2.19 \mathrm{eV}$ and absorption wavelength of $561 \mathrm{~nm}$ was reported. The composite gave the photodegradation of rhB about $90 \%$ in $190 \mathrm{~min}$ under solar light and $24 \%$ in dark. The scheme of process of particles is shown in (Figure 23) [147].

Cho et al. prepared three different types of 3D ZnSe/ZnO heterostructures by simple solution-based surface modification reactions. Three different types of heterostructures demonstrated higher photocatalytic activities by exhibiting absorption in visible region (at $\lambda>486 \mathrm{~nm}$ ) as compared to pure $3 \mathrm{D} \mathrm{ZnSe}$ and $\mathrm{ZnO}$ structures, the visible light activity of heterostructures varied according to the crystal structures. As shown in (Figure 24) the $\mathrm{CB}$ of $\mathrm{ZnO}$ is in between the $\mathrm{CB}$ and $\mathrm{VB}$ of $\mathrm{ZnSe}$ showing the type II band alignment, before exposure to sunlight the catalysts and orange II (targeted pollutant) were kept at stirring for $30 \mathrm{~min}$ in dark to attain an equilibrium for adsorption and desorption, upon exposure to visible light the $\mathrm{e}^{-} / \mathrm{h}^{+}$pair was generated in $\mathrm{ZnSe}$ crystal, electron transferred to the $\mathrm{CB}$ of $\mathrm{ZnO}$ to reduce oxygen and holes could oxidize either the water or $\mathrm{OH}$ ion or directly oxidize the orange II, ended with the mineralization of organic compound [148].

Zeyan et al. has produced the $\operatorname{In}_{2} \mathrm{O}_{3} / \mathrm{ZnO}$ heteronanostructures by the coprecipitation method having average size of $40-60 \mathrm{~nm}$ by using the respective precursors. The composite was annealed at different temperatures ranging from 600 to $1000^{\circ} \mathrm{C}$, among changed compositions and annealing temperatures the highest photocatalytic activity for the degradation of methylene blue was shown by the composite annealed at $800^{\circ} \mathrm{C}$ with $\mathrm{In} / \mathrm{Zn}$ molar ratio of $1: 1$ and the maximum absorption was about $\lambda=663 \mathrm{~nm}$. A p-n junction was established at the SCs interface and presence of $\mathrm{Zn}^{2+}$ and $\mathrm{In}^{3+}$ was reported in lattice, that enhanced the charge separation and production of $\mathrm{OH}^{*}$ and $\mathrm{O}_{2}{ }^{-}$attributed as the main reason for enhanced photocatalytic activity semiconductor coupling ([149]). Coupling of

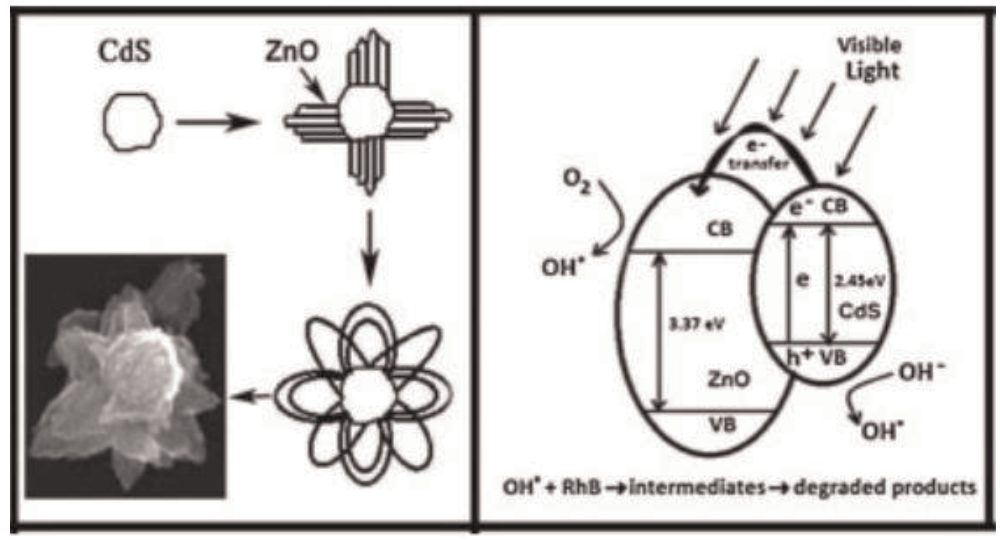

Figure 23.

Structure of flower shaped nanocomposite and admirable charge transfer due to heterostructure formation [147]. 


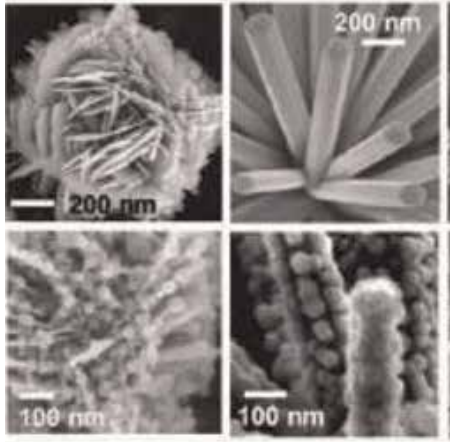

(a)

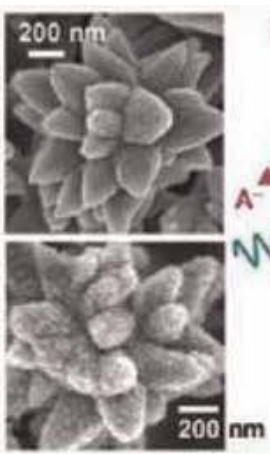

$200 \mathrm{~nm}$

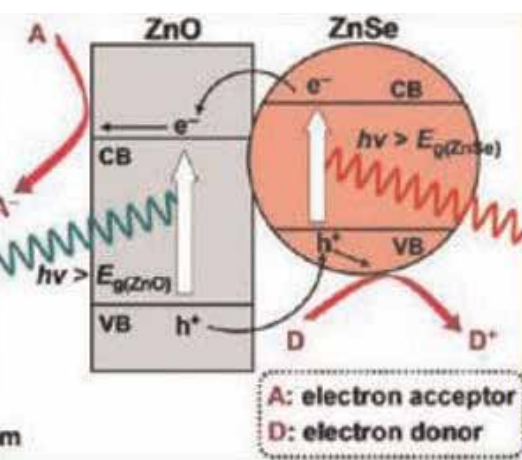

(b)

Figure 24 .

(a) SEM images of different ${ }_{3} \mathrm{D} \mathrm{ZnO/ZnSe} \mathrm{heterostructures} \mathrm{and;} \mathrm{(b)} \mathrm{schematic} \mathrm{diagram} \mathrm{of} \mathrm{charge} \mathrm{separation} \mathrm{by}$ coupling of two SCs [148].

mixed oxide SC with metal oxide has also been reported and have shown some modified properties, example for this type of heterojunction is the nanocomposite of $\mathrm{ZnO}-\mathrm{ZnWO}_{4}$ (both are the n-type SCs) prepared by the sol-gel method and was analysed by XRD, BET, SEM and TEM. The nanocomposites were prepared by varying the molar ratio of $\mathrm{ZnO}$ and $\mathrm{ZnWO}_{4}$ to study the influence of molarity on photoactivity and $\mathrm{Zn}-\mathrm{ZW}_{0.25}$ calcined for $2 \mathrm{~h}$ at $600^{\circ} \mathrm{C}$ shown greater photodegradation of 4-nitrophenol (target pollutant). The band gaps for $\mathrm{ZnO}$ and $\mathrm{ZnWO}_{4}$ was calculated to be 3.21 and $3.14 \mathrm{eV}$, when the nanocomposite was exposed to UV light the electron transferred from the $\mathrm{CB}$ of $\mathrm{ZnO}\left(\mathrm{E}_{\mathrm{CB}}=-0.36 \mathrm{eV}\right)$ to $\mathrm{CB}$ of $\mathrm{ZnWO}_{4}\left(\mathrm{E}_{\mathrm{CB}}=-0.14 \mathrm{eV}\right)$ due to difference in the position of CBs (from cathodic to anodic condition) and same behaviour was proposed for hole to transfer from $\mathrm{VB}$ of $\mathrm{ZnWO}_{4}\left(\mathrm{E}_{\mathrm{VB}}=3.00 \mathrm{eV}\right)$ to $\mathrm{VB}$ of $\mathrm{ZnO}\left(\mathrm{E}_{\mathrm{VB}}=2.84 \mathrm{eV}\right)$, thus enhancing the charge separation and completion of circuit due to formation of heterostructures which resulted from the mixing of two SCs with dissimilar energy levels of VB and CB [150]. In addition to the above mentioned heterostructures other structures like nanorods, nano sheets, nanowires, $\mathrm{CdSe} / \mathrm{ZnO}, \mathrm{CdsSe} / \mathrm{ZnO}$ [17], $\mathrm{TiO}_{2} / \mathrm{ZnO}$ [151], $\mathrm{CuS} / \mathrm{ZnO}$ [152] has also been found to enhance visible light activity either for pollutant degradation, overall water splitting or hydrogen production.

$\mathrm{BiOCl} / \mathrm{BiVO}_{4}$, another novel $\mathrm{p}-\mathrm{n}$ heterostructure of coupled semiconductors with type II band alignment was prepared by hydrothermal method for the decomposition of methyl orange under visible light irradiation having ability for active separation of charges (Figure 25 ), the powders were prepared by using $\mathrm{NH}_{4} \mathrm{VO}_{3}, \mathrm{Bi}$ $\left(\mathrm{NO}_{3}\right)_{3} \cdot 5 \mathrm{H}_{2} \mathrm{O}, \mathrm{NaOH}$ and $\mathrm{HCl}$ as precursors for $\mathrm{BiVO}_{4}$ and $\mathrm{BiOCl}$, followed by the stirring, heating and washing. Catalysts having different molar concentrations were prepared by varying the amount of $\mathrm{HCl}$ in the mixture and the catalyst having the molar ratio of $0.75 \mathrm{BiOCl} / \mathrm{BiVO}_{4}$ was seemed to be more active. Analysis and characterizations determined th-presence of $\mathrm{Bi}$ as $\mathrm{Bi}^{3+}$ and vanadium as $\mathrm{V}^{5+}$ and $\mathrm{O}$ as $\mathrm{O}_{2}{ }^{--}$and $\mathrm{Cl}_{\text {as }} \mathrm{Cl}^{-}$. For the tests of photocatalytic activity, Degussa P25 was used as control group, and results determined the increased degradation of $\mathrm{MO}$ in $\mathrm{BiOCl} /$ $\mathrm{BiVO}_{4}$ system and it was about 1.89 times greater than that of $\mathrm{TiO}_{2}$ and 3.54 times from $\mathrm{BiVO}_{4}$. Free radical scavengers illuminated that the holes in the valence band of $p$-type part of heterojunction played an important role in the direct oxidation of $\mathrm{MO}, \mathrm{OH}^{\circ}$ were the dominant species and $\mathrm{DO}$ acted as electron acceptor from the $\mathrm{CB}$. The stability of catalyst was tested and after the use of 5 cycles, it did not show any significant loss, which indicated the effectiveness and stability against photocorrosion [153]. Zhijie et al. has reported the fabrication of a novel 


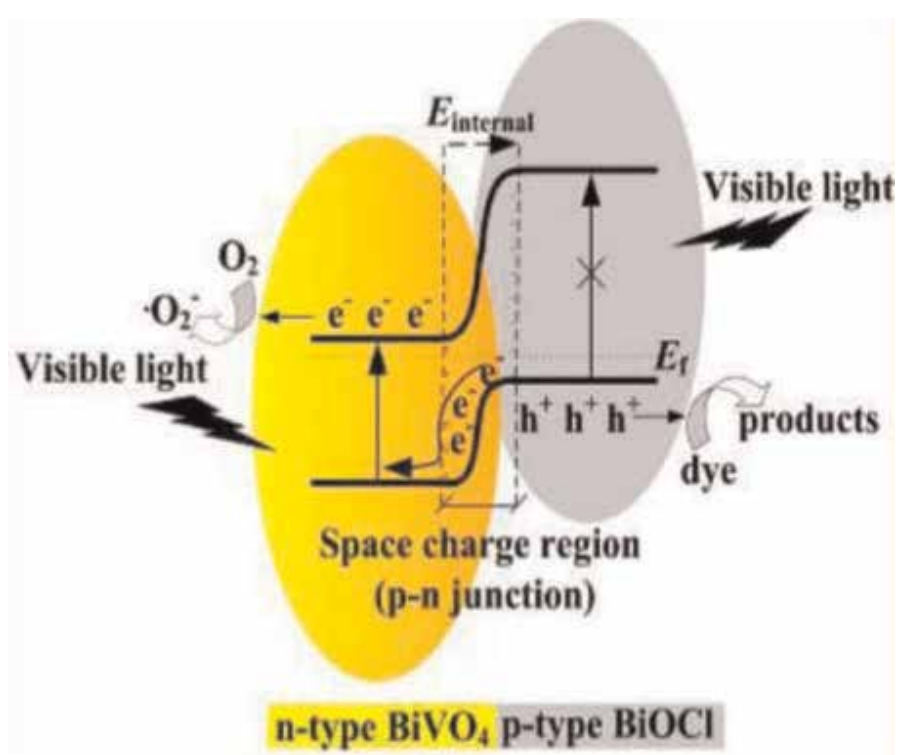

Figure 25.

Schematic illustration of effective charge separation between $n$ - and p-type SC upon exposure to UV and Vis light [153].

nanocomposite of $\mathrm{Bi}_{2} \mathrm{~S}_{3} / \mathrm{Bi}_{2} \mathrm{WO}_{6}$ by hydrothermal method to reduce the limitation of low photocatalytic ability of $\mathrm{Bi}_{2} \mathrm{WO}_{6}$ resulted from the potential relaxation of electron into hole. In this structure $\mathrm{Bi}_{2} \mathrm{~S}_{3}$ acted as a sensitizer having the band gap of $1.3 \mathrm{eV}$ and the system possessed the photoabsorption of $800 \mathrm{~nm}$ which meant it covered almost whole range of visible region. The equipped photocatalyst exhibited much enhanced photocatalytic activity for the degradation of phenol (a colorless pollutant) under visible light which was about 6.2 times greater than that of original $\mathrm{Bi}_{2} \mathrm{WO}_{6}$. Thanks to efficient charge separation for the enhanced photocatalytic activity resulted from the formation of heterojunction at the semiconductor interface $[82,83]$. The heterostructure formed by mixing of graphene with $\mathrm{BiFeO}_{3}$ was prepared by one-pot hydrothermal method. The band gap of composite could be fabricated from 1.78 to $2.24 \mathrm{eV}$ by changing the concentration of $\mathrm{OH}$ groups during the synthesis. Raman and XPS analysis revealed that the formation of Fe-O-C bonds enhanced the stability of composite. The increased photodegradation of Congo Red (CR) dye was observed in $2 \mathrm{~h}$ which increased from 40 to $71 \%$ due to the breakage of azo bonds and naphthalene rings at different wavelengths which can be due to the increased adsorption of CR on the graphene due to the infinite numbers of conjugated $\pi$-bond ([122]).

$\mathrm{WO}_{3}$ is a known semiconductor due to its polycrystalline forms and smaller band gap of about 2.4-2.8 eV depending on crystal structure; which means its electrons can be excited by visible light irradiation, the main limitations of this SC which keep it far from becoming a useful semiconductor are; higher rate of recombination and its unstability against photocorrosion [154]. $\mathrm{WO}_{3}$ is incorporated in heterojunctions in order to increase the absorption in visible light region. Shamaila et al. has reported the formation of $\mathrm{WO}_{3} / \mathrm{BiOCl}$ heterojunction or the degradation of

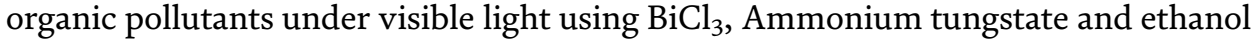
as precursors, 2D nanoflakes of $\mathrm{BiOCl}$ of the size of 75-200 $\mathrm{nm}$ were fabricated (Figure 26) by following a new low temperature route and nanocomposite was prepared to enhance the visible light response, $\mathrm{BiOCl}$ performed the role of a main photocatalyst while $\mathrm{WO}_{3}$ worked as a sensitizer. For the prepared composite the absorption range increased from 360 to $500 \mathrm{~nm}$ as the quantity of $\mathrm{WO}_{3}$ increased 


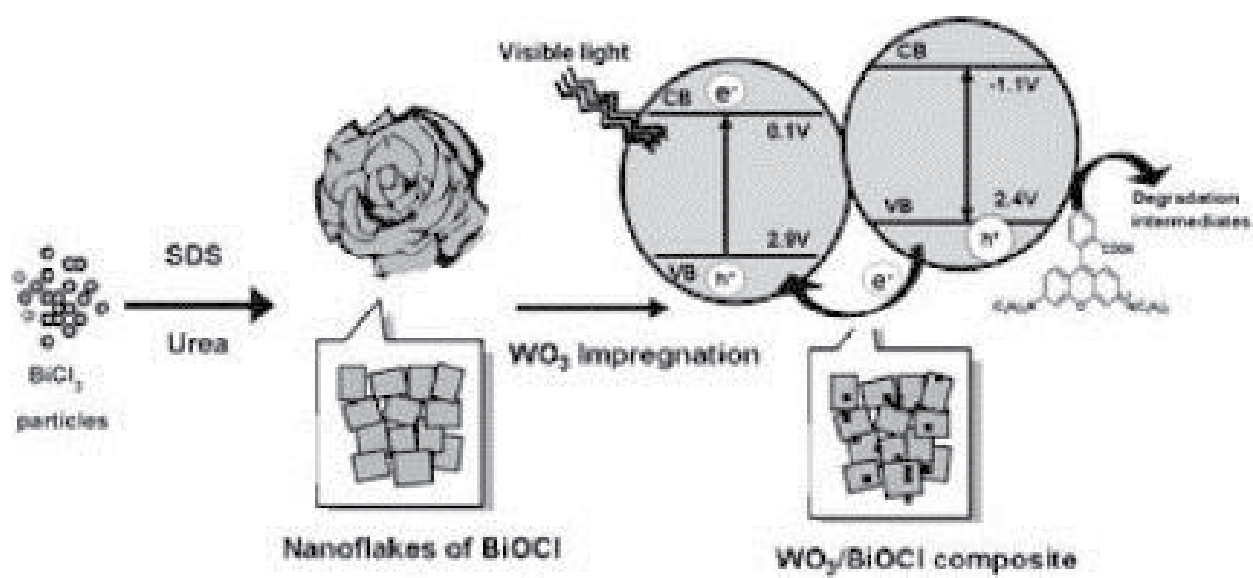

Figure 26.

Composite synthesis route and proposed mechanism for photodegradation of $r h B$ [155].

while synthesis, the catalyst gave $100 \%$ deterioration of Rhodamine B was under visible light during the irradiation time of $180 \mathrm{~min}$, which was greater than the activity of $\mathrm{WO}_{3}, \mathrm{BiOCl}$ and Degussa P25 [155].

Another heterojunction photocatalyst with high photocatalytic activity is $\mathrm{WO}_{3} /$ $\mathrm{SrNb}_{2} \mathrm{O}_{6}$, was prepared by the milling-annealing method which was found to be better than the direct mixing method as this method could build a firm chemically bonded interface between two semiconductors. Results determined that the composite had higher photocatalytic activity as compared to pure $\mathrm{WO}_{3}$ and $\mathrm{SrNb}_{2} \mathrm{O}_{6}$. As we know that anything which can scavenge the excited electron can be a reason for increased photocatalytic process so, the effective charge separation among semiconductors and formation of holes and radicals led to the direct or indirect degradation of methyl orange [156]. $\mathrm{Ag}_{3} \mathrm{PO}_{4} / \mathrm{WO}_{3}$ nanocomposites were prepared by a deposition-precipitation method using $\mathrm{Na}_{2} \mathrm{WO}_{4} \cdot 2 \mathrm{H}_{2} \mathrm{O}, \mathrm{NH}_{4} \mathrm{Cl}, \mathrm{AgNO}_{3}$ and $\mathrm{Na}_{2} \mathrm{HPO}_{4}$ as precursors and prepared powders were characterized by SEM, XRD and UV-Vis. Catalysts were prepared of variable molar ratios of $\mathrm{Ag}_{3} \mathrm{PO}_{4}: \mathrm{WO}_{3}$ and the catalyst having ratio of $6: 4\left(\mathrm{AW}_{6 / 4}\right)$ shown the greater photocatalytic activity for the degradation of $\mathrm{rhB}$ and $\mathrm{MO}$ at the wavelength $\lambda>420 \mathrm{~nm}$, mainly due to the excellent separation of charge carriers. Reusability tests indicated that composite had higher recyclability as compared to $\mathrm{Ag}_{3} \mathrm{PO}_{4}$ alone as $\mathrm{AW}_{6 / 4}$ gave $97 \%$ removal of $\mathrm{rhB}$ and $\mathrm{MO}$ in 6 and $35 \mathrm{~min}$ (after being exposed to visible light) even after the fifth run (had same efficiency for first run) while $\mathrm{Ag}_{3} \mathrm{PO}_{4}$ gave only $25 \%$ degradation at the fifth run due to the absence of sacrificial donor. Stability analysis revealed that catalyst $\mathrm{AW}_{6 / 4}$ was stable against photocorrosion as it retained the XRD pattern even after 5 cycles for degrading fresh rhB, only a small amount of metallic Silver was observed on $\mathrm{Ag}_{3} \mathrm{PO}_{4}$ after use, SEM analysis also supported stability result [157].

A hybrid photocatalyst $\mathrm{W}_{18} \mathrm{O}_{49} / \mathrm{TiO}_{2}$ having an urchin like structure (Figure 27) was prepared by an alcohol thermal method, which had high surface area of $178 \mathrm{~m}^{2} \mathrm{~g}^{-1}$ and shown absorption in the wide range of $200-800 \mathrm{~nm}$ and tested for the photodisintegration of $\mathrm{MO}$ and phenol under UV-visible irradiation. The hybrid photocatalyst attained synergetic increase in photoactivity and photostability of $\mathrm{W}_{18} \mathrm{O}_{49}$, well-related band structure enhanced the charge separation and transfer which led to the production of free radicals as well as prevented the $\mathrm{W}_{18} \mathrm{O}_{49}$ from self-oxidation due to holes as they moved towards $\mathrm{TiO}_{2}$. Free radical scavenging tests indicated that $\mathrm{O}_{2}{ }^{--}$was reactive oxidizing specie for the degradation of MO and phenol. Reusability tests revealed the stability of catalyst as it maintained its 


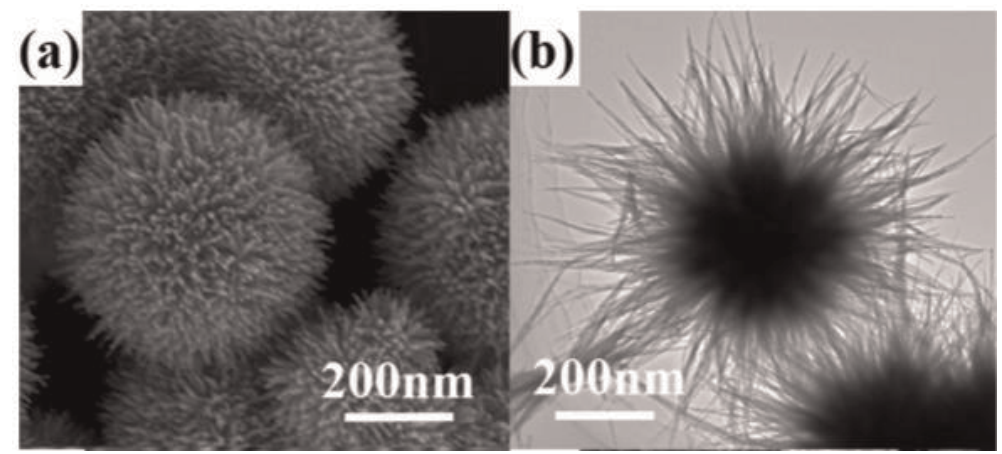

Figure 27.

(a) SEM image of $\mathrm{W}_{18} \mathrm{O}_{49}$ (b) TEM image of $\mathrm{W}_{18} \mathrm{O}_{49}$ [158].

XRD spectra even after the fifth cycle which meant catalyst did not suffer any noticeable loss, hybrid composite also maintained its original blue color at the end of fifth run [158].

From metal tungstate an example of a $\mathrm{p}-\mathrm{n}$ heterojunction is the fabrication of a novel Z-scheme $\mathrm{WO}_{3} / \mathrm{CdWO}_{4}$ photocatalyst by the fusion of sheet like $\mathrm{WO}_{3}$ (n-type) and rod like nanostructure of $\mathrm{CdWO}_{4}$ (p-type), for this purpose the catalyst were prepared separately by using respective precursors and fusion was done by using hydrothermal and chemisorption methods. As-prepared catalysts were used for the degradation of organic dyes like Methly orange, Rhodamine B and methylene blue, upon exposure of light the transfer of electrons and holes occurs from the $\mathrm{CdWO}_{4}$ to $\mathrm{WO}_{3}$ and vice versa which led to circuit completion and efficient increase in charge separation, PL spectra gave the smaller curve peak proving the less relaxation of electron towards VB and the absorption intensity of $\lambda>476 \mathrm{~nm}$. Stability tests were performed to check the structural reliability of catalyst, it did not show any significant loss even after 3 cycles of reuse for the degradation of fresh dyes. Results also indicated the degradation of dye was about 7 and 2.3 times greater than $\mathrm{CdWO}_{4}$ and $\mathrm{WO}_{3}$ alone which was credited to enhanced surface area and effective separation of charge carriers [159].

In addition to the binary composites, some tertiary (complex) composites have been reported, where the multi-photon excitation took place in the photoactive materials and charge transfer and separation was increased due to increased surface area and different transition states. $\mathrm{KTaO}_{3}-\mathrm{CdS}-\mathrm{MoS}_{2}$ is an example of tertiary composite which was prepared by hydrothermal method by rigorously following the temperature and pressure conditions, the obtained powders were of different structures like nanoleaf, cubic and hexagonal spheres exhibiting activity under both visible and UV light and were used for the degradation of toluene and phenol. The catalysts shown $42 \%$ degradation under visible light and $80 \%$ degradation of pollutants under UV light. Prepared catalyst exhibited good stability (about 50\%) even after 4 cycles for the degradation of fresh toluene [160]. In case of some ternary composites like $\mathrm{ZnO}-\mathrm{AgBr}-\mathrm{Ag}_{2} \mathrm{CrO}_{4}$ (n-n junctions), two SCs worked as donors of photoexcited electrons and oxidation of pollutants occurred by the formation of superoxide radicals at the CB. By the charge separation the phocatalytic activity of composite was 16 and 7 times higher than those of $\mathrm{ZnO}$ and $\mathrm{ZnO} / \mathrm{AgBr}$ for the degradation of $\mathrm{rhB}$ [161]. Rhodamine $\mathrm{B}$ also suffered degradation by the photocatalytic activity of $\operatorname{In}_{2} \mathrm{O}_{3}-\mathrm{AgBr}-\mathrm{BiWO}_{6}$ (Figure 28), prepared by microwave assisted irradiation method, optical, morphological and structural properties were analysed by XRD, SEM, TEM, XPS, HRTEM which indicated the flower-like pattern of assembled nanoparticles. The increased photoactivity under UV, visible and solar 


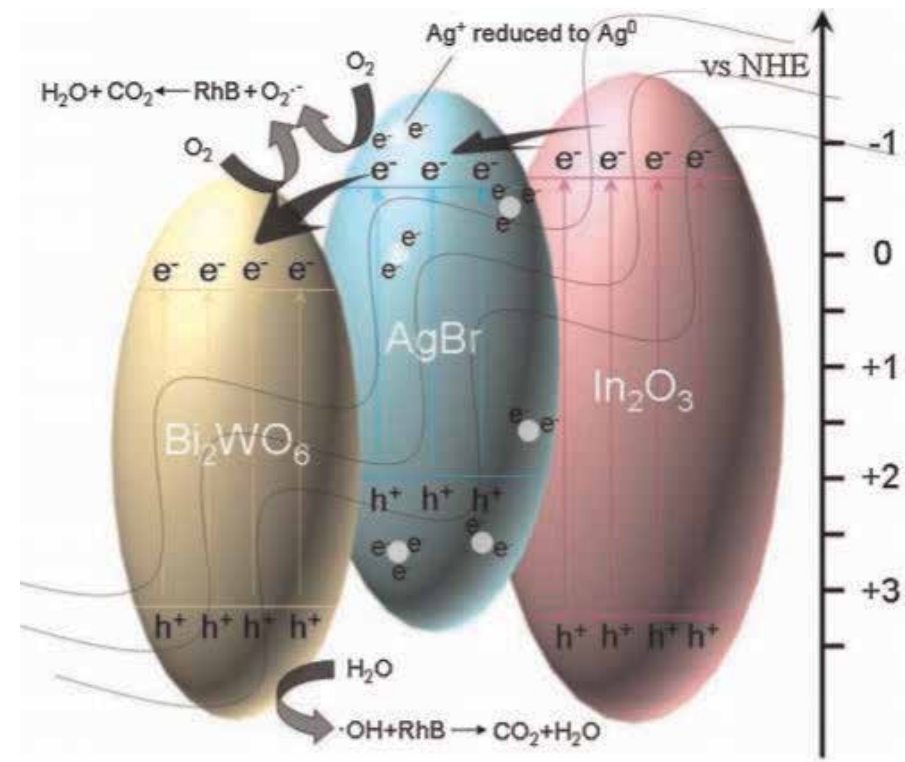

Figure 28.

Proposed mechanism for the degradation of rhB on ternary composite [162].

light was attributed to increased surface area and charge separation due to differences in the redox potentials of SCs bands. Reactive species scavenging testes determined that $\mathrm{OH}^{\bullet}$ and superoxide radicals were dominant reactive species [162].

Besides all of the above discussed heterostructures, nanocomposites, coupled semiconductors, either oxides or sulfides, there are numerous other heterojunctions like $\mathrm{WO}_{3} / \mathrm{NiWO}_{4}$ [163], $\mathrm{Ag}_{3} \mathrm{PO}_{4} / \mathrm{Bi}_{2} \mathrm{MoO}_{6}$ [164], $\mathrm{Ag}_{3} \mathrm{PO}_{4} / \mathrm{AgBr}$ [165], CdS/ $\mathrm{Bi}_{2} \mathrm{MoO}_{6}$ [166], CdS/ $\mathrm{Ta}_{2} \mathrm{O}_{5}$ [167], $\mathrm{BiOBr} / \mathrm{ZnFe}_{2} \mathrm{O}_{4}$ [168], $\mathrm{Cu}_{2} \mathrm{O} / \mathrm{SrTiO}_{3}$ ([169]), $\mathrm{ZnS} / \mathrm{CuS} / \mathrm{CdS}$ [170], $\mathrm{SnO}_{2} / \mathrm{ZnO} / \mathrm{ZnWO}_{4}$ [171] and many more have been reported to increase the ability of pure SCs to harvest the sun light either in the field of water or wastewater treatment for the overall splitting of water, degradation of Organic, inorganic pollutants, phenols, MCs, POPs and other emerging contaminants.

\section{A glance at g- $\mathrm{C}_{3} \mathrm{~N}_{4}$-based heterostructures/nanocomposites}

It has been more than a decade that people are being aware from environmental protection and conservation, the era of industrialization besides increasing the gross productivity also posed serious effects on the health of water bodies by discharging unchecked amounts of effluents and other chemicals, in order to improve the water quality the focuses are being paid to treat water and wastewater, the idea of semiconductor photocatalysis has been emerged which uses solar energy in its full potential, for this purpose many SCs either in single or in heterostructures have been discussed in Section 6.

In addition to first generation photocatalysts, an emerging polymeric photocatalyst is Graphitic Carbon Nitride $\left(\mathrm{g}-\mathrm{C}_{3} \mathrm{~N}_{4}\right)$ which is an earth copious visible light active catalyst, having unique 2D structure with high stability and flexible structure (which can be tailored) and low band gap of $2.7 \mathrm{eV}$. Pure gCN have high rate of recombination, smaller surface area and low ability to exploit visible light thus reducing the quantum efficiency of photosystem, the VL activity of gCN has been reported to increase by making heterostructures with other SCs by taking the advantage of its layered structure which assisted in hybridization with other 
constituents like CdS, $\mathrm{TiO}_{2}, \mathrm{ZnWO}_{4}, \mathrm{ZnO}$, etc. either for the degradation of pollutants or for the evolution of $\mathrm{O}_{2}$ or $\mathrm{H}_{2}$ gas [172]. Some examples of gCN HSs/HJs/ Composites are discussed below.

Novel g- $\mathrm{C}_{3} \mathrm{~N}_{4} / \mathrm{TiO}_{2}$ composites were prepared by the facile sonication method using melamine and titanium tetrachloride as precursors followed by stirring, sonication and drying at room temperature. Different catalysts were prepared by varying the concentrations of precursors and $g-\mathrm{C}_{3} \mathrm{~N}_{4} / \mathrm{TiO}_{2}-1.5$ was found to be more active among other catalysts, as it shown higher photocatalytic degradation of MB under UV and visible light. Results demonstrated that catalyst shown 6.92 and 2.65 time greater activity than pure gCN and $\mathrm{TiO}_{2}$ under UV light, while 9.27 (gCN) and $7.03\left(\mathrm{TiO}_{2}\right)$ folds greater photoactivity under visible light, which can be attributed the increased visible light absorption and efficient charge transfer in composite at interfaces of SCs. In the hybrid catalyst gCN could be triggered under visible light and the photoexcited electrons of gCN transferred to the $\mathrm{CB}$ of $\mathrm{TiO}_{2}$ due to interfacial connections and differences of redox potentials [173]. Tunable band gap of some semiconductors is an effective way to harness solar light and among those $\mathrm{gCN}$ is a known SC. Two SCs having smaller band gaps ( $\mathrm{gCN}$ and $\mathrm{Bi}_{2} \mathrm{MoO}_{6}$ ) were coupled to prepare a $\mathrm{Z}$-scheme nanocomposite, number of catalysts were prepared by varying the concentrations of precursors and $25 \%$ g- $\mathrm{C}_{3} \mathrm{~N}_{4} / \mathrm{Bi}_{2} \mathrm{MoO}_{6}$ was seemed to be most active, structure, morphology, light absorption spectra and charge carriers separation efficiency was analyzed and photocatalytic activities were evaluated for the degradation of MB. Both SCs in composite were excited at the $\lambda=410 \mathrm{~nm}$, due to the negative redox potentials of gCN (as compared to $\mathrm{Bi}_{2} \mathrm{MoO}_{6}$ ), excited electrons of gCN transferred to $\mathrm{CB}$ of $\mathrm{Bi}_{2} \mathrm{MoO}_{6}$ and holes of later should had been migrated to the VB of gCN, but by this route the holes at the VB of gCN could not react with water of $\mathrm{OH}$ ion near its surface and same for $\mathrm{Bi}_{2} \mathrm{MoO}_{6}$, so it was observed that the excited electrons transferred to their respective $\mathrm{CB}$, the relectrons from the $\mathrm{CB}$ of $\mathrm{Bi}_{2} \mathrm{MoO}_{6}$ were transferred to the $\mathrm{VB}$ of gCN (spatial separation) which inhibited the local recombination (Figure 29) thus completing the Z-scheme route, the $\mathrm{CB}$ of $\mathrm{Bi}_{2} \mathrm{MoO}_{6}$ and $\mathrm{VB}$ of gCN could not react with molecules in their vicinity and the catalyst shown 4.8 and 8.2 folds greater photoactivity than pristine SCs [174].

Feng et al. reported the fabrication of S-doped g- $\mathrm{C}_{3} \mathrm{~N}_{4} / \mathrm{Au} / \mathrm{CdS}$ composite as $\mathrm{Z}$-scheme photocatalyst where $\mathrm{CdS}$ was deposited on g-CNS system in which $\mathrm{Au}$ nanoparticles were sandwiched between g-CNS and CdS (two visible light responsive SCs) by the chemical bath deposition and worked as charge transporter (Figure 30), whole system increased the degradation of $\mathrm{rhB}, \mathrm{MO}, \mathrm{MB}$ and increased
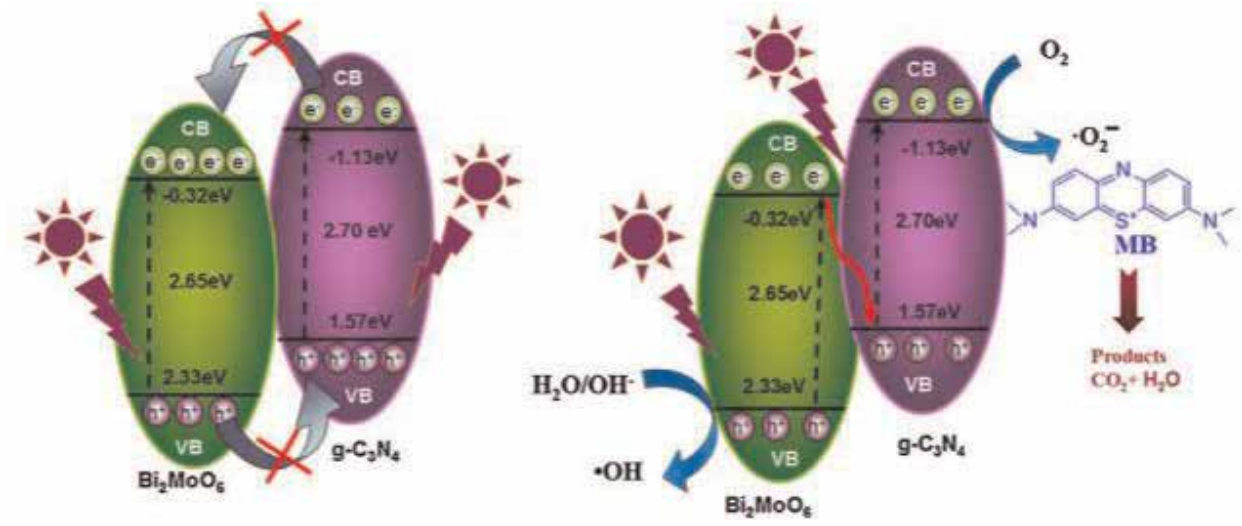

Figure 29.

Proposed mechanism of charge transfer in Z-scheme photocatalyst [174]. 


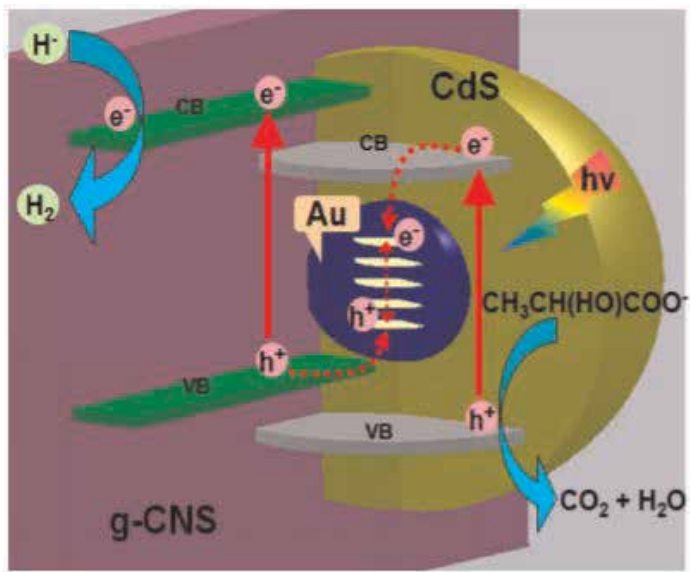

Figure 30.

Proposed mechanism of Z-scheme charge separation and transportation in g-CNS/Au/CdS [175].

reduction of water to hydrogen was observed under visible light $(\lambda=560 \mathrm{~nm})$. The Z-scheme photocatalyst was characterized by SEM, HRTEM, PL spectra, Visdiffuse spectra. These elementary, crystal and microcrystal analysis demonstrated the uniformity of novel composition, results revealed that the catalyst exhibited great photocatalytic activity as compared to g-CNS, g-CNS/Au, g-CNS/CdS, and pure CdS [175]. Novel organic-inorganic composite of $g-\mathrm{C}_{3} \mathrm{~N}_{4}$-CdS has been prepared which gave the degradation of organic pollutants under visible light. Results indicated the higher photocatalytic activity of about 20.5 and 3.1 times for degradation of MO as compared to gCN and CdS alone and 41.6 and 2.7 times higher for the degradation of 4-aminobenzoic acid [176].

GCN has also been reported to be composed with 2D graphene which is being focused due to its unique properties like amazing thermal, mechanical, surficial and electric properties. Tong et al. has prepared 3D porous gCN/graphene oxide aerogel structure by using gCN sheets and graphene oxide as precursors by following hydrothermal treatment method this composition resulted to enhanced visible light absorption, decreased charge relaxation and increased adsorption capacity. Analysis and characterizations were performed to check intrinsic properties. As-prepared catalyst was used for the $\mathrm{CO}_{2}$ evolution and $\mathrm{MO}$ degradation which was about $92 \%$ in $4 \mathrm{~h}$ under visible light [177]. Han et al. has reported different $\mathrm{g}-\mathrm{C}_{3} \mathrm{~N}_{4}$ /graphene nanocomposites which were proved to be effective for the degradation of dyes under visible light, different hybrids of gCN/graphene were prepared by using different methodologies and synthesis processes like solvothermal treatment, hydrothermal treatment, electrochemical reactions, etc. and their photoactivity was investigated for the hydrogen, oxygen, $\mathrm{CO}_{2}$ evolution and degradation of different organic compounds [178].

Among ternary composites the novel magnetically recoverable composite of g- $\mathrm{C}_{3} \mathrm{~N}_{4} / \mathrm{Fe}_{3} \mathrm{O}_{4} / \mathrm{NiWO}_{4}$ was prepared by refluxing calcination method, different hybrids were prepared by varying the precursor's concentration among which $\mathrm{gCN} / \mathrm{Fe}_{3} \mathrm{O}_{4} / \mathrm{NiWO}_{4}(30 \%)$ was found to be more active, catalysts were characterized for their morphology, texture, electronic, thermal and magnetic properties. Hybrid catalyst shown their high photocatalytic activity under visible light for the degradation of $\mathrm{rhB}, \mathrm{MO}, \mathrm{MB}$, fuchsine and phenolic compounds. Results confirmed that formation of $\mathrm{HJs}$ between $\mathrm{gCN} / \mathrm{M} / \mathrm{NiWO}_{4}$ increased the surface area and charge separation (Figure 31), thus increasing the quantum efficiency of system, photocatalytic activity of gCN/M/NiWO 4 (30\%) was 12, 30, 52 and 6 folds greater for rhB, $\mathrm{MB}, \mathrm{MO}$, fuchsine and phenol as compared to $\mathrm{gCN}, \mathrm{Fe}_{2} \mathrm{O}_{3}$ and $\mathrm{NiWO}_{4}$ 


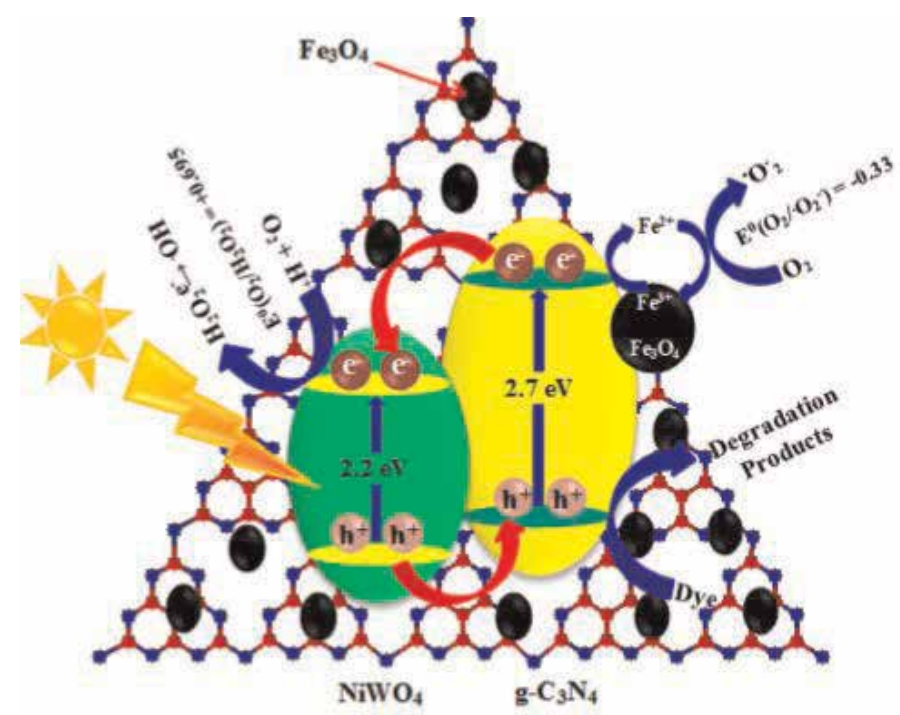

Figure 31.

Proposed mechanism of charge transfer in gCN/M/NiWO ${ }_{4}$ nanocomposites [179].

alone. Additionally the prepared composites exhibited high degree of stability even after the 4 cycles of reusability as it degraded about $87 \%$ of rhB at fourth cycle, unluckily, nanohybrid suffered from reduced surface area after the last run which was attributed to the blockage of degradation reaction intermediates at surface sites [179]. Zhang et al. has used one-step solvothermal method for the preparation of spinel $\mathrm{ZnFe}_{2} \mathrm{O}_{4}$ nanoparticles and its decoration on $\mathrm{g}-\mathrm{C}_{3} \mathrm{~N}_{4}$ sheets for formation of water soluble magnetic-functionalized $\mathrm{g}-\mathrm{C}_{3} \mathrm{~N}_{4} / \mathrm{ZnFe}_{2} \mathrm{O}_{4}$. The magnetic properties of composite were controlled by the size of composite and decorated quantity of $\mathrm{ZnFe}_{2} \mathrm{O}_{4}$. Results indicated that catalyst exhibited efficient photocatalytic activity for degradation of MO under visible light and it was mainly due to the synergist effect of both SCs like smaller particle size and high solubility in water, interestingly the catalyst could be separated from aqueous solution by magnet. $\mathrm{CN}-\mathrm{ZnFe}$ showed $98 \%$ of degradation of $\mathrm{MO}$ in 180 min which was 6.4 and 5.6 times higher than $\mathrm{g}-\mathrm{C}_{3} \mathrm{~N}_{4}$ and $\mathrm{ZnFe}_{2} \mathrm{O}_{4}$ alone. Free radical scavenging test revealed the decrease in efficiency indicated the vital role of $\mathrm{OH}^{\circ}$ and superoxide radical in the pollutant degradation. The increased photocatalytic activity was credited to sufficient charge separation ([180]). Synthesis of novel magnetic CdS/ $\mathrm{ZnFe}_{2} \mathrm{O}_{4}$ nanocomposites has been reported (by two-step hydrothermal method) in order to enhance photocatalytic activity and photostability of SCs under visible region [181].

Heterojunctions of $\mathrm{g}-\mathrm{C}_{3} \mathrm{~N}_{4}$ with carbonaceous particles has been reported to make recyclable, stable and more efficient photocatalyst for the water treatment purposes. Chai et al. synthesized the $\mathrm{g}-\mathrm{C}_{3} \mathrm{~N}_{4}$ modified with fullerene for the removal of dyes from water under visible light. Fullerenes $\left(\mathrm{C}_{60}\right)$ are known to have 30 molecular orbits with $60 \pi$ electrons with closed shell structure which helped in separation and transport of charge carriers, especially the photoexcited electrons. Because of the larger surface area and unique morphology, the electrons excited from $g-\mathrm{C}_{3} \mathrm{~N}_{4}$ shifted on $\mathrm{C}_{60}$ thus got separated from hole and lessened the electron relaxation towards hole, the electron hole pair separation resulted in the opening of benzene ring during the process of organic molecule degradation [182, 183]. Bai et al. prepared $\mathrm{g}-\mathrm{C}_{3} \mathrm{~N}_{4}$ /fullerene composite using thermal polymerization of dicyandiamide in the availability of $\mathrm{C}_{60}$ at $550^{\circ} \mathrm{C}$. Addition of $\mathrm{C}_{60}$ in the gCN, 
shifted the VB of gCN at lower energy level thus its oxidation potential under visible light was increased. Figure 32 demonstrate the increased photocatalytic activity due to effective electron hole pair separation, when the catalyst was exposed to visible light electrons got excited from VB (formed by N2p orbitals) to CB (formed by $2 \mathrm{Cp}$ orbitals) of $g-\mathrm{C}_{3} \mathrm{~N}_{4}$ leaving the holes behind in the $\mathrm{VB}$, the excited electrons jumped to $\mathrm{C}_{60}$ from $\mathrm{CB}$ of $\mathrm{gCN}$ thus retaining the separation. Results demonstrated the enhanced degradation of $\mathrm{MB}$ and phenol at $\lambda>420 \mathrm{~nm}$, degradation was about 2.9 and 3.2 time greater than that of bulk gCN, due to the efficient production of $\mathrm{OH}^{\circ}$ from holes, which acted as oxidation species and played a vital role in opening of benzene rings ([184]).

In addition to above discussed $\mathrm{g}-\mathrm{C}_{3} \mathrm{~N}_{4}$-based nanocomposites, there is a lot of literature based on the synthesis, uses and types of heterostructures based on the multifunctional approaches, as $\mathrm{g}-\mathrm{C}_{3} \mathrm{~N}_{4}$-based nanostructures (either with oxides or sulfides, either binary or tertiary) have become the main member of semiconductor photocatalysis family for the degradation of pollutants in environment specially in water. Besides g- $\mathrm{C}_{3} \mathrm{~N}_{4} / \mathrm{Fe}_{2} \mathrm{O}_{3}, \mathrm{~g}-\mathrm{C}_{3} \mathrm{~N}_{4} / \mathrm{CeO}_{2} \mathrm{~g}-\mathrm{C}_{3} \mathrm{~N}_{4} / \mathrm{MoO}_{3}, \mathrm{~g}-\mathrm{C}_{3} \mathrm{~N}_{4} / \mathrm{Fe}_{3} \mathrm{O}_{4}, \mathrm{~g}-\mathrm{C}_{3} \mathrm{~N}_{4} /$ $\mathrm{Ni}(\mathrm{OH})_{2}, \mathrm{~g}-\mathrm{C}_{3} \mathrm{~N}_{4} / \mathrm{Ag}_{2} \mathrm{O}, \mathrm{g}-\mathrm{C}_{3} \mathrm{~N}_{4} / \mathrm{MoS}_{2}, \mathrm{~g}-\mathrm{C}_{3} \mathrm{~N}_{4} / \mathrm{NiS}, \mathrm{g}-\mathrm{C}_{3} \mathrm{~N}_{4} / \mathrm{TaON}, \mathrm{g}-\mathrm{C}_{3} \mathrm{~N}_{4} / \mathrm{ZnO}$, g- $\mathrm{C}_{3} \mathrm{~N}_{4} / \mathrm{g}-\mathrm{C}_{3} \mathrm{~N}_{4}, \mathrm{~g}-\mathrm{C}_{3} \mathrm{~N}_{4} / \mathrm{In}_{2} \mathrm{O}_{3}, \mathrm{~g}-\mathrm{C}_{3} \mathrm{~N}_{4} / \mathrm{WO}_{3}, \mathrm{SiO}_{2} / \mathrm{g}-\mathrm{C}_{3} \mathrm{~N}_{4}$ and some ternary composites like, gCN/Fe $\mathrm{O}_{4} / \mathrm{CuWO}$, $\mathrm{BiOCl} / \mathrm{Bi}_{2} \mathrm{MoO}_{6} / \mathrm{g}-\mathrm{C}_{3} \mathrm{~N}_{4}, \mathrm{Ag}_{2} \mathrm{CrO}_{4} / \mathrm{g}-\mathrm{C}_{3} \mathrm{~N}_{4} / \mathrm{GO}$, g- $\mathrm{C}_{3} \mathrm{~N}_{4} / \mathrm{TiO}_{2} / \mathrm{CNT}, \mathrm{G}-\mathrm{C}_{3} \mathrm{~N}_{4} / \mathrm{CeO}_{2} / \mathrm{ZnO}$ there are innumerable gCN composites, some composites with their photocatalytic activity and efficiency under visible light are mentioned in Table 2.

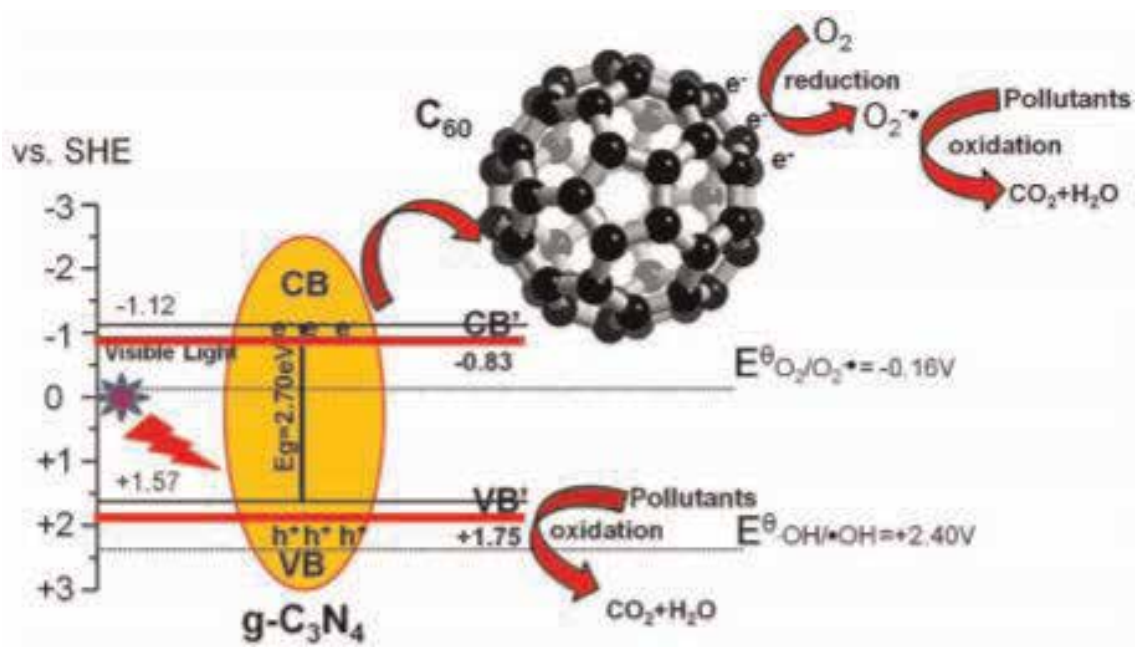

Figure 32.

Schematic illustration of charge separation and decomposition mechanism of organic pollutants by production of free radicals ([184]).

\begin{tabular}{|c|c|c|c|c|}
\hline Composite & $\begin{array}{l}\text { Precursor/synthesis } \\
\text { method }\end{array}$ & $\begin{array}{l}\text { Targeted } \\
\text { pollutant }\end{array}$ & $\begin{array}{l}\text { Degradation efficiency/reason } \\
\text { under visible light }\end{array}$ & References \\
\hline $\mathrm{TiO}_{2} / \mathrm{g}-\mathrm{C}_{3} \mathrm{~N}_{4}$ & $\begin{array}{l}\text { P-25 and } \\
\text { dicyandiamide }\end{array}$ & $\begin{array}{l}\text { Methylene } \\
\text { blue }\end{array}$ & $\begin{array}{l}90 \% \text { degradation in } 300 \mathrm{~min}, 3.5 \\
\text { greater efficiency than SC alone. }\end{array}$ & [185] \\
\hline $\mathrm{WO}_{3} / \mathrm{g}-\mathrm{C}_{3} \mathrm{~N}_{4}$ & $\begin{array}{l}\text { Dicyandiamide and } \\
\left(\mathrm{NH}_{4}\right)_{5} \mathrm{H}_{5}\left[\mathrm{H}_{2}\left(\mathrm{WO}_{4}\right)_{6}\right] \text {. } \\
\mathrm{H}_{2} \mathrm{O}\end{array}$ & $\begin{array}{l}\mathrm{MB} \text { and } \\
4-\mathrm{CP}\end{array}$ & $\begin{array}{l}\text { Degraded } 97 \% \text { of } \mathrm{MB} \text { and } 43 \% \text { of } \\
4-\mathrm{CP}\end{array}$ & [186] \\
\hline $\begin{array}{l}\mathrm{CdWO}_{4} / \mathrm{g}- \\
\mathrm{C}_{3} \mathrm{~N}_{4}\end{array}$ & $\begin{array}{l}\text { Melamine/mixed } \\
\text { calcination synthesis }\end{array}$ & $\mathrm{rhB}$ & $\begin{array}{l}\text { Degradation of rhB due to } \mathrm{O}_{2}^{\circ-} \\
\text { radical formation, } 1.6 \text { and } 54.6\end{array}$ & [187] \\
\hline
\end{tabular}




\begin{tabular}{|c|c|c|c|c|}
\hline Composite & $\begin{array}{l}\text { Precursor/synthesis } \\
\text { method }\end{array}$ & $\begin{array}{l}\text { Targeted } \\
\text { pollutant }\end{array}$ & $\begin{array}{l}\text { Degradation efficiency/reason } \\
\text { under visible light }\end{array}$ & References \\
\hline & & & $\begin{array}{l}\text { times greater efficiency than } \\
\text { gCN and CWO. }\end{array}$ & \\
\hline $\mathrm{In}_{2} \mathrm{~S}_{3} / \mathrm{g}-\mathrm{C}_{3} \mathrm{~N}_{4}$ & $\begin{array}{l}\text { Urea/hydrothermal } \\
\text { synthesis }\end{array}$ & $\mathrm{rhB}$ & $\begin{array}{l}\mathrm{HJ} \text { formation widened the light } \\
\text { absorption spectra, increased } \\
\text { EHP separation and } \mathrm{O}_{2}{ }^{--} \text {were } \\
\text { reactive OS. }\end{array}$ & {$[188]$} \\
\hline $\mathrm{V}_{2} \mathrm{O}_{5} / g-\mathrm{C}_{3} \mathrm{~N}_{4}$ & $\begin{array}{l}\text { Melamine/one-pot } \\
\text { synthesis }\end{array}$ & $\mathrm{rhB}$ & $\begin{array}{l}\text { Deterioration of rhB due to } \mathrm{O}_{2}{ }^{--} \\
\text {and } \mathrm{OH}^{*} \text {, charge separation } \\
\text { increased quantum efficiency } \\
\text { under visible light. }\end{array}$ & [189] \\
\hline $\mathrm{ZnO} / \mathrm{g}-\mathrm{C}_{3} \mathrm{~N}_{4}$ & $\begin{array}{l}\text { Melamine and zinc } \\
\text { acetate/simple } \\
\text { calcination method }\end{array}$ & $\begin{array}{l}\text { MO and p- } \\
\text { nitrophenol }\end{array}$ & $\begin{array}{l}\text { Degraded } 97 \% \text { of } \mathrm{MO} \text { in } 80 \mathrm{~min} \text {, } \\
\text { which was three and six times } \\
\text { greater than gCN and } \mathrm{ZnO} \text { alone. }\end{array}$ & [190] \\
\hline $\begin{array}{l}\mathrm{ZnWO}_{4} / \mathrm{g}- \\
\mathrm{C}_{3} \mathrm{~N}_{4}\end{array}$ & $\begin{array}{l}\text { Melamine/facile } \\
\text { chemisorption }\end{array}$ & MB & $\begin{array}{l}\text { Higher electron hole pair } \\
\text { separation, } \mathrm{OH} \text { and } \mathrm{O}_{2}^{\cdot-} \text { were } \\
\text { reactive species }\end{array}$ & [191] \\
\hline $\begin{array}{l}\mathrm{BiOI} / \\
\mathrm{BiOBr} / \mathrm{g}- \\
\mathrm{C}_{3} \mathrm{~N}_{4}\end{array}$ & Dicyandiamide & MB & $\begin{array}{l}\text { Effective charge separation, } \\
\text { production of } \mathrm{OH}^{*}, \mathrm{O}_{2}{ }^{--} \text {and } \mathrm{h}^{+}\end{array}$ & [192] \\
\hline $\begin{array}{l}\mathrm{ZnO} / \mathrm{ZnS} / \mathrm{g}- \\
\mathrm{C}_{3} \mathrm{~N}_{4}\end{array}$ & $\begin{array}{l}\text { Melamine/two-step } \\
\text { facile synthesis }\end{array}$ & $\begin{array}{l}\mathrm{H}_{2} \\
\text { Production }\end{array}$ & $\begin{array}{l}\text { Hydrogen production } 1205 \\
\mu \mathrm{mol} / \mathrm{g}-\mathrm{C}_{3} \mathrm{~N}_{4}: 16 \mu \mathrm{mol} / \mathrm{g}\end{array}$ & [193] \\
\hline $\begin{array}{l}\mathrm{YVO}_{4} / \mathrm{g}- \\
\mathrm{C}_{3} \mathrm{~N}_{4} / \mathrm{Ag}\end{array}$ & $\begin{array}{l}\text { Hydrothermal/urea } \\
\text { deposition method }\end{array}$ & MO & $\begin{array}{l}3 \text { times higher activity as } \\
\text { compared to gCN alone }\end{array}$ & [194] \\
\hline $\begin{array}{l}\mathrm{C}_{3} \mathrm{~N}_{4} / \mathrm{CNT} / \\
\mathrm{NiS}\end{array}$ & $\begin{array}{l}\text { Sol-gel method/direct } \\
\text { precipitation of } \\
\text { cyanamide }\end{array}$ & $\begin{array}{l}\mathrm{H}_{2} \\
\text { Production }\end{array}$ & $\begin{array}{l}148 \text { times higher activity than } \\
\text { pure gCN/CNT }\end{array}$ & [195] \\
\hline $\begin{array}{l}\mathrm{Ag}_{3} \mathrm{PO}_{4} / \\
\mathrm{GO} / \mathrm{g}-\mathrm{C}_{3} \mathrm{~N}_{4}\end{array}$ & $\begin{array}{l}\text { Dicyandiamide/ } \\
\text { precipitation }\end{array}$ & $\begin{array}{l}\text { RhB } \\
\text { degradation }\end{array}$ & $94.8 \%$ degradation in $50 \mathrm{~min}$. & [196] \\
\hline $\begin{array}{l}\mathrm{g}-\mathrm{C}_{3} \mathrm{~N}_{4} / \mathrm{AgBr} / \\
\mathrm{RGO}\end{array}$ & $\begin{array}{l}\text { Urea/hydrothermal } \\
\text { treatment }\end{array}$ & $\begin{array}{l}\text { Tetracycline } \\
\text { and 2,4-DP }\end{array}$ & $\begin{array}{l}78.4 \% \text { degradation in } 90 \mathrm{~min} \text { and } \\
68.2 \% \text { within } 6 \mathrm{~h} \text {. }\end{array}$ & [197] \\
\hline $\begin{array}{l}\mathrm{g}-\mathrm{C}_{3} \mathrm{~N}_{4} / \mathrm{TiO}_{2} / \\
\mathrm{ZnO}\end{array}$ & $\begin{array}{l}\text { Hydrothermal } \\
\text { treatment }\end{array}$ & $\begin{array}{l}\text { p-toluene } \\
\text { sulfonic acid }\end{array}$ & $\begin{array}{l}90 \% \text { degradation by composite, } \\
\text { while only } 40 \% \text { by gCN }\end{array}$ & [198] \\
\hline $\begin{array}{l}\mathrm{g}-\mathrm{C}_{3} \mathrm{~N}_{4} / \\
\mathrm{CeO}_{2} / \mathrm{ZnO}\end{array}$ & $\begin{array}{l}\text { Urea/pyrolysis and } \\
\text { exfoliation method }\end{array}$ & MB & $\begin{array}{l}11 \text { times greater degradation } \\
\text { than bare gCN }\end{array}$ & [199] \\
\hline $\begin{array}{l}\mathrm{Ag} / \mathrm{g}-\mathrm{C}_{3} \mathrm{~N}_{4} / \\
\mathrm{NaTaO}_{3}\end{array}$ & $\begin{array}{l}\text { Melamine/photo } \\
\text { deposition process }\end{array}$ & $\begin{array}{l}\text { Dyes and } \\
\text { tetracycline }\end{array}$ & $\begin{array}{l}\text { Improved dye degradation and } \\
95.47 \% \text { removal of tetracycline. }\end{array}$ & [200] \\
\hline
\end{tabular}

Table 2.

g-C ${ }_{3} N_{4}$-based heterostructures/nanocomposite.

\section{Conclusions}

Majority organic, inorganic and other numerous pollutants which are either in the records of EPAs or not, are the refractory compounds and tend to become the part of fresh or potable water thus making it unfit for use. Besides employing membrane systems, VLA semiconductor photocatalysis has gained fame due to their cost effectiveness and eco-friendly nature and becoming a promising phenomenon for the treatment of water on global scale. The rapid development in field of nanotechnology has opened the doors for various advanced photocatalytic systems which includes the formation of complex structures by doping, co-doping, 
heterostructures, $0 \mathrm{D}$ to 3D structures and nanocomposites as heterogeneous photocatalysts, has been developed in recent decades and has helped the environment and water to get rid of stubborn pollutant species, such as bacteria like E. coli, B. subtilis, giardia cysts, harmful cyanobacteria and their toxins like microcystins LR, RR, YR, LA (types of Microcystins), etc. which are harmful for different life forms. However, the application of visible light active semiconductors in the long run will be a reason of development of sustainable environment, due to development of advanced oxidation processes which are triggered by sunlight, will become a renewable energy source for example the evolution of hydrogen, oxygen and carbon dioxide gas. Therefore, an effective assessment of SCs nanomaterials is still required to test true photoactivity and to enhance the commercialization for future regards.

\section{Author details}

Fatima Imtiaz ${ }^{1}$, Jamshaid Rashid ${ }^{1,2 *}$ and Ming $\mathrm{Xu}^{2}$

1 Department of Environmental Science, Faculty of Biological Sciences, Quaid-i-Azam University, Islamabad, Pakistan

2 Key Laboratory of Geospatial Technology for the Middle and Lower Yellow River Regions, College of Environment and Planning, Henan University, Jinming Avenue, Kaifeng, China

*Address all correspondence to: jamshaidrashid@gmail.com; jrashid@qau.edu.pk

\section{IntechOpen}

(C) 2019 The Author(s). Licensee IntechOpen. This chapter is distributed under the terms of the Creative Commons Attribution License (http://creativecommons.org/licenses/ by/3.0), which permits unrestricted use, distribution, and reproduction in any medium, provided the original work is properly cited. (cc) BY 


\section{References}

[1] Serpone N. Advanced oxidation processes. In: Kirk-Othmer

Encyclopedia of Chemical Technology. Vol. 1. Toronto, Canada: John Wiley and Sons, Inc.; 2000. pp. 1-17

[2] Fujishima A, Zhang X, Tryk DA. $\mathrm{TiO}_{2}$ photocatalysis and related surface phenomena. Surface Science Reports. 2008;63:515-582. DOI: 10.1016/j. surfrep.2008.10.001

[3] Mills A, Le Hunte S. An overview of semiconductor photocatalysis. Journal of Photochemistry and Photobiology A: Chemistry. 2000;108:1-35

[4] Ohtani B. Photocatalysis A to ZWhat we know and what we do not know in a scientific sense. Journal of Photochemistry and Photobiology, C: Photochemistry Reviews. 2011;11: 157-178. DOI: 10.1016/j.jphotochemrev. 2011.02.001

[5] Goodeve CF, Kitchener JA. Photosensitisation by titanium dioxide. Transactions of the Faraday Society. 1938;34:570-579. DOI: 10.1039/ TF9383400570

[6] Nuno M, Ball RJ, Bowen CR. Photocatalytic properties of commercially available $\mathrm{TiO}_{2}$ powders for pollution control. In: Semiconductor Photocatalysis-Materials, Mechanisms and Applications. United Kingdom: IntechOpen; 2016. pp. 613-633. DOI: $10.5772 / 62894$

[7] Serpone N, Emeline AV.

Semiconductor photocatalysis-Past, present, and future outlook. Journal of Physical Chemistry Letters. 2012;3: 673-677. DOI: 10.1021/jz300071j

[8] Hoffmann MR, Martin ST, Choi W, Bahnemann DW. Environmental applications of semiconductor photocatalysis. Chemical Reviews. 1995; 95:69-96. DOI: 10.1021/cr00033a004
[9] Kisch H. Semiconductor photocatalysis-Mechanistic and synthetic aspects. Angewandte Chemie, International Edition. 2013;52:812-847.

DOI: 10.1002/anie.201201200

[10] Herrmann J. Titania-based true heterogeneous photocatalysis. Environmental Science and Pollution Research. 2012;19:3655-3665. DOI: 10.1007/s11356-011-0697-8

[11] Herrmann J. Heterogeneous photocatalysis: Fundamentals and applications to the removal of various types of aqueous pollutants. Catalysis Today. 1999;53:115-129

[12] Pelaez M, Nolan NT, Pillai SC, Seery MK, Falaras P, Kontos AG, et al. A review on the visible light active titanium dioxide photocatalysts for environmental applications. Applied Catalysis B: Environmental. 2012;125: 331-349. DOI: 10.1016/j.apcatb.2012. 05.036

[13] Agrawal A. Chapter 4 type I and type II band alignments in $\mathrm{ZnO} / \mathrm{MgZnO}$ bilayer films. Applied Physics Letters. 2014;105:081603

[14] Kroemer H. Band Diagrams in Real Space: I2009. pp. 1-13

[15] Wang Y, Wang Q. Visible light driven type II heterostructures and their enhanced photocatalysis properties: A review nanoscale. Nanoscale. 2015;5:8326-8339. DOI: $10.1039 / \mathrm{c} 3 \mathrm{nr} 01577 \mathrm{~g}$

[16] Opoku F, Govender KK, van Sittert CGCE, Govender PP. Recent progress in the development of semiconductorbased photocatalyst materials for applications in photocatalytic water splitting and degradation of pollutants. Advanced Sustainable Systems. 2017;1: 1700006. DOI: 10.1002/adsu.2017 00006 
[17] Wang Y, Wang Y, Li Y, Shi H, Xu Y, Qin H, et al. Simple synthesis of Zr-doped graphitic carbon nitride towards enhanced photocatalytic performance under simulated solar light irradiation. Catalysis Communications. 2015;72:24-28. DOI: 10.1016/j. catcom.2015.08.022

[18] Ibhadon AO, Fitzpatrick P. Heterogeneous photocatalysis: Recent advances and applications. 2013;3: 189-218. DOI: 10.3390/catal3010189

[19] Fragalà ME, Di Mauro A, Cristaldi DA, Cantarella M, Impellizzeri G, Privitera $\mathrm{V}$. $\mathrm{ZnO}$ nanorods grown on ultrathin $\mathrm{ZnO}$ seed layers: Application in water treatment. Journal of Photochemistry and Photobiology A: Chemistry. 2017;332: 497-504. DOI: 10.1016/j.jphotochem. 2016.09.032

[20] Martyna M, Diak M, Kozak M, Adriana Zaleska-Medynska EG. Some unitary, binary, and ternary non- $\mathrm{TiO}_{2}$ photocatalysts. In: Semiconductor Photocatalysis-Materials, Mechanisms and Applications. United Kingdom: IntechOpen; 2016. DOI: 10.5772/62583

[21] Gaya UI. Heterogenous Photocatalysis Using Inorganic Semiconductor Solids. Switzerland: Springer; 2014

[22] Medina-Ramírez AH-RI. Photocatalytic Semiconductors. Switzerland: Springer; 2015. DOI: 10.1007/978-3-319-10999-2

[23] Turchi CS. Photocatalytic degradation of organic water contaminants: Mechanisms involving hydroxyl radical attack. Journal of Catalysis. 1990;192:178-192

[24] Ray MB. Photocatalytic oxidation of paracetamol: Dominant reactants, intermediates, and reaction mechanisms. Environmental Science \& Technology. 2009;43:460-465
[25] Wang J, Tafen DN, Lewis JP, Hong Z, Manivannan A, Zhi M, et al. Origin of photocatalytic activity of nitrogendoped $\mathrm{TiO}_{2}$ nanobelts. JACS. 2009;131: 12290-12297

[26] Yongquan Quab XD. Progress, challenge and perspective of heterogeneous photocatalysts. The Royal Society of Chemistry. 2012;42: 2568-2580. DOI: $10.1039 / \mathrm{c} 2 \mathrm{cs} 35355 \mathrm{e}$

[27] Marschall R, Wang L. Non-metal doping of transition metal oxides for visible-light photocatalysis. Catalysis Today. 2014;225:111-135. DOI: 10.1016/ j.cattod.2013.10.088

[28] Livraghi S, Paganini MC, Giamello E, Selloni A, Di Valentin C, Pacchioni G. Origin of photoactivity of nitrogendoped titanium dioxide under visible light. Journal of the American Chemical Society. 2006;128:15666-15671. DOI: 10.1021/ja064164c

[29] Sato S, Nakamura R, Abe S. Visiblelight sensitization of $\mathrm{TiO}_{2}$ photocatalysts by wet-method $\mathrm{N}$ doping. Applied Catalysis A: General. 2005;284:131-137. DOI: 10.1016/j.apcata.2005.01.028

[30] Asahi AR, Morikawa T, Ohwaki T, Aoki K, Taga Y, Lee V, et al. Visiblelight photocatalysis in nitrogen-doped titanium oxides. Science. 2001;293: 269-271

[31] Abadias G, Paumier F, Eyidi D, Gu P, Girardeau T, Wiley J. Structure and properties of nitrogen-doped titanium dioxide thin films produced by reactive magnetron sputtering. Surface and Interface Analysis. 2010;42:970-973. DOI: $10.1002 /$ sia. 3220

[32] Martínez-ferrero BE, Sakatani Y, Boissière C, Grosso D, Fuertes A. Nanostructured titanium oxynitride porous thin films as efficient visibleactive photocatalysts. Advanced Functional Materials. 2007;17: 
3348-3354. DOI: 10.1002/adfm. 200700396

[33] Premkumar J. Development of super-hydrophilicity on nitrogen-doped $\mathrm{TiO}_{2}$ thin film surface by photoelectrochemical method under. Chemistry of Materials. 2004;16: 3980-3981. DOI: $10.1021 / \mathrm{cm} 049055 \mathrm{~g}$

[34] Choi H, Antoniou MG, Pelaez M, De la Cruz AA, Shoemaker JA, Dionysiou DD. Mesoporous nitrogendoped $\mathrm{TiO}_{2}$ for the photocatalytic destruction of the cyanobacterial toxin microcystin-LR under visible light irradiation. Environmental Science \& Technology. 2007;41:7530-7535. DOI: $10.1021 /$ es0709122

[35] Yang J, Chen DX, Deng AP, Huang YP, Chen CC. Visible-light-driven photocatalytic degradation of microcystin-LR by Bi-doped $\mathrm{TiO}_{2}$. Research on Chemical Intermediates. 2011;37:47-60. DOI: 10.1007/ s11164-010-0224-4

[36] Vitiello RP, Macak JM, Ghicov A, Tsuchiya H, Dick LFP, Schmuki P. $\mathrm{N}$-doping of anodic $\mathrm{TiO}_{2}$ nanotubes using heat treatment in ammonia.

Electrochemistry Communications. 2006;8:544-548. DOI: 10.1016/j. elecom.2006. 01.023

[37] Zong X, Sun C, Yu H, Chen ZG, Xing Z, Ye D, et al. Activation of photocatalytic water oxidation on $\mathrm{N}$ doped $\mathrm{ZnO}$ bundle-like nanoparticles under visible light. The Journal of Physical Chemistry. 2013;117:4937-4942. DOI: 10.1021/ jp311729b

[38] Zhang D, Gong J, Han G, Tong Z. A facile method for synthesis of $\mathrm{N}$-doped $\mathrm{ZnO}$ mesoporous nanospheres and enhanced photocatalytic activity. Dalton Transactions. 2013;42:16556-16561. DOI: $10.1039 / \mathrm{c} 3 \mathrm{dt} 52039 \mathrm{k}$

[39] Kumar R, Abdel-wahab MS, Barakat MA, Rashid J, Salah N, Al-ghamdi AA.
Role of $\mathrm{N}$ doping on the structural, optical and photocatalytic properties of the silver deposited $\mathrm{ZnO}$ thin films. Journal of the Taiwan Institute of Chemical Engineers. 2016; 69:131-138. DOI: 10.1016/j.jtice.2016. 09.027

[40] Tuomisto F, Rauch C, Wagner MR, Hoffmann A, Eisermann S, Meyer BK, et al. Nitrogen and vacancy clusters in $\mathrm{ZnO}$. Journal of Materials Research. 2013;28:1977-1983. DOI: 10.1557/jmr. 2013.195

[41] Barnes TM, Olson K, Wolden CA. On the formation and stability of type conductivity in nitrogen-doped zinc oxide. Applied Physics Letters. 2005;86: 112. DOI: $10.1063 / 1.1884747$

[42] Tuzemen ES, Kara K, Elagoz S, Takci DK, Altuntas I, Esen R. Structural and electrical properties of nitrogendoped $\mathrm{ZnO}$ thin films. Applied Surface Science. 2014;318:157-163. DOI: 10.1016/j.apsusc.2014.02.118

[43] Di Valentin C, Pacchioni G, Selloni A. Theory of carbon doping of titanium dioxide. Chemistry of Materials. 2005; 17:6656-6665. DOI: 10.1021/cm051921h

[44] Dong F, Guo S, Wang H, Li X, Wu $\mathrm{Z}$. Enhancement of the visible light photocatalytic activity of C-doped $\mathrm{TiO}_{2}$ nanomaterials prepared by a green synthetic approach. The Journal of Physical Chemistry. 2011;115: 13285-13292. DOI: 10.1021/jp111916q

[45] Cong Y, Li X, Qin Y, Dong Z, Yuan G, Cui Z, et al. Carbon-doped $\mathrm{TiO}_{2}$ coating on multiwalled carbon nanotubes with higher visible light photocatalytic activity. Applied Catalysis B: Environmental. 2011;107: 128-134. DOI: 10.1016/j.apcatb.2011. 07.005

[46] Gamage McEvoy J, Cui W, Zhang Z. Degradative and disinfective properties of carbon-doped anatase-rutile $\mathrm{TiO}_{2}$ 
mixtures under visible light irradiation. Catalysis Today. 2013;207:191-199. DOI: 10.1016/j.cattod.2012.04.015

[47] Rockafellow EM, Stewart LK, Jenks WS. Is sulfur-doped $\mathrm{TiO}_{2}$ an effective visible light photocatalyst for remediation? Applied Catalysis B: Environmental. 2009;91:554-562. DOI: 10.1016/j.apcatb.2009.06.027

[48] Umebayashi T, Yamaki T, Itoh $\mathrm{H}$, Asai $\mathrm{K}$. Band gap narrowing of titanium dioxide by sulfur doping. Applied Physics Letters. 2002;454:3-6. DOI: 10.1063/1.1493647

[49] Xu H, Zhou Y-N, Lu F, Fu Z-W. Electrochemistry of $\mathrm{ZnO}_{1-\mathrm{x}} \mathrm{S}_{\mathrm{x}}$ thin film with lithium. Journal of the Electrochemical Society. 2011;158:A285. DOI: 10.1149/1.3532037

[50] Meyer BK, Polity A, Farangis B, He Y, Hasselkamp D, Krämer T, et al. Structural properties and bandgap bowing of thin films deposited by reactive sputtering. Applied Physics Letters. 2004;4929:2002-2005. DOI: $10.1063 / 1.1825053$

[51] Ratheesh R, Thankalekshmi ACR. Structure and optical band gap of $\mathrm{ZnO}_{1-\mathrm{x}} \mathrm{S}_{\mathrm{x}}$ thin films synthesized by chemical spray pyrolysis for application in solar cells. Journal of Applied Physics. 2012;112:063708. DOI: 10.1063/ 1.4754014

[52] Patil AB, Patil KR, Pardeshi SK. Ecofriendly synthesis and solar photocatalytic activity of S-doped $\mathrm{ZnO}$. Journal of Hazardous Materials. 2010; 183:315-323. DOI: 10.1016/j.jhazmat. 2010.07.026

[53] Zheng YZ, Tao X, Hou Q, Wang DT, Zhou WL, Chen JF. Iodine-doped $\mathrm{ZnO}$ nanocrystalline aggregates for improved dye-sensitized solar cells. Chemistry of Materials. 2011;23:3-5. DOI: 10.1021/ cm101525p
[54] Iwase M, Yamada K, Kurisaki T, Prieto-mahaney OO, Ohtani B, Wakita H. Applied catalysis B: Environmental visible-light photocatalysis with phosphorus-doped titanium (IV) oxide particles prepared using a phosphide compound. Applied Catalysis B: Environmental. 2013;132-133:39-44. DOI: 10.1016/j.apcatb.2012.11.014

[55] Mu X, Hou T, Zhang L, Jiang Y, Guan J, Chen X. Facile synthesis of phosphorus doped graphitic carbon nitride polymers with enhanced visiblelight photocatalytic activity. Materials Research Bulletin. 2013;48:3485-3491. DOI: 10.1016/j.materresbull.2013. 05.040

[56] Chai B, Yan J, Wang C, Ren Z, Zhu Y. Enhanced visible light photocatalytic degradation of Rhodamine B over phosphorus doped graphitic carbon nitride. Applied Surface Science. 2017; 391:376-383. DOI: 10.1016/j.apsusc. 2016.06.180

[57] Fan Q, Liu J, Yu Y, Zuo S, Li B. A simple fabrication for sulfur doped graphitic carbon nitride porous rods with excellent photocatalytic activity degrading RhB dye. Applied Surface Science. 2017;391:360-368. DOI: 10.1016/j.apsusc.2016.04.055

[58] Yan SC, Li ZS, Zou ZG.

Photodegradation of rhodamine $\mathrm{B}$ and methyl Orange over boron-doped g$\mathrm{C}_{3} \mathrm{~N}_{4}$ under visible light irradiation. Langmuir. 2010;26:3894-3901. DOI: 10.1021/la904023j

[59] Dong G, Zhao K, Zhang L. Carbon self-doping induced high electronic conductivity and photoreactivity of g$\mathrm{C}_{3} \mathrm{~N}_{4}$. Chemical Communications. 2012; 48:6178-6180. DOI: $10.1039 / c 2 c c 32181$ e

[60] Gole JL, Stout JD, Burda C, Lou Y, Chen $X$. Highly efficient formation of visible light tunable $\mathrm{TiO}_{2-\mathrm{x}} \mathrm{N}_{\mathrm{x}}$ photocatalysts and their transformation 
at the nanoscale. The Journal of Physical Chemistry. B. 2004;108:1230-1240

[61] Jiang W, Ullah N, Divitini G, Ducati C, Kumar RV, Ding Y, et al. Vertically oriented $\mathrm{TiO}_{\mathrm{x}} \mathrm{N}_{\mathrm{y}}$ nanopillar arrays with embedded Ag nanoparticles for visible-light photocatalysis. Langmuir. 2012;28:5427-5431. DOI: 10.1021/ la203617u

[62] Rhee CH, Bae SW, Lee JS. Template-free hydrothermal synthesis of high surface area nitrogen-doped Titania photocatalyst active under visible light. Chemistry Letters. 2005;34:660-661. DOI: $10.1246 /$ cl.2005.660

[63] Livraghi S, Pelaez M, Biedrzycki J, Corazzari I, Giamello E, Dionysiou DD. Influence of the chemical synthesis on the physicochemical properties of N$\mathrm{TiO}_{2}$ nanoparticles. Catalysis Today. 2013;209:54-59. DOI: 10.1016/j. cattod.2012.12.020

[64] Fang J, Shi F, Bu J, Ding J, Xu S, Bao $J$, et al. One-step synthesis of bifunctional $\mathrm{TiO}_{2}$ catalysts and their photocatalytic activity. Journal of Physical Chemistry C. 2010;114: 7940-7948

[65] Cong Y, Zhang J, Chen F, Anpo M. Synthesis and characterization of nitrogen-doped $\mathrm{TiO}_{2}$ nanophotocatalyst with high visible light activity. Journal of Physical Chemistry C. 2007;111: 6976-6982. DOI: 10.1021/jp0685030

[66] Lin L, Zheng RY, Xie JL, Zhu YX, Xie YC. Synthesis and characterization of phosphor and nitrogen co-doped titania. Applied Catalysis B: Environmental. 2007;76:196-202. DOI: 10.1016/j.apcatb.2007.05.023

[67] Li F, Yin X. Investigation on F-B-S tri-doped nano- $\mathrm{TiO}_{2}$ films for the photocatalytic degradation of organic dyes. Journal of Nanoparticle Research.
2011;13:4839-4846. DOI: $10.1007 /$ s11051-011-0461-5

[68] Zhao W, Ma W, Chen C, Zhao J, Shuai Z. Efficient degradation of toxic organic pollutants with $\mathrm{Ni}_{2} \mathrm{O}_{3} / \mathrm{TiO}_{2-\mathrm{x}} \mathrm{B}_{\mathrm{x}}$ under visible irradiation. Journal of the American Chemical Society. 2004;126: 4782-4783. DOI: 10.1021/ja0396753

[69] Dong F, Zhao W, Wu Z.

Characterization and photocatalytic activities of $\mathrm{C}, \mathrm{N}$ and $\mathrm{S}$ co-doped $\mathrm{TiO}_{2}$ with $1 \mathrm{D}$ nanostructure prepared by the nano-confinement effect.

Nanotechnology. 2008;19:10. DOI:

10.1088/0957-4484/19/36/365607

[70] Ohno T, Tsubota T, Toyofuku M, Inaba R. Photocatalytic activity of a $\mathrm{TiO}_{2}$ photocatalyst doped with $\mathrm{C}^{4+}$ and $\mathrm{S}^{4+}$ ions having a rutile phase under visible light. 2004;98:255-258

[71] Hamal DB, Haggstrom JA, Marchin GL, Ikenberry MA, Hohn K, Klabunde KJ. A multifunctional biocide/sporocide and photocatalyst based on titanium dioxide $\left(\mathrm{TiO}_{2}\right)$ Codoped with silver, carbon, and sulfur. Langmuir. 2010;26: 2805-2810. DOI: 10.1021/la902844r

[72] Pelaez M, Falaras P, Likodimos V, Kontos AG, De AA, Kevin O, et al. Synthesis, structural characterization and evaluation of sol-gel-based $\mathrm{NF}-\mathrm{TiO}_{2}$ films with visible light-photoactivation for the removal of microcystin-LR. Applied Catalysis B: Environmental. 2010;99:378-387. DOI: 10.1016/j. apcatb.2010.06.017

[73] Huang D, Liao S, Liu J, Dang Z, Petrik L. Preparation of visible-light responsive $\mathrm{N}-\mathrm{F}$-codoped $\mathrm{TiO}_{2}$ photocatalyst by a sol-gel-solvothermal method. Journal of Photochemistry and Photobiology A: Chemistry. 2006;184: 282-288. DOI: 10.1016/j.jphotochem. 2006.04.041

[74] Lv Y, Fu Z, Yang B, Xu J, Wu M, Zhu C, et al. Preparation N-F-codoped 
$\mathrm{TiO}_{2}$ nanorod array by liquid phase deposition as visible light photocatalyst. Materials Research Bulletin. 2011;46: 361-365. DOI: 10.1016/j.materresbull. 2010.12.011

[75] Ao Y, Xu J, Fu D, Yuan C. Synthesis of C, N, S-tridoped mesoporous titania with enhanced visible light-induced photocatalytic activity. Microporous and Mesoporous Materials. 2009;122: 1-6. DOI: 10.1016/j.micromeso.2008. 11.010

[76] Wang P, Yap P, Lim T. C-N-S tridoped $\mathrm{TiO}_{2}$ for photocatalytic degradation of tetracycline under visible-light irradiation. Applied Catalysis A: General. 2011;399:252-261. DOI: 10.1016/j.apcata.2011.04.008

[77] Ohno T, Tsubota T, Nakamura Y, Sayama K. Preparation of S, C cationcodoped $\mathrm{SrTiO}_{3}$ and its photocatalytic activity under visible light. Applied Catalysis A: General. 2005;288:74-79. DOI: 10.1016/j.apcata.2005.04.035

[78] Zou F, Jiang Z, Qin X, Zhao Y, Jiang L, Zhi J. Template-free synthesis of mesoporous $\mathrm{N}$-doped $\mathrm{SrTiO}_{3}$ perovskite with high visible-light-driven photocatalytic activity. Chemical Communications. 2012;48:8514-8516. DOI: $10.1039 / \mathrm{c} 2 \mathrm{cc} 33797 \mathrm{e}$

[79] Han P, Su Y, Meng Y, Wang S, Jia Q, Wang $X$. Preparation and photocatalytic performance of iodine-doped $\mathrm{NaTaO}_{3}$ nanoparticles. Journal of Nanoscience and Nanotechnology. 2011;11: 9600-9606. DOI: 10.1166/jnn.2011.5277

[80] Fu H, Zhang S, Zhang L, Zhu Y. Visible-light-driven $\mathrm{NaTaO}_{3-\mathrm{x}} \mathrm{N}_{\mathrm{x}}$ catalyst prepared by a hydrothermal process. Materials Research Bulletin. 2008;43:864-872. DOI: 10.1016/j. materresbull.2007.05.013

[81] Jiang L, Wang Q, Li C, Yuan J, Shangguan $W . \mathrm{ZrW}_{2} \mathrm{O}_{8}$ photocatalyst and its visible-light sensitization via sulfur anion doping for water splitting.

International Journal of Hydrogen

Energy. 2010;35:7043-7050. DOI:

10.1016/j.ijhydene.2009.12.187

[82] Zhang J, Huang Z, Xu Y, Kang F.

Hydrothermal synthesis of iodine-doped $\mathrm{Bi}_{2} \mathrm{WO}_{6}$ nanoplates with enhanced visible and ultraviolet-induced photocatalytic activities. International Journal of Photoenergy. 2012;2012. DOI: 10.1155/2012/915386

[83] Zhang Z, Wang W, Wang L, Sun S. Enhancement of visible-light photocatalysis by coupling with narrowband-gap semiconductor: A case study on $\mathrm{Bi}_{2} \mathrm{~S}_{3} / \mathrm{Bi}_{2} \mathrm{WO}_{6}$. Applied Materials \& Interfaces. 2012;4:593-597. DOI: 10.1021/am2017199

[84] Shi R, Huang G, Lin J, Zhu Y.

Photocatalytic activity enhancement for $\mathrm{Bi}_{2} \mathrm{WO}_{6}$ by fluorine substitution. Journal of Physical Chemistry C. 2009;113: 19633-19638

[85] Shifu C, Wei Z, Sujuan Z, Wei L. Preparation, characterization and photocatalytic activity of $\mathrm{N}$-containing $\mathrm{ZnO}$ powder. Chemical Engineering Journal. 2009;148:263-269. DOI: 10.1016/j.cej.2008.08.039

[86] Li X, Pan H, Hu Q, Zhang C. Nitrogen-doped $\mathrm{SiO}_{2}-\mathrm{HNb}_{3} \mathrm{O}_{8}$ for rhodamine $\mathrm{B}$ photodegradation under visible light. Journal of Alloys and Compounds. 2011;509:6252-6256. DOI: 10.1016/j.jallcom.2011.03.033

[87] Takeuchi M, Shimizu Y, Yamagawa $\mathrm{H}$, Nakamuro T, Anpo M. Preparation of the visible light responsive $\mathrm{N}_{3}$-doped $\mathrm{WO}_{3}$ photocatalyst by a thermal decomposition of ammonium paratungstate. Applied Catalysis B: Environmental. 2011;110:1-5. DOI: 10.1016/j.apcatb.2011.08.004

[88] Liu Y, Li Y, Li W, Han S, Liu C. Photoelectrochemical properties and photocatalytic activity of 
nitrogen-doped nanoporous $\mathrm{WO}_{3}$ photoelectrodes under visible light. Applied Surface Science. 2012;258: 5038-5045. DOI: 10.1016/j.apsusc. 2012.01.080

[89] Liu S, Yin K, Ren W, Cheng B, Yu J. Tandem photocatalytic oxidation of Rhodamine B over surface fluorinated bismuth vanadate crystals. Journal of Materials Chemistry. 2012;22:

17759-17767. DOI: 10.1039/c2jm33337f

[90] Ji K, Jiang H, Liu Y, Deng J, Dai H, Zhang L. Porous F-doped $\mathrm{BiVO}_{4}$ : Synthesis and enhanced photocatalytic performance for the degradation of phenol under visible-light illumination. Solid State Sciences. 2013;17:2127. DOI: 10.1016/j. solidstatesciences.2012.12.009

[91] Zhao Z, Dai H, Deng J, Liu Y, Au CT. Enhanced visible-light photocatalytic activities of porous olive-shaped sulfur-doped $\mathrm{BiVO}_{4}$ supported cobalt oxides. Solid State Sciences. 2013;18:98-104. DOI: 10.1016/j.solidstatesciences.2013.01.009

[92] Jia L, Li J, Fang W, Song H, Li Q Tang Y. Visible-light-induced photocatalyst based on C-doped $\mathrm{LaCoO}_{3}$ synthesized by novel microorganism chelate method. Catalysis

Communications. 2009;10:12301234. DOI: 10.1016/j.catcom.2009. 01.025

[93] Martha S, Parida KM. Fabrication of nano $\mathrm{N}$-doped $\mathrm{In}_{2} \mathrm{Ga}_{2} \mathrm{ZnO}_{7}$ for photocatalytic hydrogen production under visible light. International Journal of Hydrogen Energy. 2012;37: 17936-17946. DOI: 10.1016/j.ijhydene. 2012.09.025

[94] Gasparotto A, Barreca D, Bekermann D, Devi A, Fischer R a, Fornasiero P, et al. F-doped $\mathrm{Co}_{3} \mathrm{O}_{4}$ photocatalysts for sustainable $\mathrm{H}_{2}$ generation from water/ethnol. Journal of the American Chemical Society.
2011;133:193-625. DOI: 10.1021/ ja210078d

[95] Sreethawong T, Ngamsinlapasathian S, Yoshikawa S. Synthesis of crystalline mesoporous-assembled $\mathrm{ZrO}_{2}$ nanoparticles via a facile surfactantaided sol-gel process and their photocatalytic dye degradation activity. Chemical Engineering Journal. 2013; 228:256-262. DOI: 10.1016/j.cej.2013. 04.111

[96] Dolat D, Quici N, Kusiak-nejman E, Morawski AW, Puma GL.

Environmental one-step, hydrothermal synthesis of nitrogen, carbon co-doped titanium dioxide $\left(\mathrm{N}, \mathrm{C} \mathrm{TiO}{ }_{2}\right)$ photocatalysts. Effect of alcohol degree and chain length as carbon dopant precursors on photocatalytic activity and cata. Applied Catalysis B: Environmental. 2012;115-116:81-89. DOI: 10.1016/j.apcatb.2011.12.007

[97] Sun H, Bai Y, Cheng Y, Jin W, Xu N. Preparation and characterization of visible-light-driven carbon-sulfurcodoped $\mathrm{TiO}_{2}$ photocatalysts. Industrial and Engineering Chemistry Research. 2006;45:4971-4976. DOI: 10.1021/ ie060350f

[98] Uk H, Chang S, Hae S, Son B, Jae S, Jin $\mathrm{H}$, et al. Highly visible-light active nanoporous $\mathrm{TiO}_{2}$ photocatalysts for efficient solar photocatalytic applications. Applied Catalysis B: Environmental. 2013;129:106-113. DOI: 10.1016/j.apcatb.2012.09.010

[99] Yang K, Dai Y, Huang B, Whangbo $\mathrm{MH}$. Density functional characterization of the band edges, the band gap states, and the preferred doping sites of halogen-doped $\mathrm{TiO}_{2}$. Chemistry of Materials. 2008;20:6528-6534. DOI: $10.1021 / \mathrm{cm} 801741 \mathrm{~m}$

[100] Zhang L, Zhang H, Xu H, Deng F, Zheng Z. Hierarchical chlorine-doped rutile $\mathrm{TiO}_{2}$ spherical clusters of 
nanorods: Large-scale synthesis and high photocatalytic activity. Journal of Solid State Chemistry. 2008;181: 2516-2522. DOI: 10.1016/j.jssc. 2008.06.019

[101] Luo H, Takata T, Lee Y, Zhao J, Domen K, Yan Y. Photocatalytic activity enhancing for titanium dioxide by Co-doping with bromine and chlorine. Chemistry of Materials. 2004;16: 846-849. DOI: $10.1021 / \mathrm{cm} 035090 w$

[102] Andersen J, Han C, O'Shea K, Dionysiou DD. Revealing the degradation intermediates and pathways of visible light-induced NF$\mathrm{TiO}_{2}$ photocatalysis of microcystin-LR. Applied Catalysis B: Environmental. 2014;154-155:259-266. DOI: 0.1016/j. apcatb.2014.02.025

[103] Nisar J, Wang B, Moyses C, Ferreira A. Band gap engineering by anion doping in the photocatalyst $\mathrm{BiTaO}_{4}$ : First principle calculations. International Journal of Hydrogen Energy. 2012;37:3014-3018. DOI: 10.1016/j.ijhydene.2011.11.068

[104] Yang K, Huang W, Xu L, Luo K, Yang Y, Huang G. Materials science in semiconductor processing insights into enhanced visible-light photocatalytic activity of $\mathrm{CeO}_{2}$ doped with nonmetal impurity from the first principles. Materials Science in Semiconductor Processing. 2016;41:200-208. DOI: 10.1016/j.mssp.2015.08.039

[105] Bagwasi S, Tian B, Zhang J, Nasir M. Synthesis, characterization and application of bismuth and boron Codoped $\mathrm{TiO}_{2}$ : A visible light active photocatalyst. Chemical Engineering Journal. 2013;217:108-118. DOI: 10.1016/j.cej.2012.11.080

[106] Di Valentin C, Pacchioni G. Trends in non-metal doping of anatase $\mathrm{TiO}_{2}$ : $\mathrm{B}$, C, N and F. Catalysis Today. 2013;206: 12-18. DOI: 10.1016/j.cattod.2011.11.030
[107] Wang G, Chen H, Wu G, Kuang A. Hybrid density functional study on mono- and Co-doped $\mathrm{NaNbO}_{3}$ for visible-light photocatalysis. ChemPhysChem. 2016;17:489-499. DOI: 10.1002/cphc.201501037

[108] Murakami N, Chiyoya T, Tsubota $\mathrm{T}$, Ohno T. Switching redox site of photocatalytic reaction on titanium(IV) oxide particles modified with transitionmetal ion controlled by irradiation wavelength. Applied Catalysis A: General. 2008;348:148-152. DOI: 10.1016/j.apcata.2008.06.040

[109] Carneiroa JO, Portinha VT, Dupak L, Magalhaes A, Coutinho P. Study of the deposition parameters and Fedopant effect in the photocatalytic activity of $\mathrm{TiO}_{2}$ films prepared by dc reactive magnetron sputtering. Vacuum. 2005;78:37-46. DOI: 10.1016/j.

vacuum.2004.12.012

[110] Wu JCS, Chen CH. A visible-light response vanadium-doped titania nanocatalyst by sol-gel method. Journal of Photochemistry and Photobiology A: Chemistry. 2004;163:509-515. DOI: 10.1016/j.jphotochem.2004.02.007

[111] Rimoldi L, Pargoletti E, Meroni D, Falletta E, Cerrato G, Turco F, et al. Concurrent role of metal (Sn, Zn) and N species in enhancing the photocatalytic activity of $\mathrm{TiO}_{2}$ under solar light.

Catalysis Today. 2018;313:4046. DOI: 10.1016/j.cattod.2017.12.017

[112] Rashid J, Barakat MA, Salah N, Habib SS. Ag/ZnO nanoparticles thin films as visible light photocatalysts. The Royal Society of Chemistry. 2014;4: 56892-56899. DOI: 10.1039/c4ra12990c

[113] Yayapao O, Thongtem T, Phuruangrat A, Thongtem S. Ultrasonicassisted synthesis of $\mathrm{Nd}$-doped $\mathrm{ZnO}$ for photocatalysis. Materials Letters. 2013; 90:83-86. DOI: 10.1016/j.matlet.2012. 09.027 
[114] Phuruangrat A, Yayapao O, Thongtem T, Thongtem S. Preparation, characterization and photocatalytic properties of Ho doped $\mathrm{ZnO}$ nanostructures synthesized by sonochemical method. Superlattices and Microstructures. 2014;67:118-126. DOI: 10.1016/j.spmi.2013.12.023

[115] Khatamian M, Khandar AA, Divband B, Haghighi M, Ebrahimiasl S. Heterogeneous photocatalytic degradation of 4-nitrophenol in aqueous suspension by $\mathrm{Ln}\left(\mathrm{La}^{3+}, \mathrm{Nd}^{3+}\right.$ or $\left.\mathrm{Sm}^{3+}\right)$ doped $\mathrm{ZnO}$ nanoparticles. Journal of Molecular Catalysis A: Chemical. 2012; 365:120-127. DOI: 10.1016/j.molcata. 2012.08.018

[116] Ding K, Wen L, Xu L, Wu H, Ye Y, Zhang Y. Predicting the electronic and optical properties of IB metals doped monoclinic $\mathrm{BiVO}_{4}$ : First principle calculations. International Journal of Quantum Chemistry. 2015;116:388-395. DOI: $10.1002 / q u a .25051$

[117] Tang JW, Wang DF, Zou ZG, Je Y. Modification of photophysical properties of $\mathrm{WO}_{3}$ by doping different metals. Materials Science Forum. 2003; 425:163-166. DOI: 10.4028/www. scientific.net/MSF.423-425.163

[118] Xue Q, Liu Y, Zhou Q, Utsumi M, Zhang Z, Sugiura N. Photocatalytic degradation of geosmin by $\mathrm{Pd}$ nanoparticle modified $\mathrm{WO}_{3}$ catalyst under simulated solar light. Chemical Engineering Journal. 2016;283:614-621. DOI: 10.1016/j.cej.2015.08.016

[119] Wei W, Ying D, Hao J, Huang B. Density functional characterization of the of Cr-doped $\mathrm{SrTiO}_{3}$. Journal of Physics D: Applied Physics. 2009;42. DOI: $10.1088 / 0022-3727 / 42 / 5 / 055401$

[120] Liu H, Peng T, Ke D, Peng Z, Yan C. Preparation and photocatalytic activity of dysprosium doped tungsten trioxide nanoparticles. Materials Chemistry and Physics. 2007;104:
377-383. DOI: 10.1016/j.matchemphys. 2007.03.028

[121] Li J, Hu W, Zhong J, Zeng J, Huang S, Xiao Z, et al. Photo-induced charge separation and photocatalytic activity of Ga-doped $\mathrm{SnO}_{2}$. Applied Physics A: Materials Science \& Processing. 2014; 116:2149-2156. DOI: $10.1007 /$ s00339-014-8428-x

[122] Li Z, Shen Y, Guan Y, Hu Y, Lin Y, Nan CW. Bandgap engineering and enhanced interface coupling of graphene- $\mathrm{BiFeO}_{3}$ nanocomposites as efficient photocatalysts under visible light. Journal of Materials Chemistry A. 2014;2:1967-1973. DOI: 10.1039/ c3ta14269h

[123] Hu S, Li F, Fan Z, Wang F, Zhao Y, Lv Z. Band gap-tunable potassium doped graphitic carbon nitride with enhanced mineralization. Dalton Transactions. 2014;44:1084-1092. DOI: $10.1039 / \mathrm{c} 4 \mathrm{dt} 02658 \mathrm{f}$

[124] Rong X, Qiu F, Rong J, Zhu X, Yan J, Yang D. Enhanced visible light photocatalytic activity of W-doped porous. Materials Letters. 2016;164: 127-131. DOI: 10.1016/j.matlet.2015. 10.131

[125] Wang Y, Li Y, Bai X, Cai Q, Liu C, Zuo Y, et al. Facile synthesis of Y-doped graphitic carbon nitride with enhanced photocatalytic performance. Catalysis Communications. 2016;84:179-182. DOI: 10.1016/j.catcom.2016.06.020

[126] Song X, Tao H, Chen L, Sun Y. Synthesis of $\mathrm{Fe} / \mathrm{g}-\mathrm{C}_{3} \mathrm{~N}_{4}$ composites with improved visible light photocatalytic activity. Materials Letters. 2014;116: 265-267. DOI: 10.1016/j.matlet.2013. 11.043

[127] Chatterjee D, Dasgupta S. Visible light induced photocatalytic degradation of organic pollutants. Journal of Photochemistry and Photobiology C: Photochemistry Reviews. 2005;6: 
186-205. DOI: 10.1016/j.jphotochemrev. 2005.09.001

[128] Abe R, Sayama K, Arakawa H. Dyesensitized photocatalysts for efficient hydrogen production from aqueous ISolution under visible light irradiation. Journal of Photochemistry and Photobiology A: Chemistry. 2004;166: 115-122. DOI: 10.1016/j.jphotochem. 2004.04.031

[129] Chu W, Chan KH, Jafvert CT, Chan YS. Removal of phenylurea herbicide monuron via riboflavinmediated photosensitization. Chemosphere. 2007;69:177-183. DOI: 10.1016/j.chemosphere.2007.04.055

[130] Whitehead K, Hedges JI. Photodegradation and photosensitization of mycosporine-like amino acids. Journal of Photochemistry and Photobiology B: Biology. 2005;80: 115-121. DOI: 10.1016/j.jphotobiol. 2005.03.008

[131] Kaur S, Singh V. Visible light induced sonophotocatalytic degradation of reactive red dye 198 using dye sensitized $\mathrm{TiO}_{2}$. Ultrasonics Sonochemistry. 2007;14:531-537. DOI: 10.1016/j.ultsonch.2006.09.015

[132] Lee C, Hyeon T, Lee H. Visible light-induced degradation of carbon tetrachloride on. Environmental Science \& Technology. 2001;35:966-970

[133] Shim M, Mcdaniel H, Oh N. Prospects for strained type-II nanorod heterostructures. The Journal of Physical Chemistry Letters. 2011;2: 2722-2727

[134] Tian J, Zhenhuan Zhaoa AK, Boughton RI, Liu H. Nanostructured surface heterostructures: A review. Chemical Society Reviews. 2014;43: 6920-6937. DOI: 10.1039/x0xx00000x

[135] Beydoun D, Amal R, Low G. Role of nanoparticles in photocatalysis.
Journal of Nanoparticle Research. 1999; 1:439-458. DOI: 10.1023/A: 1010044830871

[136] Ghows N, Entezari MH. Fast and easy synthesis of core-Shell nanocrystal $\left(\mathrm{CdS} / \mathrm{TiO}_{2}\right)$ at low temperature by micro-emulsion under ultrasound. Ultrasonics Sonochemistry. 2011;18:629-634. DOI: 10.1016/j. ultsonch.2010.08.003

[137] Jia H, Xu H, Hu Y, Tang Y, Zhang L. $\mathrm{TiO}_{2} @ \mathrm{CdS}$ core-Shell nanorods films: Fabrication and dramatically enhanced photoelectrochemical properties. Electrochemistry Communications. 2007;9:354-360. DOI: 10.1016/j.elecom.2006.10.010

[138] Covei M, Perniu D, Bogatu C, Duta A. CZTS-TiO 2 thin film heterostructures for advanced photocatalytic wastewater treatment. Catalysis Today. 2019;321322:172-177. DOI: 10.1016/j.cattod.2017. 12.003

[139] Rashid J, Barakat MA, Ruzmanova Y. $\mathrm{Fe}_{3} \mathrm{O}_{4} / \mathrm{SiO}_{2} / \mathrm{TiO}_{2}$ nanoparticles for photocatalytic degradation of 2chlorophenol in simulated wastewater. Environmental Science and Pollution Research. 2015;22:3149-3157. DOI: 10.1007/s11356-014-3598-9

[140] Pan L, Shen G, Zhang J, Wei X, Wang $\mathrm{L}$, Zou J, et al. $\mathrm{TiO}_{2}-\mathrm{ZnO}$ composite sphere decorated with $\mathrm{ZnO}$ clusters for $\mathrm{E}$ ff ective charge isolation in photocatalysis. Industrial and Engineering Chemistry Research. 2015; 54:7226-7232. DOI: 10.1021/acs. iecr.5b01471

[141] Lee G, Kang M. Physicochemical properties of core/shell structured pyrite $\mathrm{FeS}_{2}$ /anatase $\mathrm{TiO}_{2}$ composites and their photocatalytic hydrogen production performances. Current Applied Physics. 2013;13:1482-1489. DOI: 10.1016/j.cap.2013.05.002

[142] Rashid J, Saleem S, Awan SU, Iqbal A, Kumar R, Barakat MA, et al. 
Stabilized fabrication of anatase- $\mathrm{TiO}_{2} /$ $\mathrm{FeS}_{2}$ (pyrite) semiconductor composite nanocrystals for enhanced solar lightmediated photocatalytic degradation of methylen blue. RSC Advances. 2018;8: 11935-11945. DOI: 10.1039/c8ra02077a

[143] Rashid J, Barakat M. InVO ${ }_{4} / \mathrm{TiO}_{2}$ composite for visible-light photocatalytic degradation of 2chlorophenol in wastewater. Environmental Technology. 2014;35: 2153-2159. DOI: $10.1080 / 09593330$. 2014.895051

[144] Rashid J, Barakat MA. $\mathrm{Ag}_{3} \mathrm{PO}_{4}$ Enhanced $\mathrm{TiO}_{2}$ for Visible Light Photocatalysis of 2-Chlorophenol in Wastewater. Institute of Research Engineers and Doctors, USA; 2014. pp. 3-7

[145] Li Y, Zhao H, Yang M. $\mathrm{TiO}_{2}$ nanoparticles supported on PMMA nanofibers for photocatalytic degradation of methyl orange. Journal of Colloid and Interface Science. 2017;508: 500-507. DOI: 10.1016/j.jcis.2017.08.076

[146] Rashid J, Abbas A, Chang LC, Iqbal A, Ihsan-ul-Haq A, Rehman SUA, et al. Butterfly cluster like lamellar $\mathrm{BiOBr} /$ $\mathrm{TiO}_{2}$ nanocomposite for enhanced sunlight photocatalytic mineralization of aqueous ciprofloxacin. Science of the Total Environment Elsevier B. 2019;665: 668-677. DOI: 10.1016/j.scitotenv. 2019.02.145

[147] Jana TK, Pal A, Chatterjee K. Self assembled flower like CdS- $\mathrm{ZnO}$ nanocomposite and its photo catalytic activity. Journal of Alloys and Compounds. 2014;583:510-515. DOI: 10.1016/j.jallcom.2013.08.184

[148] Cho S, Jang JW, Kim J, Lee JS, Choi $\mathrm{W}$, Lee KH. Three-dimensional type II $\mathrm{ZnO} / \mathrm{ZnSe}$ heterostructures and their visible light photocatalytic activities. Langmuir. 2011;27:10243-10250. DOI: 10.1021/la201755w

[149] Wang Z, Huang B, Dai Y, Qin X, Zhang X, Wang $\mathrm{P}$, et al. Highly photocatalytic $\mathrm{ZnO} / \mathrm{In}_{2} \mathrm{O}_{3}$

heteronanostructures synthesized by a coprecipitation method. The Journal of Physical Chemistry. 2009;113:4612-4617

[150] Hamrouni A, Moussa N, Di Paola A, Parrino F, Houas A, Palmisano L. Characterization and photoactivity of coupled $\mathrm{ZnO}-\mathrm{ZnWO}_{4}$ catalysts prepared by a sol-gel method. Applied Catalysis B: Environmental. 2014;154155:379-385. DOI: 10.1016/j.apcatb. 2014.02.042

[151] Hernández S, Hidalgo D, Sacco A, Chiodoni A, Lamberti A, Cauda V, et al. Comparison of photocatalytic and transport properties of $\mathrm{TiO}_{2}$ and $\mathrm{ZnO}$ nanostructures for solar-driven water splitting. Physical Chemistry Chemical Physics. 2015;17:7775-7786. DOI:

10.1039/c4cp05857g

[152] Katsumata H, Gomathisankar P, Funasaka K, Kaneco S, Suzuki T, Hachisuka K. Photocatalytic hydrogen production with $\mathrm{CuS} / \mathrm{ZnO}$ from aqueous $\mathrm{Na}_{2} \mathrm{~S}+\mathrm{Na}_{2} \mathrm{SO}_{3}$ solution. International Journal of Hydrogen Energy. 2013;38: 8625-8630. DOI: 10.1016/j.ijhydene. 2013.04.131

[153] He Z, Shi Y, Gao C, Wen L, Chen J, Song S. BiOCl/ $/ \mathrm{BiVO}_{4} \mathrm{p}-\mathrm{n}$ heterojunction with enhanced photocatalytic activity under visiblelight irradiation. The Journal of Physical Chemistry. 2014;118:389-398. DOI: 10.1021/jp409598s

[154] Tahir MB, Nabi G, Rafique M, Khalid NR. Nanostructured-based $\mathrm{WO}_{3}$ photocatalysts: Recent development, activity enhancement, perspectives and applications for wastewater treatment. International journal of Environmental Science and Technology. 2017;14: 2519-2542. DOI: 10.1007/s13762-0171394-z

[155] Shamaila S, Khan A, Sajjad L, Chen $\mathrm{F}$, Zhang J. $\mathrm{WO}_{3} / \mathrm{BiOCl}$, a novel heterojunction as visible light 
photocatalyst. Journal of Colloid and Interface Science. 2011;356:465-472. DOI: $10.1016 /$ j.jcis.2011.01.015

[156] Huang T, Lin X, Xing J, Wang W, Shan Z, Huang F. Photocatalytic activities of hetero-junction semiconductors $\mathrm{WO}_{3} / \mathrm{SrNb}_{2} \mathrm{O}_{6}$. Materials Science \& Engineering, B: Solid-State Materials for Advanced Technology. 2007;141:49-54. DOI: 10.1016/j.mseb.2007.05.007

[157] Zhang J, Yu K, Yu Y, Lou LL, Yang $Z$, Yang J, et al. Highly effective and stable $\mathrm{Ag}_{3} \mathrm{PO}_{4} / \mathrm{WO}_{3}$ photocatalysts for visible light degradation of organic dyes. Journal of Molecular Catalysis A: Chemical. 2014;391:12-18. DOI: 10.1016/j.molcata.2014.04.010

[158] Huang Z, Zou J, Pan L, Wang S, Zhang X, Wang L. Synergetic promotion on photoactivity and stability of $\mathrm{W}_{18} \mathrm{O}_{49} / \mathrm{TiO}_{2}$ hybrid. Applied Catalysis B: Environmental. 2014;147: 167-174. DOI: 10.1016/j.apcatb.2013. 08.038

[159] Aslam I, Cao C, Tanveer M, Farooq MH, Khan SW, Tahir M, et al. A novel $\mathrm{Z}$-scheme $\mathrm{WO}_{3} / \mathrm{CdWO}$ photocatalyst with enhanced visible-light photocatalytic activity for the degradation of organic pollutants. RSC Advances. 2015;5:6019-6026. DOI: 10.1039/C4RA15847D

[160] Zaleska A, Winiarski M, Klimczuk T, Bajorowicz B, Cybula A. Surface properties and photocatalytic activity of $\mathrm{KTaO}_{3}, \mathrm{CdS}, \mathrm{MoS}_{2}$ semiconductors and their binary and ternary semiconductor composites. Molecules. 2014;19:

15339-15360. DOI: $10.3390 /$

molecules190915339

[161] Pirhashemi M, Habibi-yangjeh A. Ternary $\mathrm{ZnO} / \mathrm{AgBr} / \mathrm{Ag}_{2} \mathrm{CrO}_{4}$ nanocomposites with tandem $\mathrm{n}-\mathrm{n}$ heterojunctions as novel visible-lightdriven photocatalysts with excellent activity. Ceramics International. 2015;
41:14383-14393. DOI: 10.1016/j. ceramint.2015.07.072

[162] Zhang W, Li Y, Song Q, Zhang J, Chen X, Liu D, et al. Multi-pathway photoelectron migration in globular flower-like $\mathrm{In}_{2} \mathrm{O}_{3} / \mathrm{AgBr} / \mathrm{Bi}_{2} \mathrm{WO}_{6}$ synthesized by microwave-assisted method with enhanced photocatalytic activity. Journal of Molecular Catalysis A: Chemical. 2015;414:27-36. DOI: 10.1016/j.molcata.2015.12.023

[163] Mohamed MM, Ahmed SA, Khairou KS. Unprecedented high photocatalytic activity of nanocrystalline $\mathrm{WO}_{3} / \mathrm{NiWO}_{4}$ heterojunction towards dye degradation: Effect of template and synthesis conditions. Applied Catalysis B: Environmental. 2014;150-151:63-73.

DOI: 10.1016/j.apcatb.2013.12.001

[164] Xu YS, De Zhang W.

Monodispersed $\mathrm{Ag}_{3} \mathrm{PO}_{4}$ nanocrystals loaded on the surface of spherical $\mathrm{Bi}_{2} \mathrm{MoO}_{6}$ with enhanced photocatalytic performance. Dalton Transactions. 2013;42:1094-1101. DOI: 10.1039/ c2dt31634j

[165] Cao J, Luo B, Lin H, Xu B, Chen S. Visible light photocatalytic activity enhancement and mechanism of $\mathrm{AgBr} /$ $\mathrm{Ag}_{3} \mathrm{PO}_{4}$ hybrids for degradation of methyl orange. Journal of Hazardous Materials. 2012;217-218:107-115. DOI: 10.1016/j.jhazmat.2012.03.002

[166] Feng Y, Yan X, Liu C, Hong Y, Zhu L, Zhou M, et al. Applied surface science hydrothermal synthesis of $\mathrm{CdS} / \mathrm{Bi}_{2} \mathrm{MoO}_{6}$ heterojunction photocatalysts with excellent visible-light-driven photocatalytic performance. Applied Surface Science. 2015;353:87-94. DOI: 10.1016/j.apsusc.2015.06.061

[167] Ghugal SG, Umare SS, Sasikala R. Photocatalytic mineralization of anionic dyes using bismuth doped $\mathrm{CdS}-\mathrm{Ta}_{2} \mathrm{O}_{5}$ composite. RSC Advances. 2015;5: 


\section{3-63400. DOI: 10.1039/ C5RA09974A}

[168] Kong L, Jiang Z, Xiao T, Lu L, Jones O, Edwards PP. Exceptional visiblelight-driven photocatalytic activity over. Chemical Communications. 2011;47: 5512-5514. DOI: 10.1039/c1cc10446b

[169] Liu C, Li P, Wu G, Luo B, Lin S, Ren A, et al. Enhanced photoelectrochemical and photocatalytic activity by $\mathrm{Cu}_{2} \mathrm{O} / \mathrm{SrTiO}_{3}$ $\mathrm{p}-\mathrm{n}$ heterojunction via a facile deposition-precipitation technique. RSC Advances. 2015;5:33938-33945. DOI: 10.1039/C5RA03086B

[170] Hong E, Kim D, Kim JH. Heterostructured metal sulfide (ZnSCuS-CdS) photocatalyst for high electron utilization in hydrogen production from solar water splitting. Journal of Industrial and Engineering Chemistry. 2014;20:3869-3874. DOI: 10.1016/j.jiec.2013.12.092

[171] Moussa N, Houas A, Parrino F, Di Paola A, Hamrouni A, Palmisano L. Photocatalytic activity of binary and ternary $\mathrm{SnO}_{2}-\mathrm{ZnO}-\mathrm{ZnWO}_{4}$ nanocomposites. Journal of Photochemistry and Photobiology A: Chemistry. 2015;309:47-54. DOI: 10.1016/j.jphotochem.2015.05.001

[172] Zhao Z, Yanjuan S, Dong F. Graphitic carbon nitride based nanocomposites: A review. Nanoscale. 2015;7:15-37. DOI: 10.1039/c4nr03008g

[173] Song G, Chu Z, Jin W, Sun H. Enhanced performance of g- $\mathrm{C}_{3} \mathrm{~N}_{4} / \mathrm{TiO}_{2}$ photocatalysts for degradation of organic pollutants under visible light. Chinese Journal of Chemical Engineering. 2015;23:1326-1334. DOI: 10.1016/j.cjche.2015.05.003

[174] Lv J, Dai K, Zhang J, Geng L, Liang $\mathrm{C}$, Liu $\mathrm{Q}$ et al. Applied surface science facile synthesis of Z-scheme graphitic$\mathrm{C}_{3} \mathrm{~N}_{4} / \mathrm{Bi}_{2} \mathrm{MoO}_{6}$ nanocomposite for enhanced visible photocatalytic properties. Applied Surface Science. 2015;358:377-384. DOI: 10.1016/j. apsusc.2015.06.183

[175] Dai S, Hua F, Li W, Hou H, Yue J, Feng C. Fabrication of sulfur-doped g$\mathrm{C}_{3} \mathrm{~N}_{4} / \mathrm{Au} / \mathrm{CdS} \mathrm{Z}$-scheme photocatalyst to improve the photocatalytic performance under visible light. Applied Catalysis B: Environmental. 2015;168-169:465-471. DOI: 10.1016/j. apcatb.2015.01.012

[176] Fu J, Chang B, Yanlong Tian FX, Dong $\mathrm{X}$. Novel $\mathrm{C}_{3} \mathrm{~N}_{4}$-CdS composite photocatalysts with organic-inorganic heterojunctions: In suit synthesis, exceptional activity, high stability and photocatalytic mechanism. Journal of Materials Chemistry A. 2013;1:30833090. DOI: $10.1039 / \mathrm{c} 2 \operatorname{ta} 00672 \mathrm{c}$

[177] Tong Z, Yang D, Shi J, Nan Y, Sun $\mathrm{Y}$, Jiang Z, et al. Three-dimensional porous aerogel constructed by $\mathrm{g}-\mathrm{C}_{3} \mathrm{~N}_{4}$ and graphene oxide nanosheets with excellent visible-light photocatalytic performance. Applied Materials \& Interfaces. 2015;7:25693-25701. DOI: 10.1021/acsami.5b09503

[178] Han Q, Chen N, Zhang J, Qu L. Graphene/graphitic carbon nitride hybrids for catalysis. Materials Horizons. 2017:832-850. DOI: 10.1039/ c7mh00379j

[179] Mousavi M, Habibi-Yangjeh A. Integration of $\mathrm{NiWO}_{4}$ and $\mathrm{Fe}_{3} \mathrm{O}_{4}$ with graphitic carbon nitride to fabricate novel magnetically recoverable visiblelight-driven photocatalysts. Journal of Materials Science. 2018;53:9046-9063. DOI: $10.1007 / \mathrm{s} 10853-018-2213-8$

[180] Zhang S, Li J, Zeng M, Zhao G, Xu $\mathrm{J}, \mathrm{Hu} \mathrm{W}$, et al. In situ synthesis of watersoluble magnetic graphitic carbon nitride photocatalyst and its synergistic catalytic performance. ACS Applied Materials \& Interfaces. 2013;5:1273512743 
[181] Zou L, Wang H, Yuan G, Wang X. Magnetically separable $\mathrm{CdS} / \mathrm{ZnFe}_{2} \mathrm{O}_{4}$ composites with highly efficient photocatalytic activity and photostability under visible light. ACS Applied Nano Materials. 2018;1:831-838. DOI: 10.1021/acsanm.7b00243

[182] Chai B, Liao X, Song F, Zhou H. Fullerene modified $\mathrm{C}_{3} \mathrm{~N}_{4}$ composites with enhanced photocatalytic activity under visible light irradiation. Dalton Transactions. 2014;43:982-989. DOI: $10.1039 / \mathrm{c} 3 \mathrm{dt} 52454 \mathrm{j}$

[183] Fu H, Xu T, Zhu S, Zhu Y. Photocorrosion inhibition and enhancement of photocatalytic activity for $\mathrm{ZnO}$ via hybridization with $\mathrm{C}_{6} \mathrm{O}$. Environmental Science \& Technology. 2008;42:8064-8069. DOI: 10.1021/ es $801484 \mathrm{x}$

[184] Zhu Y, Bai X, Yao W, Wang L, Wang Y. Enhanced oxidation ability of g- $\mathrm{C}_{3} \mathrm{~N}_{4}$ photocatalyst via $\mathrm{C} 60$ modification. Applied Catalysis B: Environmental. 2014b;152-153:262-270. DOI: 10.1016/j.apcatb.2014.01.046

[185] Zhu H, Chen D, Yue D. In-situ synthesis of $\mathrm{g}-\mathrm{C}_{3} \mathrm{~N}_{4}-\mathrm{P}_{25} \mathrm{TiO}_{2}$ composite with enhanced visible light photoactivity. Journal of Nanoparticle Research. 2014;16:1-10. DOI: 10.1007/ s11051-014-2632-7

[186] Huang L, Xu H, Li Y, Li H, Cheng $\mathrm{X}$, Xia J, et al. Visible-light-induced $\mathrm{WO}_{3} / \mathrm{g}-\mathrm{C}_{3} \mathrm{~N}_{4}$ composites with enhanced photocatalytic activity. Dalton Transactions. 2013;4:8606-8616. DOI: $10.1039 / \mathrm{c} 3 \mathrm{dt} 00115 \mathrm{f}$

[187] Tian N, Huang H, Zhang Y. Mixedcalcination synthesis of $\mathrm{CdWO}_{4} / \mathrm{g}-\mathrm{C}_{3} \mathrm{~N}_{4}$ heterojunction with enhanced visiblelight-driven photocatalytic activity. Applied Surface Science. 2015;358: 343-349. DOI: 10.1016/j.apsusc.2015. 07.154
[188] Xing C, Wu Z, Jiang D, Chen M. Hydrothermal synthesis of $\operatorname{In}_{2} \mathrm{~S}_{3} / g-\mathrm{C}_{3} \mathrm{~N}_{4}$ heterojunctions with enhanced photocatalytic activity. Journal of Colloid and Interface Science. 2014;433:

9-15. DOI: 10.1016/j.jcis.2014.07.015

[189] Liu Q, Fan C, Tang H, Sun X, Yang J, Cheng X. One-pot synthesis of g$\mathrm{C}_{3} \mathrm{~N}_{4} / \mathrm{V}_{2} \mathrm{O}_{5}$ composites for visible lightdriven photocatalytic activity. Applied Surface Science. 2015;358:188-195. DOI: 10.1016/j.apsusc.2015.09.010

[190] Sun JX, Yuan YP, Qiu LG, Jiang X, Xie AJ, Shen $\mathrm{YH}$, et al. Fabrication of composite photocatalyst g- $\mathrm{C}_{3} \mathrm{~N}_{4}-\mathrm{ZnO}$ and enhancement of photocatalytic activity under visible light. Dalton Transactions. 2012;41:6756-6763. DOI: $10.1039 / \mathrm{c} 2 \mathrm{dt} 12474 \mathrm{~b}$

[191] Wang Y, Wang Z, Muhammad S, He J. Graphite-like $\mathrm{C}_{3} \mathrm{~N}_{4}$ hybridized $\mathrm{ZnWO}_{4}$ nanorods: Synthesis and its enhanced photocatalysis in visible light. CrystEngComm. 2012;14:5065-5070. DOI: $10.1039 / \mathrm{c} 2 \mathrm{ce} 25517 \mathrm{k}$

[192] Yuan D, Huang L, Li Y, Xu Y, $\mathrm{Xu} \mathrm{H}$, Huang S, et al. Synthesis and photocatalytic activity of g- $\mathrm{C}_{3} \mathrm{~N}_{4} / \mathrm{BiOI} /$ $\mathrm{BiOBr}$ ternary composites. RSC Advances. 2016;6:41204-41213. DOI: 10.1039/C6RA05565F

[193] Dong Z, Wu Y, Thirugnanam N, Li G. Applied surface science double $\mathrm{Z}$-scheme $\mathrm{ZnO} / \mathrm{ZnS} / \mathrm{g}-\mathrm{C}_{3} \mathrm{~N}_{4}$ ternary structure for efficient photocatalytic $\mathrm{H}_{2}$ production. Applied Surface Science. 2018;430:293-300. DOI: 10.1016/j. apsusc.2017.07.186

[194] Gao Y, Lin J, Zhang Q, Yu H, Ding $\mathrm{F}, \mathrm{Xu} \mathrm{B}$, et al. Facile synthesis of heterostructured $\mathrm{YVO} 4 / \mathrm{g}-\mathrm{C}_{3} \mathrm{~N}_{4} / \mathrm{Ag}$ photocatalysts with enhanced visiblelight photocatalytic performance. Applied Catalysis B: Environmental. 2018;224:586-593. DOI: 10.1016/j. apcatb.2017.11.003 
[195] Zhong Y, Yuan J, Wen J, Li X, Xu $\mathrm{Y}$, Liu W, et al. Earth-abundant NiS cocatalyst modified metal-free mpg- $\mathrm{C}_{3} \mathrm{~N}_{4} /$ CNT nanocomposites for highly efficient visible-light photocatalytic $\mathrm{H}_{2}$ evolution. Dalton Transactions. 2015; 44:18260-18269. DOI: 10.1039/ c5dt02693h

[196] Yan J, Song Z, Wang X, Xu Y, Pu $\mathrm{W}, \mathrm{Xu} \mathrm{H}$, et al. Enhanced photocatalytic activity of ternary $\mathrm{Ag}_{3} \mathrm{PO}_{4} / \mathrm{GO} / \mathrm{g}-\mathrm{C}_{3} \mathrm{~N}_{4}$ photocatalysts for rhodamine $\mathrm{B}$ degradation under visible light radiation. Applied Surface Science. 2019;466:70-77. DOI: 10.1016/j. apsusc.2018.09.234

[197] Zhou Y, Li J, Liu C, Huo P, Wang $\mathrm{H}$. Construction of $3 \mathrm{D}$ porous $\mathrm{g}-\mathrm{C}_{3} \mathrm{~N}_{4} /$ $\mathrm{AgBr} / \mathrm{rGO}$ composite for excellent visible light photocatalytic activity. Applied Surface Science. 2018;458: 586-596. DOI: 10.1016/j. apsusc.2018.07.121

[198] Jiang D, Yu H, Yu H. Modified g- $\mathrm{C}_{3} \mathrm{~N}_{4} / \mathrm{TiO}_{2}$ nanosheets/ZnO ternary facet coupled heterojunction for photocatalytic degradation of p-toluenesulfonic acid ( $p$-TSA) under visible light. Physica E: Lowdimensional Systems and Nanostructures. 2017;85:1-6. DOI: 10.1016/j.physe.2016.08.014

[199] Yuan Y, Huang G, Hu W, Xiong D, Zhou B, Chang S. Construction of g- $\mathrm{C}_{3} \mathrm{~N}_{4} / \mathrm{CeO}_{2} / \mathrm{ZnO}$ ternary photocatalysts with enhanced photocatalytic performance. Journal of Physics and Chemistry of Solids. 2017; 106:1-9. DOI: 10.1016/j.jpcs.2017.02.015

[200] Deng Y, Wang J, Liu Y, Wang J, Feng H, Tang L, et al. Enhanced photocatalytic activity of ternary $\mathrm{Ag} / \mathrm{g}$ $\mathrm{C}_{3} \mathrm{~N}_{4} / \mathrm{NaTaO}_{3}$ photocatalysts under wide spectrum light radiation: The high potential band protection mechanism. Applied Catalysis B: Environmental. 2018;230:102-114. DOI: 10.1016/j. apcatb.2018.02.031 



\title{
$\mathrm{TiO}_{2}$ Nanoparticles Supported on Hierarchical Meso/Macroporous $\mathrm{SiO}_{2}$ Spheres for Photocatalytic Applications
}

\author{
Keyla M. Fuentes, Margarita Sánchez-Dominguez \\ and Sara A. Bilmes
}

\begin{abstract}
Supporting a photocatalyst, such as titania nanoparticles $\left(\mathrm{TiO}_{2} \mathrm{NPs}\right)$, is a good strategy to improve its performance since it can facilitate the photocatalyst recovery from the aqueous media and provides a high surface area for pollutant adsorption. Among the several advanced functional materials used as $\mathrm{TiO}_{2} \mathrm{NP}$ support, the hierarchical meso/macroporous $\mathrm{SiO}_{2}$ spheres not only show the advantages associated to its chemical nature but also the dendritic fibrous structure provides a porous network that offers many benefits to be exploited in optical and catalytic devices. In this chapter, different synthetic approaches to design hierarchical meso/macroporous silica and the strategies to support $\mathrm{TiO}_{2} \mathrm{NPs}$ regarding the photocatalytic performance of these materials are shown.
\end{abstract}

Keywords: hierarchical $\mathrm{SiO}_{2}$ spheres, meso/macroporous network, dendritic silica, supported $\mathrm{TiO}_{2}$ nanoparticles, $\mathrm{TiO}_{2}$ photocatalysis

\section{Introduction}

The practical applications of semiconductor photocatalysis using $\mathrm{TiO}_{2}$ nanoparticles $\left(\mathrm{TiO}_{2} \mathrm{NPs}\right)$ are still limited by the catalyst recovery from the aqueous media. Supporting $\mathrm{TiO}_{2}$ NPs on suitable materials is an advantageous strategy to overcome this issue. The effectiveness of this process requires that the supporting material has mechanical and thermal strength, high surface area for the loading of NPs, and surface sites for covalent binding to avoid NPs detachment. Nevertheless, the support must not modify the electronic structure of $\mathrm{TiO}_{2}$ nor reduce the density of the surface defects that promotes the adsorption of reactive molecules [1-3]. Silica-based materials are attractive supports for $\mathrm{TiO}_{2}$ due to several reasons: (i) it enhances the thermal stability of the photocatalytically active anatase phase, (ii) it avoids the particles agglomeration [4], (iii) the establishment of an Si-O-Ti interaction prevents the NPs detachment, and (iv) $\mathrm{SiO}_{2}$ is transparent in UV-vis region and it does not interfere with the generation of electron-hole pairs in $\mathrm{TiO}_{2}$ [5]. Additionally, $\mathrm{SiO}_{2} @ \mathrm{TiO}_{2}$ core@shell structures enhance the absorption of photons due to the contrast between the refractive index producing a light-harvesting effect, which favors the photoactivity [6]. 
The optimal $\mathrm{TiO}_{2}$ photocatalysts are 5-50 nm NPs in the anatase phase [7]. High loadings of NPs within this size range could be challenging for supports with low surface areas. Mesoporous silica with high surface area $\left(500-1000 \mathrm{~m}^{2} / \mathrm{g}\right)$, such as MCM-41, MCM-48, SBA-15, and KIT-6 has been widely used to deposit $\mathrm{TiO}_{2}$ NPs [8-11]. However, the pore diameters in these materials usually range from 2 to $15 \mathrm{~nm}$ [12]; hence, the crystallization of NPs with sizes comparable to the pores entrances will cause, inevitably, the clogging of the pores and a significant decrease in the surface area [13].

Hierarchically porous materials have the advantage that micro- and mesopores provide the size and shape selectivity for guest molecules, enhancing the host-guest interactions, whereas macropores favor the diffusion and accessibility of guest molecules [14]. The need for tailored porous materials for different applications has motivated the design of hierarchical meso/macroporous silica by different synthetic approaches [15]; most of them are based on the sol-gel chemistry at liquid interfaces using arrangements of amphiphilic molecules as templates [16-18]. Interesting examples of these materials are the so-called dendritic fibrous nanosilicas (DFNS) [19-21], such as KCC-1 spheres (KAUST Catalysis Center-1) that are potentially useful for solving problems in catalysis, photocatalysis, DNA adsorption, $\mathrm{CO}_{2}$ capture, optical devices, and drug delivery [22].

For photocatalytic applications, the location of the $\mathrm{TiO}_{2} \mathrm{NPs}$ plays an important role in the photoactivity, since NPs should be accessible for both, photons and reactive molecules. Figure 1 illustrates the different locations of the $\mathrm{TiO}_{2} \mathrm{NPs}$ deposited on the fibrous silica KCC-1 in comparison with conventional mesoporous silica such as MCM41 or SBA-15. In case of NPs deposited on KCC-1, the broad size of pore entrances facilitates the accessibility to the particles located closer to the center of the sphere.

In this chapter, we describe the synthesis pathways and the strategies for turning fibrous silica as support for photocatalytic $\mathrm{TiO}_{2} \mathrm{NPs}$ for applications in dye-sensitized solar cells, water splitting, and photodegradation of dyes. The advantages of using these materials as support for $\mathrm{TiO}_{2}$ in relation to photocatalytic processes are addressed by comparing the photocatalytic activity of $\mathrm{TiO}_{2} \mathrm{NPs}$ deposited by different routes, as well as with $\mathrm{TiO}_{2} \mathrm{NPs}$ on mesoporous materials. Since the structure of these materials in the nanometer scale presents many analogies with forms of
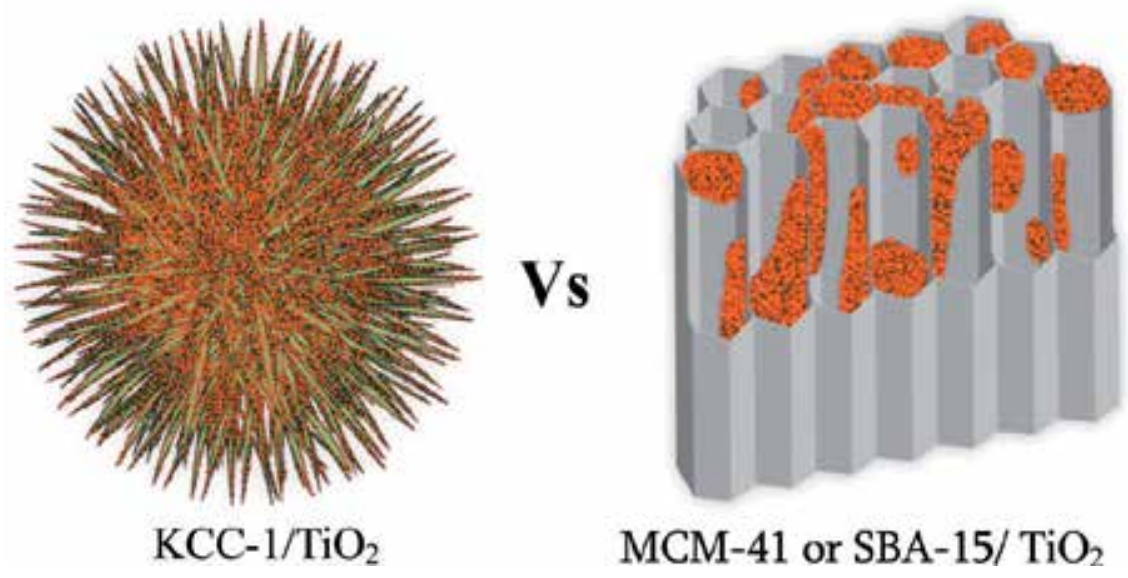

Figure 1.

Representation of $\mathrm{TiO}_{2} \mathrm{NPs}$ supported on fibrous nanosilica KCC-1 versus conventional mesoporous support (e.g., MCM-41 or SBA-15). The orange dots symbolize the $\mathrm{TiO}_{2} \mathrm{NPs}$. Reprinted with permission from Reference [23]. Copyright 2016 American Chemical Society. 

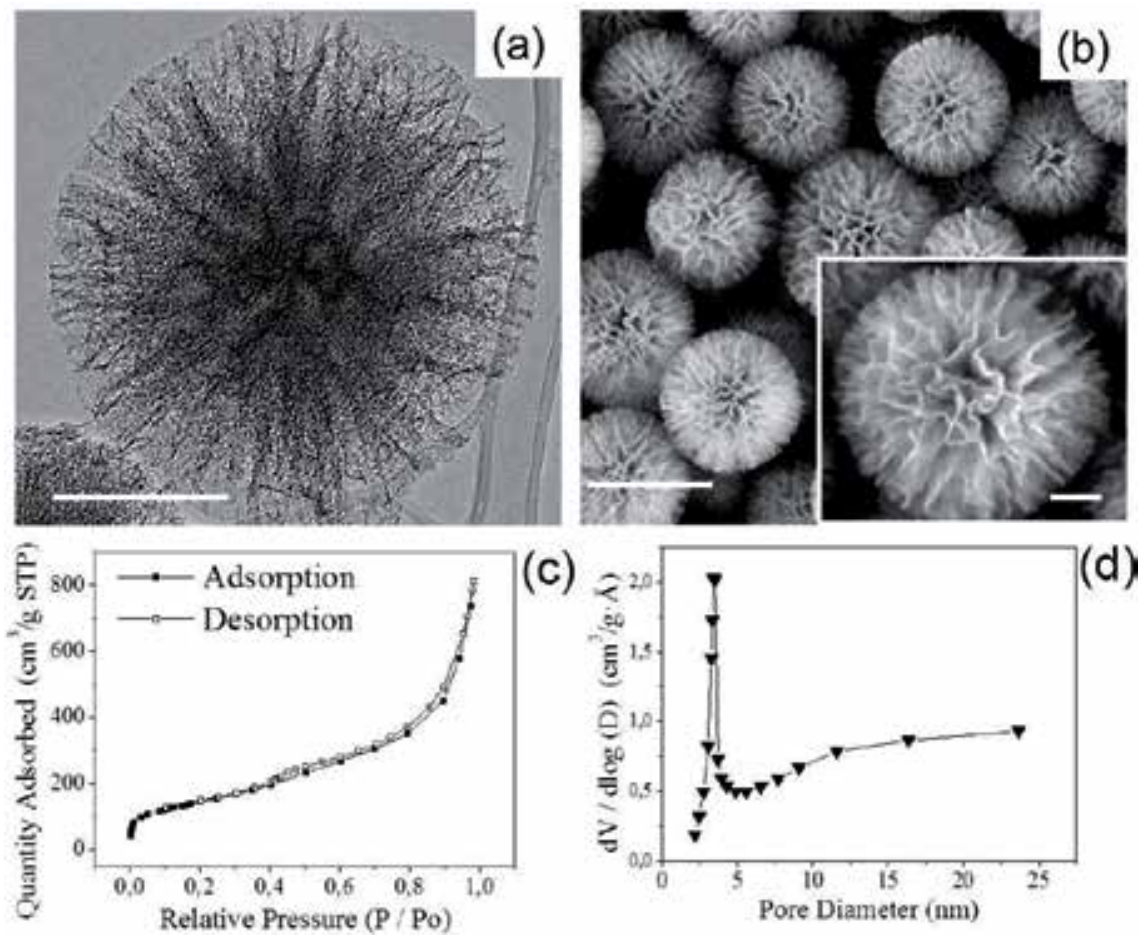

Figure 2.

TEM (a) and SEM (b) images for a representative hierarchical meso/macroporous $\mathrm{SiO}_{2}$ spheres obtained through the synthesis by type III Winsor emulsion (see below). For the TEM image, the scale bar is 200 and $500 \mathrm{~nm}$ for the SEM image (scale bar of $100 \mathrm{~nm}$ for the inset). (c) $\mathrm{N}_{2}$ adsorption-desorption isotherm and (d) pores size distribution (calculated by the BJH model) for the particles shown in ( $a$ and b). Unpublished results of the authors.

the micro- and macroscopic world: dendrites, carnations, wrinkles, fibers, in what follows, we will use indistinguishably the terms fibrous, dendritic, or wrinkled to refer to structures like those in Figure 2.

\section{Synthesis of the hierarchical meso/macroporous $\mathrm{SiO}_{2}$ spheres}

Most of the novel methods for building nanostructures with tunable morphology and pore size are based on the application of an oil—water interface using amphiphilic molecules as template, which allows the preparation of materials with well-defined structures in a confined reaction media [24, 25]. By changing the oil phase, surfactant, or reaction parameters, several morphologies can be obtained, such as rod-like [26], vesicle-like [27], cage-like [28], or fibrous structures [29].

The morphological and textural characteristics of a fibrous structure are shown in Figure 2. Transmission electron microscopy (TEM) image reveals a darker core surrounded by a meso/macroporous shell (Figure 2a). Unlike the narrow pore-size distribution of common mesoporous silica materials (e.g., MCM-41 and SBA-15), these particles have radially oriented pores whose diameter increases from the center of the sphere. The scanning electron microscopy (SEM) images show a narrow distribution of particle size, and the surface of each sphere presents cavities with a broad distribution of sizes limited by folded walls (Figure $2 \mathbf{b}$ ). The associated nitrogen adsorption-desorption isotherm shown in Figure 2c could be classified as type IV isotherm with $\mathrm{H}_{3}$ hysteresis loop. Materials with $\mathrm{H}_{3}$ hysteresis do not 
show any limiting adsorption at high $P / P$ o associated with nonrigid aggregates of plate-like particles and have slit-shaped pores [30]. These particles have a complex porous structure (Figure 2d) with pores of $3.5 \mathrm{~nm}$, resulting from the surfactant assemblies that define the pore structure of the walls [31], as derived from $\mathrm{BJH}$ analysis of adsorption-desorption isotherms. Additionally, there is a broad distribution of larger pores related to the lamellar structure unfolding toward the particle surface.

This type of morphology with radially oriented channels can be obtained in a ternary confined reaction media composed by a surfactant and a co-surfactant, a hydrocarbon, and water. In case of particles presented in Figure 2, the reaction media is composed by cetyltrimethylammonium bromide (CTAB) and 1-butanol, cyclohexane, and water. Usually, the silicon sources are alkoxides, such as tetraethyl or tetramethyl orthosilicates (TEOS, TMOS) that give rise to the $\mathrm{SiO}_{2}$ structure through sol-gel reactions.

The water-surfactant (+co-surfactant)-oil system may present one or more phases depending on the chemical composition. For instance, a thermodynamically stable microemulsion phase or multiphase systems containing a microemulsion layer can be obtained [32]. To follow the description of the formation mechanism, it is necessary to introduce some concepts related to the system.

Micelle: structures formed by self-assembly of amphiphiles in aqueous solutions giving separate regions with opposite affinities toward a given solvent. Normally, micelles have characteristic size within the 2-50 $\mathrm{nm}$ range and form spontaneously under certain conditions of concentration and temperature [33].

Reverse micelle: spheroidal aggregates formed by amphiphiles in organic solvents. They can be formed both in the presence and in the absence of water. In a medium free of water, the aggregates are small and polydisperse [34].

Microemulsion: system composed of water, oil, and an amphiphile, which is a single optically, isotropic, and thermodynamically stable liquid solution [35]. The microemulsions can exist as oil-swollen direct micelles dispersed in water $(\mathrm{O} / \mathrm{W}$ microemulsions), water-swollen reverse micelles dispersed in oil (W/O microemulsions), or with both aqueous and oily continuous domains as interconnected sponge-like channels (bicontinuous microemulsions) [36].

Winsor emulsion systems: the Winsor classification of ternary systems, i.e., types I-IV, can be made according to the numbers and type of phases in the equilibrium state. Except for the single-phase microemulsion (type IV), the structure of the microemulsion is determined through the separation of the solvent from the dispersed phase of the microemulsion layer. Type I: at equilibrium, superfluous oil separates from the oil-in-water microemulsion. Type II: superfluous water separated from the microemulsion layer. Type III: both superfluous oil and water separated from the water-in-oil microemulsion [32].

Mesophase: a phase occurring over a defined range of temperature, pressure, or composition within the mesomorphic state. This is a state of matter in which the degree of molecular order is intermediate between the three-dimensional, longrange order found in solid crystals and the order found in isotropic liquids, gases, and amorphous solids [37].

Sol-gel reactions: these are kinetically controlled hydrolysis and polycondensation reactions of a metallic precursor (e.g., inorganic or alkoxide), which give rise to a metal oxide structure. The precursor, building blocks, evolves in several steps from dispersions of colloidal particles in a liquid (Sol) to interconnected polymeric chains forming a porous rigid network (gel) [38]. The most generally accepted model to describe silica polymerization in aqueous media is nucleation and growth [39]. 
$\mathrm{TiO}_{2}$ Nanoparticles Supported on Hierarchical Meso/Macroporous $\mathrm{SiO}_{2}$ Spheres...

DOI: http://dx.doi.org/10.5772/intechopen.86153

\subsection{Proposed mechanism for the formation of the hierarchical porous $\mathrm{SiO}_{2}$ using oil-in-water emulsions}

The general mechanism for the formation of hierarchical porous silica using oil-in-water emulsion made from a type III Winsor system can be described in the following steps, also schematized in Figure 3 [20]:

1. The silicon source dissolved in the oil layer meets the water layer-an aqueous solution of a base-at the emulsion interface; the sol-gel reactions take place at this stage. In the basic solution, the reaction mixture contains ionized silicate monomers and oligomers negatively charged. As the silica condensation proceeds, the amount of partially condensed silicates decreases and that of fully condensed silicates increases.

2. Silicate oligomers interact with the surfactant heads giving rise to a change in the curvature of the interface.

3. As the curvature increases, a closed structure such as spherical or cylindrical shapes can be formed. These surfactant-silicate systems with closed structure lead to the formation of micelles or micellar emulsions inside the channels of the bicontinuous microemulsion.

4. The aggregation of these micelles leads to the formation of a repetitive mesophase.

However, in this mechanism, the growth of the particle is still unclear. It can be thought that the formed mesophase may act as a seeding site were the wrinkles grow through the water channels. As particles start growing, the structure of the microemulsion is rearranged, and according to Moon and Lee [20], the walls of wrinkles are formed in the water layers and the valleys are consequences of the oil phase in the microemulsion.

An alternative mechanism was proposed by Febriyanti et al. [40], considering the optimal conditions for the synthesis of KCC-1 [29]. They suggest the formation of reverse micelles in which the sol-gel reactions take place at higher rate in the center of the droplet. This mechanism is schematized in Figure 4. Although this mechanism explains the TEM images in which the density of the particles seems to decrease from the center to the surface of the sphere, experiments using real-time small angle X-ray scattering and 3D tomography demonstrate that the fibers grow uniformly from the
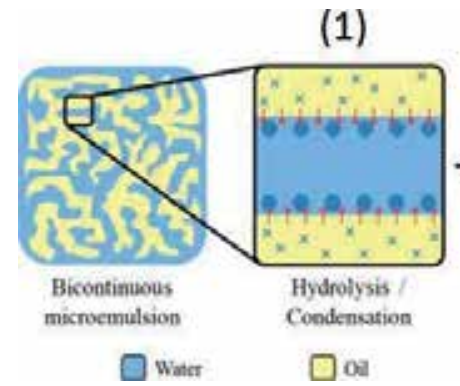

(2)

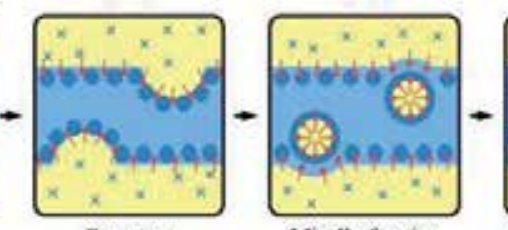

Micelle forming

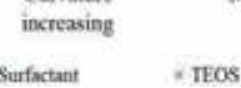

(4)

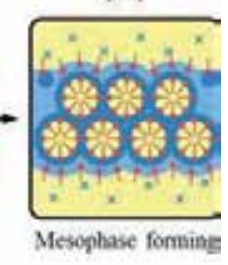

- Silicate oliponer

Figure 3.

Schematic illustration of the mesophase-forming mechanism from the microemulsion interface. Reprinted with permission from Reference [20]. Copyright 2012 American Chemical Society. 


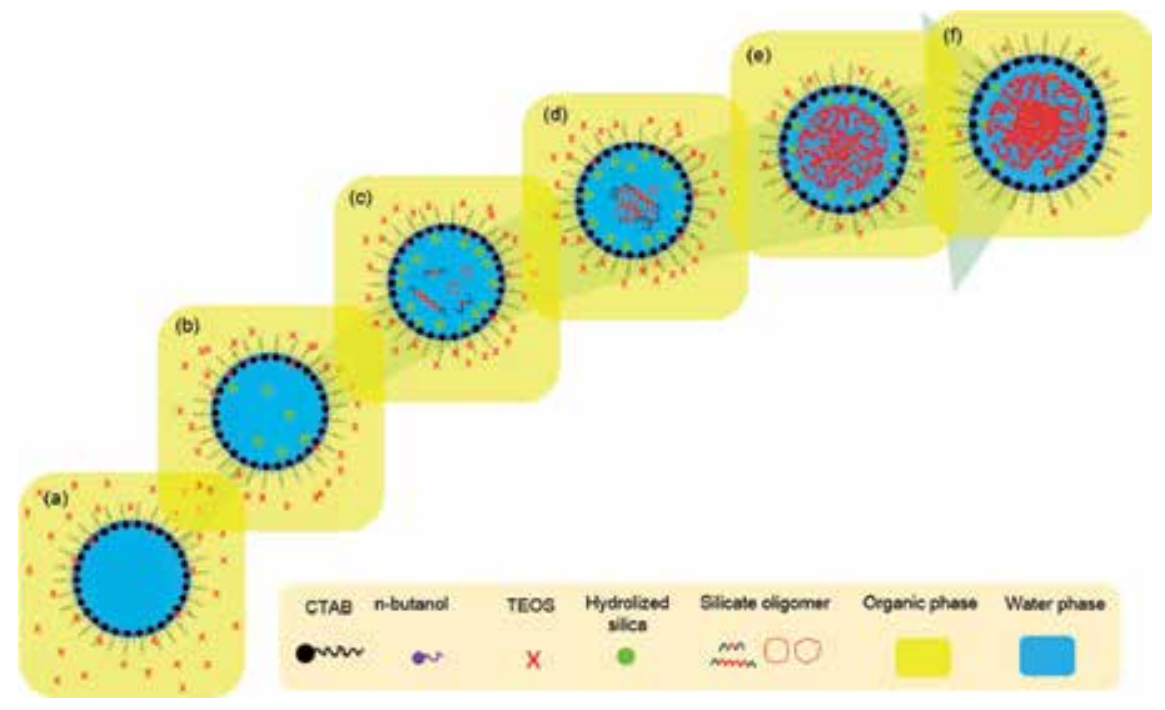

Figure 4.

Schematic representation of the KCC-1 synthesis in the reverse emulsion system proposed by Febriyanti et al. Reprinted with permission from Reference [36]. Copyright (C) 2016, American Chemical Society.

center of the spheres along the free radial directions to form fibrous spherical silica particles. Based on these results, Maity et al. [41] described the microemulsiondroplet-coalescence mechanism.

\subsection{Tuning the morphology and pore size distribution of the hierarchical meso/ macroporous silica spheres}

The possibility to obtain tailor-made supports for specific guest molecules and tunable pore volume for loading control is the most attractive feature of the threephase synthesis approach. In case of fibrous nanosilica KKC-1, the surface area may vary from 450 to $1244 \mathrm{~m}^{2} / \mathrm{g}$, and the tunable pore sizes (3.7-25 nm) allow to increase the pore volume up to $2.18 \mathrm{~cm}^{3} / \mathrm{g}$. Likewise, the particle size can be controlled from 40 to $1120 \mathrm{~nm}$. [42]. Parameters controlling particle size, pore volume, and surface area are discussed below.

\subsubsection{Oil phase}

Shen et al. developed a stratification approach to obtain a three-generation pore size by changing the oil phase in a biphasic system [43]. They used 1-octadecene, decahydronaphthalene (decalin), and cyclohexane to pores of sizes $2.8,5.5$, and $7.0 \mathrm{~nm}$ in the same particle. Each mesoporous shell was obtained in a synthesis step using the corresponding oil phase. This confirms that the organic solvent not only provides a storage medium for the silicon source (TEOS), but also interacts and assembles with the surfactant molecules in the interface to form oil-in-water microemulsion droplets. Figure 5 shows the dendritic particles obtained by the biphasic stratification approach.

\subsubsection{Surfactant}

Depending on the molar ratio of surfactant to silicon, the surfactant participates in the synthesis with different functional roles: controlling the particle diameter, the particle dispersion in the medium, and the degree of mesophase formation. 

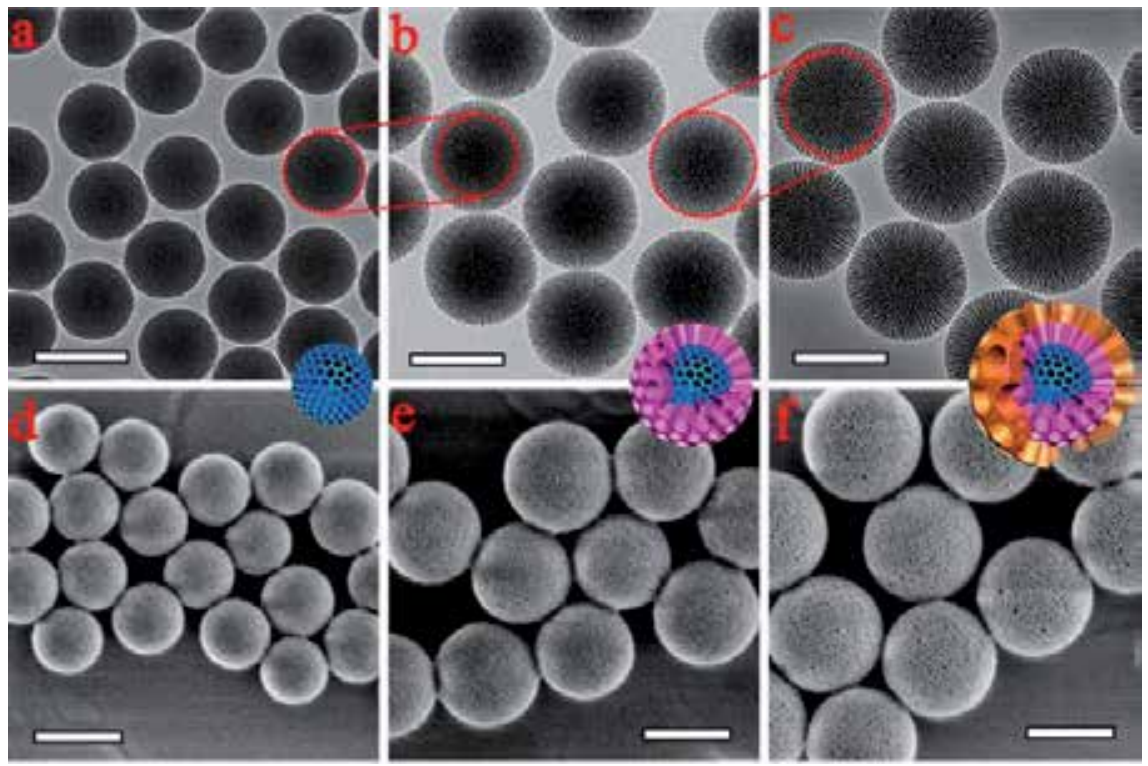

Figure 5 .

TEM (a-c) and SEM (d-f) images of the extracted $3 D$-dendritic MSNSs with one ( $a$ and $d$ ), two ( $b$ and $e$ ), and three generations ( $c$ and $f$ ) prepared via the biphase stratification approach. All scale bars in TEM and SEM images are $200 \mathrm{~nm}$.

As the surfactants favor the dispersion of the alkoxysilanes in water, the hydrolysis reactions are favored in comparison with the condensation reactions leading to an increased nucleation rate. The net effect is that increasing the surf/Si ratio, the particle diameter decreases. Moreover, at a high surf/Si ratio, free micelles may adsorb in the primary particles, allowing the dispersion of the particles due to electrostatic and/or steric repulsion. In contrast, at low surf/Si ratios, the surfactants mainly act as porogen [44]. For the KCC-1 synthesis using benzyldimethylhexadecyl ammonium chloride (16- BAC) instead of CTAB, the fibrous morphology is lost due to the differences in the packing parameters, which in turn depend on the length of the nonpolar chain and the effective area of the polar head [29].

\subsubsection{Co-surfactant}

By increasing the alkyl chain length of the co-surfactant (linear $\mathrm{C}_{3}-\mathrm{C}_{20}$ alcohols), the distance between wrinkle walls increases, as shown in Figure 6. As the affinity between oil and surfactant defines the valleys of the wrinkles, an increase in the hydrophobicity of the aqueous phase by enlarging the co-surfactant alkylchain broadens the distance between the wrinkle walls. It can be considered that this distance is directly related to the density of fibers by changing this parameter, the pore size distribution in the region related to the lamellar structure and the pore volume also changes, but the surface area remains unaltered [20].

\subsubsection{Composition of the water phase}

The type and concentration of the base catalyst dissolved in the aqueous phase affects the diameter of the spheres, as it controls the hydrolysis rate of the silicon source. Due to their buffer capacity, weak bases are preferred. For instance, basic amino acids, such as arginine or lysine, keep the reaction under weakly basic conditions leading to spherical particles with dendritic pores $[18,45]$. The same particles 


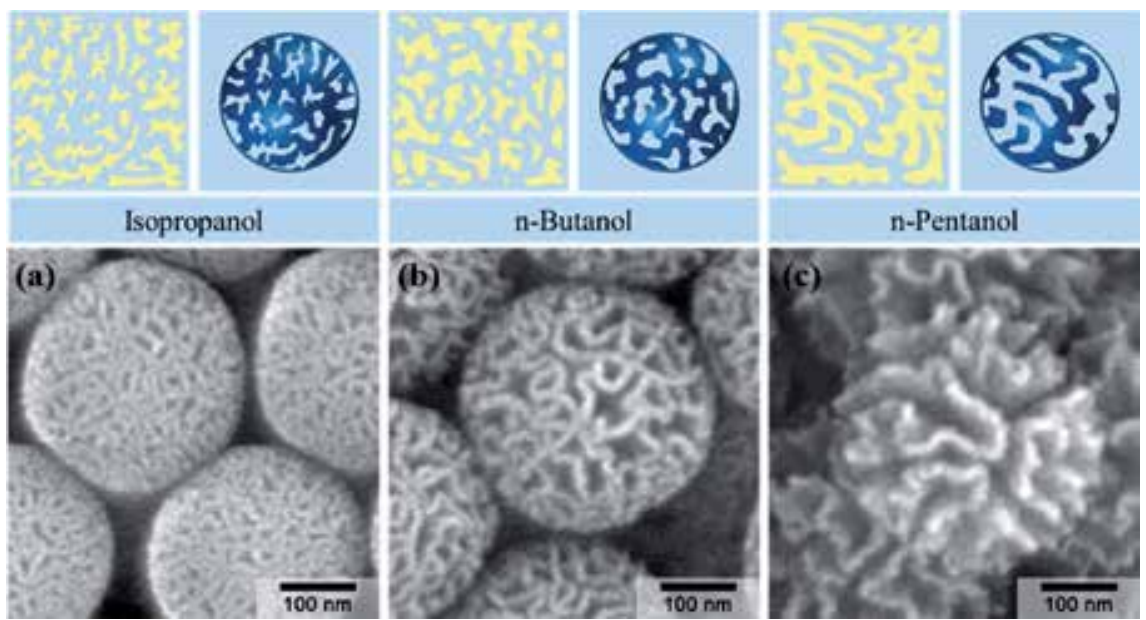

Figure 6.

Schematic illustrations of microemulsion phases of reaction mixtures with different co-solvents (6.o mmol) and corresponding SEM images of the resulting wrinkled $\mathrm{SiO}_{2}$ spheres: (a) isopropanol, (b) n-butanol, and

(c) n-pentanol. Reprinted with permission from Reference [20]. Copyright 2012 American Chemical Society.

can be obtained with urea, whose thermal decomposition above $70^{\circ} \mathrm{C}$ maintains the solution $\mathrm{pH}$ between 7 and 9.5, depending on the urea concentration [46]. Nevertheless, the increase in urea concentration rises the nucleation rate leading to smaller particles.

\subsubsection{Stirring}

Jin et al. [47] found that keeping constant the emulsion composition to obtain rod-like structures at low stirring speeds (i.e., $<300 \mathrm{rpm}$ ) produces twisted-ribbon or twisted-rod-like structures with changes in the length and the diameter of the rods. On the other side, high stirring speeds (i.e., $1200 \mathrm{rpm}$ ) yield spherical or irregular morphologies. The stirring speed has two main effects in the synthesis: (i) it alters the self-assembly of the template and (ii) it affects the diffusion of the reagents to the interface [17]. In the synthesis of wrinkled $\mathrm{SiO}_{2}$, high stirring speeds (around $900 \mathrm{rpm}$ ) are preferred to obtain a spherical morphology.

\subsubsection{Reaction time}

Hydrolysis and condensation rates for silica at $\mathrm{pH}$ 7-9 are slow processes occurring simultaneously with changes in surfactant assemblies. The synthesis of dendritic particles in the conditions giving the product as depicted in Figure 2 requires around $20 \mathrm{~h}$ to be completed. The particle evolution during these conditions monitored by SEM is shown in Figure 7. After $4 \mathrm{~h}$, slightly structured particles $(\leq 100 \mathrm{~nm})$ are formed. As the reaction proceeds, lamellae are defined and particles grow, reaching an average diameter of $300 \mathrm{~nm}$ with high size dispersion after $6 \mathrm{~h}$. Once lamellae are formed, the effect of reaction time is a slow increase of particle size up to $500 \mathrm{~nm}$ in $24 \mathrm{~h}$, less polydispersion, and well-defined planes of wrinkles with deep valleys.

Several processes converge to achieve these corrugated particles. On the one hand, the silicon precursor condenses on the already formed silica units. On the other hand, there is a simultaneous silicate dissolution and re-precipitation (Oswald ripening) that generates hydrophilic silica surfaces. This process induces the formation of hydrophobic regions where the organic phase is accumulated giving 


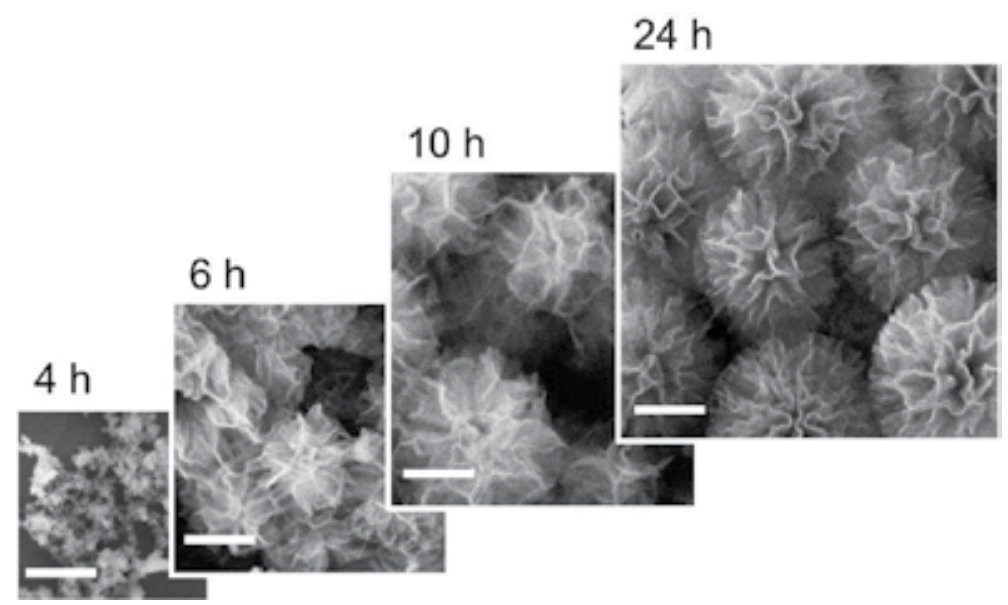

Figure 7.

Evolution of the growth in time of the particles shown in Figure 2 monitored by SEM. Scale bars are $200 \mathrm{~nm}$. Unpublished result from authors.

rise to the deep valleys observed for $24 \mathrm{~h}$. Although data on the kinetics of dendritic particles formation are scarce, it is known that the reaction may be accelerated by the assistance of microwave radiation, as proposed for the synthesis of the KCC-1. Under these conditions, particles are formed in few minutes but for longer reaction times (>60 min); the lamellae collapse producing denser particles [42]. This experiment reinforces the idea that the necessary condition for having a dendritic structure is the formation of hydrophobic "pockets," a process that is inhibited when microwave radiation is applied.

In summary, the main advantage of the synthesis using oil-in-water Winsor III emulsion is the production of dendritic particles that can be tailored by the synthesis parameters for a specific need. The adjustment of pore sizes is important for trapping biomolecules or nanoparticles and for diverse catalytic applications that require high surface area and pore volume. Moreover, for environmental applications, the particle size is a key factor for catalyst recovery. The surfactant to Si ratio and the concentration of the base catalyst are important parameters for controlling the particle diameter, whereas the microemulsion phase behavior defines the distance between the wrinkle walls, i.e., the macroporosity. For a given surfactant, the microemulsion structure is affected by the organic solvent and the co-surfactant chain length, which will tailor the size of cavities and fiber density. The reaction time is an empiric variable for each reaction set-up, which needs to be optimized to get the required product.

\section{Strategies for supporting $\mathrm{TiO}_{2} \mathrm{NPs}$ on hierarchical meso/macroporous silica spheres and photocatalytic performance}

Catalysts based on Ti-containing mesoporous silica, e.g., MCM-41. SBA-15 has been developed from different synthetic pathways for applications such as selective oxidation of bulky organic compounds and photoreduction of greenhouse gases $[48,49]$.

Typically, two synthesis strategies could be applied depending on the stage of incorporation of the $\mathrm{TiO}_{2}$ precursor: (i) one-pot: added directly to the $\mathrm{SiO}_{2}$ reaction mixture (co-condensation route) or (ii) postsynthesis: added after the consolidation of the $\mathrm{SiO}_{2}$ network by deposition, impregnation, atomic layer deposition, among 
others. In the one-pot approach, the co-condensation of titanium precursor with the silicon source faces with the problem that $\mathrm{Ti}$ alkoxides are much more reactive than $\mathrm{Si}(\mathrm{OR})_{4}$ [50]; thus, it is necessary to control the Ti precursor hydrolysis in order to have an appropriate distribution of Ti species that lead to the formation of anatase nanocrystals, a necessary component for efficient photocatalysis [51].

In this section, we focus on different postsynthesis pathways leading to photocatalytic systems for energy conversion, $\mathrm{H}_{2}$ production, or photodegradation of dyes. The consolidated $\mathrm{SiO}_{2}$ porous network must ensure high loadings of homogeneously distributed $\mathrm{TiO}_{2}$ NPs attached by covalent interactions, while the deposition method determines the location and structure of the nanoparticles, e.g., particle size and crystallinity. All these features affect the photocatalytic performance of the semiconductor.

$\mathrm{TiO}_{2}$ NPs deposited on KCC-1 by atomic layer deposition (ALD) alternating titanium tetra-butoxide and hydrogen peroxide produces anatase NPs of 3-12 nm highly dispersed on the fibers (Figure 8a) whose diameter increases with the number of ALD cycles [21]. The anatase phase was obtained after the ALD cycles by calcination at $300-700^{\circ} \mathrm{C}$. This material exhibits high photocatalytic activity and turnover frequency (TOF) towards the Rhodamine B (Rh-B) photodegradation under UV light, even better than the one obtained using the same ALD procedure with MCM-41 and SBA-15 substrates (Figure $8 \mathbf{b}$ and $\mathbf{c}$ ). This higher photoactivity may be a consequence of the location and distribution of $\mathrm{TiO}_{2} \mathrm{NPs}_{\mathrm{s}}$ on the support allowing an optimal dye- $\mathrm{TiO}_{2}$ interaction for a hole transfer or improved $\mathrm{OH} \bullet$ attack

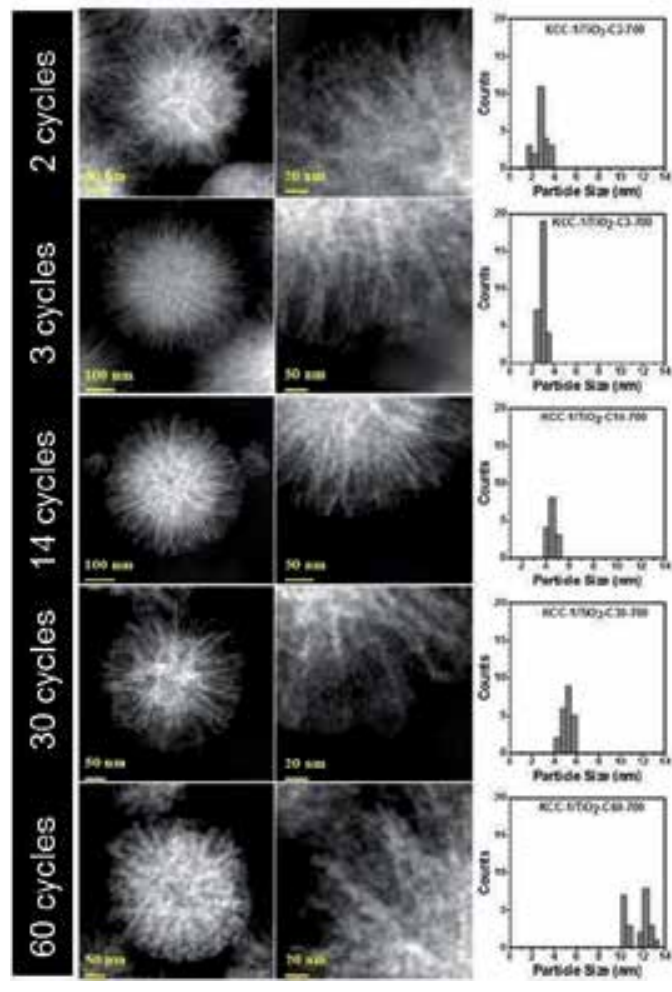

(a)
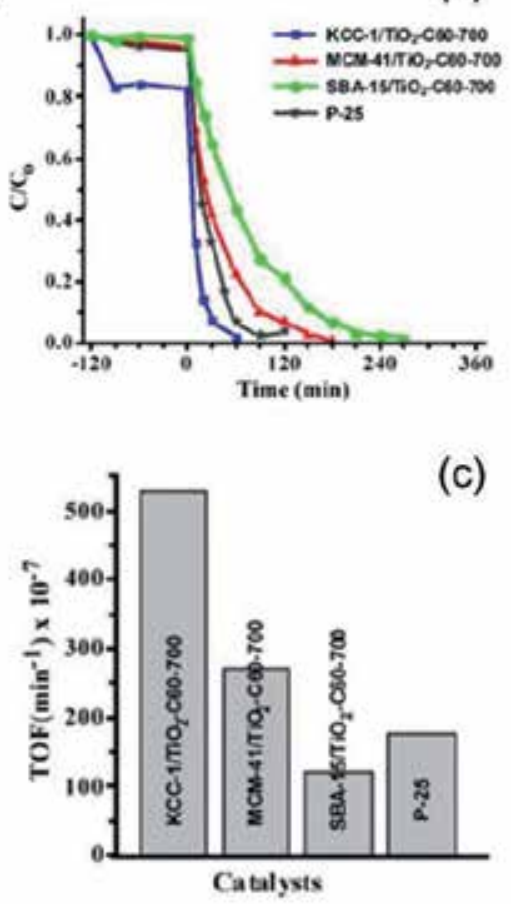

Figure 8.

(a) Scanning transmission electron microscopic images (STEM) of KCC-1/TiO after several ALD cycles and heat treatment at $700^{\circ} \mathrm{C}$, the corresponding histogram for the average particle size is showed next to each image. (b) Photocatalytic degradation of rhodamine $\mathrm{B}$ using $\mathrm{KKC}-1 / \mathrm{TiO}_{2}$ compared to equivalent catalyst using common mesoporous silica and a commercial Degussa P25. (c) Turnover frequency (TOF) for the reaction: it was estimated as the moles of dye degraded per mole of $\mathrm{TiO}_{2}$ per minute. Adapted from Reference [23]. Copyright 2016 American Chemical Society. 
to the dye. The open structure of the fibrous silica admits higher $\mathrm{TiO}_{2}$ loading accessible to the dye, while the ordered array of mesoporous channels in MCM-41 and SBA-15 is easily clogged by $\mathrm{TiO}_{2} \mathrm{NPs}$ as schematized in Figure 1. The $\mathrm{TiO}_{2}$ loading on $\mathrm{SiO}_{2}$ is determined by the surface silanol/siloxane ratio which is independent on synthesis method [52]. Thus, even all substrates exhibit nearly the same $\mathrm{TiO}_{2}$ loading in weight (Figure 9), the more open structure of KCC-1 allow better accessibility to Ti precursors as ALD cycles increase.

Enhanced photocatalytic activity can also be explained by higher photon harvesting in the fibrous structure of the KCC-1 [42], as these structures enable incident light to pass through the cavities and reduce optical loss due to multiple light scattering and reflection [53]. The efficient photon harvesting of dendritic particles was also exploited for the design of dye-sensitized solar cells (DSCs) [48]. By modifying the interwrinkle distances in the silica spheres with the co-surfactant's length of the carbon chain, the fiber density changes from narrow (NWSNs) to wide (WWSNs) wrinkled silica. In this case, $\mathrm{TiO}_{2} \mathrm{NPs}$ were deposited by dispersing the $\mathrm{SiO}_{2}$ spheres in a mixture of acetonitrile- ethanol (1:1) using ammonia solution to conduct the hydrolysis/condensation reactions of titanium ter-butoxide. Using this approach, $4 \mathrm{~nm}$ anatase crystallites were obtained after calcination at $500^{\circ} \mathrm{C}$ under air atmosphere. The dependence of photovoltaic parameters with the fiber density is interpreted as a consequence of the effective refractive index resulting from the combination of two materials with different optical properties, supporting the idea of improved photon harvesting promoted by the fibrous nature of the $\mathrm{SiO}_{2}$ spheres.

In the latter cases, the crystallization of $\mathrm{TiO}_{2}$ was conducted by calcination at temperatures higher than $300^{\circ} \mathrm{C}$. Despite the fact that porous silica spheres have good thermal stability, the calcination presents several drawbacks for the photocatalytic process: (i) it reduces the surface hydroxyl groups and surface area [54] and (ii) it induces the anatase to rutile transformation leading to a decrease in photoactivity [55]. Although anatase-rutile phase transition can be managed with the calcination temperature and by the introduction of defects, hydrothermal synthesis

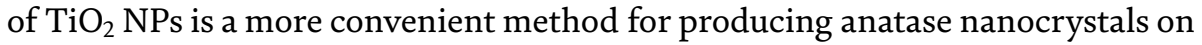
silica substrate [6].

On the hydrothermal route, the solvent has a strong impact on the $\mathrm{TiO}_{2} \mathrm{NP}$ size and distribution [56]. Under soft conditions $\left(180^{\circ} \mathrm{C}, 20 \mathrm{~h}\right)$ in ethanol-water mixtures, the $\mathrm{TiO}_{2}$ NPs are homogeneously located in the outermost zone of KCC-1 particles when using pure water. This causes an increment in the specific surface area and pore volume; whereas, by using absolute ethanol, the particles are dispersed in the fibers (see TEM images and particle size distribution in Figure 10a). Regarding
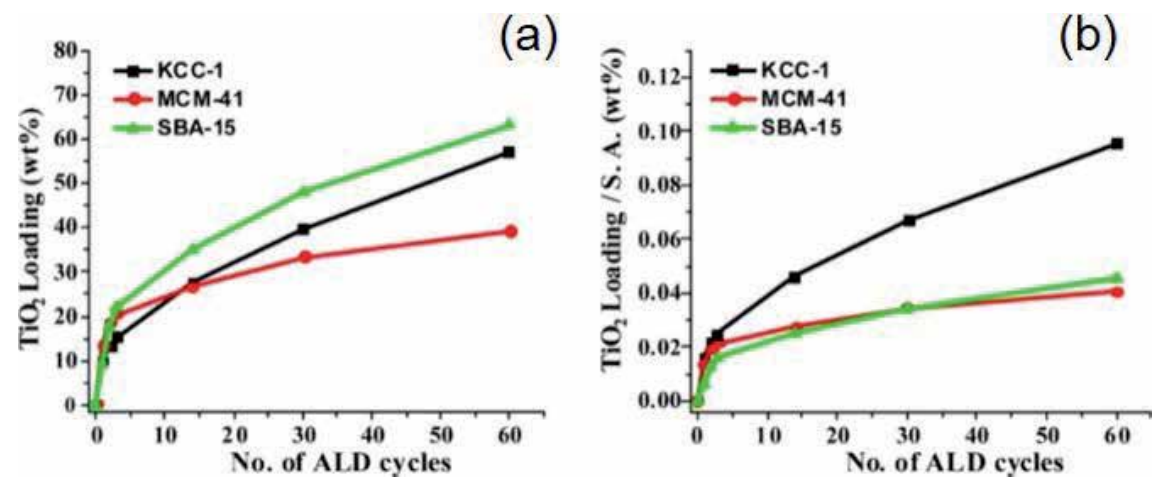

Figure 9.

$\mathrm{TiO}_{2}$ loading on KCC-1, MCM-41, and SBA-15 deposited by ALD. The loading is expressed as wt\% (a) and $w t \%$ per unit surface area (b). Reprinted from Reference [23]. Copyright 2016 American Chemical Society. 
the $\mathrm{TiO}_{2} \mathrm{NPs}$ sizes, it goes from $8 \mathrm{~nm}$ to $17.5 \mathrm{~nm}$ by increasing the ethanol/water ratio from $0 / 100$ to $28.5 / 1.5$. Then, it decreases to $5 \mathrm{~nm}$ in a $100 / 0$ ratio; under this condition, a narrower size distribution is obtained. As far as photocatalytic activity is concerned, particles prepared with absolute ethanol showed the highest activity for water splitting under UV light (Figure 10b). This result points out that the size and location of the $\mathrm{TiO}_{2} \mathrm{NPs}$ plays a significant role in the photocatalytic performance. $\mathrm{The}_{\mathrm{TiO}} \mathrm{NP}_{2}$ distribution leads to different morphologies with a characteristic effective refractive index, which defines the interaction with the incident photons. Thus, by controlling the accessibility of the $\mathrm{TiO}_{2} \mathrm{NPs}$ to the porous system, it is possible to design suitable morphologies for improving photocatalysis.

Another alternative to control the $\mathrm{TiO}_{2} \mathrm{NP}$ location is by taking advantage of the reagents used during the synthesis of the support. As shown in the previous section, the synthesis of wrinkled $\mathrm{SiO}_{2}$ spheres (see Figure 2) requires high amounts of CTAB acting as a pore template. Thus, it is possible to imagine that before removing the template, the pores are "filled" with CTAB molecules blocking the transport of Ti precursors. On this basis, our group developed a practical approach to handle the $\mathrm{TiO}_{2}$ NP distribution on wrinkled $\mathrm{SiO}_{2}$ spheres $\left(460 \mathrm{~nm}\right.$ in diameter, B.E.T. area $=550 \mathrm{~m}^{2} / \mathrm{g}$ ) produced by hydrothermal synthesis using $\mathrm{Ti}$ isopropoxide in isopropanol. With this hydrothermal synthesis, $\mathrm{TiO}_{2}$ NPs of $10 \mathrm{~nm}$ with 6-nm anatase crystallites are obtained. The loading and location of the NPs significantly differ depending on the presence of $\mathrm{CTAB}$ during the hydrothermal treatment. Figure 11a summarizes the experimental approach for controlling the $\mathrm{TiO}_{2} \mathrm{NP}$ location and their corresponding TEM and SEM images (Figure 11b). In Figure 11,w-SiO $@ \mathrm{TiO}_{2}$ refers to NPs deposited after the removal of $\mathrm{CATB}$ and $\mathrm{w}-\mathrm{SiO}_{2} / \mathrm{CTAB} @ \mathrm{TiO}_{2}$ to NPs deposited in the spheres containing CTAB. By eliminating $\mathrm{CTAB}$ prior to $\mathrm{TiO}_{2}$ deposition, $\mathrm{NPs}$ are highly dispersed in a hybrid $\mathrm{SiO}_{2}-\mathrm{TiO}_{2}$ shell, resulting in a greater decrease in surface area than when $\mathrm{TiO}_{2}$ NP growth is performed in the presence of CTAB. This morphology resembles that

(a)

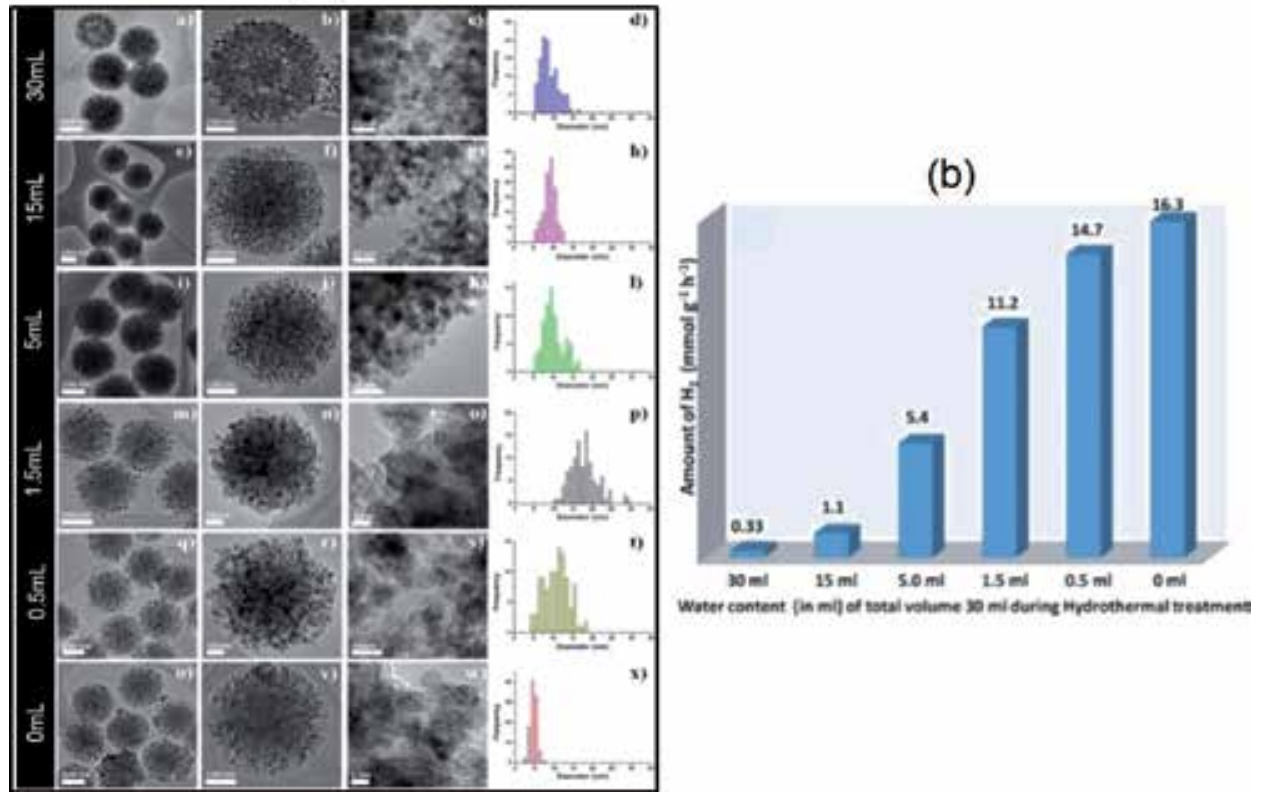

Figure 10.

(a) TEM images in three magnifications and corresponding histograms for the particle size distribution after hydrothermal treatment at $180^{\circ} \mathrm{C}$ obtained in varying water content (inset: $a-x$ ). (b) $\mathrm{H}_{2}$ evolution using the samples showed in the SEM images [56]. 
(a)
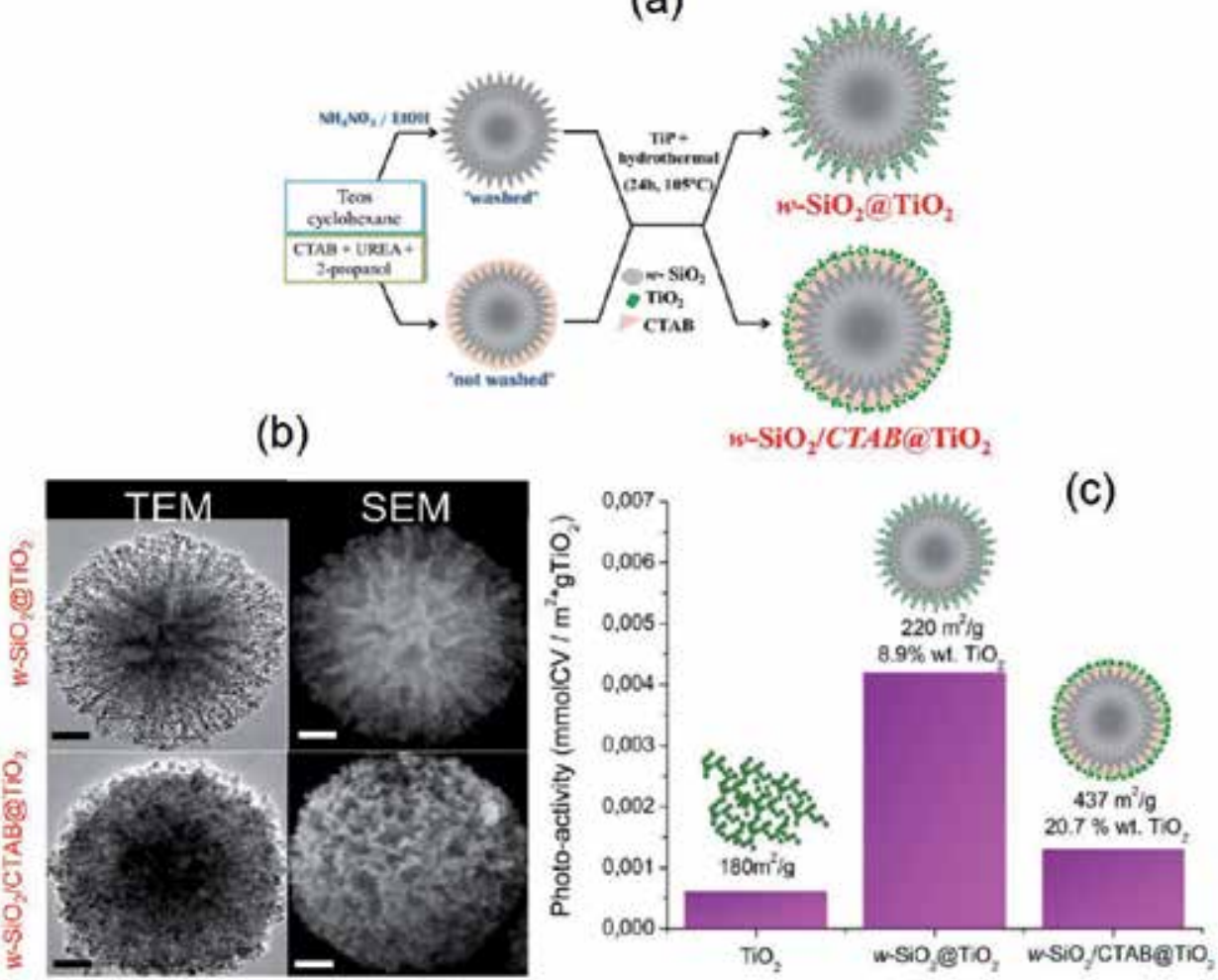

Figure 11.

(a) Experimental scheme for the synthesis of wrinkled-SiO $\mathrm{S}_{2} @ \mathrm{TiO}_{2}$ particles, (b) corresponding TEM and SEM images, the scale bar are $100 \mathrm{~nm}$, and (c) photoactivity of the wrinkled-SiO ${ }_{2} @ \mathrm{TiO}_{2}$ particles in comparison with the unsupported $\mathrm{TiO}_{2} \mathrm{NPs}$. Unpublished results of the authors.

obtained by atomic layer deposition (ALD) [21], as shown in Figure 8a. On the other side, when the hydrothermal process is carried out in the presence of CTAB, the NPs are arranged as a mesoporous $\mathrm{TiO}_{2}$ layer in the same way as the particles obtained by hydrothermal crystallization described in Figure 10a [51]. Therefore, this synthetic approach provides different morphologies simply by taking advantage of CTAB molecules from the synthesis of $\mathrm{SiO}_{2}$ particles. The photoactivity of these particles was tested in the degradation of crystal violet (CV). As seen in Figure 11c, CV photodegradation occurs at higher rate when using $\mathrm{SiO}_{2}-\mathrm{TiO}_{2}$ hybrid layer particles $\left(\mathrm{w}-\mathrm{SiO}_{2} @ \mathrm{TiO}_{2}\right)$ whose morphology allows better photon harvesting. In case of w- $-\mathrm{SiO}_{2} @ \mathrm{CTAB} \mathrm{TiO} 2$ particles, the presence of CTAB increases the adsorption of the dye, thus providing a basis to functionalize the $\mathrm{SiO}_{2}$ particles for a more specific interaction with the targets. Finally, the dimensions of the support are adequate for a good recovery of the reaction medium providing an efficient system for environmental applications.

\section{Summary and outlook}

Meso/macroporous silica spheres are remarkable supports for $\mathrm{TiO}_{2} \mathrm{NPs}$ as compared to conventional silica mesoporous materials, such as MCM-41 and SBA15. The main advantage of this morphology is the accessibility of the molecules to the silica surface provided by the broad pore size distribution. For photocatalytic applications, the location of $\mathrm{TiO}_{2}$ nanoparticles is a critical parameter to optimize the photoactivity. Supported $\mathrm{TiO}_{2}$ NPs in these materials exhibit: 
i. better accessibility to the active sites ensuring high $\mathrm{TiO}_{2}$ loadings;

ii. high surface area, which favors higher adsorption of the pollutants;

iii. enhanced photocatalytic performance for several target molecules;

iv. improved light harvesting; and

v. facile recovery from the reaction media compared to unsupported $\mathrm{TiO}_{2} \mathrm{NPs}$.

The easy tailoring of the surface properties provides photocatalysts for specific applications that can be rationalized by considering the location of $\mathrm{TiO}_{2} \mathrm{NPs}$ on the porous support, which in turn can be managed by the synthesis variables. Understanding the internal nature of the hierarchical supports of the photoactive $\mathrm{TiO}_{2}$ allows the development of value in photocatalysis for energy and environmental applications-a contribution of material's scientists to a better world.

\section{Acknowledgements}

The authors are grateful with CONICET for the postdoctoral scholarship of K.M.F., and University of Buenos Aires for funding, UBACyT $20020170200298 B A$. We are in indebted to Nanoandes Network and ERANET-LAC FP7 project Recola for the continuous support. Also, we acknowledge Stefanie Kodjikian (Institut NÉEl, Grenoble) and Maria Claudia Marchi (CMA-CONICET) for TEM and SEM images, respectively.

\section{Conflict of interest}

There are no conflict of interest to declare. 
$\mathrm{TiO}_{2}$ Nanoparticles Supported on Hierarchical Meso/Macroporous $\mathrm{SiO}_{2}$ Spheres...

DOI: $h t t p: / / d x$.doi.org/10.5772/intechopen.86153

\section{Author details}

Keyla M. Fuentes ${ }^{1,2 *}$, Margarita Sánchez-Dominguez ${ }^{2}$ and Sara A. Bilmes ${ }^{1}$

1 Instituto de Química Física de los Materiales, Medio Ambiente y Energía(INQUIMAE-CONICET), Departamento de Química Inorgánica, Analítica y Química Física (DQIAQF), Facultad de Ciencias Exactas y Naturales, Universidad de Buenos Aires, Ciudad Universitaria (C1428EHA), Ciudad Autónoma de, Buenos Aires, Argentina

2 Centro de Investigación en Materiales Avanzados, S.C. (CIMAV), Apodaca, Nuevo León, México

*Address all correspondence to: keylafuentesflores@gmail.com

\section{IntechOpen}

(C) 2019 The Author(s). Licensee IntechOpen. This chapter is distributed under the terms of the Creative Commons Attribution License (http://creativecommons.org/licenses/ by/3.0), which permits unrestricted use, distribution, and reproduction in any medium, provided the original work is properly cited. (cc) BY 


\section{References}

[1] Miar Alipour S, Friedmann D, Scott J, Amal R. $\mathrm{TiO}_{2}$ /porous adsorbents: Recent advances and novel applications. Journal of Hazardous Materials. 2018;341:404-423. DOI: 10.1016/j. jhazmat.2017.07.070

[2] Schneider J, Matsuoka M, Takeuchi M, Zhang J, Horiuchi Y, Anpo M, et al. Understanding $\mathrm{TiO}_{2}$ photocatalysis: Mechanisms and materials. Chemical Reviews. 2014;114:9919-9986. DOI: $10.1021 /$ cr5001892

[3] Regazzoni AE, Mandelbaum P, Matsuyoshi M, Schiller S, Bilmes SA, Blesa MA. Adsorption and photooxidation of salicylic acid on titanium dioxide: A surface complexation description. Langmuir. 1998;14:868-874. DOI: 10.1021/ la970665n

[4] Lee D-W, Park S-J, Ihm S-K, Lee $\mathrm{K}-\mathrm{H}$. Synthesis of bimodal mesoporous titania with high thermal stability via replication of citric acid-templated mesoporous silica. Chemistry of Materials. 2007;19:937-941. DOI: $10.1021 / \mathrm{cm} 062465 \mathrm{f}$

[5] Fuentes KM, Betancourt P, Marrero S, García S. Photocatalytic degradation of phenol using doped titania supported on photonic $\mathrm{SiO}_{2}$ spheres. Reaction Kinetics, Mechanisms and Catalysis. 2017;120:403-415. DOI:10.1007/ s11144-016-1097-3

[6] Ullah S, Ferreira-Neto EP, Pasa AA, Alcântara CCJ, Acuña JJS, Bilmes SA, et al. Enhanced photocatalytic properties of core@shell $\mathrm{SiO}_{2} @ \mathrm{TiO}_{2}$ nanoparticles. Applied Catalysis B: Environmental. 2015;179:333-343. DOI: 10.1016/j.apcatb.2015.05.036

[7] Chen J, Qiu F, Xu W, Cao S, Zhu H. Recent progress in enhancing photocatalytic efficiency of $\mathrm{TiO}_{2}$-based materials. Applied Catalysis A: General.
2015;495:131-140. DOI: 10.1016/j. apcata.2015.02.013

[8] Zhang F, Zheng Y, Cao Y, Chen C, Zhan Y, Lin X, et al. Ordered mesoporous $\mathrm{Ag}-\mathrm{TiO}_{2}-\mathrm{KIT}-6$ heterostructure: Synthesis, characterization and photocatalysis. Journal of Materials Chemistry. 2009;19:2771. DOI: 10.1039/b818495j

[9] Li Y, Li N, Tu J, Li X, Wang B, Chi $\mathrm{Y}$, et al. $\mathrm{TiO}_{2}$ supported on rod-like mesoporous silica SBA-15: Preparation, characterization and photocatalytic behaviour. Materials Research Bulletin. 2011;46:2317-2322. DOI: 10.1016/j. materresbull.2011.08.044

[10] Tian L, Liu H, Gao Y. Degradation and adsorption of rhodamine $\mathrm{B}$ and phenol on $\mathrm{TiO}_{2} / \mathrm{MCM}-41$. Kinetics and Catalysis. 2012;53:554-559. DOI: $10.1134 /$ S0023158412050175

[11] Mureseanu M, Parvulescu V, Radu T, Filip M, Carja G. Mesoporous CeTiSiMCM-48 as novel photocatalyst for degradation of organic compounds. Journal of Alloys and Compounds. 2015;648:864-873. DOI: 10.1016/j. jallcom.2015.07.078

[12] Garg S, Narayan R, Nayak UY, Raichur AM. Mesoporous silica nanoparticles: A comprehensive review on synthesis and recent advances. Pharmaceutics. 2018;10:1-50. DOI: 10.3390/pharmaceutics10030118

[13] Fei X, Dong Y, Liu Y. Study on synthesis and properties of composite mesoporous $\mathrm{TiO}_{2} / \mathrm{MCM}$ 41 photocatalysts. Materials and Technologies. 2016;31:423-429. DOI: 10.1179/1753555715Y.0000000073

[14] Su B-L, Sanchez C, Yang X-Y, editors. Hierarchically Structured Porous Materials. Weinheim, Germany: Wiley-VCH Verlag GmbH \& Co. KGaA; 2011. DOI: $10.1002 / 9783527639588$ 
$\mathrm{TiO}_{2}$ Nanoparticles Supported on Hierarchical Meso/Macroporous $\mathrm{SiO}_{2}$ Spheres...

DOI: http://dx.doi.org/10.5772/intechopen.86153

[15] Sun M-H, Huang S-Z, Chen

L-H, Li Y, Yang X-Y, Yuan Z-Y, et al. Applications of hierarchically structured porous materials from energy storage and conversion, catalysis, photocatalysis, adsorption, separation, and sensing to biomedicine. Chemical Society Reviews. 2016;45:3479-3563.

DOI: 10.1039/C6CS00135A

[16] Yokoi T, Karouji T, Ohta S, Kondo JN, Tatsumi T. Synthesis of mesoporous silica nanospheres promoted by basic amino acids and their catalytic application. Chemistry of Materials. 2010;22:3900-3908. DOI: 10.1021/ cm9037846

[17] Sun B, Zhou G, Zhang H. Synthesis, functionalization, and applications of morphology-controllable silicabased nanostructures: A review. Progress in Solid State Chemistry. 2016;44:1-19. DOI: 10.1016/j. progsolidstchem.2016.01.001

[18] Gustafsson H, Isaksson S, Altskär A, Holmberg K. Mesoporous silica nanoparticles with controllable morphology prepared from oil-in-water emulsions. Journal of Colloid and Interface Science. 2016;467:253-260. DOI: 10.1016/j.jcis.2016.01.026

[19] Maity A, Polshettiwar V. Scalable and sustainable synthesis of sizecontrolled monodisperse dendritic fibrous nanosilica quantified by E-factor. ACS Applied Nano Materials. 2018;1:3636-3643. DOI: 10.1021/ acsanm.8b00761

[20] Moon D-S, Lee J-K. Tunable synthesis of hierarchical mesoporous silica nanoparticles with radial wrinkle structure. Langmuir. 2012;28:

12341-12347. DOI: 10.1021/la302145j

[21] Yu Y-J, Xing J-L, Pang J-L, Jiang S-H, Lam K-F, Yang T-Q, et al. Facile synthesis of size controllable dendritic mesoporous silica nanoparticles. ACS Applied Materials \& Interfaces.
2014;6:22655-22665. DOI: 10.1021/ am506653n

[22] Maity A, Polshettiwar V. Dendritic fibrous nanosilica for catalysis, energy harvesting, carbon dioxide mitigation, drug delivery, and sensing. ChemSusChem. 2017;10:3866-3913.

DOI: $10.1002 /$ cssc. 201701076

[23] Singh R, Bapat R, Qin L, Feng $\mathrm{H}$, Polshettiwar V. Atomic layer deposited (ALD) $\mathrm{TiO}_{2}$ on fibrous nano-silica (KCC-1) for photocatalysis: Nanoparticle formation and size quantization effect. ACS Catalysis. 2016;6:2770-2784. DOI: 10.1021/ acscatal.6b00418

[24] Schacht S, Huo Q, Voigt-Martin IG, Stucky GD, Schuth F. Oil-water interface templating of mesoporous macroscale structures. Science (80-.). 1996;273:768-771. DOI: 10.1126/ science. 273.5276 .768

[25] Sanchez-Dominguez M, Pemartin K, Boutonnet M. Preparation of inorganic nanoparticles in oil-in-water microemulsions: A soft and versatile approach. Current Opinion in Colloid \& Interface Science. 2012;17:297-305. DOI: 10.1016/j.cocis.2012.06.007

[26] Kuijk A, van Blaaderen A, Imhof A. Synthesis of monodisperse, rodlike silica colloids with tunable aspect ratio. Journal of the American Chemical Society. 2011;133:2346-2349. DOI: 10.1021/ja109524h

[27] Lind A, Spliethoff B, Lindén M. Unusual, vesicle-like patterned, mesoscopically ordered silica. Chemistry of Materials. 2003;15: 813-818. DOI: $10.1021 / \mathrm{cm} 0212430$

[28] Wang S, Chen M, Wu L. One-step synthesis of cagelike hollow silica spheres with large through-holes for macromolecule delivery. ACS Applied Materials \& Interfaces. 2016;8:3331633325. DOI: $10.1021 /$ acsami.6b11639 
[29] Polshettiwar V, Cha D, Zhang X, Basset JM. High-surface-area silica nanospheres (KCC-1) with a fibrous morphology. Angewandte Chemie International Edition. 2010;49:9652-9656. DOI: 10.1002/anie.201003451

[30] ALOthman Z. A review: Fundamental aspects of silicate mesoporous materials. Materials (Basel). 2012;5:2874-2902. DOI: $10.3390 / \mathrm{ma} 5122874$

[31] Putz A-M, Cecilia S, Ianăşi C, Dudás Z, Székely KN, Plocek J, et al. Pore ordering in mesoporous matrices induced by different directing agents. Journal of Porous Materials. 2015;22:321-331. DOI: $10.1007 /$ s10934-014-9899-z

[32] Moon D-S, Lee J-K. Formation of wrinkled silica mesostructures based on the phase behavior of pseudoternary systems. Langmuir. 2014;30:15574-15580. DOI: $10.1021 / \mathrm{la504207k}$

[33] Rana S, Bhattacharjee J, Barick KC, Verma G, Hassan PA, Yakhmi $J V$. Interfacial engineering of nanoparticles for cancer therapeutics. In: Nanostructures Cancer Therapy. Amsterdam: Elsevier; 2017. pp. 177-209. DOI: $10.1016 /$ B978-0-323-46144-3.00007-6

[34] Pileni MP. Reverse micelles as microreactors. The Journal of Physical Chemistry. 1993;97:6961-6973. DOI: 10.1021/j100129a008

[35] Danielsson I, Lindman B. The definition of microemulsion. Colloids and Surfaces. 1981;3:391-392. DOI: 10.1016/0166-6622(81)80064-9

[36] Aubery C, Solans C, Prevost S, Gradzielski M, Sanchez-Dominguez M. Microemulsions as reaction media for the synthesis of mixed oxide nanoparticles: Relationships between microemulsion structure, reactivity, and nanoparticle characteristics. Langmuir.
2013;29:1779-1789. DOI: 10.1021/

la303817w

[37] Nič M, Jirát J, Košata $B$, Jenkins A, McNaught A, editors. IUPAC Compendium of Chemical Terminology. Research Triagle Park, NC: IUPAC; 2009. DOI: $10.1351 /$ goldbook

[38] Hench LL, West JK. The sol-gel process. Chemical Reviews. 1990;90: 33-72. DOI: 10.1021/cr00099a003

[39] Brinker CJ. Hydrolysis and condensation of silicates: Effects on structure. Journal of Non-Crystalline Solids. 1988;100:31-50. DOI: 10.1016/0022-3093(88)90005-1

[40] Febriyanti E, Suendo V, Mukti RR, Prasetyo A, Arifin AF, Akbar MA, et al. Ismunandar, further insight into the definite morphology and formation mechanism of mesoporous silica KCC-1. Langmuir. 2016;32:5802-5811. DOI: 10.1021/acs.langmuir.6b00675

[41] Maity A, Das A, Sen D, Mazumder S, Polshettiwar V. Unraveling the formation mechanism of dendritic fibrous nanosilica. Langmuir. 2017;33:13774-13782. DOI: 10.1021/acs. langmuir.7b02996

[42] Bayal N, Singh B, Singh R, Polshettiwar V. Size and fiber density controlled synthesis of fibrous nanosilica spheres (KCC-1). Scientific Reports. 2016;6:24888. DOI: 10.1038/ srep24888

[43] Shen D, Yang J, Li X, Zhou L, Zhang $\mathrm{R}, \mathrm{Li} \mathrm{W}$, et al. Biphase stratification approach to three-dimensional dendritic biodegradable mesoporous silica nanospheres. Nano Letters. 2014;14: 923-932. DOI: 10.1021/nl404316v

[44] Yamada H, Urata C, Higashitamori S, Aoyama Y, Yamauchi Y, Kuroda K. Critical roles of cationic surfactants in the preparation of colloidal mesostructured silica nanoparticles: Control of mesostructure, particle size, 
and dispersion. ACS Applied Materials \& Interfaces. 2014;6:3491-3500. DOI: 10.1021/am405633r

[45] Yokoi T, Yoshitake H, Tatsumi T. Synthesis of amino-functionalized MCM-41 via direct co-condensation and post-synthesis grafting methods using mono-, di- and tri-aminoorganoalkoxysilanes. Electronic supplementary information (ESI) available: XRD patterns of (A) $\mathrm{x}-\mathrm{dNN}$ MCM-41 and (B) $x$-dNNN. Journal of Materials Chemistry. 2004;14:951. DOI: 10.1039/b310576h

[46] Clark KG, Gaddy VL, Rist CE. Equilibria in the ammonium carbamateurea-water system. Industrial and Engineering Chemistry. 1933;25:10921096. DOI: $10.1021 / \mathrm{ie} 50286 \mathrm{a} 008$

[47] Jin H, Liu Z, Ohsuna T, Terasaki O, Inoue Y, Sakamoto K, et al. Control of morphology and helicity of chiral mesoporous silica. Advanced Materials. 2006;18:593-596. DOI: 10.1002/ adma.200502038

[48] Hu Y, Martra G, Zhang J, Higashimoto S, Coluccia S, Anpo M. Characterization of the local structures of Ti-MCM-41 and their photocatalytic reactivity for the decomposition of $\mathrm{NO}$ into $\mathrm{N}_{2}$ and $\mathrm{O}_{2}$. The Journal of Physical Chemistry. B. 2006;110:1680-1685. DOI: 10.1021/ jp058240u

[49] Li J, Zhou C, Xie H, Ge Z, Yuan L, Li X. Titanium-containing mesoporous materials: Synthesis and application in selective catalytic oxidation. Journal of Natural Gas Chemistry. 2006;15:164-177. DOI: 10.1016/ S1003-9953(06)60023-6

[50] Livage J, Sanchez C. Sol-gel chemistry. Journal of Non-Crystalline Solids. 1992;145:11-19. DOI: 10.1016/ S0022-3093(05) 80422-3

[51] Angelomé PC, Andrini L, Calvo ME, Requejo FG, Bilmes SA, Soler-Illia
GJAA. Mesoporous anatase $\mathrm{TiO}_{2}$ films: Use of Ti K XANES for the quantification of the nanocrystalline character and substrate effects in the photocatalysis behavior. Journal of Physical Chemistry C. 2007;111: 10886-10893. DOI: $10.1021 /$ jp069020z

[52] Zhuravlev LT. Concentration of hydroxyl groups on the surface of amorphous silicas. Langmuir. 1987;3:316-318

[53] Kamegawa T, Yamashita H. Photocatalytic properties of $\mathrm{TiO}_{2-}$ loaded porous silica with hierarchical macroporous and mesoporous architectures. Nanostructures Science and Technology. Switzerland: Springer International Publishing; In: 2016: pp. 229-240. DOI: 10.1007/978-3-319-26079-2_13

[54] Ding Z, Lu GQ, Greenfield PF. Role of the crystallite phase of $\mathrm{TiO}_{2}$ in heterogeneous photocatalysis for phenol oxidation in water. The Journal of Physical Chemistry. B. 2000;104: 4815-4820. DOI: 10.1021/jp993819b

[55] Hanaor DAH, Sorrell CC. Review of the anatase to rutile phase transformation. Journal of Materials Science. 2011;46:855-874. DOI: 10.1007/ s10853-010-5113-0

[56] Kundu S, Polshettiwar V. Hydrothermal crystallization of nano-titanium dioxide for enhanced photocatalytic hydrogen generation. ChemPhotoChem. 2018;2:796-800 (Copyright Wiley-VCH Verlag GmbH \& Co. KGaA. Reproduced with permission. DOI: $10.1002 /$ cptc. 201800101 



\title{
Toward the Creation of Highly Active Photocatalysts That Convert Methane into Methanol
}

\author{
Yuichi Negishi, Seiichiro Watanabe, Marika Aoki, \\ Sakiat Hossain and Wataru Kurashige
}

\begin{abstract}
Methane exists abundantly around Japan as methane hydrate. As the effective use of such methane, the conversion of methane into methanol has recently attracted much attention. Photocatalytic reaction is one of the methods which convert methane into methanol without using much energy. However, it is indispensable to improve the photocatalytic activity for their practical use. Our group has attempted to improve the activity of mesoporous tungsten trioxide and titanium dioxide $\left(\mathrm{m}-\mathrm{WO}_{3}\right.$ and $\left.\mathrm{m}-\mathrm{TiO}_{2}\right)$ photocatalysts, which convert methane into methanol, by loading the ultrafine metal clusters as cocatalyst on the photocatalysts. As a result, we have succeeded in loading ultrafine metal-cluster cocatalysts onto $\mathrm{m}-\mathrm{WO}_{3}$ and $\mathrm{m}-\mathrm{TiO}_{2}$ and thereby improving their photocatalytic activity. Our study also demonstrated that the kind of metal element suitable for each photocatalyst depends on the kind of the photocatalysts, and thereby it is important to select the metal clusters suitable for each photocatalyst for improving its photocatalytic activity.
\end{abstract}

Keywords: photocatalyst, methane, methanol, activation, cocatalyst

\section{Introduction}

In recent years, the effective use of methane $\left(\mathrm{CH}_{4}\right)$ has attracted attention owing to the large amount of methane hydrate which is estimated to exist under the sea around Japan (Figure 1(a)) [1]. When $\mathrm{CH}_{4}$ is burnt for generating energy, it generates small amounts of compounds which cause environmental problems, such as carbon dioxide, nitrogen oxide, and sulfur oxide (Figure 1(b)), [2]. Therefore, $\mathrm{CH}_{4}$ can be used as a comparatively clean energy source. However, since $\mathrm{CH}_{4}$ is a gas state at room temperature, it occupies a large volume and therefore costs for the transportation. On the other hand, if $\mathrm{CH}_{4}$ is converted to liquid methanol $\left(\mathrm{CH}_{3} \mathrm{OH}\right)$, the transportation costs could be reduced. Furthermore, the generated $\mathrm{CH}_{3} \mathrm{OH}$ could be effectively used as a raw material for producing various chemical compounds. Therefore, in recent years, considerable attention has been focused on the development of a methodology for efficiently converting $\mathrm{CH}_{4}$ into $\mathrm{CH}_{3} \mathrm{OH}$.

Regarding such a conversion, the current main methods require extreme conditions such as high temperature of around $500^{\circ} \mathrm{C}$ and high pressure of $50 \mathrm{~atm}$ or more [3]. Furthermore, since the reaction proceeds in two stages, the conversion consumes a large amount of energy. Therefore, many studies have been conducted to find a 
(a)

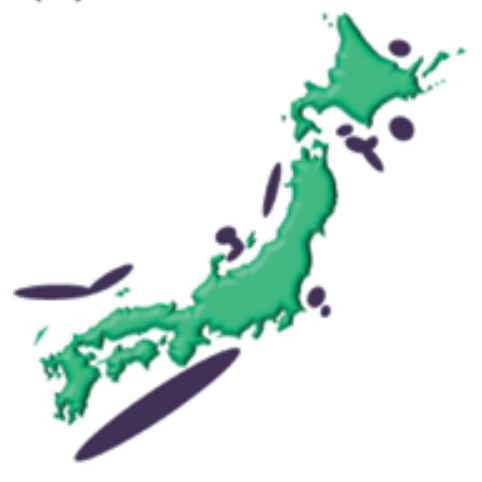

(b)

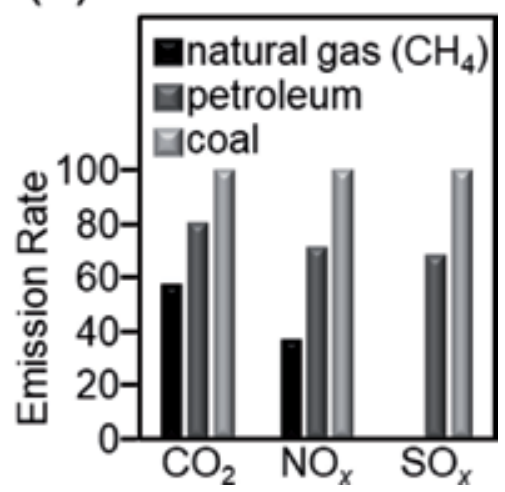

Figure 1.

(a) Estimated distribution of methane hydrate lying under the sea around Japan. (b) emission rate of each gas $\left(\mathrm{CO}_{2}, \mathrm{NO}_{x}\right.$, or $\left.\mathrm{SO}_{x}\right)$ from $\mathrm{CH}_{4}$, petroleum, and coal. In (b), emission rate of each gas is normalized by letting the emission rate of $\mathrm{CO}_{2}$ from coal be 10o. Adapted from [1, 2].

method for the direct conversion of $\mathrm{CH}_{4}$ to $\mathrm{CH}_{3} \mathrm{OH}$ under mild conditions. However, most direct reactions require also high temperature and pressure conditions together with the use of an oxidizing agent [4]. Using a photocatalytic reaction for this conversion, the reaction can be conducted under moderate conditions [5]. However, the catalytic activity is still low, and further improvement is required for practical application. Then, our group has attempted to improve the photocatalytic activity of the photocatalyst used in this conversion. Our strategy was to load the controlled metal clusters on the surface of the photocatalyst as active sites (cocatalyst).

\section{Research examples}

Both tungsten oxide $\left(\mathrm{WO}_{3}\right)$ and titanium oxide $\left(\mathrm{TiO}_{2}\right)$ have redox potentials that are sufficient to generate hydroxyl radicals (.OH) (Figure 2(a)), which is necessary for the reaction to proceed (Figure 2(b)) [6]. Furthermore, in their mesoporous structures $\left(\mathrm{m}-\mathrm{WO}_{3}\right.$ and $\left.\mathrm{m}-\mathrm{TiO}_{2}\right)$, surface area becomes large and thereby the adsorption of reactive molecules is enhanced. In addition, in $\mathrm{m}-\mathrm{WO}_{3}$ and $\mathrm{m}-\mathrm{TiO}_{2}$, since the regular arrangement of pores suppresses the recombination of electrons and holes generated by the light irradiation, electrons and holes can be efficiently used in the reaction [7]. Then, in our study, we attempted to activate such $\mathrm{m}-\mathrm{WO}_{3}$ and $\mathrm{m}-\mathrm{TiO}_{2}$ by loading the ultrafine metal clusters as cocatalyst on the photocatalysts.

\section{$2.1 \mathrm{~m}-\mathrm{WO}_{3}$ photocatalyst}

\subsubsection{Preparation and loading of cocatalyst}

$\mathrm{m}-\mathrm{WO}_{3}$ was prepared using a hard template method in the same manner as that reported in the literature [8]. First, mesoporous silica (KIT-6) was prepared to be used as a template (Figure 3(a)). Then, the obtained KIT-6 was mixed with 12-tungsto(VI) phosphoric acid $n$-hydrate $\left(\mathrm{H}_{3}\left(\mathrm{PW}_{12} \mathrm{O}_{40}\right) \bullet n \mathrm{H}_{2} \mathrm{O}\right)$ in ethanol. The product was dried and then calcined at $350^{\circ} \mathrm{C}$ for $4 \mathrm{~h}$. To the obtained powder, a further $\mathrm{H}_{3}\left(\mathrm{PW}_{12} \mathrm{O}_{40}\right) \bullet n \mathrm{H}_{2} \mathrm{O}$ ethanol solution was added and the mixture was stirred for $30 \mathrm{~min}$. The product was again dried and then calcined at $550^{\circ} \mathrm{C}$ for $6 \mathrm{~h}$. Finally, $\mathrm{m}-\mathrm{WO}_{3}$ was obtained by removing the KIT-6 template using hydrofluoric acid (HF) (Figure 3(b)). 

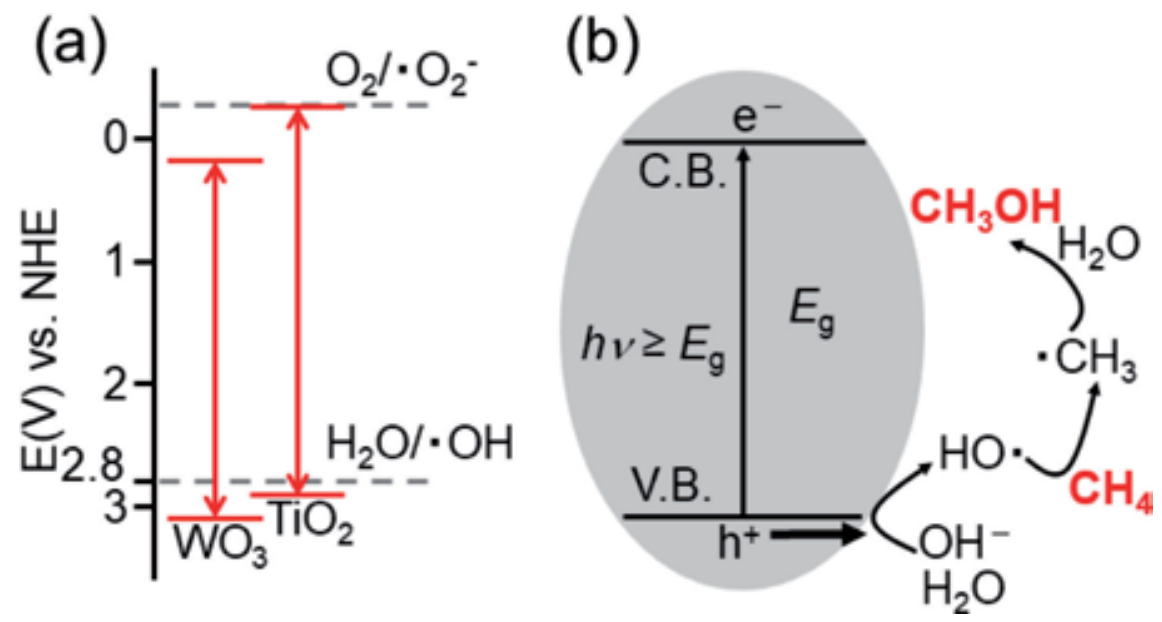

Figure 2.

(a) Redox potentials of $\mathrm{WO}_{3}$ and $\mathrm{TiO}_{2}$. Adapted from [4]. (b) Mechanism of the conversion of $\mathrm{CH}_{4}$ to $\mathrm{CH}_{3} \mathrm{OH}$ by photocatalytic reaction; C.B., V.B., and $E_{g}$ indicate conduction band, valence band, and band gap, respectively.

Next, metal clusters were loaded onto the obtained $\mathrm{m}-\mathrm{WO}_{3}$. Our previous research on water-splitting photocatalysts [9-13] revealed that when a chemicallysynthesized ligand-protected metal cluster is adsorbed onto a photocatalyst and its ligand is removed by the calcination, the controlled metal clusters can be loaded on the photocatalyst. Then, in this study, each metal cluster was loaded onto $\mathrm{m}-\mathrm{WO}_{3}$ using such a method (Figure 3(c)). Silver (Ag), nickel (Ni), and cobalt (Co) were chosen as metal element because they were expected to work as cocatalyst $[14,15]$. Glutathionate (SG) was used as the ligand of the metal cluster. SG-protected silver clusters $\left(\mathrm{Ag}_{n}(\mathrm{SG})_{m}\right)$ were synthesized using the solid phase method reported by Bakr et al [16]. $\mathrm{Ni}_{n}(\mathrm{SG})_{m}$ and $\mathrm{Co}_{n}(\mathrm{SG})_{m}$ clusters were synthesized using the liquid phase method reported for SG-protected gold clusters $\left(\mathrm{Au}_{n}(\mathrm{SG})_{m}\right)$ [17]. The $\mathrm{M}_{n}(\mathrm{SG})_{m}$ clusters $(\mathrm{M}=\mathrm{Ag}, \mathrm{Ni}$, or $\mathrm{Co})$ thus obtained were dissolved in water, and $\mathrm{m}-\mathrm{WO}_{3}$ was added to this solution to adsorb the $\mathrm{M}_{n}(\mathrm{SG})_{m}$ clusters on $\mathrm{m}-\mathrm{WO}_{3}\left(\mathrm{M}_{n}(\mathrm{SG})_{m}-\mathrm{m}-\mathrm{WO}_{3}\right.$; $\mathrm{M}=\mathrm{Ag}, \mathrm{Ni}$, or $\mathrm{Co})$. The obtained $\mathrm{M}_{n}(\mathrm{SG})_{m}-\mathrm{m}-\mathrm{WO}_{3}$ was calcined at $500^{\circ} \mathrm{C}$ under atmospheric pressure to remove the ligand of the $\mathrm{M}_{n}(\mathrm{SG})_{m}$ cluster, and thereby, each metal cluster was loaded on $\mathrm{m}-\mathrm{WO}_{3}\left(\mathrm{M}_{n}-\mathrm{m}-\mathrm{WO}_{3} ; \mathrm{M}=\mathrm{Ag}\right.$, Ni, or Co $)$.

\subsubsection{Structural characterization}

In the transmission electron microscope (TEM) image of $\mathrm{m}-\mathrm{WO}_{3}$, pores of $10 \mathrm{~nm}$ or less were observed (Figure $4(\mathbf{a}, \mathbf{b})$ ). In the small angle X-ray diffraction (XRD) pattern of $\mathrm{m}-\mathrm{WO}_{3}$ (Figure 4(c)), similar to the literature [18], a peak assigned to the (211) plane of KIT- 6 was observed, in addition to the peak attributed to the (110) plane derived from cubic $\mathrm{I}_{1} 32$ or $\mathrm{I}_{3} 32$. These results indicate that the synthesized $\mathrm{m}-\mathrm{WO}_{3}$ has an arranged structure with regular pores.

Figure 5(a,b) shows the TEM images of $\mathrm{Co}_{n}(\mathrm{SG})_{m}-\mathrm{m}-\mathrm{WO}_{3}$ and $\mathrm{Co}_{n}-\mathrm{m}-\mathrm{WO}_{3}$, respectively, as representative examples of photocatalysts after adsorption and calcination. Particles with a size of $0.93 \pm 0.20 \mathrm{~nm}$ could be observed in the TEM image of $\mathrm{Co}_{n}(\mathrm{SG})_{m}-\mathrm{m}-\mathrm{WO}_{3}$. This indicates that ultrafine $\mathrm{Co}_{n}(\mathrm{SG})_{m}$ clusters were synthesized with a narrow distribution. Particles of a similar size $(0.96 \pm 0.19 \mathrm{~nm})$ were also observed for $\mathrm{Co}_{n}-\mathrm{m}-\mathrm{WO}_{3}$. This indicates that $\mathrm{Co}_{n}$ clusters were loaded onto $\mathrm{m}-\mathrm{WO}_{3}$ during calcination without the aggregation. Based on the bulk density of Co $\left(8.900 \mathrm{~g} / \mathrm{cm}^{3}\right)$, it can be estimated that each loaded particle contains about 40 Co atoms. The loading of ultrafine particles was similarly observed in other 
(a)

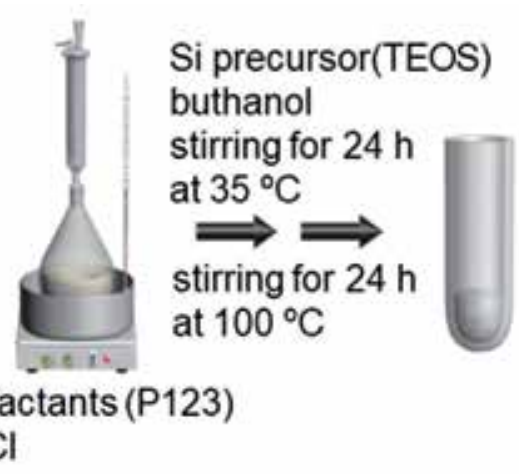

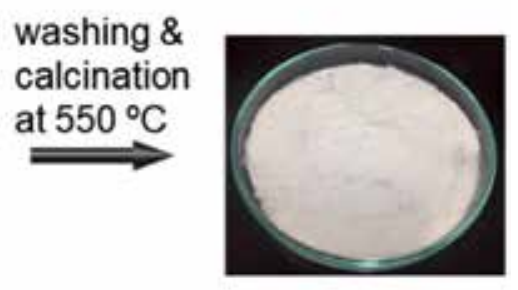

KIT-6

\section{$/ \mathrm{HCl}$}

(b)
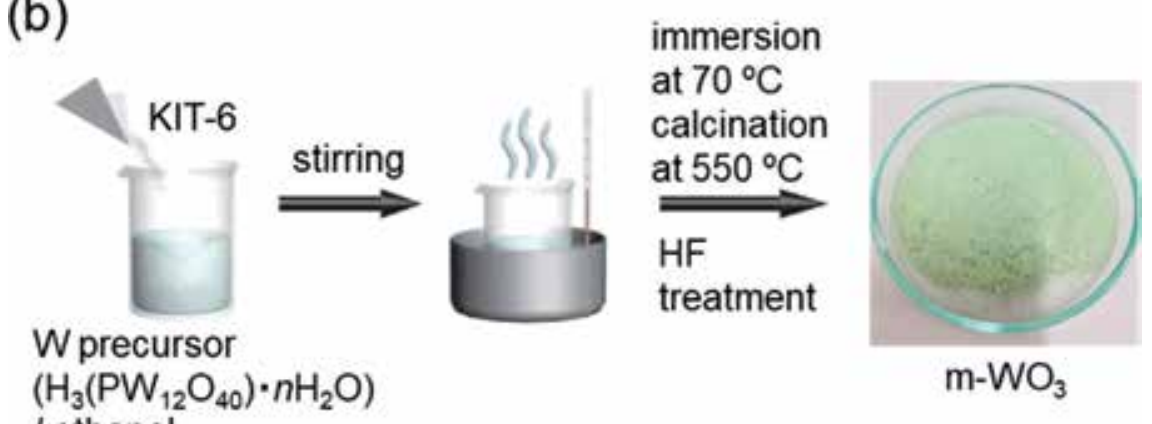

/ ethanol

(c)

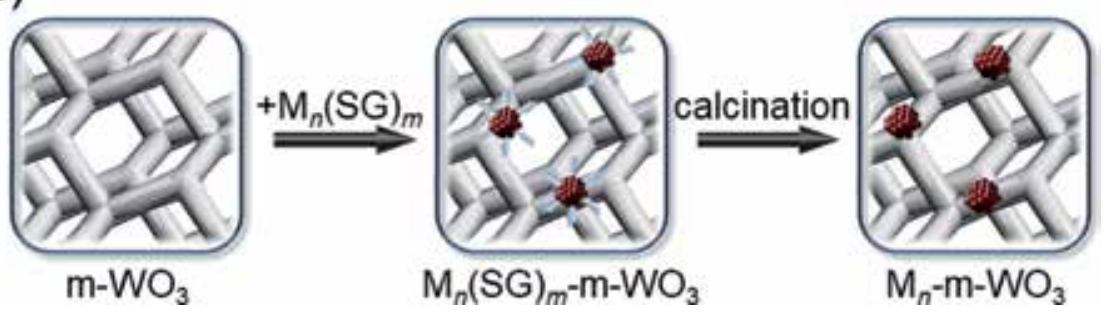

Figure 3 .

Preparation methods of (a) KIT-6, (b) $m-W O_{3}$, and (c) $M_{n}-m-W O_{3}(M=A g, N i$, or Co).

$\mathrm{M}_{n}-\mathrm{m}-\mathrm{WO}_{3}(\mathrm{M}=\mathrm{Ag}$ or $\mathrm{Ni})$. In this way, we have succeeded in loading ultrafine $\mathrm{M}_{n}$ clusters on $\mathrm{m}-\mathrm{WO}_{3}$ with a narrow size distribution.

\subsubsection{Evaluation of photocatalytic activity}

The photocatalytic activity was measured using an experimental apparatus built in-house consisting of a high-pressure mercury ( $\mathrm{Hg})$ lamp (400 W) and a quartz cell (Figure 6) [11]. First, $300 \mathrm{mg}$ of $\mathrm{M}_{n}-\mathrm{m}-\mathrm{WO}_{3}(\mathrm{M}=\mathrm{Ag}, \mathrm{Ni}$, and Co) was dispersed in $300 \mathrm{~mL}$ of water. Then, $\mathrm{CH}_{4}$ and helium carrier gas were passed through this solution at a flow rate of $4.5-5 \mathrm{~mL} / \mathrm{min}$ and $18 \mathrm{~mL} / \mathrm{min}$, respectively. The reaction was performed by the irradiation of ultraviolet light using a highpressure Hg lamp. The temperature of the reaction system was maintained at $55-60^{\circ} \mathrm{C}$ by a circulator, and the gas generated by the reaction was analyzed with gas chromatography.

Figure 7 shows the rate of $\mathrm{CH}_{3} \mathrm{OH}$ evolution from an aqueous solution containing $\mathrm{M}_{n}-\mathrm{m}-\mathrm{WO}_{3}$ or $\mathrm{m}-\mathrm{WO}_{3}$. All the photocatalysts loaded with $\mathrm{M}_{n}$ clusters evolved $\mathrm{CH}_{3} \mathrm{OH}$ at faster rate as compared with $\mathrm{m}-\mathrm{WO}_{3}$ without cocatalyst. This indicates 
(a)

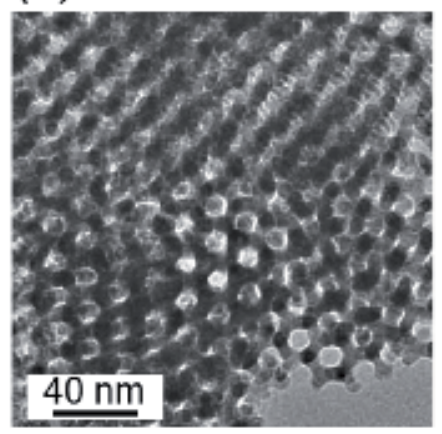

(b)

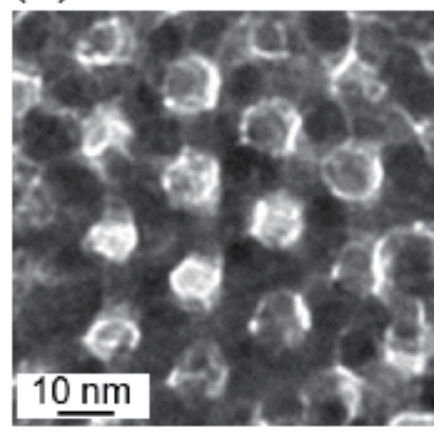

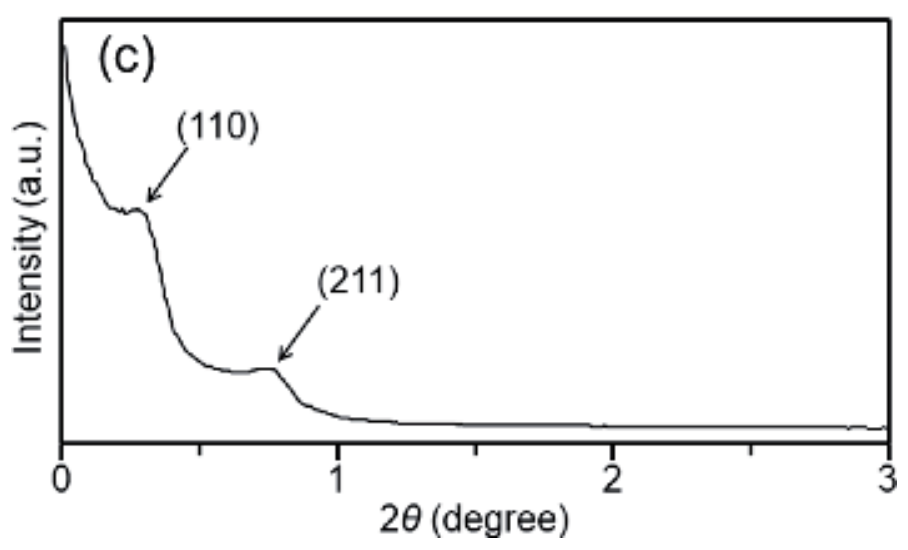

Figure 4.

Characterization of $m-W_{3}$. (a) TEM image, (b) expanded TEM image, and (c) small angle XRD pattern.

that the loading of the $\mathrm{M}_{n}$ clusters improved the rate of the conversion of $\mathrm{CH}_{4}$ to $\mathrm{CH}_{3} \mathrm{OH}$. It was found that the $\mathrm{Co}_{n}$ clusters have the largest improvement effect among the $\mathrm{M}_{n}$ clusters used in this study.

According to a previous study on $\mathrm{m}-\mathrm{WO}_{3}$ [8], in the conversion of $\mathrm{CH}_{4}$ to $\mathrm{CH}_{3} \mathrm{OH}$, first, the holes generated via photoexcitation oxidize the hydroxyl groups $\left(\mathrm{OH}^{-}\right)$on the photocatalyst surface and/or water $\left(\mathrm{H}_{2} \mathrm{O}_{\mathrm{ad}}\right)$ adsorbed on the surface to form $\cdot \mathrm{OH}$ radicals. The $\cdot \mathrm{OH}$ radicals have intense oxidizing power and attack $\mathrm{CH}_{4}$ to generate methyl radicals $\left(\cdot \mathrm{CH}_{3}\right)$. The $\cdot \mathrm{CH}_{3}$ radicals thus produced react with $\mathrm{H}_{2} \mathrm{O}$ to produce $\mathrm{CH}_{3} \mathrm{OH}$ (Figure 2(b)). It can be considered that loading $\mathrm{M}_{n}$ clusters onto $\mathrm{m}-\mathrm{WO}_{3}$ promotes the charge separation between the electrons and holes, and thereby, the holes are efficiently consumed [15], leading to the improvement of the activity. It is presumed that highest activity was observed in the reaction using $\mathrm{Co}_{n}-\mathrm{m}-\mathrm{WO}_{3}$, since the relationship between the positions of valence band of the photocatalyst and the orbitals of the loaded $\mathrm{M}_{n}$ cluster and/or the relationship between the redox potential of . $\mathrm{OH}$ radical and that of the loaded $\mathrm{M}_{n}$ cluster was effective for accelerating the reaction in $\mathrm{Co}_{n}-\mathrm{m}-\mathrm{WO}_{3}$ compared with the other photocatalysts $\left(\mathrm{Ag}_{n}-\mathrm{m}-\mathrm{WO}_{3}\right.$ or $\left.\mathrm{Ni}_{n}-\mathrm{m}-\mathrm{WO}_{3}\right)$.

\section{$2.2 \mathrm{~m}-\mathrm{TiO}_{2}$ photocatalyst}

\subsubsection{Preparation and loading of cocatalyst}

A $\mathrm{m}-\mathrm{TiO}_{2}$ photocatalyst was prepared according to a method reported in the literature [19]. Specifically, $\mathrm{m}-\mathrm{TiO}_{2}$ photocatalyst was prepared by forming a 
(a)

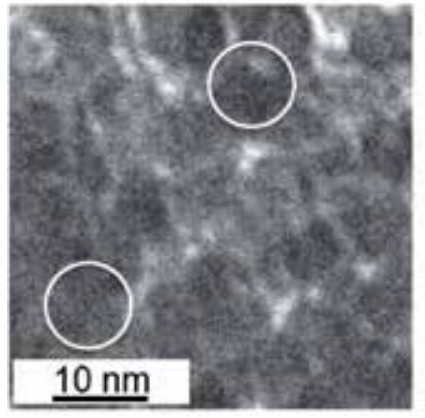

(b)

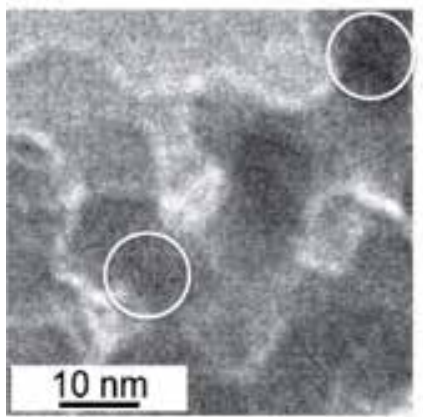

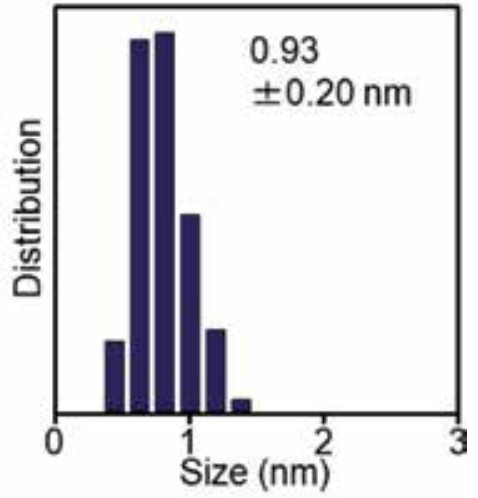

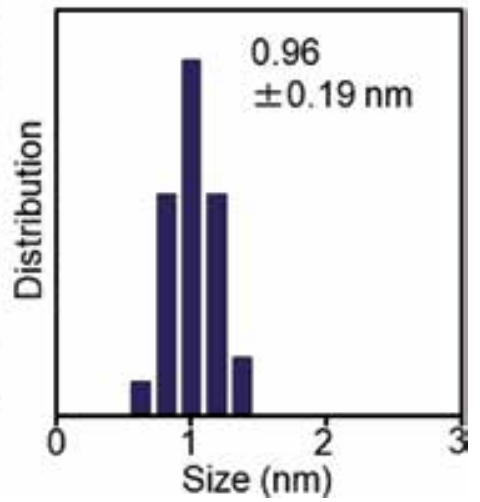

Figure 5.

TEM image and particle size distribution of (a) $\mathrm{Co}_{n}(\mathrm{SG})_{m}-m-W O_{3}$ and (b) $\mathrm{Co}_{n}-m-W O_{3}$. Multiple ultrafine particles can be seen in the white circles.

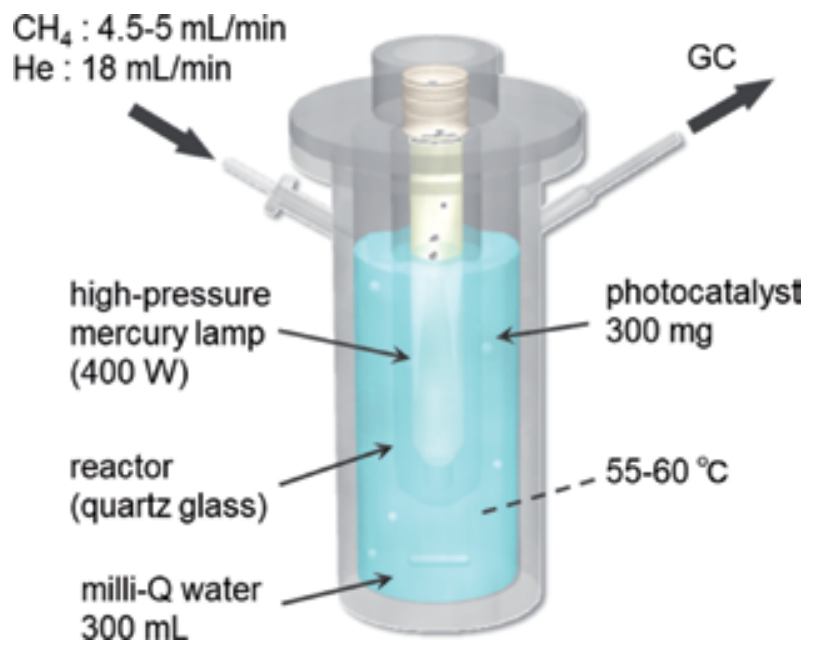

Figure 6.

Experimental apparatus built in-house consisting of a high-pressure mercury $(\mathrm{Hg}) \operatorname{lamp}(400 \mathrm{~W})$ and a quartz cell. GC means gas chromatograph.

photocatalyst around the micelle composed of surfactants. First, hexadecyltrimethylammonium bromide $\left(\left[\left(\mathrm{C}_{16} \mathrm{H}_{33}\right) \mathrm{N}\left(\mathrm{CH}_{3}\right)_{3}\right] \mathrm{Br}\right)$ was added to an aqueous solution of titanyl oxysulfate sulfuric acid hydrate $\left(\mathrm{TiOSO}_{4}\right)$, and the solution 


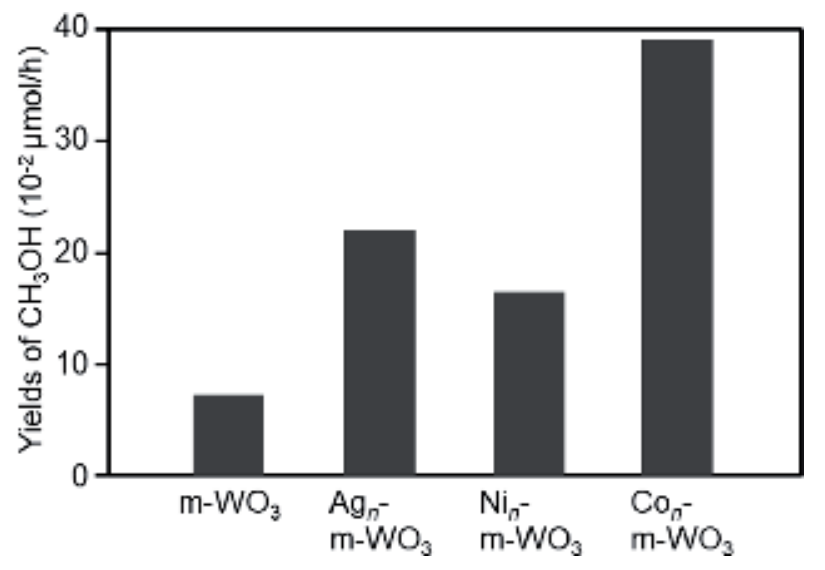

Figure 7.

Rate of $\mathrm{CH}_{3} \mathrm{OH}$ evolution from an aqueous solution containing $M_{n}-m-W O_{3}$ or $m-W O_{3}$.
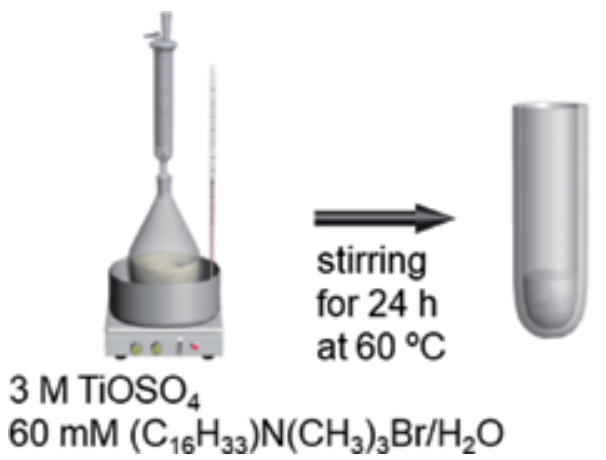

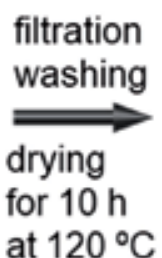

at $120^{\circ} \mathrm{C}$

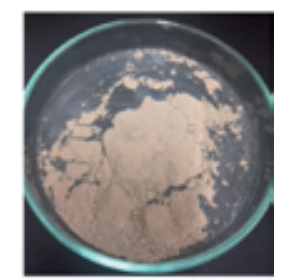

$\mathrm{m}-\mathrm{TiO}_{2}$

Figure 8.

Preparation methods of $m-\mathrm{TiO}_{2}$.

was stirred at $60^{\circ} \mathrm{C}$ for $24 \mathrm{~h}$. The obtained precipitate was washed with water and dried at $120^{\circ} \mathrm{C}$ for $10 \mathrm{~h}$. Then, the dried sample was calcined at $450^{\circ} \mathrm{C}$ for $2 \mathrm{~h}$ to obtain $\mathrm{m}-\mathrm{TiO}_{2}$ (Figure 8). The $\mathrm{M}_{n}$ clusters $(\mathrm{M}=\mathrm{Ag}, \mathrm{Ni}$, or $\mathrm{Co}$ ) were loaded onto the surface of the obtained $\mathrm{m}-\mathrm{TiO}_{2}$ using the same method as that described for $\mathrm{M}_{n}-\mathrm{m}-\mathrm{WO}_{3}$ (Figure 3(c)).

\subsubsection{Structural characterization}

Figure 9(a) shows a TEM image of the prepared $\mathrm{m}-\mathrm{TiO}_{2}$. It can be confirmed from this image that the material has a mesoporous structure different from that of $\mathrm{m}-\mathrm{WO}_{3}$ (Figure $4(\mathrm{~b})$ ). The diffuse reflection (DR) spectrum of $\mathrm{m}-\mathrm{TiO}_{2}$ revealed that the obtained $\mathrm{m}-\mathrm{TiO}_{2}$ has a band gap of around $3.24 \mathrm{eV}$, indicating that the obtained $\mathrm{m}-\mathrm{TiO}_{2}$ has an anatase type structure [19].

Figure 10(a) shows a TEM image of the $\mathrm{Ni}_{n}(\mathrm{SG})_{m}$ cluster, as a representative example of a synthesized $\mathrm{M}_{n}(\mathrm{SG})_{m}$ cluster. The particles with a size of $0.70 \pm 0.14 \mathrm{~nm}$ can be observed in Figure 10(a). On the other hand, the particles with a slightly larger size of $0.92 \pm 0.17 \mathrm{~nm}$ were observed in the TEM image of $\mathrm{Ni}_{n}$ $\mathrm{m}-\mathrm{TiO}_{2}$ (Figure 10(b)). This indicates that, in the synthesis of $\mathrm{Ni}_{n}(\mathrm{SG})_{m}-\mathrm{m}-\mathrm{TiO}_{2}$, some cluster aggregation occurred during the adsorption or calcination processes. However, the size distribution of the observed particles is very narrow even for loaded particles. The number of $\mathrm{Ni}$ atoms contained in each particle was estimated to be about 40 , based on the bulk density of $\mathrm{Ni}\left(8.908 \mathrm{~g} / \mathrm{cm}^{3}\right)$. Loading of such 
ultrafine particles was similarly observed for the other $\mathrm{M}_{n}-\mathrm{m}-\mathrm{TiO}_{2}(\mathrm{M}=\mathrm{Ag}$ or $\mathrm{Co})$. These results indicate that $\mathrm{m}-\mathrm{TiO}_{2}$ ultrafine clusters were successfully loaded on a photocatalyst with a narrow distribution of the particle size.

(a)

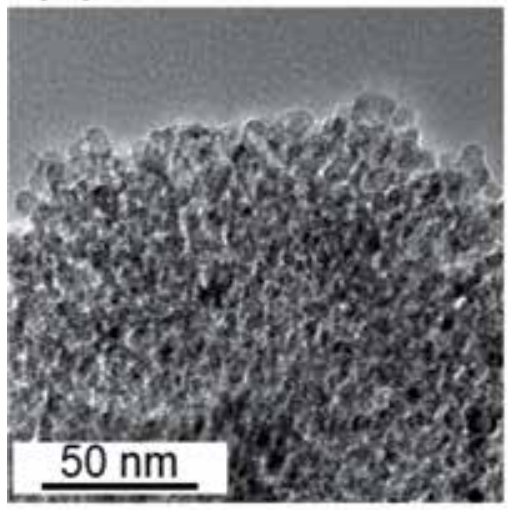

(b)

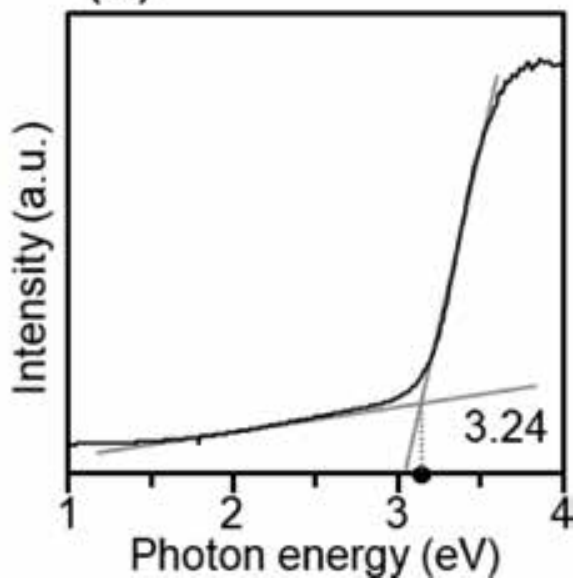

Figure 9.

Characterization of $m-\mathrm{TiO}_{2}$. (a) TEM image and (b) DR spectrum.

(a)

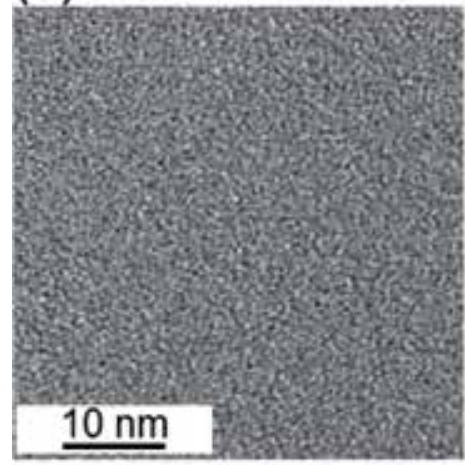

(b)

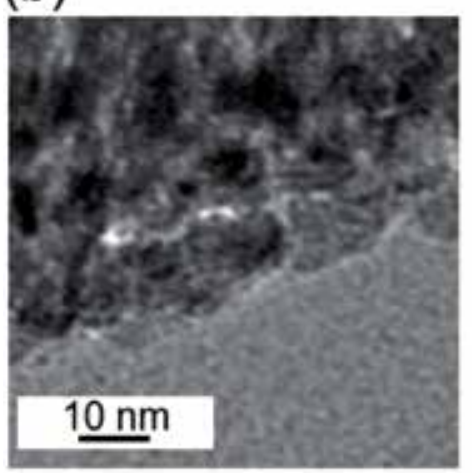

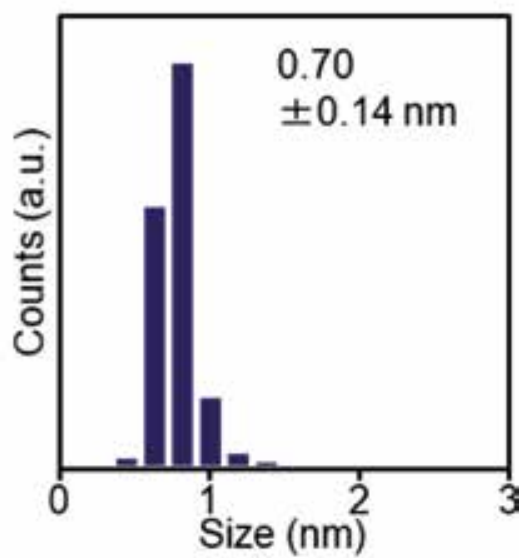

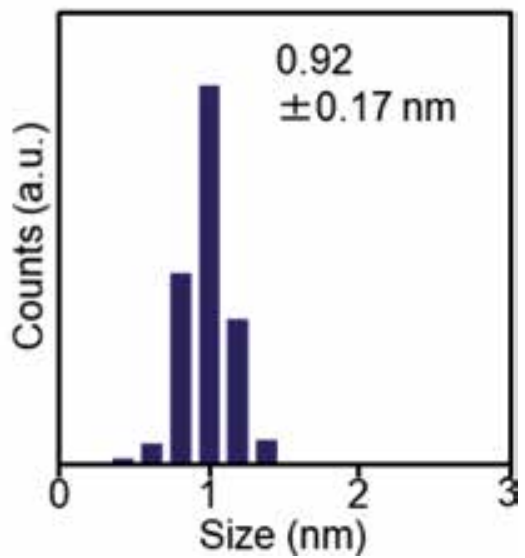

Figure 10.

TEM image and particle size distribution of (a) $\mathrm{Ni}_{n}(\mathrm{SG})_{m}$ and (b) $\mathrm{Ni} i_{n}-\mathrm{m}-\mathrm{TiO}_{2}$. 


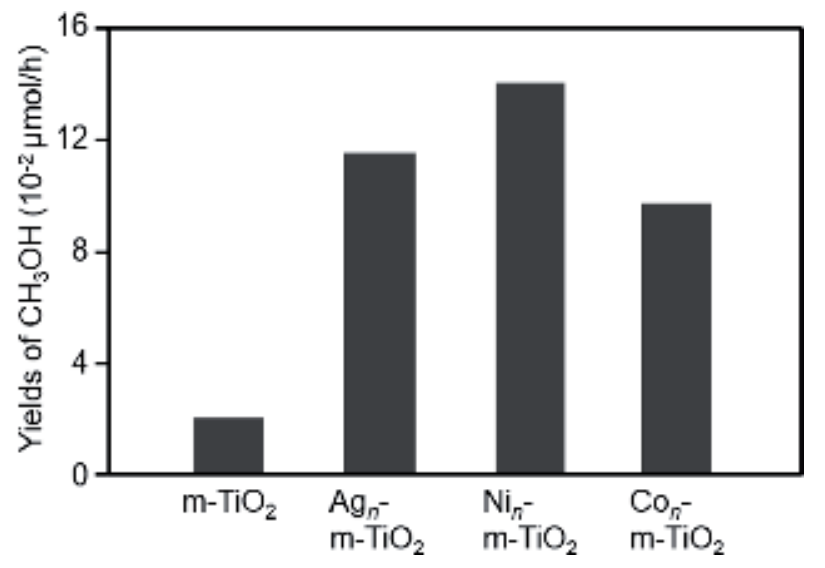

Figure 11.

Rate of $\mathrm{CH}_{3} \mathrm{OH}$ evolution from an aqueous solution containing $\mathrm{M}_{n}-m-\mathrm{TiO}_{2}$ or $m-\mathrm{TiO}_{2}$.

\subsubsection{Evaluation of photocatalytic activity}

The photocatalytic activity of a series of $\mathrm{M}_{n}-\mathrm{m}-\mathrm{TiO}_{2}$ obtained in this manner was estimated in the same manner as that described in Section 2.1.3. Figure 11 shows the rate of $\mathrm{CH}_{3} \mathrm{OH}$ evolution from aqueous solutions containing either $\mathrm{M}_{n}-\mathrm{m}-\mathrm{TiO}_{2}$ or $\mathrm{m}-\mathrm{TiO}_{2}$. Overall, the rate of $\mathrm{CH}_{3} \mathrm{OH}$ evolution from $\mathrm{M}_{n}-\mathrm{m}-\mathrm{TiO}_{2}$ or $\mathrm{m}-\mathrm{TiO}_{2}$ was lower than that from $\mathrm{M}_{n}-\mathrm{m}-\mathrm{WO}_{3}$ or $\mathrm{m}-\mathrm{WO}_{3}$. Since the position of conduction band is relatively high in $\mathrm{TiO}_{2}$ (Figure 2(a)), the superoxide radicals with strong oxidizing power can be generated from aqueous solution containing $\mathrm{M}_{n}-\mathrm{m}-\mathrm{TiO}_{2}$ or $\mathrm{m}-\mathrm{TiO}_{2}$ by photoirradiation. It can be considered that since the superoxide radicals such generated attacked $\mathrm{CH}_{3} \mathrm{OH}$ and thereby the excessive oxidation (decomposition) of $\mathrm{CH}_{3} \mathrm{OH}$ occurred [20], the rate of the $\mathrm{CH}_{3} \mathrm{OH}$ evolution decreased as a whole in the case of $\mathrm{M}_{n}-\mathrm{m}-\mathrm{TiO}_{2}$ or $\mathrm{m}-\mathrm{TiO}_{2}$ compared to the case of $\mathrm{M}_{n}-\mathrm{m}-\mathrm{WO}_{3}$ or $\mathrm{m}-\mathrm{WO}_{3}$. Figure 11 also revealed that the loading of $\mathrm{M}_{n}$ clusters has the effect of promoting the conversion of $\mathrm{CH}_{4}$ into $\mathrm{CH}_{3} \mathrm{OH}$ also in the case of $\mathrm{M}_{n}-\mathrm{m}-\mathrm{TiO}_{2}$.

On the other hand, regarding the metal elements, Ni showed a particularly high cocatalytic effect in $\mathrm{M}_{n}-\mathrm{m}-\mathrm{TiO}_{2}$, unlike the case of $\mathrm{m}-\mathrm{WO}_{3}$ (Figure 11). The relationship between the position of the valence band of the photocatalyst and the position of the orbitals of the loaded $\mathrm{M}_{n}$ cluster and/or the relationship between the redox potential of $\cdot \mathrm{OH}$ radical and that of the loaded $\mathrm{M}_{n}$ cluster are considered to be strongly related to these phenomena. These results indicate that choosing an appropriate cocatalyst depending on the type of photocatalyst is very important to improve the photocatalytic activity.

\section{Conclusions}

Ultrafine $\mathrm{M}_{n}$ clusters $(\mathrm{M}=\mathrm{Ag}, \mathrm{Ni}$, or $\mathrm{Co})$ with a particle size of around $1 \mathrm{~nm}$ were successfully loaded onto $\mathrm{m}-\mathrm{WO}_{3}$ and $\mathrm{m}-\mathrm{TiO}_{2}$ with a narrow distribution. The photocatalytic activity measurements clearly demonstrated that the loading of such cocatalysts is effective in improving the activity for both types of photocatalysts. Furthermore, our study also revealed that it is important to appropriately selecting the element of the cocatalyst according to the photocatalyst to improve the photocatalytic activity. In these experiments, the particle diameter of the cocatalyst was reduced to approximately $1 \mathrm{~nm}$ to increase the reactive surface area. However, this size of a cocatalyst particle might not be optimal for promoting the reaction. In fact, our previous studies on water-splitting photocatalysts showed that extreme refining 
of the cocatalyst particles reduces the activity per a surface atom of cocatalysts [8]. Therefore, in future studies, we would like to clarify the correlation between the particle size and activity of the cocatalyst. Furthermore, it seems also necessary to consider the method for efficiently consuming the excited electrons to accelerate the reaction.

\section{Acknowledgements}

We thank Mr. Shun Yoshino for technical assistance. This work was supported by the Japan Society for the Promotion of Science (JSPS) KAKENHI (grant numbers JP16H04099 and 16 K21402), Scientific Research on Innovative Areas “Coordination Asymmetry" (grant number 17H05385), and Scientific Research on Innovative Areas "Innovations for Light-Energy Conversion" (grant number 18H05178). Funding from the Takahashi Industrial and Economic Research Foundation, Futaba Electronics Memorial Foundation, Iwatani Naoji Foundation, and Asahi Glass Foundation is also gratefully acknowledged.

\section{Author details}

Yuichi Negishi ${ }^{1,2 *}$, Seiichiro Watanabe ${ }^{1}$, Marika Aoki ${ }^{1}$, Sakiat Hossain ${ }^{1}$ and Wataru Kurashige ${ }^{1}$

1 Department of Applied Chemistry, Faculty of Science, Tokyo University of Science, Tokyo, Japan

2 Photocatalysis International Research Center, Tokyo University of Science, Chiba, Japan

*Address all correspondence to: negishi@rs.kagu.tus.ac.jp

\section{IntechOpen}

(C) 2019 The Author(s). Licensee IntechOpen. This chapter is distributed under the terms of the Creative Commons Attribution License (http://creativecommons.org/licenses/ by/3.0), which permits unrestricted use, distribution, and reproduction in any medium, provided the original work is properly cited. (cc) BY 


\section{References}

[1] Tsuji Y, Ishida $H$, Nakamizu M, Matsumoto R, Shimizu S. Overview of the MITI nankai trough wells: A milestone in the evaluation of methane hydrate resources. Resource Geology. 2004;54:3-10. DOI: 10.1111/j.17513928.2004.tb00182.x

[2] Pascoli SD, Femia A, Luzzati T. Natural gas, cars and the environment. A (relatively) 'clean' and cheap fuel looking for users. Ecological Economics. 2001;38:179-189. DOI: 10.1016/S0921-8009(01)00174-4

[3] Sushkevich VL, Palagin D, Ranocchiari M, Bokhoven JAV. Selective anaerobic oxidation of methane enables direct synthesis of methanol. Science. 2017;356:523-527. DOI: 10.1126/science. aam9035

[4] Zakaria Z, Kamarudin SK. Direct conversion technologies of methane to methanol: An overview. Renewable and Sustainable Energy Reviews. 2016;65: 250-261. DOI: 10.1016/j.rser.2016.05.082

[5] Zhu W, Shen M, Fan G, Yang A, Meyer JR, Ou Y, et al. Facet-dependent enhancement in the activity of bismuth vanadate microcrystals for the photocatalytic conversion of methane to methanol. ACS Applied Nano Materials. 2018;1:6683-6691. DOI: 10.1021/ acsanm.8b01490

[6] Murcia-López SM, Villa K, Andreu T, Morante JR. Partial oxidation of methane to methanol using bismuthBased photocatalysts. ACS Catalysis. 2014;4:3013-3019. DOI: 10.1021/ cs500821r

[7] Li L, Krissanasaeranee M, Pattinson SW, Stefik M, Wiesner U, Steiner U, et al. Enhanced photocatalytic properties in well-ordered mesoporous $\mathrm{WO}_{3}$. Chemical Communications. 2010;46:7620-7622. DOI: 10.1039/ $\mathrm{C} 0 \mathrm{CC} 01237 \mathrm{H}$
[8] Villa K, Murcia-López S, Andreu T, Morante JR. Mesoporous $\mathrm{WO}_{3}$ photocatalyst for the partial oxidation of methane to methanol using electron scavengers. Applied Catalysis B:

Environmental. 2015;163:150-155. DOI: 10.1016/j.apcatb.2014.07.055

[9] Negishi Y, Mizuno M, Hirayama M, Omatoi M, Takayama T, Iwase A, et al. Enhanced photocatalytic water splitting by $\mathrm{BaLa}_{4} \mathrm{Ti}_{4} \mathrm{O}_{15}$ loaded with $\sim 1 \mathrm{~nm}$ gold nanoclusters using glutathioneprotected $\mathrm{Au}_{25}$ clusters. Nanoscale. 2013;5:7188-7192. DOI: 10.1039/ c3nr01888A

[10] Negishi Y, Matsuura Y, Tomizawa R, Kurashige W, Niihori Y, Takayama $\mathrm{T}$, et al. Controlled loading of small $\mathrm{Au}_{\mathrm{n}}$ clusters $(\mathrm{n}=10-39)$ onto $\mathrm{BaLa}_{4} \mathrm{Ti}_{4} \mathrm{O}_{15}$ photocatalysts: Toward an understanding of size effect of cocatalyst on water-splitting photocatalytic activity. The Journal of Physical Chemistry C. 2015;119: 11224-11232. DOI: $10.1021 /$ jp5122432

[11] Kurashige W, Kumazawa R, Ishii D, Hayashi R, Niihori Y, Hossain S, et al. $\mathrm{Au}_{25}$-loaded $\mathrm{BaLa}_{4} \mathrm{Ti}_{4} \mathrm{O}_{15}$ watersplitting photocatalyst with enhanced activity and durability produced using new chromium oxide shell formation method. The Journal of Physical Chemistry C. 2018;122:13669-13681. DOI: $10.1021 /$ acs.jpcc.8b00151

[12] Negishi Y. Toward the creation of functionalized metal nanoclusters and highly active photocatalytic materials using thiolate-protected magic gold clusters. Bulletin of the Chemical Society of Japan. 2014;87:375-389. DOI: 10.1246/bcsj.20130288

[13] Kurashige W, Niihori Y, Sharma S, Negishi Y. Precise synthesis, functionalization and application of thiolate-protected gold clusters. Coordination Chemistry Reviews. 
2016;320-321:238-250. DOI: 10.1016/j. ccr.2016.02.013

[14] Hameed A, Ismail IMI, Aslam M, Gondal MA. Photocatalytic conversion of methane into methanol: Performance of silver impregnated $\mathrm{WO}_{3}$. Applied Catalysis A: General. 2014;470:327-335. DOI: 10.1016/j.apcata.2013.10.045

[15] Liu L, Ji Z, Zou W, Gu X, Deng Y, Gao F, et al. In situ loading transition metal oxide clusters on $\mathrm{TiO}_{2}$ Nanosheets as Co-catalysts for exceptional high photoactivity. ACS Catalysis. 2013;3:2052-2061. DOI: $10.1021 / \operatorname{cs} 4002755$

[16] Bootharaju MS, Burlakov VM, Besong TMD, Joshi CP, AbdulHalim LG, Black DM, et al. Reversible size control of silver nanoclusters via ligandExchange. Chemistry of Materials. 2015;27:4289-4297. DOI: 10.1021/acs. chemmater.5b00650

[17] Negishi Y, Nobusada K, Tsukuda T. Glutathione-protected gold clusters revisited: bridging the gap between gold(I) - thiolate complexes and thiolate-protected gold nanocrystals. Journal of the American Chemical Society. 2005;127:5261-5270. DOI: 10.1021/ja042218h

[18] Rossinyol E, Arbiol J, Peiró F, Cornet A, Morante JR, Tian B, et al. Nanostructured metal oxides synthesized by hard template method for gas sensing applications. Sensors and Actuators B: Chemical. 2005;109:57-63. DOI: 10.1016/j.snb.2005.03.016

[19] Shibata H, Ogura T, Mukai T, Ohkubo T, Sakai H, Abe M. Direct synthesis of mesoporous titania particles having a crystalline wall. Journal of the American Chemical Society. 2005;127:16396-16397. DOI: 10.1021/ja0552601

[20] Gondal MA, Hameed A, Yamani ZH, Arfaj A. Photocatalytic transformation of methane into methanol under UV laser irradiation over $\mathrm{WO}_{3}, \mathrm{TiO}_{2}$ and $\mathrm{NiO}$ catalysts. Chemical Physics Letters. 2004;392: 372-377. DOI: 10.1016/j.cplett.2004.05.0 


\title{
Rare-Earth-Based Materials for Heterogeneous Photocatalysis
}

\author{
Sahar Zinatloo-Ajabshir and Zahra Sayyar
}

\begin{abstract}
Recently, the synthesis of rare-earth-based nanostructures as a significant class of materials with photocatalysis activity has attracted the attention of researchers. Many studies have shown their applications in various fields, specifically in photocatalysis. There are different methods to synthesis of rare-earth nanostructures. In this study, we discuss about modification of rare-earth-based materials. Also production methods and their advantages and disadvantages have been presented, briefly. Finally, photocatalytic applications of rare-earth nanostructures are highlighted.
\end{abstract}

Keywords: rare-earth materials, heterogeneous photocatalysis, nanostructure, methods, modification

\section{Introduction}

Nanostructures especially rare-earth-based materials have attracted interest of researches in recent decade due to their unique and important properties such as electronic, optical, photocatalytic and magnetic. These materials with different shapes can be used in various fields because of potential applications. Because their dimension and shape the behavior of nanoscale compounds is greatly sensitive [1].

A set of chemical elements in the periodic table, specifically scandium (Sc), yttrium (Y), lanthanum (La) and all of the lanthanide series ( $\mathrm{Ln})$, are rare-earth materials. All rare-earth materials have unique properties corresponding to the filling of their orbitals and their ability to display a $3+$ oxidation state $[2,3]$. The results of researchers show that rare-earth material properties changes with doping or co-doping of them with oxides because of their crystalline structure variation.

Rare-earth-based materials were generally applied in high and low temperature fuel cells [4], gas storage/separation, chemical sensing [5], heterogeneous photocatalysis [6], wastewater treatment [7], fluorescence [8], photoelectrochemical Water [9], etc. Nanostructure of rare-earth material is appropriate for these applications that can be synthesized with different methods for example coprecipitation, hydrothermal, sol-gel, combustion, stearic acid route, pechini, cathode plasma, electrolysis, co-ions complexation, molten salt and other approaches [7]. Each of these methods has its own advantages and disadvantages which are discussed in the following.

This study is being focused on heterogeneous photocatalytic activity of rareearth-based material and their methods of preparation. 


\section{Modification of rare-earth-based materials}

Efficiency of nanostructured compounds depend their grain size, morphology, structure and components. Study on properties of rare-earth oxide and doped with other material has increased due to their wide usages in various fields [10]. In order to develop properties, excessive effort has been done in the modification of morphology and structure of rare-earth materials.

Praseodymium oxide $\left(\mathrm{Pr}_{6} \mathrm{O}_{11}\right)$, neodymium oxide $\left(\mathrm{Nd}_{2} \mathrm{O}_{3}\right)$, holmium oxide $\left(\mathrm{Ho}_{2} \mathrm{O}_{3}\right), \mathrm{Dy}_{2} \mathrm{Ce}_{2} \mathrm{O}_{7}, \mathrm{Nd}_{2} \mathrm{Zr}_{2} \mathrm{O}_{7}-\mathrm{Nd}_{2} \mathrm{O}_{3}, \mathrm{NdOCl}-\mathrm{Nd}_{2} \mathrm{Sn}_{2} \mathrm{O}_{7}-\mathrm{SnO}_{2}, \mathrm{Nd}_{2} \mathrm{Sn}_{2} \mathrm{O}_{7}-\mathrm{SnO}_{2}$, $\mathrm{Pr}_{2} \mathrm{Ce}_{2} \mathrm{O}_{7}, \mathrm{Nd}_{2} \mathrm{Sn}_{2} \mathrm{O}_{7}, \mathrm{Nd}_{2} \mathrm{Zr}_{2} \mathrm{O}_{7}-\mathrm{ZrO}_{2}, \mathrm{Nd}_{2} \mathrm{Zr}_{2} \mathrm{O}_{7}, \mathrm{Dy}_{2} \mathrm{Sn}_{2} \mathrm{O}_{7}-\mathrm{SnO}_{2}, \mathrm{Ho}_{2} \mathrm{O}_{3}-\mathrm{SiO}_{2}$, $\mathrm{Nd}_{2} \mathrm{O}_{3}-\mathrm{SiO}_{2}$, are various families of rare-earth-based materials that were synthesized by researchers [10-20] to modify their properties and other modified rareearth materials will be presented in the following.

\subsection{Rare-earth-based coordination polymers}

Rare-earth-based coordination polymers (CPs) have been studied due to their expanded structures and applications [5]. These materials contain catalytic active sites in both the organic linkers and metal centers. The modified of new and selective heterogeneous catalysts is suitable for photocatalytic processes, mainly in the oxidation of organic compounds.

Aguirre-Díaz et al. [5] synthesized five new lanthanide CPs (Ln-CPs) by solvothermal method using $\mathrm{La}, \mathrm{Nd}, \mathrm{Sm}, \mathrm{Ho}$, and Er as metal sources in order to offer a remarkable platform which contains antennas and catalytic active centers to achieve solar-energy conversion as green alternatives.

Also Le Natur et al. [21] synthesized a series of hexanuclear complexes based coordination polymers (CPs). They showed that CPs contain rare-earth material exhibit very high optical, luminescent properties and tunable systems at low cost. Therefore they demonstrated that this modified materials had high photocatalytic activity.

\subsection{Rare-earth-based metal organic frameworks}

Metal organic frameworks (MOFs) are crystalline porous materials with bridging organic ligands, which inorganic metal place in center. Nevertheless, applications of MOFs were limited because of their weak coordination capability and the stability. To solve this problem, Feng et al. [22] synthesized stable and functional 8-connected hexanuclear rare-earth MOFs platform based on $\mathrm{Re}_{6} \mathrm{O}_{4}(\mathrm{OH})_{4}(\mathrm{COO})_{8}$ Clusters. They showed that these structural characteristics cause that MOFs perform as a multipurpose platform for future applications, including recognition and high adsorption.

\section{Methods for preparing rare-earth-based nanostructures}

Shape of material as well as dimension will be influenced by the preparation method of nanoscale compounds. Therefor selection of technique is essential to control the shape of nanostructure [7]. In this section, we study some of methods for preparing rare-earth-based nanostructures.

\subsection{Solid state reaction}

In the solid state reaction as conventional method for synthesis, rare-earth oxide and other material are mixed using mechanical instrument and the achieved powders are calcined at very high temperature for very long time [23]. 
$\mathrm{Eu}^{3+}$ doped $\mathrm{Gd}_{2} \mathrm{Mo}_{3} \mathrm{O}_{9}$ was prepared using solid-state reaction method and $\mathrm{Na}_{2} \mathrm{CO}_{3}$ as flux by Xiaoxia [24]. The results showed that the luminescent and photocatalytic properties depend to flux content and sintering temperature.

\subsection{Hydrothermal}

In the hydrothermal method, materials solutions are placed in the autoclave under high temperature and pressure conditions therefore the hydroxides are precipitated and the powders are formed through nucleation and growth. This method is suitable, simple, and effective controlled synthetic process and cheap because water is solvent [25].

Li et al. [26] used the low temperature hydrothermal method to synthesize nanosized $\mathrm{Y}_{2} \mathrm{Sn}_{2} \mathrm{O}_{7}$ composite with the particle size from 10 to $300 \mathrm{~nm}$ using different organic agents. They demonstrated that these nanocomposites can be shown photocatalytic properties in water purification.

\subsection{Combustion}

When metal precursors (oxidants) and fuel react using combustion, these reactions can cause to produce rare-earth-based powders. In this method, a mixed solution consists of rare-earth material as precursors and urea as fuel were prepared then other solution ( $\mathrm{pH}$ control agent) was added to this solution for gel formation. The prepared gel was dried and heated at high temperature to obtain rare-earthbased nanostructures [7, 27].

Zinatloo et al. [13] used combustion method to fabricate $\mathrm{Nd}_{2} \mathrm{Sn}_{2} \mathrm{O}_{7}-\mathrm{SnO}_{2}$ nanocomposites as novel and non-toxic biofuel using extract of pineapple. They showed that produced nanocomposites had high photocatalytic activity to degrade environmental pollution.

\subsection{Coprecipitation}

In the coprecipitation technique, the hydroxides are instantaneously precipitated from precursor solutions via adding a base solution. The formed hydroxide precipitates is then calcined to prepare rare-earth nanostructures. Ziarati et al. [28] synthesized $\mathrm{NiFe}_{2-\mathrm{x}} \mathrm{Eu}_{\mathrm{x}} \mathrm{O}_{4}$ nanostructure using coprecipitation method and calcination. They showed that samples had high yields in presence of the rare-earth-based catalyst.

\subsection{Sol-gel}

In the sol-gel technique, hydrolysis and poly-condensation reactions of metal alkoxides occur to form gels. Afterwards, the achieved gels are calcined to obtain rare-earth nanoparticles. The sol-gel technique is low-cost, simple, friendly to the environment and less complicated than the others [7].

Li et al. [2] synthesized $\mathrm{LnFeO}_{3}(\mathrm{Ln}=\mathrm{Pr}, \mathrm{Y})$ powders using sol-gel method with utilizing, lanthanide metal $(\mathrm{Ln}=\mathrm{Pr}, \mathrm{Y})$ with the assistance of glycol at $800^{\circ} \mathrm{C}$ for $4 \mathrm{~h}$. Photodecomposition rate of $\mathrm{RhB}$ was improved by $\mathrm{LnFeO}_{3}(\mathrm{Ln}=\mathrm{Pr}, \mathrm{Y})$ nanoparticles.

Nowadays, there are different ways for the production of rare-earth nanostructure such as sol-gel combined electrospinning, complex precipitation, pechini polymeric route, molten salt synthesis, co-ions complexation method, Cathode plasma electrolysis, Complex precipitation method, Precursor route and Floating zone technique. 


\subsection{Advantages and disadvantages of these methods}

In this section, the advantages and disadvantages of each preparation technique have been discussed, briefly. Some nanostructured samples in this chapter have been synthesized using various methods by our research group.

There are different wet chemistry techniques to synthesize rare-earth-based nanostructures with suitable properties. In the wet chemistry technique, materials are mixed with together therefore the final powders have excellent compositional homogeneity. However, the solid state reaction technique is one of them that can cause the undesirable properties of final powders such as poor control of morphology and particle size and nonhomogeneity of distribution [23].

Hydrothermal method is homogeneous nucleation processes as remarkable advantage that can cause to synthesize particles with small size without the calcination stage. However, reaction rate and formation of rare-earth nanostructures are slow thus, a moderate heating stage at low temperature is necessary after the hydrothermal stage to accelerate the solid reaction [25].

The combustion technique can cause to synthesize powders with high purity, small size and uniform distribution. Nevertheless, the combustion reaction is not easy to control. Also, the combustion reaction can lead to agglomeration of the formed nanoparticles due to high temperature [27].

Coprecipitation method can lead to synthesize high purity compounds with a homogeneous composition at relatively low temperature but the obtained powders have large size. Thus a grinding stage is essential to synthesize a compound with small size $[29,30]$.

The sol-gel method is as an appropriate technique for compositional controlling the metallic species that the final powders are prepared through calcining stage with small size [31].

The type of method is effective on the characteristics of the powder therefore, selection of the right method is essential to prepare the powder with small particles, high uniform and purity. Also energy and cost is important to choose method.

\section{Application of rare-earth-based material}

Rare-earth-based materials were used in different fields. Some of rare-earth materials have been used for multipurpose applications such as gas sensors, solar cells, rechargeable batteries, supercapacitors, and transparent conducting electrodes, electronic and optical properties. The rare earth doped with some semiconductors such as $\mathrm{SnO}_{2}$ can be used for temperature sensing. Recently, Eu ${ }^{3+}$-ions doped $\mathrm{SnO}_{2}$ has attracted the research attention as a candidate for thermometry applications [5].

Also, rare-earth-based perovskite oxides can be applied as catalysts for lowtemperature fuel cells. The dimensions of the unit cell can be changed by varying the lanthanide ion which this unique property is an interesting characteristic of rare-earth perovskites $\left(\mathrm{LnMO}_{3}\right)$ [2].

According to the information of other researchers, rare-earth-based perovskites have been applied as fuel cell catalysts for methanol oxidation and oxygen reduction in alkaline medium. The results showed that these materials enhanced the kinetics of the methanol oxidation reaction in alkaline medium. On the other hand rareearth-based perovskite oxides were used as cathode and anode catalysts for oxygen reduction in alkaline medium [9]. 
Rare-earth-based materials such as $\mathrm{CeO}_{2}$ also were added as an additive for Nafion membranes to improve their chemical stability. Hydrogen peroxide and its decomposition produce $\mathrm{HO}^{\circ}$ and $\mathrm{HOO}^{\circ}$ during the fuel cell operation that they have been considered as a key factors leading to membrane degradation therefore, $\mathrm{CeO}_{2}$ nanoparticles act as mitigating free-radical-induced or free radical scavenger in biological systems due to their higher surface area and ability to undergo faster redox reaction. All studies suggested that $\mathrm{CeO}_{2}$ nanoparticles have incredible potential to improve membrane permanence [4].

In this section, we study a brief review of rare-earth-doped materials, rare-earth-based oxide-oxide composites, metal-modified semiconductors and mixed-oxide materials in the fields of photocatalytic application as solar energy generation (Figure 1) [9].

Rare-earth-based material play a key role in important photocatalytic and energy production processes such as catalysts. Rare-earth material such as the lanthanide elements can perform as catalysts to enhance the efficiency by:

1. Developing properties of the catalyst surface,

2. Improving the thermal stability of catalytic oxides,

3. Enhancing the catalytic efficiency due to their redox capabilities and conductivity development,

\section{Increasing oxygen uptake [9].}

After a brief introduction of rare-earth materials and their properties ions and oxide materials. In the next sections will be discussed perspectives of rare-earth materials in photocatalytic processes and their potential as active catalysts or support materials.

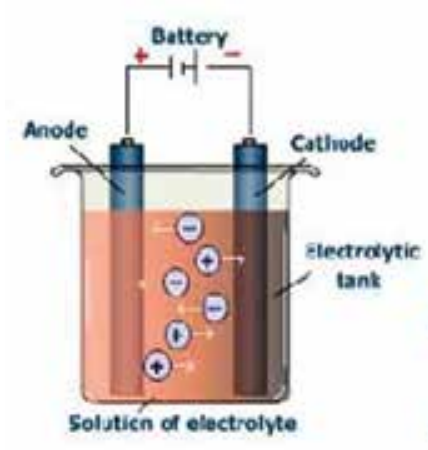

(B)

Photootectrochemical

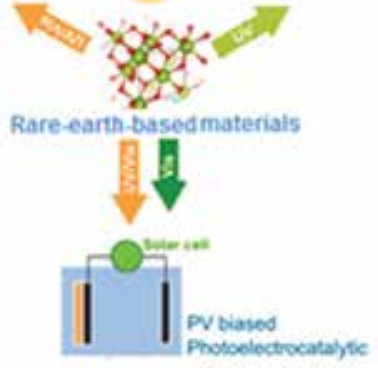

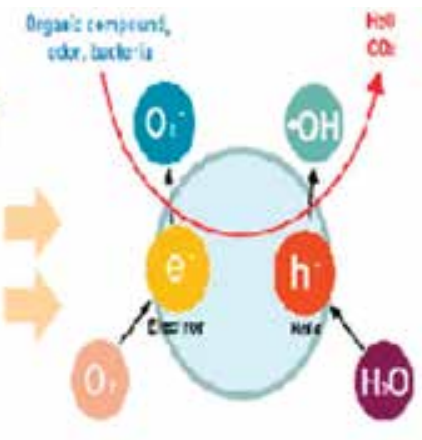

(A) Photocatalytic

(C) Photoanode

Figure 1.

Applications of rare-earth-based materials in solar energy generation: (A) photocatalytic,

(B) photoelectrochemical, (C) cell approach (photoelectrocatalytic). 


\subsection{Heterogeneous photocatalysis}

One of the progressive knowledge is heterogeneous photocatalysis that can be applied in diverse fields. Photocatalytic materials are used to degrade organic and inorganic pollutants in both the vapor and liquid phases [6].

When a photon is absorbed by rare-earth-based material using the energy gap of the materials, electron-hole pairs are generated in the photocatalysis mechanism.

\begin{tabular}{|c|c|c|c|c|}
\hline Photocatalyst & Synthetic method & Light source & Removal percentage (\%) & Ref. \\
\hline $\begin{array}{l}\mathrm{RVO}_{4} ; \mathrm{R}_{5} \mathrm{La}, \mathrm{Ce}, \\
\mathrm{Nd}, \mathrm{Sm}, \text { Eu and } \\
\mathrm{Gd}\end{array}$ & Sonication & $\begin{array}{l}8 \mathrm{~W} \text { mercury UV lamps } \\
\text { of } 365 \mathrm{~nm} \text { wavelength }\end{array}$ & $\begin{array}{l}70 \% \text { of methylene blue } \\
\text { after } 90 \text { min illumination }\end{array}$ & [1] \\
\hline $\begin{array}{l}\mathrm{LnFeO}_{3}(\mathrm{Ln}=\mathrm{Pr} \\
\mathrm{Y})\end{array}$ & Sol-gel & 500 W Xe lamp & $\begin{array}{l}96 \% \text { of } \mathrm{RhB} \text { after } 2 \mathrm{~h} \\
\text { illumination }\end{array}$ & [2] \\
\hline La-doped $\mathrm{TiO}_{2}$ & Sol-gel & $\begin{array}{l}\text { UV irradiation at specific } \\
\text { wavelength, } 254 \text { or } \\
365 \mathrm{~nm}\end{array}$ & $\begin{array}{l}\geq 90 \% \text { of methylene blue } \\
\text { after } 90 \text { min illumination }\end{array}$ & {$[8]$} \\
\hline $\mathrm{Dy}_{2} \mathrm{Ce}_{2} \mathrm{O}_{7}$ & $\begin{array}{l}\text { Green synthesis } \\
\text { using juice of } \\
\text { Punica }\end{array}$ & 125 W Osram lamp & $\begin{array}{l}92.8 \% \text { of methylene blue } \\
\text { after } 70 \text { min illumination }\end{array}$ & [10] \\
\hline $\mathrm{Dy}_{2} \mathrm{Sn}_{2} \mathrm{O}_{7}-\mathrm{SnO}_{2}$ & Pechini & $400 \mathrm{~W}$ mercury lamps & $\begin{array}{l}81 \% \text { of methyl orange } \\
\text { after } 50 \text { min illumination }\end{array}$ & [11] \\
\hline $\mathrm{Nd}_{2} \mathrm{Sn}_{2} \mathrm{O}_{7}$ & $\begin{array}{l}\text { Green synthesis } \\
\text { using pomegranate } \\
\text { juice }\end{array}$ & 125 W Osram lamp & $\begin{array}{l}96.7 \% \text { of methyl violet } \\
\text { after } 70 \text { min illumination }\end{array}$ & [12] \\
\hline $\mathrm{Nd}_{2} \mathrm{Sn}_{2} \mathrm{O}_{7}-\mathrm{SnO}_{2}$ & Combustion & 125 W Osram lamp & $\begin{array}{l}88.7 \% \text { of rhodamine B } \\
\text { after } 70 \text { min illumination }\end{array}$ & [13] \\
\hline $\mathrm{Nd}_{2} \mathrm{O}_{3}$ & $\begin{array}{l}\text { Simple } \\
\text { precipitation }\end{array}$ & $125 \mathrm{~W}$ mercury lamps & $\begin{array}{l}89.6 \% \text { of methylene blue } \\
\text { after } 90 \text { min illumination }\end{array}$ & [14] \\
\hline $\mathrm{Ho}_{2} \mathrm{O}_{3}-\mathrm{SiO}_{2}$ & Sonochemical & $125 \mathrm{~W}$ mercury lamp & $\begin{array}{l}94.9 \% \text { of methylene blue } \\
\text { after } 70 \text { min illumination }\end{array}$ & [15] \\
\hline $\mathrm{Ho}_{2} \mathrm{O}_{3}$ & Sonochemical & $125 \mathrm{~W}$ mercury lamp & $\begin{array}{l}82.2 \% \text { of erythrosine after } \\
70 \text { min illumination }\end{array}$ & {$[16]$} \\
\hline $\mathrm{Nd}_{2} \mathrm{O}_{3}-\mathrm{SiO}_{2}$ & Sonochemical & 125 W Osram lamp & $\begin{array}{l}93.1 \% \text { of methyl violet } \\
\text { after } 70 \text { min illumination }\end{array}$ & [17] \\
\hline $\mathrm{Nd}_{2} \mathrm{Zr}_{2} \mathrm{O}_{7}-\mathrm{ZrO}_{2}$ & Modified Pechini & $400 \mathrm{~W}$ mercury lamps & $\begin{array}{l}85 \% \text { of methylene blue } \\
\text { after } 50 \text { min illumination }\end{array}$ & [20] \\
\hline $\mathrm{Pr}_{2} \mathrm{Ce}_{2} \mathrm{O}_{7}$ & Pechini & $400 \mathrm{~W}$ mercury lamps & $\begin{array}{l}92.1 \% \text { of methyl orange } \\
\text { after } 50 \text { min illumination }\end{array}$ & [35] \\
\hline $\mathrm{GdFeO}_{3}$ & Sol-gel & 500 W Xe lamp & $\begin{array}{l}100 \% \text { of } \mathrm{RhB} \text { after } 2 \mathrm{~h} \\
\text { illumination }\end{array}$ & [36] \\
\hline $\mathrm{Dy}_{2} \mathrm{Ce}_{2} \mathrm{O}_{7}$ & $\begin{array}{l}\text { Green synthesis } \\
\text { using Ananas } \\
\text { comosus }\end{array}$ & 125 W Osram lamp & $\begin{array}{l}91.7 \% \text { of black } \mathrm{T} \text { after } 1 \mathrm{~h} \text {. } \\
\text { illumination }\end{array}$ & [37] \\
\hline $\mathrm{Dy}_{2} \mathrm{Ce}_{2} \mathrm{O}_{7}$ & $\begin{array}{l}\text { Green synthesis } \\
\text { using Vitis vinifera } \\
\text { juice }\end{array}$ & 125 W Osram lamp & $\begin{array}{l}92.4 \% \text { of methyl orange } \\
\text { after } 80 \text { min illumination }\end{array}$ & [38] \\
\hline $\mathrm{Nd}_{2} \mathrm{O}_{3}$ & Hydrothermal & $\begin{array}{l}\text { UV light from the } 400 \mathrm{~W} \\
\text { mercury lamps }\end{array}$ & $\begin{array}{l}79 \% \text { of black } \mathrm{T} \text { after } \\
100 \text { min illumination }\end{array}$ & [39] \\
\hline
\end{tabular}

Table 1.

Rare-earth-based materials for photocatalytic application in the degradation of organic pollutants. 
Therefore light absorption with energy equal to or greater than the band gap of the material can cause an electron to be excited from the valence band to the conduction band [32]. These electrons and holes can be recombination with together that it is a major limiting factor to control its photocatalytic efficiency in the degradation of pollutant. Therefore, selection of material is a major challenge in heterogeneous photocatalysis that rare-earth-based nanostructure can be increased the efficiency of the photocatalysts [33]. To improve the efficiency of photocatalysis and reduce the recombination of electrons and holes, modification of rare-earth-based material is necessary. Therefore these materials have been doped with various transition metal ions [34]. The photocatalytic mechanism to degrade the pollutant contaminant may write as below [35]:

$$
\begin{aligned}
& \text { Prepared nanostructures }+\mathrm{hv} \rightarrow \text { Prepared nanostructures }\left(\mathrm{e}^{-}(\mathrm{CB})+\mathrm{h}^{+}(\mathrm{VB})\right) \\
& \mathrm{OH}^{-}+\mathrm{h}^{+}(\mathrm{VB}) \rightarrow \mathrm{OH}^{\cdot} \\
& \mathrm{O}_{2}+\mathrm{e}^{-}(\mathrm{CB}) \rightarrow \mathrm{O}_{2} \cdot{ }^{-} \\
& \mathrm{O}_{2}^{\cdot-}+\mathrm{H}^{+} \rightarrow \mathrm{HO}_{2} \cdot \\
& \mathrm{HO}_{2}{ }^{\cdot}+\mathrm{HO}_{2}^{\cdot} \rightarrow \mathrm{O}_{2}+\mathrm{H}_{2} \mathrm{O}_{2} \\
& \mathrm{H}_{2} \mathrm{O}_{2}+\mathrm{O}_{2}^{\cdot-} \rightarrow \mathrm{OH}^{\cdot-}+\mathrm{OH}^{\cdot}+\mathrm{O}_{2} \\
& \mathrm{OH}^{\cdot}+\text { Organic } \rightarrow \text { Intermediates } \rightarrow \mathrm{CO}_{2}+\mathrm{H}_{2} \mathrm{O}+\text { Products }
\end{aligned}
$$

\subsection{Photocatalytic applications}

Rare-earth-based materials are applied as catalysts in different industrial applications, e.g., petroleum refining (lanthanum chloride), automobile emission reduction (cerium oxide), organic polymerization (neodymium versatate), hydrogen and synthesis gas production (ceria, lanthania), plastics decomposition, and dechlorination (samarium iodide), solar thermochemical water splitting and photocatalytic reactions have been investigated thoroughly, especially for $\mathrm{La}^{-}, \mathrm{Ce}^{-}, \mathrm{Eu}^{-}$, and $\mathrm{Gd}^{-}$ modified materials [9].

The mixed oxide photocatalysts have attracted attention because of their abilities to remove pollutant or split water into $\mathrm{H}_{2}$ and $\mathrm{O}_{2}$ under solar irradiation. Among the mixed oxides, rare-earth-based materials contained mixed oxide photocatalysts are important, because the $4 \mathrm{f}$-levels of lanthanide elements play a key role in photocatalytic reactions. Some researches are shown in Table 1 that they include photocatalysts of rare-earth elements for degradation of organic pollutants. For example, Zinatloo et al. [13] synthesized $\mathrm{Nd}_{2} \mathrm{Sn}_{2} \mathrm{O}_{7}-\mathrm{SnO}_{2}$ nanocomposites as high-efficiency visible-light responsive photocatalyst through an environmentfriendly procedure (Green synthesis) using extract of pineapple. Extract of pineapple that employed in this research, is natural source of sugar (glucose as well as fructose) and harmless for the environment.

\section{Conclusions}

This book chapter includes the recent advances related to synthesis method and photocatalytic applications of rare-earth-based nanostructures. Several techniques for preparation of rare-earth-based nanostructures have been introduced to achieve nanostructure with desirable characterizes. 


\section{Author details}

Sahar Zinatloo-Ajabshir ${ }^{1 *}$ and Zahra Sayyar ${ }^{2}$

1 Department of Chemical Engineering, University of Bonab, Bonab, Iran

2 Faculty of Chemical Engineering, Sahand University of Technology, Tabriz, Iran

*Address all correspondence to: s.zinatloo@bonabu.ac.ir

\section{IntechOpen}

(C) 2019 The Author(s). Licensee IntechOpen. This chapter is distributed under the terms of the Creative Commons Attribution License (http://creativecommons.org/licenses/ by/3.0), which permits unrestricted use, distribution, and reproduction in any medium, provided the original work is properly cited. (cc) BY 


\section{References}

[1] Selvan RK, Gedanken A, Anilkumar P, Manikandan G, Karunakaran C.

Synthesis and characterization of rare earth orthovanadate $\left(\mathrm{RVO}_{4}\right.$; Rá = La, $\mathrm{Ce}, \mathrm{Nd}, \mathrm{Sm}, \mathrm{Eu} \& \mathrm{Gd}$ ) nanorods/ nanocrystals/nanospindles by a facile sonochemical method and their catalytic properties. Journal of Cluster Science. 2009;20:291-305

[2] Li L, Zhang M, Tian P, Gu W, Wang $\mathrm{X}$. Synergistic photocatalytic activity of $\mathrm{LnFeO}_{3}(\mathrm{Ln}=\mathrm{Pr}, \mathrm{Y})$ perovskites under visible-light illumination. Ceramics International. 2014;40:13813-13817

[3] Bingham S, Daoud WA. Recent advances in making nano-sized $\mathrm{TiO}_{2}$ visible-light active through rare-earth metal doping. Journal of Materials Chemistry. 2011;21:2041-2050

[4] Antolini E, Perez J. The use of rare earth-based materials in lowtemperature fuel cells. International Journal of Hydrogen Energy. 2011;36: 15752-15765

[5] Aguirre-Díaz LM, Snejko N, Iglesias M, Sánchez F, Gutiérrez-Puebla E, Monge MÁ. Efficient rare-earth-based coordination polymers as green photocatalysts for the synthesis of imines at room temperature. Inorganic Chemistry. 2018;57(12):6883-6892

[6] Marcì G, García-López EI, Palmisano L. Heteropolyacid-based materials as heterogeneous photocatalysts. European Journal of Inorganic Chemistry. 2014; 2014:21-35

[7] Zinatloo-Ajabshir S, Salavati-Niasari M, Sobhani A, Zinatloo-Ajabshir Z. Rare earth zirconate nanostructures: Recent development on preparation and photocatalytic applications. Journal of Alloys and Compounds. 2018;767: 1164-1185

[8] Anandan S, Ikuma Y, Murugesan V. Highly active rare-earth-metal La-doped photocatalysts: Fabrication, characterization, and their photocatalytic activity. International Journal of Photoenergy. 2012;2012: 921412

[9] Leduc J, Gönüllü Y, Raauf A, Fischer T, Mathur S. Rare-earth-containing materials for photoelectrochemical water splitting applications. In: Semiconductors and Semimetals. Vol. 97. United States: Elsevier; 2017. pp. 185-219

[10] Zinatloo-Ajabshir S, Salehi Z, Salavati-Niasari M. Green synthesis of $\mathrm{Dy}_{2} \mathrm{Ce}_{2} \mathrm{O}_{7}$ ceramic nanostructures using juice of Punica granatum and their efficient application as photocatalytic degradation of organic contaminants under visible light. Ceramics International. 2018;44:3873-3883

[11] Zinatloo-Ajabshir S, Morassaei MS, Salavati-Niasari M. Facile fabrication of $\mathrm{Dy}_{2} \mathrm{Sn}_{2} \mathrm{O}_{7}-\mathrm{SnO}_{2}$ nanocomposites as an effective photocatalyst for degradation and removal of organic contaminants. Journal of Colloid and Interface Science. 2017;497:298-308

[12] Zinatloo-Ajabshir S, Morassaei MS, Salavati-Niasari M. Nd2Sn2O7 nanostructures as highly efficient visible light photocatalyst: Green synthesis using pomegranate juice and characterization. Journal of Cleaner Production. 2018;198:11-18

[13] Zinatloo-Ajabshir S, Morassaei MS, Salavati-Niasari M. Facile synthesis of $\mathrm{Nd}_{2} \mathrm{Sn}_{2} \mathrm{O}_{7}-\mathrm{SnO}_{2}$ nanostructures by novel and environment-friendly approach for the photodegradation and removal of organic pollutants in water. Journal of Environmental Management. 2019;233: 107-119

[14] Zinatloo-Ajabshir S, MortazaviDerazkola S, Salavati-Niasari M. $\mathrm{Nd}_{2} \mathrm{O}_{3}$ nanostructures: Simple synthesis, characterization and its photocatalytic 
degradation of methylene blue. Journal of Molecular Liquids. 2017;234:430-436

[15] Zinatloo-Ajabshir S, MortazaviDerazkola S, Salavati-Niasari M. Simple sonochemical synthesis of $\mathrm{Ho}_{2} \mathrm{O}_{3}-\mathrm{SiO}_{2}$ nanocomposites as an effective photocatalyst for degradation and removal of organic contaminant. Ultrasonics Sonochemistry. 2017;39: 452-460

[16] Zinatloo-Ajabshir S, MortazaviDerazkola S, Salavati-Niasari M. Sonosynthesis and characterization of $\mathrm{Ho}_{2} \mathrm{O}_{3}$ nanostructures via a new precipitation way for photocatalytic degradation improvement of erythrosine. International Journal of Hydrogen Energy. 2017;42:15178-15188

[17] Zinatloo-Ajabshir S, MortazaviDerazkola S, Salavati-Niasari M. $\mathrm{Nd}_{2} \mathrm{O}_{3}$ $\mathrm{SiO}_{2}$ nanocomposites: A simple sonochemical preparation, characterization and photocatalytic activity. Ultrasonics Sonochemistry. 2018;42:171-182

[18] Zinatloo-Ajabshir S, Salavati-Niasari M. Nanocrystalline $\operatorname{Pr}_{6} \mathrm{O}_{11}$ : Synthesis, characterization, optical and photocatalytic properties. New Journal of Chemistry. 2015;39:3948-3955

[19] Zinatloo-Ajabshir S, Salavati-Niasari $\mathrm{M}$, Zinatloo-Ajabshir Z. $\mathrm{Nd}_{2} \mathrm{Zr}_{2} \mathrm{O}_{7^{-}}$ $\mathrm{Nd}_{2} \mathrm{O}_{3}$ nanocomposites: New facile synthesis, characterization and investigation of photocatalytic behaviour. Materials Letters. 2016; 180:27-30

[20] Zinatloo-Ajabshir S, ZinatlooAjabshir Z, Salavati-Niasari M, Bagheri $S$, Hamid SBA. Facile preparation of $\mathrm{Nd}_{2} \mathrm{Zr}_{2} \mathrm{O}_{7}-\mathrm{ZrO}_{2}$ nanocomposites as an effective photocatalyst via a new route. Journal of Energy Chemistry. 2017;26: 315-323

[21] Le Natur F, Calvez G, Daiguebonne C, Guillou O, Bernot K, Ledoux J, et al.
Coordination polymers based on heterohexanuclear rare earth complexes: Toward independent luminescence brightness and color tuning. Inorganic Chemistry. 2013;52:6720-6730

[22] Feng Y, Xin X, Zhang Y, Guo B, Li $\mathrm{F}$, Kong $\mathrm{X}$, et al. Rational design and synthesis of hexa-nuclear rare earth thea MOFs platform based on $\mathrm{Re}_{6} \mathrm{O}_{4}(\mathrm{OH})_{4}(\mathrm{COO})_{8}$ clusters. Crystal Growth \& Design. 2019;19(3):1509-1513

[23] Tong Y, Zhu J, Lu L, Wang X, Yang $X$. Preparation and characterization of $\mathrm{Ln}_{2} \mathrm{Zr}_{2} \mathrm{O}_{7}$ ( $\mathrm{Ln}=\mathrm{La}$ and $\mathrm{Nd}$ ) nanocrystals and their photocatalytic properties. Journal of Alloys and Compounds. 2008; 465:280-284

[24] Xiaoxia Z, Xiaojun W, Baojiu C, Qingyu M, Weihua D, Guozhong R, et al. Photoluminescence characteristics of $\mathrm{Gd}_{2} \mathrm{Mo}_{3} \mathrm{O}_{9}$ : Eu phosphor particles by solid state reaction method. Journal of Rare Earths. 2007;25:15-18

[25] Byrappa K, Adschiri T. Hydrothermal technology for nanotechnology. Progress in Crystal Growth and Characterization of Materials. 2007;53:117-166

[26] Li K, Wang H, Yan H. Hydrothermal preparation and photocatalytic properties of $\mathrm{Y} 2 \mathrm{Sn} 2 \mathrm{O} 7$ nanocrystals. Journal of Molecular Catalysis A: Chemical. 2006;249:65-70

[27] Tong Y, Zhao S, Feng W, Ma L. A study of Eu-doped $\mathrm{La}_{2} \mathrm{Zr}_{2} \mathrm{O}_{7}$ nanocrystals prepared by salt-assistant combustion synthesis. Journal of Alloys and Compounds. 2013;550:268-272

[28] Ziarati A, Sobhani-Nasab A, Rahimi-Nasrabadi M, Ganjali MR, Badiei A. Sonication method synergism with rare earth based nanocatalyst: Preparation of $\mathrm{NiFe}_{2}-\mathrm{xEuxO}_{4}$ nanostructures and its catalytic applications for the synthesis of benzimidazoles, benzoxazoles, and 
benzothiazoles under ultrasonic irradiation. Journal of Rare Earths. 2017; 35:374-381

[29] Duarte W, Meguekam A, Colas M, Vardelle M, Rossignol S. Effects of the counter-cation nature and preparation method on the structure of $\mathrm{La}_{2} \mathrm{Zr}_{2} \mathrm{O}_{7}$. Journal of Materials Science. 2015;50: 463-475

[30] Kong L, Karatchevtseva I, Gregg DJ, Blackford MG, Holmes R, Triani G. A novel chemical route to prepare $\mathrm{La}_{2} \mathrm{Zr}_{2} \mathrm{O}_{7}$ pyrochlore. Journal of the American Ceramic Society. 2013;96: 935-941

[31] Mahdiani M, Sobhani A, SalavatiNiasari M. Enhancement of magnetic, electrochemical and photocatalytic properties of lead hexaferrites with coating graphene and CNT: Sol-gel autocombustion synthesis by valine.

Separation and Purification Technology. 2017;185:140-148

[32] Zou Z, Ye J, Arakawa H. Role of R in $\mathrm{Bi}_{2} \mathrm{RNbO}_{7}(\mathrm{R}=\mathrm{Y}$, rare earth): Effect on band structure and photocatalytic properties. The Journal of Physical Chemistry B. 2002;106:517-520

[33] El-Bahy ZM, Ismail AA, Mohamed RM. Enhancement of titania by doping rare earth for photodegradation of organic dye (direct blue). Journal of Hazardous Materials. 2009;166: 138-143

[34] Liang C-H, Li F-B, Liu C-S, Lü J-L, Wang X-G. The enhancement of adsorption and photocatalytic activity of rare earth ions doped $\mathrm{TiO} 2$ for the degradation of Orange I. Dyes and Pigments. 2008;76:477-484

[35] Zinatloo-Ajabshir S, Salehi Z, Salavati-Niasari M. Preparation, characterization and photocatalytic properties of $\mathrm{Pr}_{2} \mathrm{Ce}_{2} \mathrm{O}_{7}$ nanostructures via a facile procedure. RSC Advances. 2016;6:107785-107792
[36] Li L, Wang X, Lan Y, Gu W, Zhang

S. Synthesis, photocatalytic and electrocatalytic activities of wormlike $\mathrm{GdFeO}_{3}$ nanoparticles by a glycolassisted sol-gel process. Industrial and Engineering Chemistry Research. 2013; 52:9130-9136

[37] Zinatloo-Ajabshir S, Salehi Z, Salavati-Niasari M. Green synthesis and characterization of $\mathrm{Dy}_{2} \mathrm{Ce}_{2} \mathrm{O}_{7}$

nanostructures using Ananas comosus with high visible-light photocatalytic activity of organic contaminants. Journal of Alloys and Compounds. 2018; 763:314-321

[38] Zinatloo-Ajabshir S, Salehi Z, Salavati-Niasari M. Green synthesis and characterization of $\mathrm{Dy}_{2} \mathrm{Ce}_{2} \mathrm{O}_{7}$ ceramic nanostructures with good photocatalytic properties under visible light for removal of organic dyes in water. Journal of Cleaner Production. 2018;192: 678-687

[39] Zinatloo-Ajabshir S, Mortazavi-

Derazkola S, Salavati-Niasari M. Schiffbase hydrothermal synthesis and characterization of $\mathrm{Nd}_{2} \mathrm{O}_{3}$ nanostructures for effective photocatalytic degradation of eriochrome black $\mathrm{T}$ dye as water contaminant. Journal of Materials Science: Materials in Electronics. 2017; 28:17849-17859 



\title{
Radiative Transference Equation Algorithm as an ANSYS $®$ User-Defined Function for Solar Technology Applications
}

\author{
Diana Barraza-Jiménez, Adolfo Ruiz-Soto, \\ Sandra Iliana Torres-Herrera, Elva Marcela Coria-Quiñones, \\ Raúl Armando Olvera-Corral, David José Romero-Soto \\ and Manuel Alberto Flores-Hidalgo
}

\begin{abstract}
Heat effects in photocatalytic reactor applications are discussed and a case study is analyzed where sunlight is used to activate a chemical reaction to degrade water pollutants. Heat is produced in the light-capturing process, and heat effects need to be better understood during the device design process. Radiative transfer equation (RTE) is the guiding equation used to calculate radiation proliferation in participating media, and it is used to describe the balance of radiative energy transport in the participating media including the interactions caused by different processes such as absorption, scattering, and emission, which also are subject to additional phenomena like weakening and magnification. This equation plays an important role in the design process since it may be included in the simulation process to represent the sunlight heat effects in the different photocatalytic reactor components. In this chapter, it is explained how to build a simplified algorithm to incorporate the RTE in a numerical calculation during the design of a photocatalytic reactor using the commercial software ANSYS $®$. In addition, simplifications are explained that enable the program to coordinate some coefficients such as absorption and dispersion so their effects are included within the numerical calculation. A user-defined function is presented in the end of the chapter as a usable algorithm in ANSYS ${ }^{\circ}$ program with acceptable results for photocatalytic reactors.
\end{abstract}

Keywords: radiative transfer equation, light source energy, radiation energy, ANSYS ${ }^{\circledR}$, photocatalysis

\section{Introduction}

Solar technology includes a wide variety of developments in environmental applications that include photovoltaic cells and photocatalytic devices, among others. Sunlight produces heat that affects the devices, components, and different processes that are carried on. The main interest in this proposal is approach heat 
effects in photocatalytic reactor applications where sunlight is used to activate a chemical reaction to degrade water pollutants. Heat is produced in the lightcapturing process, and heat effects need to be better understood during the device design process $[1,2]$.

Radiative transfer equation (RTE) is the guiding equation used to calculate radiation proliferation in participating media, and it is used to describe the balance of radiative energy transport in the participating media including the interactions caused by different processes such as absorption, scattering, and emission which also are subject to additional phenomena like weakening and magnification $[3,4]$. This equation plays an important role in the design process since it may be included in the simulation process to represent the sunlight heat effects in the different photocatalytic reactor components. In this chapter, it is explained how to build a simplified algorithm to incorporate the RTE in a numerical calculation during the design of a photocatalytic reactor using the commercial software ANSYS Fluent ${ }^{\circledR}$ [5]. This represents a numerical solution of one of the possible presentations of the RTE that can be easily programmed and incorporated in extensive calculations. In addition, simplifications are explained which enable the program to coordinate some coefficients such as absorption and dispersion so their effects are included within the numerical calculation. A user-defined function is presented in this chapter as a usable algorithm in ANSYS ${ }^{\circledR}$ program with acceptable results for photocatalytic reactors.

Simplifications have been done in order to focus on reaching the main goal of this chapter which is study the requirements to have a programmed UDF that resolves the radiation transfer energy equation. It is difficult to find out a generalized program so this chapter will assume the mathematical model applies for a photocatalytic reactor with a light source so the light energy is transferred into the system of study. There might be a transparent wall that the light needs to go through as well as water or polluted water as the fluid media. Above all, the goal is simplifying as much as possible the mathematical model and developments within the chapter in order to focus in an analysis on how to program RTE equation.

The program will be written similarly compared to $C$ language, but the language is considered a property of ANSYS $\AA$ but more specifically in ANSYS Fluent ${ }^{\circledR}$. That means the programming language is its own language for ANSYS Fluent ${ }^{\circledR}$, but it follows a syntaxis and structure very similar to $C$ language. It is highly recommended to have $C$ language programming skills and ANSYS Fluent ${ }^{\circledR}$ userdefined functions training. These skills may be achieved after one is an advanced user in ANSYS Fluent ${ }^{\circledR}$ so the programming can be coupled with CFD calculations and then the problem at hand with hydrodynamics numerical results will be complemented with light source effects, which at the end is the main purpose of this chapter.

\section{Radiative energy basic concept}

As we shall see, radiative heat transfer rates are generally proportional to differences in temperature to the fourth (or higher) power, i.e.,

$$
q \propto T^{4}-T_{\infty}^{4}
$$

Then, if temperature rises, radiative heat transfer relevance grows and may become the dominant factor over conduction and convection phenomena at very high temperatures. In this way, one may understand thermal radiation is a meaningful factor in combustion applications (fires, furnaces, rocket nozzles, engines, 
and others) and in nuclear reactions (such as in a fusion reactor or in nuclear bombs), during atmospheric reentry of space vehicles, among others. Since contemporary technology's main goal is an increased efficiency, it is expected temperature will increase accordingly, and this situation will reflect in making thermal radiation even more important. In addition, emergent applications gaining importance are solar energy and greenhouse effect (both as a result of our sun's heating effects). Derived from the previous effects, one of the human kind problems in these days is global warming which is provoked by solar energy absorption mainly by carbon dioxide released into our atmosphere primarily by fuel burning technological devices created by men.

In the same way that factors such as vacuum and high temperature become more important for thermal radiation effects, also the analysis methodology to study thermal radiation becomes more complicated or at least requires to involve additional aspects if compared to analyses in normal conditions. One can say, in general, thermal radiation is a comprehensive matter to analyze. The average distance traveled by a photon previously to interact with a molecule is also known as the photon mean free path may be as short as $10^{-10} \mathrm{~m}$ (absorption process) but may be very long in the possible maximum distance reaching up to $10^{+10} \mathrm{~m}$ or even more (e.g., sunlight over the Earth's surface). Then, it is natural to conclude conservation of energy will not be applicable on an infinitesimal volume, but must be applied on the entire volume of interest. Therefore, an integral equation with seven independent variables (radiation frequency, three space coordinates, two coordinates to define photons travelling direction, and time) may be proposed.

The effects caused by the radiative properties of materials complicate even more the thermal radiation analysis. Measuring the radiative properties is usually difficult and displays erratic behavior most of the times. Properties for liquids and solids depend on a really thin surface layer, so it is natural that these properties may be affected if there is a surface preparation for this purpose and then the properties may change when this occurs. When it refers to gases, all radiative properties may vary by much with wavelength if another dimension is added to the governing equation. It may be assumed as well that this equation is nonlinear and rarely can be considered otherwise. There are different methods to solve the governing energy equation for radiative transport but escape the scope of this chapter, and the reader is referred to related literature such as whole books that deal with the mathematical details of this equation.

\section{Radiative energy transfer equation}

The radiative equation has different applications, for example, in aerospace, physics, and astrophysics. Fundamentally, this equation describes a field of radiation called spectral radiance in radiometric terms.

For example, to determine the radiative flux onto a surface (or at any point inside the medium) requires knowledge of the radiative intensity at that point, for all directions and for all wavelengths or wavenumbers. In an application such as a photocatalytic reactor, the importance of energy relates to the intensity field inside a participating medium that is governed by the radiative transfer equation, which is a radiative energy balance along a thin group of rays, but for a medium that emits, absorbs, and/or scatters radiation.

The equation of radiative transfer describes mathematically interactions derived from the propagation of radiation through a medium that means that phenomena such as absorption, emission, and scattering processes are contained in an equation. 
The radiative transfer equation (RTE) describes the radiation intensity $I_{\kappa}$ at any position along a ray path through a medium. This equation can be applied to evaluate the radiation field in the heterogeneous system constituted by a photocatalyst particulate suspension in water. RTE equation may be presented in different forms; in our case we are interested in the application for a photocatalytic reactor. In such application the energy of a light source is used to activate a photocatalyst that will participate in the chemical degradation of a pollutant in water. In a reactor like this one, the energy path starts at the light source, passes through a transparent wall that may be a glass or quartz or similar, and then travels through polluted water until the energy reaches the photocatalyst. Then, for a participating medium, with absorption and scattering (no emission is considered), the RTE can be written as

$$
\frac{d I_{K \Omega}}{d s}=\underbrace{-k_{y} I_{K, \Omega}}_{\text {Absorption }}-\underbrace{\sigma_{K} I_{K, \Omega}}_{\substack{\text { Outgong } \\ \text { dispersion }}}+\underbrace{\frac{\sigma_{\Lambda}}{4 \pi} \int_{\Omega^{\prime}=4 \pi} p\left(\Omega^{\prime} \rightarrow \Omega\right) I_{K, \Omega^{\prime}} d \Omega^{\prime}}_{\text {incoming dispersion }}
$$

where $\mathrm{I}_{\kappa, \Omega}$ is the intensity of photons with wavelength $\kappa$, propagated in the direction $\Omega, k_{\kappa}$ is the volumetric absorption coefficient, $\sigma \kappa$ is the volumetric dispersion coefficient, and $p\left(\Omega^{\prime}, \rightarrow \Omega\right.$, ) is the phase function that describes the dispersed radiation direction distribution.

\section{Numerical solution for radiative energy problems}

Therefore, there are systems or devices where radiative heat transfer becomes more important with rising temperature levels and may be totally dominant over conduction and convection at very high temperatures. Resolution of RTE equation is complex for real systems such as a photochemical reactor. There are different approaches to resolve this equation from making assumptions of ideality for the system or using empirical data. Let's discuss how can a resolution be reached next.

\subsection{An approach to solve RTE}

Analytic solutions to the radiative transfer equation (RTE) exist for simple cases, but for more realistic media, with complex multiple scattering effects, numerical methods are required. Before reaching the numerical method approach, one may notice that in order to resolve Eq. (2), the volumetric scattering coefficient $\sigma_{\kappa}$ and the phase function that describes the directional distribution of scattered radiation $p$ $\left(\Omega^{\prime} \rightarrow \Omega\right)$ are needed mainly due to the volumetric absorption coefficient $\kappa_{\kappa}$, which displays strong spectral dependence. From this calculation, the intensity of photons with wavelength $\Lambda$ propagated along direction $\Omega$, and $I_{\kappa, \Omega}$ is the result that may be obtained. An integral on all the spatial directions may be used to account for the whole radiation field for any point of the reactor space, and by multiplying this value by the absorption coefficient, one may obtain the local volumetric rate of energy absorption (VREA).

\subsection{Discrete ordinate method and numerical solution}

Resolution of RTE may be reached using a numerical technique known as the discrete ordinate method (DOM). An advantage to use DOM is that this method is incorporated in ANSYS Fluent ${ }^{\circledR}$. This method solves the RTE for a finite number of discrete solid angles, each one associated with a vector direction. For the case where 


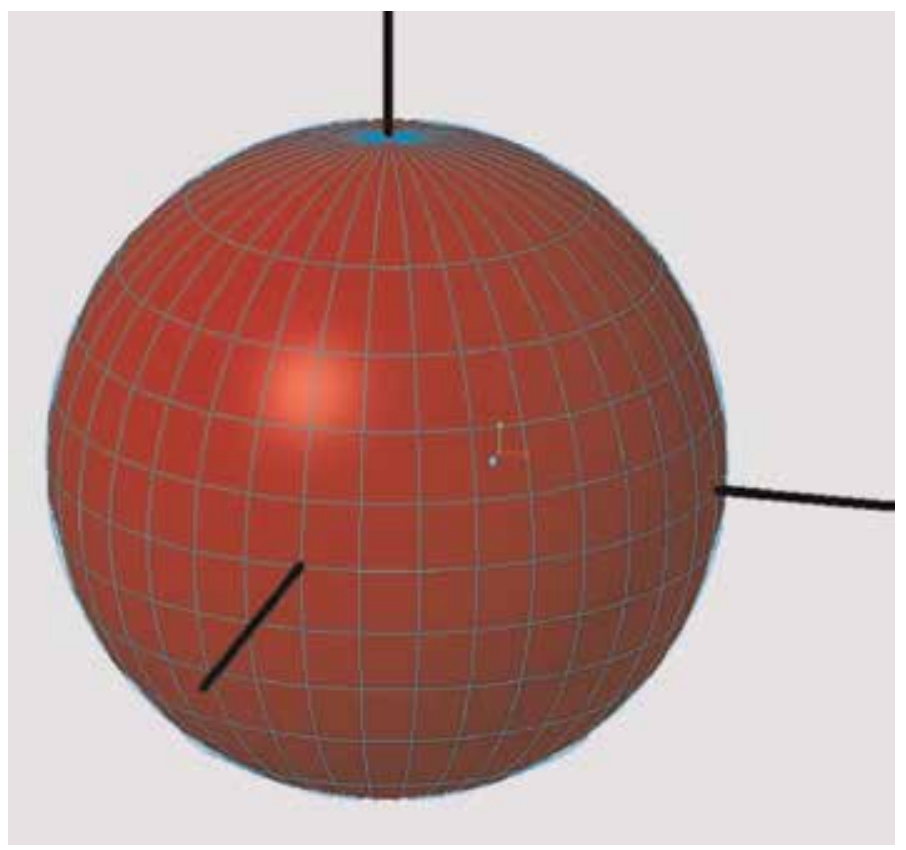

Figure 1.

Geometry assuming a spherical shape with an $n \times m$ control elements division of $10 \times 10$ for numerical calculations using DOM.

a computational tool such as ANSYS Fluent ${ }^{\circledR}$ is used, the spatial discretization of the computational region of interest may be taken from the mesh grid created during the discretization step required by this program. However, the directional discretization for the RTE has to be specified using an angular discretization of the sphere octant of $m \times n$ divisions (divisions should be enough to avoid the wellknown "ray effect") and $p \times q$ pixelation (enough to overcome angle overhanging). ANSYS Fluent ${ }^{\circledR}$ has more models for radiation calculation incorporated that may be more simplified than DOM, but the discrete ordinate method is able to define optical processes considering wavelength; also, it considers dispersion effects, absorption, and emission of radiation in media and surfaces.

DOM may be able to resolve RTE based on a finite number of discrete solids with an angle and direction which may be related with a vector. ANSYS Fluent ${ }^{\circledR}$ provides this information by means of the meshing process which contains region location data needed by DOM, but direction of discretization for RTE evaluation should be specified by the user by means of an angular discretization. To address the direction of discretization, each octant in the $4 \pi$ angular space may be discretized in $N_{\theta p} \times N_{\phi p}$ control angles. These angles relate with polar and azimuthal directions and are fundamental for RTE resolution. Figure 1 displays an example of control elements.

Each control element may be subdivided $N_{\theta p} \times N_{\phi p}$ for a bigger discretization, and calculations will refer to the pixels generated either for incoming or outgoing energy. This is an optional technique to obtain a further division of the surface in case it is required.

\subsection{Programming a numerical method to resolve RTE}

Programming a method to resolve the RTE is a way to carry on with a numerical solution. There are different options to program the RTE; among the more common choices may be MATLAB which is a numerical computation system by itself with its 
own language, Fortran, $\mathrm{C}, \mathrm{C}_{++}$, and ANSYS ${ }^{\circledR}$, among others. The programming that will be displayed in the next paragraphs is built for ANSYS Fluent ${ }^{\circledR}$ so it needs some $\mathrm{C}$ or $\mathrm{C}_{++}$knowledge because even though ANSYS Fluent ${ }^{\circledR}$ is considered to use its own language, it is similar to $\mathrm{C}$ or $\mathrm{C}_{++}$given that ANSYS Fluent ${ }^{\circledR}$ itself was built in that language.

This chapter does not intent to educate the reader in programming but assumes some basic knowledge is needed in order to keep up with the next paragraphs. Also, there is some knowledge in ANSYS Fluent ${ }^{\circledR}$ needed; more likely, the reader might need to be an advanced user of this program since we will mention briefly some of the basics only when it is absolutely needed.

Some essential comments related to programming C language are included because it is relevant to understand UDFs in ANSYS Fluent ${ }^{\circledR}$. These comments are really basic because they are intended to provide only a hint to the reader, but a $\mathrm{C}$ language programming book is highly recommended. So, in this context, this chapter will not cover important $\mathrm{C}$ programming topics such as while and do-while, unions, cycles, structures, and reading and writing files. For further developing your programming skills, one may consult a C book or guide $[6,7]$; this is highly recommended before starting to build or program your own UDFs.

\subsection{Programming and user-defined functions}

The ANSYS Fluent ${ }^{\circledR}$ has a tool to input complementary code with customized functions or actions. This complementary code is known in ANSYS ${ }^{\circledR}$ user manual as user-defined functions (UDFs). User-defined functions are the more common tool to customize calculations in ANSYS Fluent ${ }^{\circledR}$; however, programming a UDF is complicated, and it is considered an advanced skill for users of ANSYS Fluent ${ }^{\circledR}$.

A UDF, in short, is a $\mathrm{C}$ or $\mathrm{C}++$ small program that acts as a function so it can be easily loaded in the ANSYS Fluent ${ }^{\circledR}$ solver with the intention of enhancing its standard features. For example, a UDF may be used to:

- Specify boundary conditions, material properties, surface and volume reaction rates, source terms in ANSYS Fluent ${ }^{\circledR}$ transport equations, user-defined scalar (UDS) for source terms in transport equations, and diffusivity functions, among others.

- Once per iteration adjustment of specific computed values.

- Solution initialization.

- Execution of a UDF performs asynchronous calculations as required.

- End of an iteration function execution, computations after exiting from ANSYS Fluent ${ }^{\circledR}$, or after loading a compiled library.

- Additional capabilities or computations during postprocessing.

- Additional capabilities or computations from existing ANSYS Fluent ${ }^{\circledR}$ models (additional to mathematical models already loaded like discrete phase model, multiphase mixture model, discrete ordinates radiation model).

For further knowledge in UDFs, the reader is referred to literature produced by ANSYS ${ }^{\circledR}$ or specialized books [8]. 
From the authors perspective, a UDF is a C program conformed by a set of macros developed specifically for ANSYS Fluent ${ }^{\circledR}$; such macros may be considered small pieces of the program or built in functions specially for ANSYS Fluent ${ }^{\circledR}$. If one takes a look at a UDF, a code will be able to identify a program in $\mathrm{C}_{\text {or }} \mathrm{C}_{++}$, but very few lines will be purely these languages because most lines are macros specifically developed for ANSYS Fluent ${ }^{\circledR}$. Then, in conclusion, if one looks at the content of an UDF, he or she will find a few lines purely programmed in C plus a series of macros built in to work only in ANSYS Fluent ${ }^{\circledR}$ all of them ready to add up a specific computation complementary to ANSYS Fluent ${ }^{\circledR}$ capabilities.

\subsection{Coupling the UDF to a multiphysics program suite}

The UDF will provide the steps to numerically resolve RTE, but there is an important action that needs to be carefully performed, and that is the coupling of the UDF in the ANSYS Fluent ${ }^{\circledR}$. The general theory in UDF development says a user-defined function may be programmed to execute steps in different stages of the problem numerical resolution. In this case, the need to resolve the RTE equation relies in the need to find out numerically the light energy influence in a photocatalytic reactor. To accomplish this purpose, the UDF will execute after hydrodynamic calculations have been completed.

Then, after the UDF is available, the user will have to perform a compilation of the program to make sure the syntaxis is correct. After compilation, the UDF is ready to be loaded into the Multiphysics program in this case ANSYS Fluent ${ }^{\circledR}$. In fact, the compilation process is also performed within ANSYS Fluent ${ }^{\circledR}$ as well as the loading process where the UDF is coupled to the main code.

A last recommendation after the UDF is compiled and loaded into ANSYS Fluent ${ }^{\circledR}$ is to perform testing runs of the problem numerical resolution to make sure the UDF works well and is returning good numerical results.

\section{User-defined functions to resolve the RTE}

In this section, examples of UDFs that can be used to resolve numerically the RTE are presented.

\subsection{UDF used to resolve the Henyey-Greenstein phase function}

As mentioned in prior paragraphs, it is needed to resolve the phase function. Since the selected phase function was the Henyey-Greenstein, it is needed to develop a UDF to have this function resolved. Next, a proposed UDF to resolve this function in pretty basic terms is shown [9]. Additional comments have been added to explain further the purpose of the programmed line. In each line or command, or cycle, or macro, the user may add comments to help out understand the UDF design intent during possible reviews, corrections, tests, improvement, etc. In these examples, comments are added for didactic reasons but in a professional UDF if may be recommended much less comments and limited to explain the more relevant parts of the program. A solution for the selected phase function was the HenyeyGreenstein which is displayed in Table 1.

\subsection{UDF to resolve radiation transfer from a light source}

This UDF represents a numerical solution to the energy transfer from a light source to a reactor. The skeleton of this UDF was recycled from the Sandia National 
$/^{*}$ Dear all: this is a UDF built specifically to resolve the

Henyey-Greenstein phase function for thermal radiation calculations ${ }^{*} / /^{*}$ comments section*/

\#include"udf.h" /* command to initiate a udf*/

DEFINE_SCAT_PHASE_FUNC(hgscat,c,f) $/ *$ DEFINE is a macro* $/$

$\left\{I^{*}\right.$ Command to start a computation* ${ }^{*}$

real $\mathrm{p}=0 . ; /^{*}$ set up a data type ${ }^{*} /$

real $\mathrm{g}=0.5161 ; /^{*}$ set up a data type $\mathrm{H}^{*}$

$\mathrm{p}=(1-\operatorname{pow}(\mathrm{g}, 2.0)) / \operatorname{pow}\left(\left(1+\mathrm{g}^{*} \mathrm{~g}-2^{*} \mathrm{~g}^{*} \mathrm{c}\right), 1.5\right) ; I^{*}$ Equation for calculation* ${ }^{*}$

return $(\mathrm{p}) ; /^{*}$ output $*$

\} $/^{*}$ Command to end a computation */

Table 1.

Proposed UDF to resolve the Henyey-Greenstein phase function.

$I^{*}$ Tested UDF to integrate UV intensity over time along a particle trajectory. */

$l^{*}$ When volume fraction is very small and a cell is reached particles are deleted from the domain * $/$

$/{ }^{*}$ Low dosed particles are identified and residence times are obtained at the reactor outlet. ${ }^{*} /$

${ }^{*}$ comments section* $/$

\#include "udf.h" /* command to initiate a udf*/

\#include "dpm.h" /* command to call a udf*/

\#include "sg_disco.h" /* command to access cell UV intensity values*/

\#define C_DO (c,t)C_STORAGE_R_XV (c,t,SV_DO_IRRAD,0) /* DEFINE is a macro*/

\#define fdout "doseout.txt" /* DEFINE is a macro*/

\#define ftrack "trackfilters.txt" /* DEFINE is a macro*/

\#define ftime "restime.txt" / DEFINE is a macro*/

FILE * pdout; $/ *$ use file*/

FILE * ptrack; /* use file*/

FILE *ptime; /* use file*/

static real uv_intensity;

$I^{*}$ This macro integrates UV intensity over time along a particle trajectory */ /* comments section* $/$

$/^{*}$ This macro writes the UV dosage, residence time and ID for low dosed particles at reactor outlet. ${ }^{*} /$ / $^{*}$ comments section*/

DEFINE_DPM_OUTPUT(uv_output, header, fp, p, thread, plane) /* Define macro, variable set up*/ \{

if (header) $/ *$ if-else loop*/

\{

\}

else

\{

$I^{*}$ write the dosage values $* / I^{*}$ comments* $/$

pdout=fopen(fdout,"a"); $/^{*}$ delete previous files $* / /^{*}$ data type, comments $*$

fprintf(pdout,"\%10.6g In",p->user[0]); /* output, comments*

fclose(pdout); /* end computation* $/$

$I^{*}$ write the particle id of low dosed particles $* / /{ }^{*}$ comments $*$

ptrack=fopen (ftrack,"a"); /* delete previous files */ /* datatype, comments*

if $(\mathrm{p}->$ user $[0]<30.0) / *$ change this value accordingly $* / /^{*}$ if-else loop, comments $*$

\{

fprintf(ptrack,"\%d,",p->part_id); /* output, calculations*/

\}

fclose(ptrack); $/^{*}$ end computation* $/$

$I^{*}$ write the particle residence times $* /{ }^{*}$ comments $* /$

ptime=fopen (ftime,"a"); /* delete previous files $* / /^{*}$ data, calculation, comments $*$

fprintf(ptime,"\%10.6g In",p->st ate.time); /* output, calculations*/

fclose(ptime); /* end computation*/

\}

\}

Table 2.

Proposed UDF to resolve the effects of a light source radiation energy to the reactor passing through transparent media, in our case, polluted water. 
Laboratories website. It was updated to suit the open channel flow application and new features were added [10]. Additional comments have been added to explain further the purpose of the programmed line. Table 2 displays a UDF to resolve the radiation energy as a result of the emission of a light source.

\section{Conclusions}

The mathematical model for numerical calculations of the effects of light into a photocatalytic reactor is discussed. Despite the difficulty of a generalized method, it is reached the goal on presenting a study of the requirements to have a programmed UDF that resolves the radiation transfer energy equation. Due to the difficulty to find out a generic code applicable in all situations, for this chapter, one may assume the mathematical model applies for a photocatalytic reactor with an external light source so the light energy is transferred into the system of study. There is a transparent wall that the light needs to go through as well as water or polluted water as the fluid media. For such system, the process to obtain a UDF that calculates numerically the effects of the light source in the reactor is explained. The program was written similarly compared to $C$ language, but the language is considered a property of ANSYS ${ }^{\circledR}$ or more specifically in ANSYS Fluent ${ }^{\circledR}$. That means the programming language is its own language for ANSYS Fluent ${ }^{\circledR}$, but it follows a syntaxis and structure very similar to $\mathrm{C}$ language. It is highly recommended to develop $C$ language programming skills and ANSYS Fluent ${ }^{\circledR}$ user-defined function training. These skills may be achieved after one is an advanced user in ANSYS Fluent ${ }^{\circledR}$ so the programming can be coupled with CFD calculations and then the problem at hand with hydrodynamics numerical results will be complemented with light source effects, which at the end is the main purpose of this chapter. The UDFs presented are displayed so the reader can understand its purpose and take advantage to develop their own program.

\section{Acknowledgements}

This work was financed by CONACyT (Mexican Science and Technology National Council) through 2015 CONACyT SEP-CB (Basic Science-Public Education Ministry) project fund 258553/CONACyT/CB-2015-01. Thanks go to the Scientific Computing Laboratory at FCQ-UJED for computational resources. Thanks go to the Academic Group UJED-CA-129 for valuable discussions.

\section{Conflict of interest}

The authors state that this research was completed without any conflicts of interest related with funding to develop the present work. 


\section{Author details}

Diana Barraza-Jiménez ${ }^{1}$, Adolfo Ruiz-Soto ${ }^{1,3}$, Sandra Iliana Torres-Herrera ${ }^{2}$, Elva Marcela Coria-Quiñones ${ }^{1,3}$, Raúl Armando Olvera-Corral ${ }^{1}$, David José Romero-Soto ${ }^{1}$ and Manuel Alberto Flores-Hidalgo ${ }^{1 *}$

1 Faculty of Chemistry Science, Juarez University of Durango State, Durango, Mexico

2 Faculty of Forestry Science, Juarez University of Durango State, Durango, Mexico

3 TecNM/Durango Institute of Technology, Durango, Mexico

*Address all correspondence to: maflores.hidalgo02@gmail.com

\section{IntechOpen}

(C) 2019 The Author(s). Licensee IntechOpen. This chapter is distributed under the terms of the Creative Commons Attribution License (http://creativecommons.org/licenses/ by/3.0), which permits unrestricted use, distribution, and reproduction in any medium, provided the original work is properly cited. (c) BY 
Radiative Transference Equation Algorithm as an ANSYS® User-Defined Function for Solar... DOI: http://dx.doi.org/10.5772/intechopen.88767

\section{References}

[1] Moreno J, Casado C, Marugán J. Improved discrete ordinate method for accurate simulation radiation transport using solar and LED light sources. Chemical Engineering Science. 2019; 205:151-164

[2] Satuf ML, Brandi RJ, Cassano AE, Alfano OM. Experimental method to evaluate the optical properties of aqueous titanium dioxide suspensions. Industrial and Engineering Chemistry Research. 2005;44:

6643-6649

[3] Schneider J, Bahnemann D, Ye J, Puma GL, Dionysiou DD.

Photocatalysis: Fundamentals and Perspectives. Cambridge, UK: Royal Society of Chemistry; 2016. pp. 351-366. ISBN: 978-1-78262-041-9

[4] Modest MF. Radiative Heat Transfer. 3d ed. Oxford, UK: Elsevier Inc; 2013. DOI: 10.1016/C2010-0-65874-3. ISBN: 978-0-12-386944-9

[5] ANSYS Fluent ${ }^{\circledR}$ Academic Research CFD; Release 19.1

[6] Kernighan B, Ritchie D. The C Programming Language. 2nd ed. New Jersey, USA: Prentice-Hall; 1988. ISBN: 0-13-110370-9

[7] Stephen GK. Practical Programming in C. 3rd ed. Indianapolis, USA: Sams Publishing; 2005. ISBN: 0-672-32666-3

[8] ANSYS® INC. ANSYS Fluent ${ }^{\circledR}$. Customization Manual; 2017

[9] Casado C, Marugán J, Timmers R, Muñoz M, van Grieken R.

Comprehensive multiphysics modeling of photocatalytic processes by computational fluid dynamics based on intrinsic kinetic parameters determined in a differential photoreactor. Chemical Engineering Journal. 2017;310(P2):

368-380

[10] Rajib Kumar S. Numerical simulation of an open channel ultraviolet waste-water disinfection reactor [thesis and dissertation repository]. Electronic; 2013. 1450 p. Available from: https://ir.lib.uwo.ca/ etd $/ 1450$ 



\title{
Chapter 7
}

\section{Effect of Annealing on Metal-Oxide Nanocluster}

\author{
Naorem Khelchand Singh and Rajshree Rajkumari
}

\begin{abstract}
Recently, the development of optoelectronic devices based on metal-oxide nanocluster has attracted intensive research interest. Nanoclusters are suitable for these because of their large surface-to-volume ratio and the presence of abundant oxygen vacancies or trap states. Metal-oxides such as $\mathrm{ZnO}, \mathrm{In}_{2} \mathrm{O}_{3}$, and $\mathrm{TiO}_{2}$ synthesized using different technique produces high surface area films consisting of clusters and provides complete control over the film morphology. In this chapter, some of the metal oxides nanocluster film has investigated, and the effect of annealing on the structural, optical and electrical properties of the grown films when subjected to different annealing temperatures will be studied. Theoretically, these properties are presumed to improve after the heat treatment as the crystallinity, and the grain size of the film has increased due to the diminishing of oxygen vacancies. Thus, the greater surface-to-volume ratio, the better stoichiometry and higher level of crystallinity compared to bulk materials make nanocluster-based devices very promising for the mentioned application.
\end{abstract}

Keywords: nanomaterials, metal oxide semiconductor nanomaterials, fabrication technique, heat treatment, nano-devices

\section{Introduction}

Surface area and quantum confinement effects are the two important key factors that cause the properties of nanomaterials to differ significantly from the normal bulk materials. Among those nanomaterials, the metal oxide nanoparticles /nanoclusters exhibit unique physical and chemical properties due to their high surface area and nanoscale size. As the particle decreases, a greater amount of atoms are found at the surface compared to those inside. The particle size is influenced to the structural characteristics namely the lattice symmetry and cell parameter) as well as electronic properties in any material. Metal oxide nanocluster finds its promising applications in optical and sensors [1], optoelectronics [2], photocatalysts [3] and biomedical applications [4]. Till now, there have been a considerable number of reports for the fabrication of various metal oxide nanocluster, such as $\mathrm{ZnO}$ [5-8], $\mathrm{TiO}_{2}[1,3,9], \mathrm{SnO}_{2}$ [10-13], $\mathrm{In}_{2} \mathrm{O}_{3}$ [14-16], $\mathrm{CuO}_{2}$ [17-19], $\mathrm{WO}_{3}[20,21]$. The reported technique for the synthesis includes (a) physical synthesis such as pulsed laser deposition [5], glancing angle deposition [2], cluster beam deposition [22], and others; (b) chemical synthesis such as sol-gel [9], hydrothermal decomposition [18], and others; (c) biological synthesis using agro wastes, algal media, plant extract, fungi, yeast, and others. 
Metal oxide nanocluster in the context of high-performance optoelectronic devices based entirely on the structural, optical and electrical properties. The electrical conductivity of the device strongly depends on the surface defects, grain boundary, surface adsorbed oxygen and unsaturated dangling bonds. In fact, metal oxide nanocluster contains a considerable number of point and surface defects associated with the deviation from the stoichiometric composition. Moreover, the generation of oxygen vacancies in metal oxide nanocluster hampers the efficiency and accuracy of the device. So, in order to reduce the deformation in the surface structure and high defect density related to oxygen vacancies, heat treatment is necessary. Many studies reported on synthesizing metal oxide nanocluster followed by annealing in the different atmosphere. They have shown that annealing at an optimal temperature obtained smooth surfaces, reduced structural defects and improved the crystallinity of the metal oxide nanocluster. Owing to the high surface area of nanocluster, most of the atoms, dangling bonds, and local atomic defects exist at the surfaces texture of nanocluster rather than the inner cores. So, the surface of the nanocluster is unstable and has high chemical activity with a strong tendency to adsorb atoms from the surrounding environments. This active surface area is an essential factor in determining the detection limits or sensitivity. Aluri et al. have demonstrated highly selective and ultra-high sensitive sensors by functionalizing the $\mathrm{TiO}_{2}$ nanoclusters on the $\mathrm{GaN}$ nanowire [23]. The deformation in the surface structure and the local defects acquire a vital role in the optical properties by creating energy bands in the band gap region which is an undesired scope in the field of optoelectronics application. Therefore, we expected that the annealing treatment can trigger the oxygen vacancies and improved the crystal quality of the nanostructure.

In this chapter, we will study the effect of annealing on different metal oxide nanoclusters for different applications. Besides reviewing the literature studied by the various groups, we will be focusing on the report from our research group.

\section{Metal oxide nanocluster}

\section{1 $\mathrm{ZnO}$ nanocluster}

$\mathrm{ZnO}$ is a striking n-type metal-oxide-semiconductor that has a wide bandgap of $3.37 \mathrm{eV}$, large exciton binding energy of $60 \mathrm{meV}$ and excellent chemical stability, electrical, optical, piezoelectric and pyroelectric properties. $\mathrm{ZnO}$ nanostructures have gained tremendous interest due to their potential applications in various nanodevices such as nanogenerators, field emitters, UV detectors, gas sensors, and solar cells. Due to their advanced technological applications, high qualities of zinc oxide nanostructures are greatly demanded.

Xuehua et al. reported the co-doped $\mathrm{ZnO}$ nanocluster fabricated by using nanocluster-beam deposition and its effect of annealing at 400 and $700^{\circ} \mathrm{C}$ on the structural, optical and magnetic properties for diluted magnetic semiconductors (DMSs) [24]. The XRD pattern showed the enhanced crystalline structure by increasing the annealing temperature. A possible explanation is that as grown nanoclusters were highly porous after the random nucleation of atoms under nanocluster-beam deposition. However, after annealing in air, the crystallite sizes were increased from 6 to $20 \mathrm{~nm}$ with fewer defects due to the agglomeration of nearby nanoclusters from the obtained thermal kinetic energy. It was also found that the absorption spectra of the annealed film become steeper as compared to the prepared sample. A blue shift appeared at $368 \mathrm{~nm}(3.37 \mathrm{eV})$ in the as-grown film mainly due to the quantum confinement effects. However, after annealing at 
$400^{\circ} \mathrm{C}$, a redshift at $365 \mathrm{~nm}(3.39 \mathrm{eV})$ observed due to the increased in the crystallite size induced by annealing. But, no change appeared as the annealing temperature increased to $700^{\circ} \mathrm{C}$. The intensity has decreased after annealing in the range of 210-350 $\mathrm{nm}$ which indicate that the annealed sample attained more enhanced structure and crystallinity. A strong UV emission observed at $379 \mathrm{~nm}$ caused by the recombination of surface-bound acceptor-exciton complexes and the peak intensity of the UV emission became stronger after annealing due to the enhanced crystallinity. The film annealed at $400^{\circ} \mathrm{C}$ exhibited the highest saturation magnetization of $36 \mu \mathrm{emu}$. The improvement in saturation magnetization is due to the exchange of F-center mediation [25]. Thus, the results further suggested that the annealing at $400^{\circ} \mathrm{C}$ strongly affect ferromagnetic performance.

Recently, Aljawfi et al. [26] studied the impact of annealing on the structural and optical properties of $\mathrm{ZnO}$ nanoparticles through auto combustion route and annealed in air at different temperatures: $200,400,600$, and $800^{\circ} \mathrm{C}$. They showed that the film annealed at $200^{\circ} \mathrm{C}$ had a low-quality crystal. As the annealing temperature increased, the crystallite size increased to $37 \mathrm{~nm}$ from $13.8 \mathrm{~nm}$. Due to annealing, the crystallites gained enough diffusion or activation energy and small crystallites migrate to relatively equilibrium sites in the crystal lattice with lower surface energy. The room temperature PL spectra with different annealing temperature were also studied. The sample annealed at low temperature $\left(200^{\circ} \mathrm{C}\right)$ exhibited anomalous behaviors; where the UV-PL band evidently diminished that indicate the low crystal quality. The results also revealed the presence of clusters in the $\mathrm{ZnO}$ NPs associated with low annealing temperature, and the existence of clusters characterized by the diminished and blue shift in the UV band to lower wavelength. The increased in the intensity of UV-PL emission bands and the decreased in the intensity of the VIS-PL band in sequence with further annealing indicated the improvement in the crystallinity and reduction in the intrinsic local atomic defects. They also revealed that the annealing of $\mathrm{ZnO}$ clusters at or above $400^{\circ} \mathrm{C}$ optimized the crystallinity and enhanced the UV spectra related to optoelectronics application.

The heat treatment in air or pure oxygen may promote the reduction in oxygen vacancy and strong emission in ultraviolet band. Gao et al. further confirmed the above statement [27]. They have prepared the $\mathrm{ZnO}$ nanocluster porous films on a glass substrate by the successive ionic layer adsorption and reaction (SILAR) method and annealed at $400^{\circ} \mathrm{C}$ in Argon and air atmosphere for $2 \mathrm{~h}$. A strong diffraction peak of (100) for the sample annealed in the air is obtained which implies that oxygen in the annealing atmosphere can enhance the crystalline properties of $\mathrm{ZnO}$. The film annealed in air/Ar posses increased in the transmittance due to the reduced porosity. Moreover, the peak emission intensity at $380 \mathrm{~nm}$ decreased after annealing which indicated the high optical quality of the $\mathrm{ZnO}$ layer. The emission at $380 \mathrm{~nm}$ corresponds to the intrinsic transition of exciton from the conduction band to the valence band. Thus, they inferred that the annealing in air enhanced the crystalline properties of $\mathrm{ZnO}$ rather than annealing in Argon but have no evident effect on the photoluminescence of $\mathrm{ZnO}$ film.

We have carried out the fabrication of $\mathrm{ZnO}$ nanocluster and $\mathrm{SiO}_{x} / \mathrm{ZnO}$ heterostructure nanocluster by using glancing angle deposition (GLAD) technique [28] . Glancing angle deposition (GLAD) technique is a physical vapor deposition technique for producing high-quality nanostructures as shown in Figure 1. The advantages of the GLAD technique are as follows: (i) the nanostructure is of high purity as they prepared in an ultra-high vacuum without any catalysts; (ii) the porosity of the nanostructure can be controlled by changing the incident angle; (iii) there is almost no restriction on materials since the growth process is thermal evaporation; (iv) the shape, and in-plane alignment of nanostructure can be easily modified; (v) self-alignment due to the shadowing effect directly on the device substrate 


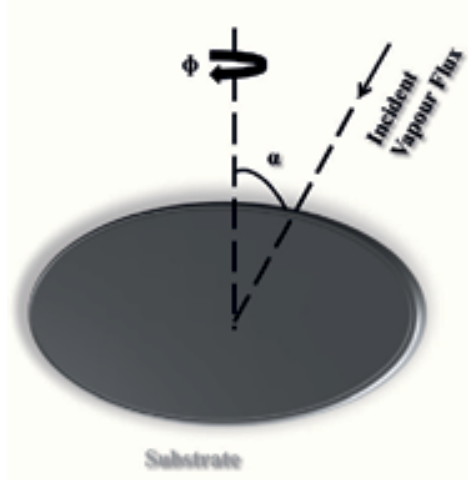

(a)

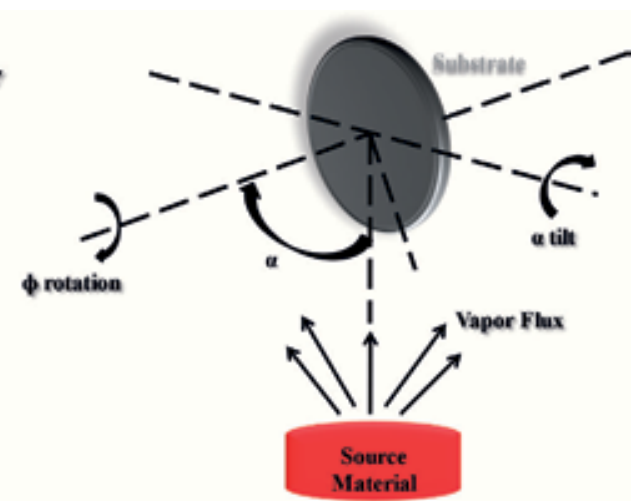

(b)

Figure 1.

(a) GLAD about incident angle $\alpha$ of the vapor flux and (b) substrate azimuthally ( $\varphi$ ) rotation.

without the need for any additional experimental set up; and (vi) the technique could be used for commercial purposes.

GLAD can be used to engineer the nanostructure films with morphological features such as nanorods, nanowires, nanoclusters, helixes, zigzags, by adjusting the deposition angle, $\alpha$ and substrate rotation angle, $\varphi$. In this technique, three parameters determine the morphology of the nanostructure: the incident angle, the growth rate, and the substrate rotational speed. The high melting point materials have relatively low surface mobilities during the film growth processes. Therefore, during the growth process, a high melting point material flux is chosen to be incident onto the surface normal, and the substrate is rotating. GLAD produces nanostructure through the effect of shadowing during film growth with low surface mobilities force the adatoms to form porous nanostructures. Nanostructure films with their high surface to volume ratio are a potential application for optoelectronic devices since their unique morphology can enhance the device performance, namely: photosensitivity, wavelength selectivity, response and reset times, and reproducibility and stability.

The basic deposition setup is the same as that of oblique angle deposition is shown in Figure 2; the only difference is that the substrate manipulated by the incident angle $\Theta$ and the azimuthal rotation of the substrate concerning the substrate surface normal. By combining the oblique angle deposition and substrate positional control, a technique is introduced which is called glancing angle deposition (GLAD). In this deposition technique, the collimated evaporation beam has a large incident angle $\alpha$ concerning the substrate surface normal therefore incoming vapor can be considered as vector $F$. This vector $F$ has two components, a vertical component $F_{\perp}=F \cos \alpha$ and $\alpha$ lateral component $\mathrm{F}_{\mathrm{I}}=\mathrm{F} \sin \alpha$. The substrate will receive the vapor from both the components, but for the growth of the nanoclusters, the deposition should be preceded by $F_{\perp}$ only, i.e., cancel out the $F_{\mid}$component. This forms the basis of the glancing angle deposition technique for the growth of nanoclusters. When the substrate rotates azimuthally, each part has an equal chance to receive the same amount of particle from the $F_{\mid}$component. After a complete revolution, the average $\sum F_{\mid}$is zero due to the cancelation of $F_{\mid}$component at the opposite directions which means that there is no preferred orientation of the nanoclusters. By this technique purely nanoclusters will grow at the substrate surface.

The optical properties were carried out on both the samples by a UV-visible NIR spectrophotometer and photoluminescence spectroscopy (HITACHI, F-7000 FL spectrophotometer). Fourier transform infrared radiation methods (PERKIN ELMER, LAMBDA 900) were also carried out on both the samples. The average 


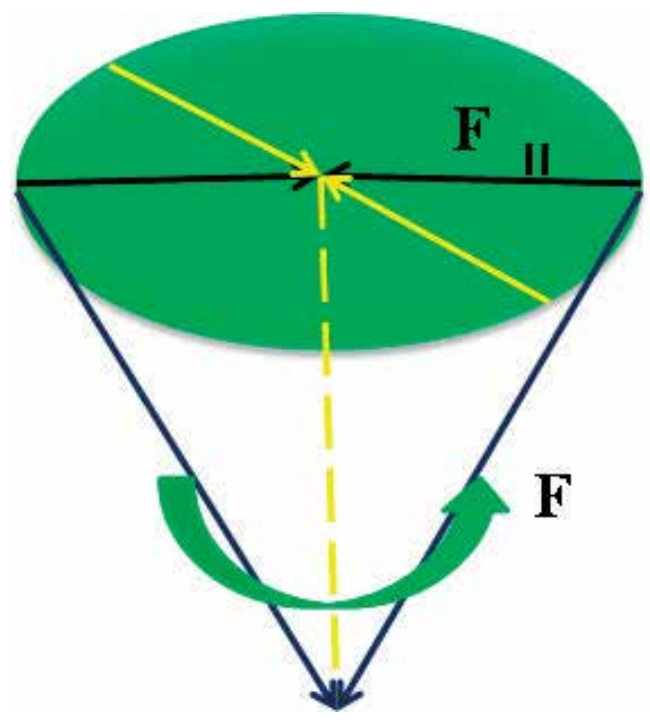

Figure 2.

The cancelation of the $F_{\mid}$component due to the rotation. Only $F_{\perp}$ contributes effectively to the increasing height of the nanostructure.

crystallite size of the $\mathrm{ZnO}$ nanocluster and $\mathrm{SiO}_{x} / \mathrm{ZnO}$ heterostructure nanocluster was found to be $\sim 7.101$ and $\sim 10.14 \mathrm{~nm}$ respectively. The increase in crystallite size suggests the decrease in the existence of grain boundaries in the $\mathrm{SiO}_{x} / \mathrm{ZnO}$ heterostructure nanocluster [29]. Moreover, the decrease in the average lattice strain observed from 0.01641 ( $\mathrm{ZnO}$ nanocluster) to $0.01336\left(\mathrm{SiO}_{x} / \mathrm{ZnO}\right.$ heterostructure nanocluster).

The optical absorption spectrum showed in the wavelength range from 320 to $800 \mathrm{~nm}$ of the $\mathrm{ZnO}$ nanocluster and $\mathrm{SiO}_{x} / \mathrm{ZnO}$ heterostructure nanoclusters in Figure 3.

$\mathrm{ZnO}$ is known to have a large number of defects like oxygen vacancies. When a photon generates an electron-hole pair, recombinations are more likely to take place in the oxygen vacancy. $\mathrm{ZnO}$ nanoclusters have a continuous absorption in the UV range as shown in Figure 3, demonstrating the presence of a noticeable amount of metallic zinc and a considerable amount of defects [30]. Some recent studies have shown that $\mathrm{SiO}_{x}$ has a conductive property. When electron-hole pairs initially generated in the $\mathrm{ZnO}$ nanocluster, the generated electrons accumulate in the conduction band, and they are attracted to the trap level of $\mathrm{SiO}_{x}$ [31]. Hence, due to the presence of $\mathrm{SiO}_{x}$ beneath the $\mathrm{ZnO}$, an enhancement of the light absorption in the visible region beyond $400 \mathrm{~nm}$ as well as the near-infrared region can be observed.

The room temperature PL spectra of $\mathrm{ZnO}$ nanocluster and $\mathrm{SiO}_{x} / \mathrm{ZnO}$ heterostructure nanocluster measured under 325 and $350 \mathrm{~nm}$ excitation (Figure 4). For comparison, PL spectrums showed for both the samples in the same figure. The excitation wavelength of $350 \mathrm{~nm}$ exhibits only a strong emission band in the blue region for both the samples attributed to near energy bandgap. The near band gap energy comes from the electron-hole recombination at a deep level (DL) emission in the band gap caused by intrinsic point defects and surface defects, e.g., oxygen vacancies, zinc interstitials. The blue emission peak at $450 \mathrm{~nm}(\sim 2.75 \mathrm{eV})$ usually results from the radiative recombination of delocalized electrons close to the conduction band with deeply trapped holes in zinc vacancy. The intensity of blue emission under excitation wavelength $325 \mathrm{~nm}$ of $\mathrm{ZnO}$ nanocluster reduced slightly and exhibited non linear increase-decrease dependence, first increasing, the saturation at the bandgap energy as the optimal excitation energy and finally decreasing 


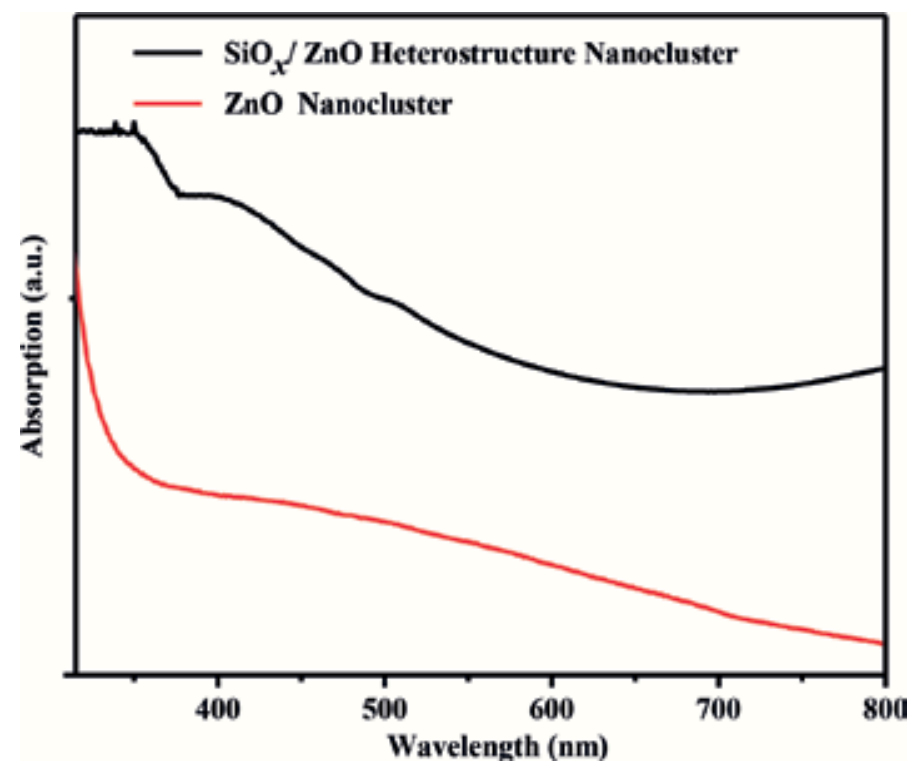

Figure 3.

The optical absorption spectrum of $\mathrm{ZnO}$ nanocluster and $\mathrm{SiO}_{x} / \mathrm{ZnO}$ heterostructure nanocluster.

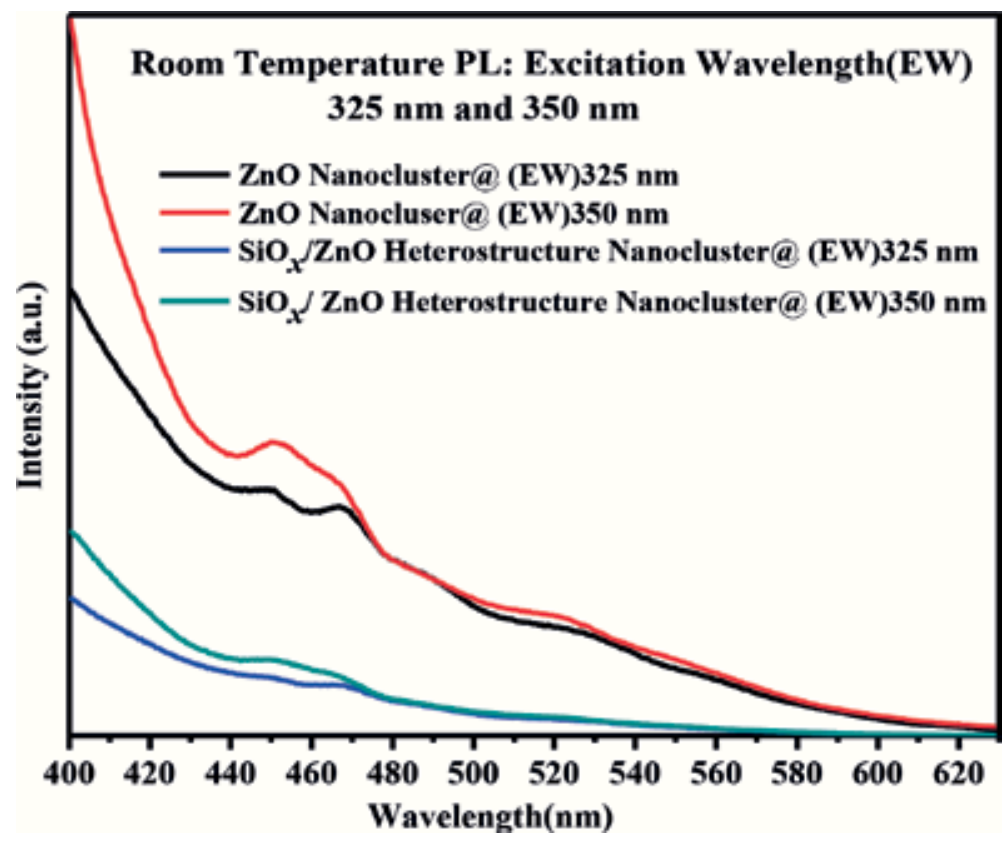

Figure 4.

Photoluminescence spectrum of $\mathrm{ZnO}$ nanocluster and $\mathrm{SiO}_{x} / \mathrm{ZnO}$ heterostructure nanocluster.

but still effectively emitting as slowly dropping tail emission peaks at $467 \mathrm{~nm}$ is attributed to the transitions from $\mathrm{Zn}_{\mathrm{i}}$ states to the valence band [32].

$\mathrm{SiO}_{x} / \mathrm{ZnO}$ heterostructure nanocluster exhibited much lower emission intensity than $\mathrm{ZnO}$ nanocluster indicating that the recombination of the photogenerated charge carrier significantly inhibited in $\mathrm{SiO}_{x} / \mathrm{ZnO}$ heterostructure nanocluster. The efficient charge separation may increase the lifetime of the charge carriers and enhance the efficiency of the interfacial transfer to adsorbed substrates and then account for the higher activity. Also, the peak shift from 450 to $457 \mathrm{~nm}$ in $\mathrm{SiO}_{x} / \mathrm{ZnO}$ 
heterostructure nanocluster may be due to the radiative recombination of photoexcited electrons. These photoexcited electrons that accumulate in the conduction band of $\mathrm{ZnO}$ are attracted to the trap level of $\mathrm{SiO}_{x}$ due to the difference in work functions of $\mathrm{ZnO}$ and $\mathrm{SiO}_{x}$ [31].

FTIR spectra of $\mathrm{ZnO}$ nanocluster and $\mathrm{SiO}_{x} / \mathrm{ZnO}$ heterostructure in the spectral range of 400 to $1500 \mathrm{~cm}^{-1}$ shown in Figure 5 consisted of several bands at 420, 610, 738,819 and $1109 \mathrm{~cm}^{-1}$. The peak at 420,610 and $738 \mathrm{~cm}^{-1}$ indicates the presence of $\mathrm{ZnO}$ which is in good agreement with the results obtained by XRD and attributed to the stretching vibration mode and also be related to the influence of shell induced strain and the appearance of $\mathrm{ZnO}$ bond between $\mathrm{Zn}$ and $\mathrm{O}$ atoms of the shell [33]. The spectra also show the bending vibration of $\mathrm{Si}-\mathrm{O}-\mathrm{Si}$ at $819 \mathrm{~cm}^{-1}$ indicating the bonding between the substrate and $\mathrm{SiO}_{x}$. The peak located at $1109 \mathrm{~cm}^{-1}$ assigned to asymmetric $\mathrm{Si}-\mathrm{O}$ stretching is due to interstitial oxygen impurities dissolved in the Si substrate. In $\mathrm{SiO}_{x} / \mathrm{ZnO}$ heterostructure nanocluster, the entire peak transmittance \% got quenched. Together these results identified the presence of $\mathrm{SiO}_{x}$ which exist near the $\mathrm{ZnO}$ surface.

The above work indicated that the $\mathrm{SiO}_{x} / \mathrm{ZnO}$ heterostructure nanocluster could account for higher activity in optoelectronic devices. So, we further annealed the $\mathrm{SiO}_{x} / \mathrm{ZnO}$ heterostructure nanocluster at $550^{\circ} \mathrm{C}$ for $1 \mathrm{~h}$ in open air [2]. The annealing treatment was carried out in the muffle furnace. The crystallinity improved after annealing owing to the decrease in the defect density. Also, the increased crystallite size attributed to the coalescence of grains. Moreover, the annealed sample becomes smoother as shown in Figure $\mathbf{6}$ and offer a large surface area ascribed to the agglomeration of smaller nanocluster. The authors also confirmed that the oxygen content increased to $20.90 \%$ due to the adsorption of $\mathrm{O}_{2}$ at the time of open-air annealing and hence, absorption is enhanced in the case of the annealed sample as shown in inset Figure 6.

The authors also reported the optical absorption spectrum in Figure 7(a) of the wavelength range from 320 to $900 \mathrm{~nm}$ of the bare $\mathrm{ZnO}$ nanocluster, as deposited and annealed $\mathrm{SiO}_{\mathrm{x}}-\mathrm{ZnO}$ heterostructure nanoclusters. An enhancement of averagely 1.5 times photon absorption is observed in the annealed sample with sharper band edge which indicated the formation of the improved crystal structure of the sample [30]. However, the decreased in the absorbance after annealing in the

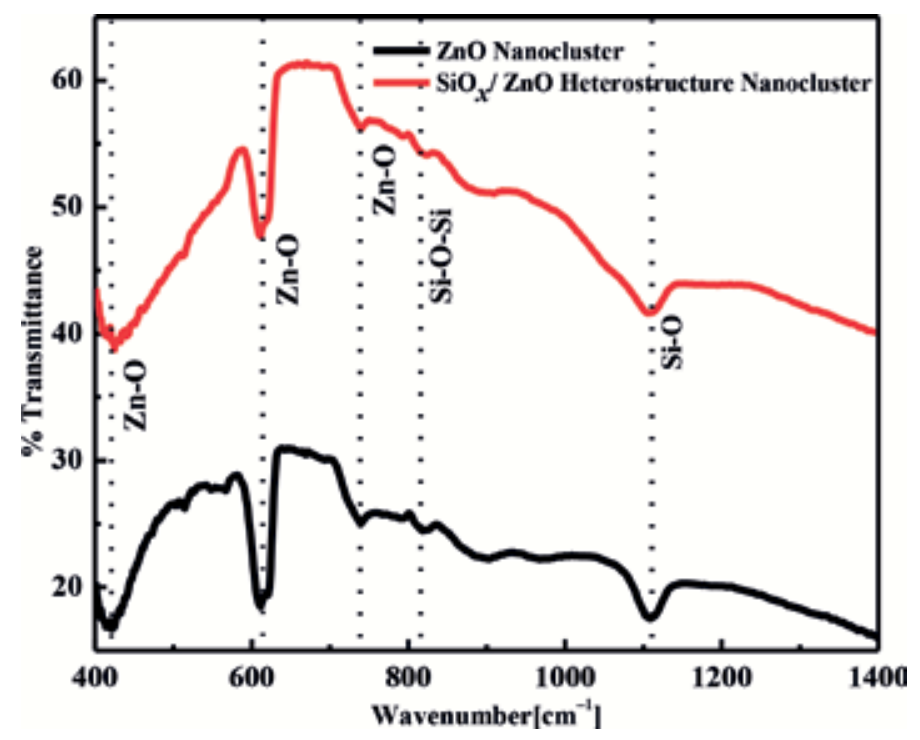

Figure 5.

FTIR spectra of $\mathrm{ZnO}$ nanocluster and $\mathrm{SiO}_{x} / \mathrm{ZnO}$ heterostructure nanocluster. 

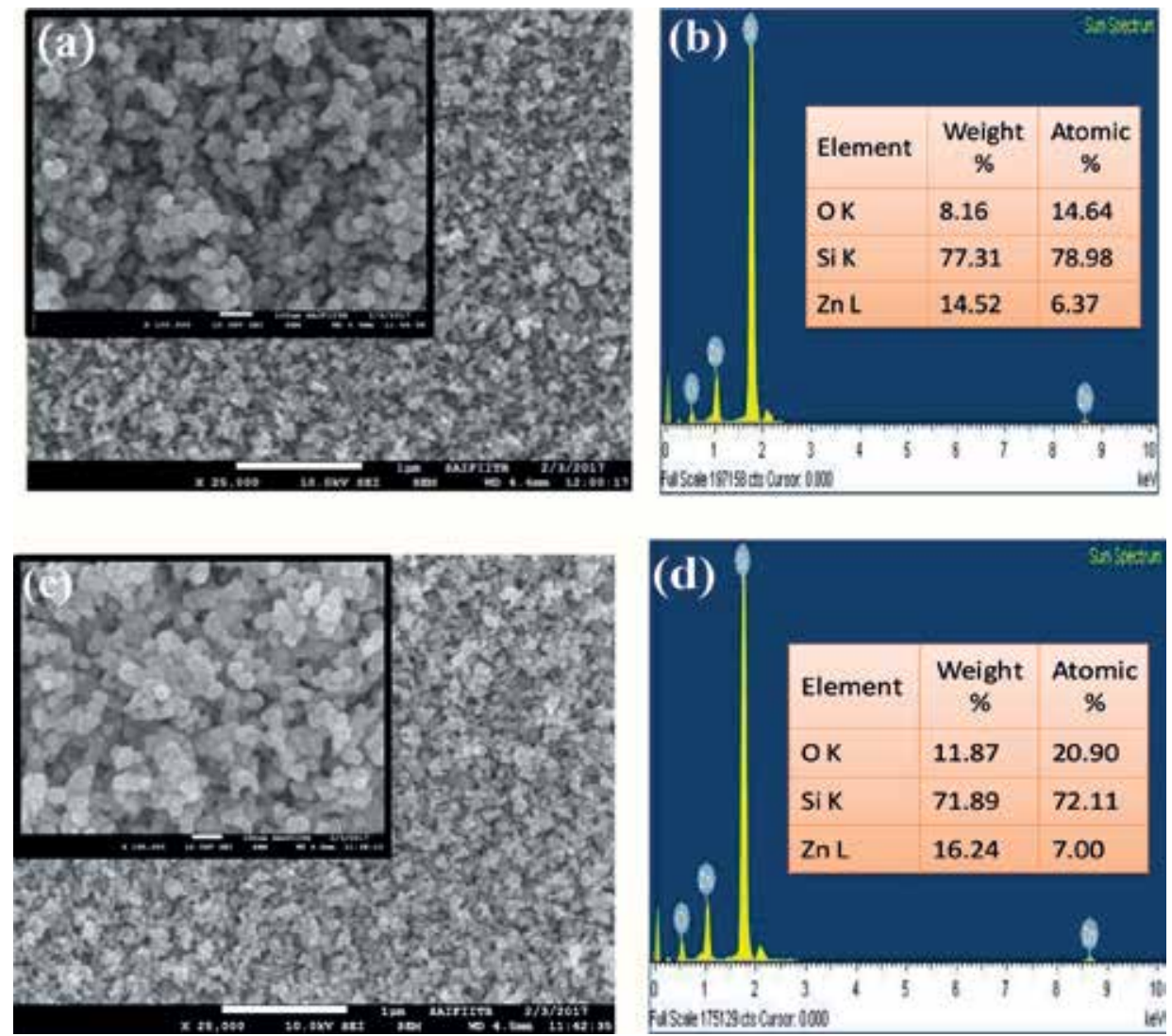

Figure 6.

FEG-SEM images of the $\mathrm{SiO}_{x}-\mathrm{ZnO}$ heterostructure nanoclusters: (a) top view (as deposited); (b) EDAX analysis of as-deposited; (c) annealed and (d) top view (annealed).

wavelength range of $\sim 374$ to $478 \mathrm{~nm}$ is attributed to the change in the band gap. A continuous absorption is seen in the visible range of the as a deposited sample due to the noticeable amount of metallic zinc and a considerable amount of defects. The light absorption is enhanced in the visible region beyond $400 \mathrm{~nm}$ to NIR regions. Additionally, the voids were filled up with the $\mathrm{O}_{2}$ after annealing which enhanced the probability of main band transitions and therefore the absorption in the UV region. Also, the subband transition of $\mathrm{SiO}_{\mathrm{x}}$ shows the maximum absorption of at around $2.7 \mathrm{eV}$ in the visible region. The interaction between $\mathrm{Si}-\mathrm{Si}$ increased and formed the $\mathrm{Si}$ nanocluster in the $\mathrm{SiO}_{\mathrm{x}}$ due to annealing. The absorption is in the near infrared region is due to the presence of $\mathrm{Si}$. However, no light absorption beyond $850 \mathrm{~nm}$ was observed because $\mathrm{Si}$ absorbed light efficiently up to near infrared region only. That is why there is a steep change of absorption at $850 \mathrm{~nm}$.

We have obtained the increase in the transmittance after annealing which attributed to the decreased in defects and an increase in the $\mathrm{ZnO}$ to $\mathrm{Zn}$ ratio [30]. The absorbed oxygen after annealing fills up the oxygen vacancies, hence reducing the density of this donor like defects. The main band gap of $\mathrm{ZnO}$ film is $3.37 \mathrm{eV}$ [34]. However, the band gap of the as deposited $\mathrm{SiO}_{x}-\mathrm{ZnO}$ heterostructure nanocluster is found to be $2.94 \mathrm{eV}$ due to the downward shift of the conduction band. The less band gap associated with many-body interactions between the carriers in the conduction band and valence band called bandgap renormalization [35]. However, after annealing, the optical band gap increases to $3.44 \mathrm{eV}$ which is influenced by the change in charge carriers and can be explained by Burstein Moss (BM) effect [35]. 

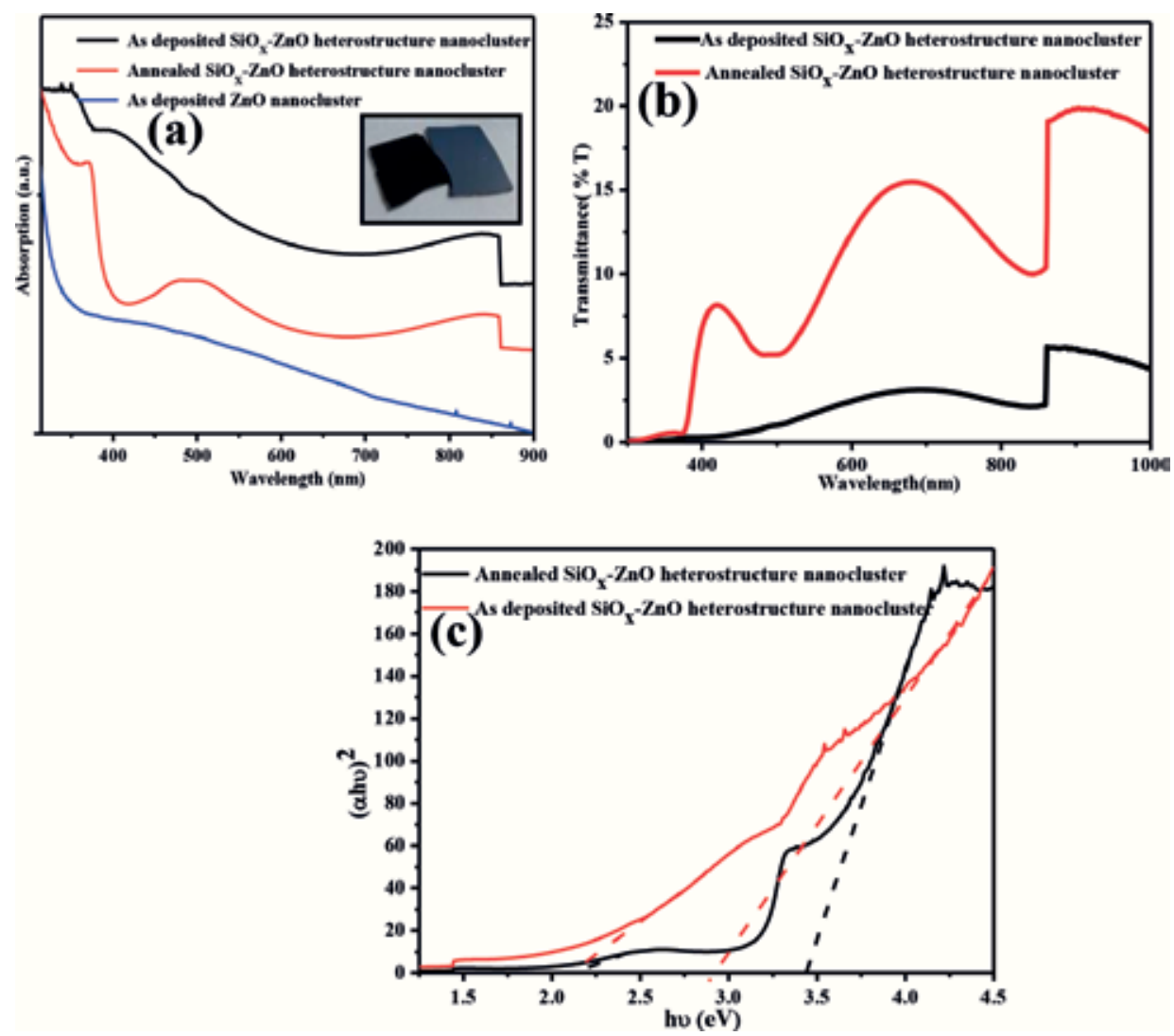

Figure 7 .

(a) Optical absorption of as deposited $\mathrm{ZnO}$ nanocluster, as deposited and annealed $\mathrm{SiO}_{x}-\mathrm{ZnO}$ heterostructure

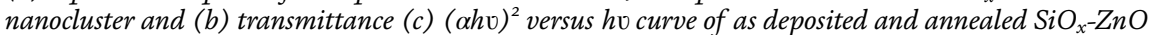
heterostructure nanocluster.

The PL spectra of the as deposited and annealed $\mathrm{SiO}_{\mathrm{x}}-\mathrm{ZnO}$ heterostructure nanoclusters with different excitation wavelengths of 325, 350 and $375 \mathrm{~nm}$ under same 370 filter (Figure 8) also studied. The peak intensity significantly increased due to the formation of $\mathrm{O}_{\mathrm{i}}$ and $\mathrm{O}_{\mathrm{Zn}}$ after annealing at $550^{\circ} \mathrm{C}$. Generally, the emission peak of $\mathrm{ZnO}$ nanostructure centered at around $415 \mathrm{~nm}$. This emission peak arises due to the radiative defects in $\mathrm{ZnO}$. However, in our case, the emission peak at around $420 \mathrm{~nm}$ is due to the radiative recombination of photoexcited electrons. These photoexcited electrons that accumulate in the $\mathrm{CB}$ of $\mathrm{ZnO}$ are attracted to the trap level of $\mathrm{SiO}_{\mathrm{x}}$ due to the difference in work functions of $\mathrm{ZnO}$ and $\mathrm{SiO}_{\mathrm{x}}$. The intensity of blue emission exhibited a non linear increase-decrease dependence, first increasing, the saturation at the bandgap energy as the optimal excitation energy and finally decreasing but still effectively emitting as slowly dropping tail emission peaks at $450 \mathrm{~nm}$ and $468 \mathrm{~nm}$ which attributed to the transitions from $\mathrm{Zn}_{\mathrm{i}}$ and extended $\mathrm{Zn}_{\mathrm{i}}$ states to the valence band respectively. These extended states formed during the annealing process according to the defect ionization reaction [32].

\section{$2.2 \mathrm{TiO}_{2}$ nanocluster}

Titanium dioxide $\left(\mathrm{TiO}_{2}\right)$ is a wide bandgap semiconductor with an indirect optical bandgap ranging from $3.2 \mathrm{eV}$ for the anatase phase to $3.0 \mathrm{eV}$ for the rutile phase. The unique physical, chemical, and optical properties have motivated more researchers in many applications such as sensors, photo-electrochemical water 


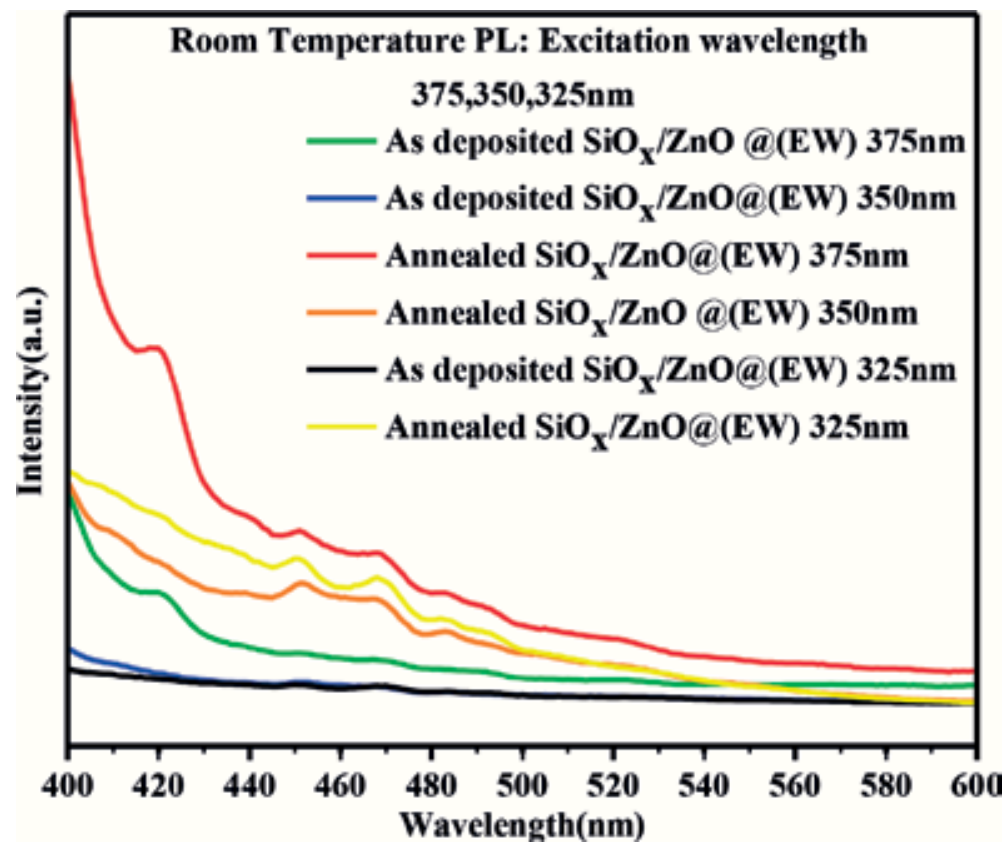

Figure 8.

Photoluminescence spectrum of as deposited and annealed $\mathrm{SiO}_{x}-\mathrm{ZnO}$ heterostructure nanocluster.

splitting, dye-sensitized solar cells, photo-catalytic performance, memory devices, and photodetector.

The surface area of the nanostructure is one of the essential factors in determining the sensitivity of the chemical sensors. However, the surface/adsorbate interactions of the nanowires are often limited and non-specific. So, the functionalization of the NWs surface with metal/metal oxide nanoparticle or nanocluster focus at resolving the deficiencies of the NW-based devices. GS Aluri et al. demonstrated $\mathrm{GaN}$ nanowires decorated with $\mathrm{TiO}_{2}$ nanoclusters for selectively sensing benzene and related aromatic environmental pollutants such as toluene, ethylbenzene and xylene [23]. The $\mathrm{TiO}_{2}$ nanoclusters act as catalysts design to increase the sensitivity, lower the detection time since nanoclusters/nanoparticles can increase the adsorption of chemical species by introducing additional adsorption sites. Herein, $\mathrm{TiO}_{2}$ nanoclusters fabricated by using RF magnetron sputtering followed by an annealing at $650-700^{\circ} \mathrm{C}$ in a rapid thermal processing system of ultrahigh purity Ar. The $\mathrm{TiO}_{2}$ were amorphous in as-deposited film. Upon annealing of $\mathrm{TiO}_{2}$ nanoclusters at $700^{\circ} \mathrm{C}$ for $3 \mathrm{~s}$, the phase changed to anatase in the $\mathrm{TiO}_{2}$ clusters. The I-V curve was nonlinear and asymmetric in the as a deposited sample but the current increased with the deposition of $\mathrm{TiO}_{2}$ nanoclusters and significant change occurred when the device annealed at $700^{\circ} \mathrm{C}$. They have also shown that the photoconductivity increased almost two orders of magnitude for the device decorated with $\mathrm{TiO}_{2}$ nanoclusters. The enhancement of photoconductance after decorating nanoclusters to nanowires is attributed to the separation of photogenerated charge carriers by a surface depletion field, thereby increasing the lifetime of the photogenerated carriers. Thus, these results demonstrated the potential of hybrid chemical sensors using $\mathrm{TiO}_{2}$ nanoclusters.

Wei et al. have prepared the $R-\mathrm{TiO}_{2}$ clusters by post-deposition oxidation of $\mathrm{Ti}$ clusters with rapid thermal annealing in an oxygen atmosphere [36]. The $R-\mathrm{TiO}_{2}$ clusters showed the highest crystalline structure as compared to $\mathrm{Ti}, \mathrm{TiO}$, and $\mathrm{A}-\mathrm{TiO}_{2}$. In a different work, $\mathrm{Ag}-\mathrm{TiO}_{2}$ nanocomposite was prepared by $\mathrm{DC}$ reactive magnetron sputtering followed by vacuum annealing treatment from 200 to $800^{\circ} \mathrm{C}$. 
The friction coefficient increased from 0.21 to 0.7 after the sample annealed at $800^{\circ} \mathrm{C}$ [37]. Recently, Song et al. fabricated the $\mathrm{TiO}_{2}$ nanocluster-SiO $\mathrm{x}_{\mathrm{x}}\left(\mathrm{x}^{<} 2\right)$ using atomic layer deposition (ALD) for the properties of resistive switching. They performed thermal annealing in $\mathrm{N}_{2}$ ambient at $900^{\circ} \mathrm{C}$ for $3 \mathrm{~h}$ using a thermal furnace. They have reported the current on/off ratio of the device is about $10^{5}$ (reading at $+1.0 \mathrm{~V}$ ), which is much higher than that of many Resistance change random access memories (RRAM) devices of $\mathrm{TiO}_{2}$ [38].

$\mathrm{TiO}_{2}$ nanocluster determined the photocatalytic activity by its crystalline phase (anatase and rutile), crystallite size, specific surface area, pore structure, and crystallinity. Khan et al. reported that the crystallization of $\mathrm{TiO}_{2}$ film to anatase crystal phase starts occurring at the annealing temperature of $300-600^{\circ} \mathrm{C}$ in the air which improves the crystal structure of the $\mathrm{TiO}_{2}$ anatase [39]. Bin et al. investigated the effect of GLAD on $\mathrm{TiO}_{2}$ nanostructure with different annealing temperature for the morphology, and crystallization and PL. The average size increased with the increase in annealing temperature, and defects were reduced [40].

Min Liu et al. reported the photochemically inactive Ti3+ self-doped $\mathrm{TiO}_{2}$ prepared by a facile one-step thermal oxidation into an efficient visible light-sensitive photocatalyst by the grafting of $\mathrm{Cu}$ (II) oxide amorphous nanoclusters [41]. The grafting of $\mathrm{Cu}$ (II) oxide onto $\mathrm{TiO}_{2} @ \mathrm{Ti} 3$ + performed by the impregnation method shown that the grafting of $\mathrm{Cu}$ (II) nanoclusters to $\mathrm{TiO}_{2}$ increased the absorption intensities in the 420-550 and 700-800 $\mathrm{nm}$ wavelength regions assigned to the interfacial charge transfer (IFCT) VB electrons to surface-grafted Cu (II) nanoclusters. On the contrary, the grafting of $\mathrm{Cu}$ (II)-TiO $\mathrm{Ti}_{2} @ \mathrm{Ti} 3+$ the absorption intensities decreased slightly in the range of 420-550 $\mathrm{nm}$ wavelength region, while the increased in the absorption intensities can also be observed in the range of 700-800 nm wavelength region attributed to the $d-d$ transition of $\mathrm{Cu}(\mathrm{II})$. They have shown that the $\mathrm{TiO}_{2} @ \mathrm{Ti} 3+$ had a negligible activity either under visible light or UV light irradiation without the grafting of nanocluster. After grafting, they have switched to an efficient photocatalyst. Further, they have studied the photocatalytic activities of $\mathrm{Cu}$ (II)-TiO $2 @ \mathrm{Ti} 3+$ under visible light irradiation at $400-530 \mathrm{~nm}\left(1 \mathrm{~mW} / \mathrm{cm}^{2}\right)$ with different annealing temperature. However, the ratio of $\mathrm{TiO}_{2}$ to $\mathrm{Ti}_{2} \mathrm{O}_{3}$ greatly influenced the morphology and the degree of oxidation states rather than annealing.

\subsection{Tungsten oxide nanocluster}

In the family of metal transition oxides, tungsten trioxide $\left(\mathrm{WO}_{3}\right)$ have attracted due to their distinctive properties such as chromogenic properties, gas sensitivity, and photosensitivity. Tungsten oxide nanoclusters were fabricated using supersonic cluster beam deposition (SCBD) by Zhao et al. [21] for examining the $\mathrm{H}_{2}$ sensing properties. Further, the sample was post-annealed at $250^{\circ} \mathrm{C}$ for $12 \mathrm{~h}$. They showed a large sensor signal of 1200 at $3000 \mathrm{ppm}$ of $\mathrm{H}_{2}$ in the air due to the small cluster size. The response of $\mathrm{H}_{2}$ was over a broad range from 4 to 20,000 ppm. Moreover, the detection limit is as low as $0.042 \mathrm{ppm}$. Lastly, the sensor exhibit fast response rate.

\subsection{Iron oxide nanocluster}

The unique properties such as superparamagnetism arise from the fluctuation in the direction of the magnetic moment in a single domain nanoparticle due to thermal agitation. Marin et al. reported a novel core-shell superparamagnetic iron oxide nanocluster under annealing treatment [42]. The annealing of iron oxide nanocluster at $300^{\circ} \mathrm{C}$ for $3 \mathrm{~h}$ in air greatly influences the magnetic properties. Due to the thermal decomposition of the surfactants during the annealing treatment and in the absence of oxygen inside the nanoclusters led to the formation of an amorphous 
carbon" coat" around the maghemite nanoparticle. After the annealing treatment, the value of saturation magnetization is increased by about $\sim 13.6 \%$. This increase in the magnetization of the annealed sample can be attributed to the degradation and decomposition of the surfactants and their release of gas products during the annealing treatment from the sample, i.e. to the higher content of the magnetic material in the annealed sample. They showed the decrease in the interactions in the annealed sample indicated that the maghemite nanoparticles are better isolated and shield each other with the amorphous carbon.

Apart from the nanoclusters, the effect of annealing on metal oxide nanostructures such as indium oxide and tin oxide will be discussed in the next section.

\subsubsection{Indium oxide}

Indium oxide $\left(\operatorname{In}_{2} \mathrm{O}_{3}\right)$, known as an n-type, is a wide-bandgap transparent semiconductor (with a direct bandgap of $\sim 3.6 \mathrm{eV}$ and an indirect bandgap of $\sim 2.5 \mathrm{eV}$ ) is of great interest for diverse technological applications in nanoelectronics and optoelectronics. Zero-dimensional $\operatorname{In}_{2} \mathrm{O}_{3}$ nanoparticles/nanoclusters, with a variety of tunable, are beneficial as building blocks for indium oxide-based or hybrid transistor. Their remarkably surface-to-volume ratio and good stability have made them promising materials in gas sensors/biosensors, photocatalysis, photoelectrochemical cells, and ultraviolet photodetectors. Despite the advantages, $\mathrm{In}_{2} \mathrm{O}_{3}$ nanostructure usually encounters low conductivity, and this could decrease the stability and efficiency of the device. Due to the weak interconnection between the nanoparticles/ nanoclusters, the carrier transportation between the NPs lost at the interface due to the charge delocalization. One way to solve this problem is to improve the structure by annealing and plasma treatment.

Kong et al. reported the zero-dimensional $\operatorname{In}_{2} \mathrm{O}_{3}$ nanoparticle sample showed an improvement in the crystallinity and a more compact structure after the thermal treatment [43]. It also showed an improvement in the optical and electrical properties of the $\mathrm{In}_{2} \mathrm{O}_{3}$ nanoparticle. Flores et al. studied the effect of annealing on the electrical, optical and structural properties of the undoped $\operatorname{In}_{2} \mathrm{O}_{3}$ nanostructure [44]. The film first annealed at $300^{\circ} \mathrm{C}$ in the air and the second annealing at $500^{\circ} \mathrm{C}$ results with a better passivation effect of the traps, whether located at grain boundaries or in the bulk of the indium oxide grains. So, the highest carrier concentration, mobilities, and band gap value obtained for the samples treated under 300 and $500^{\circ} \mathrm{C}$. Sudha et al. [45] also investigated the crystallinity of $\operatorname{In}_{2} \mathrm{O}_{3}$ nanostructures along with the grain size augmented with annealing temperature. They observed that average grain size increased with increasing annealing temperature and explained by considering the thermal annealing-induced coalescence of small grains by grain boundary diffusion which caused significant grain growth. Microstrain and dislocation density present in the $\operatorname{In}_{2} \mathrm{O}_{3}$ nanostructure are found to decrease due to thermal annealing implies that the stress is compressive which is likely to be governed by the dominant crystallization process. Senthilkumar et al. presented the influence of annealing temperature on the structural and optical properties of the $\operatorname{In}_{2} \mathrm{O}_{3}$ films deposited by electron beam evaporation technique in the presence of oxygen [46]. They have also proved that the crystallinity of $\operatorname{In}_{2} \mathrm{O}_{3}$ films improved with annealing temperature. The optical band gap is found to vary from 3.65 to $3.86 \mathrm{eV}$ with increasing annealing temperature. The shift in the band gap to higher energies attributed to the increase in carrier density which arises from the filling of states near the bottom of the lowest state in the conduction band. The results also show that by increasing the annealing temperature, the electrical resistivity of $\operatorname{In}_{2} \mathrm{O}_{3}$ thin films decreases which is related to the increase of the mobility and carrier density. Thus, the annealing temperature plays a vital role in the conductivity of the $\mathrm{In}_{2} \mathrm{O}_{3}$ nanostructure as well. 


\subsubsection{Tin oxide}

In recent years $\mathrm{SnO}_{2}$ has attracted a lot of interest because of its outstanding electrical, optical and electrochemical properties and these properties enabled the application of $\mathrm{SnO}_{2}$ in solar cells, catalytic support materials, transparent electrodes, and solid-state chemical sensors. Among the various phases of tin oxides, $\mathrm{SnO}$ is the most metastable phase, which is mostly formed at high annealing temperatures $\left(450\right.$ and $\left.750^{\circ} \mathrm{C}\right)$. The size, morphology, and phase of the tin oxide nanoparticles can be effectively modified by the process of annealing. The effect of $\mathrm{pH}$ and annealing temperature on the properties of tin oxide nanoparticles prepared by the sol-gel method has reported [47]. The samples were annealed at $200,400,600$, and $800^{\circ} \mathrm{C}$. The average crystallite size increased with the increase in annealing temperature. The surface morphology of the tetragonal $\mathrm{SnO}_{2}$ nanoparticles studied by scanning electron microscope revealed the formation of spherically shaped agglomerations.

On the other hand, carbon nanomaterials composed of $\mathrm{sp}^{2}$ bonded graphitic carbon are found in different dimensions including zero-dimensional fullerenes, one-dimensional carbon nanotubes (CNTs), and two-dimensional graphene. Owing to the unique structure and physical properties, carbon-based nanomaterials have gained lots of interests in electronic, optoelectronic, photovoltaic, and sensing applications. Among the different carbon nanomaterials, CNTs provides unique opportunities for novel optoelectronic properties since semiconducting CNTs are direct bandgap materials that possess free electron-hole pair excitations as well as strongly bound electron-hole pair states called excitons. One dimensional nature of CNTs produces van Hove singularities in the density of states that result in strong optical absorption and emission with energies. The use of graphene for optoelectronic devices is limited due to its zero band gap at the Fermi level. However, by tuning the band gap, graphene can be an ideal candidate for optoelectronic devices [48]. CNTs are also chemically inactive due to their strong $\mathrm{sp}^{2}$ bonding in a near perfect hexagonal network and this prevents the formation of chemical bonds with most molecules. Its reactivity can be improved towards different gases by decorating the CNTs wall by metal or metal oxide nanocluster due to its physico-chemical properties (e.g. high catalytic activity, adsorption capacity, efficient charge transfer, etc.). Nanoclusters play a major role in the gas detection pathway, in which sensitivity and selectivity can be tuned based on the reactivity of the nanoclusters surfaces and on the nature of the charge transfer between carbon nanotubes and nanoclusters induced by gas adsorption [12]. In addition, the incorporation of metal nanoclusters $(\mathrm{Ag}, \mathrm{Au})$ inside carbon host matrix can add functionality to carbon films. However, the high internal stress of carbon can affect the structural evolution of metal incorporated carbon film. Jose et al. [49] studied the influence of annealing in argon at $300^{\circ} \mathrm{C}$ on the conductivity, phase stability and electronic structure of hydrogen-free amorphous carbon (a-C) films containing copper $(\mathrm{aC}: \mathrm{Cu})$ and gold $(\mathrm{a}-\mathrm{C}: \mathrm{Au})$ nanoclusters. They showed that the a-C host matrix increased its graphitic character and stress was relieved upon annealing due to increase in the high energy side of the $\sigma^{*}$ region. Also, the structural transformation after annealing the carbon incorporated nanoclusters changes their electronic conductivity and apparent optical bandgap.

\section{Conclusions}

The chapter reviewed the effect of annealing on $\mathrm{ZnO}, \mathrm{SiO}_{x}$, and $\mathrm{TiO}_{2}$ nanocluster for different applications. $\mathrm{ZnO}, \mathrm{SiO}_{x}$, and $\mathrm{TiO}_{2}$ have been fabricated using 
different physical and chemical method. Our work demonstrated the influence of annealing on optoelectronics properties on GLAD synthesized $\mathrm{SiO}_{\mathrm{x}}-\mathrm{ZnO}$ heterostructure nanoclusters. The post-annealing treatment in oxygen ambient improved the structural, optical and electrical properties. Nanocluster based devices outperform their bulk counterparts. In addition, some different metal oxide nanostructure and its effect of annealing also discussed. Therefore, we may conclude that future nanodevices based on nanocluster should be paid attention to the industrial and commercial applications.

\section{Acknowledgements}

The authors would like to thank especially the initiator of this book for making them a part of this vital endeavor.

\section{Conflict of interest}

The author declares that there is no conflict of interests regarding the publication of this book chapter.

\section{Appendices and nomenclature}

$\begin{array}{ll}\mathrm{V}_{\mathrm{Zn}} & \text { zinc vacancy } \\ \mathrm{O}_{\mathrm{i}} & \text { oxygen interstitial } \\ \mathrm{O}_{\mathrm{Zn}} & \text { antisite oxygen } \\ \mathrm{Zn}_{\mathrm{i}} & \text { interstitial zinc ion }\end{array}$

\section{Author details}

Naorem Khelchand Singh ${ }^{*}$ and Rajshree Rajkumari

Department of Electronics and Communication Engineering, National Institute of Technology, Nagaland, Dimapur, India

*Address all correspondence to: khelchand.singh@gmail.com

\section{IntechOpen}

(C) 2019 The Author(s). Licensee IntechOpen. This chapter is distributed under the terms of the Creative Commons Attribution License (http://creativecommons.org/licenses/ by/3.0), which permits unrestricted use, distribution, and reproduction in any medium, provided the original work is properly cited. (cc) BY 


\section{References}

[1] Liu H, Yang W, Wang M, Xiao L, Liu S. Fabrication of lotus-like Au@ $\mathrm{TiO}_{2}$ nanocomposites with enhanced gas sensing properties. Sensors and Actuators B. 2016:236-490. DOI: 10.1016/j.snb.2016.06.039

[2] Rajkumari R, Singh NK. Influence of annealing on the optoelectronic properties of the GLAD synthesized $\mathrm{SiO}_{\mathrm{x}}-\mathrm{ZnO}$ heterostructure nanoclusters. Applied Physics A: Materials Science \& Processing. 2018:124-264. DOI: 10.1007/ s00339-018-1687-1

[3] Frederick RT, Novotny Z, Netzer FP, Herman GS, Dohnalek Z. Growth and stability of titanium dioxide nanoclusters on graphene/Ru (0001). The Journal of Physical Chemistry. B. 2018:122-640. DOI: 10.1021/acs. jpcb.7b05518

[4] Lu Y, Xu YJ, Zhang GB, Ling D, Wang MQ, Zhou Y, et al. Iron oxide nanoclusters for $\mathrm{T} 1$ magnetic resonance imaging of non-human primates. Nature Biomedical Engineering. 2017;1(8): 637-643. DOI: 10.1038/s41551-017-0116-7

[5] Dinh LN, Schildbach MA, Balloch M, McLean IIW. Pulsed laser deposition of $\mathrm{ZnO}$ nanocluster films by $\mathrm{Cu}$-vapor laser. Journal of Applied Physics. 1999:86-1149. DOI: 10.1063/1.370857

[6] Slaughter G, Sunday J. Fabrication of enzymatic glucose hydrogel biosensor based on hydrothermally grown $\mathrm{ZnO}$ nanoclusters. IEEE Sensors Journal. 2014:14-1573. DOI: 10.1109/ JSEN.2014.2298359

[7] Li X, Zhao Z. Co-doped ZnO thin films fabricated by a nanocluster-beam deposition system and the influence of flow rate of helium gas on their properties. Journal of Superconductivity and Novel Magnetism. 2016;29:357. DOI: $10.1007 / \mathrm{s} 10948-015-3230-3$
[8] Wu S, Yuan N, Xu H, Wang X, Schelly ZA. Synthesis and bandgap oscillation of uncapped, $\mathrm{ZnO}$ clusters by electroporation of vesicles. Nanotechnology. 2006:17-4713. DOI: 10.1088/0957-4484/17/18/031

[9] Liu M, Inde R, Nishikawa M, Qiu X, Atarashi D, Sakai E, et al. Enhanced photo activity with nanocluster-grafted titanium dioxide photocatalysts. ACS Nano. 2014:8-7229. DOI: 10.1021//nn5 $10.1021 / \mathrm{nn} 502247 \mathrm{x}$

[10] Yeow SC, Ong WL, Wong ASW, Ho GW. Template-free synthesis and gas sensing properties of well-controlled porous tin oxide nanospheres. Sensors and Actuators B: Chemical. 2009: 143-295. DOI: 10.1016/j.snb.2009.08.050

[11] Lassesson A, Schulze M, Lith JV, Brown SA. Tin oxide nanocluster hydrogen and ammonia sensors. Nanotechnology. 2008:19-015502. DOI: 10.1088/0957-4484/19/01/015502

[12] Leghrib R, Pavelko RG, Felten A, Vasiliev A, Cané C, Gràcia I, et al. Gas sensors based on multiwall carbon nanotubes decorated with tin oxide nanoclusters. Sensors and Actuators B: Chemical. 2010:145-411. DOI: 10.1016/j. snb.2009.12.044

[13] Salavati-Niasari M, Mir N, Davar F. A novel precursor for the synthesis of metallic copper nanocrystals by thermal decomposition approach. Applied Surface Science. 2010:256-4003. DOI: 10.1016/j.apsusc.2010.01.067

[14] Amoli V, Farooqui S, Rai A, Santra C, Rahman S, Sinha A, et al. Indium oxide nanocluster doped $\mathrm{TiO}_{2}$ catalyst for activation of molecular $\mathrm{O}_{2}$. RSC Advances. 2015;5. DOI: 10.1039/ C5RA13104A

[15] Amoli V, Malayil MGS, Banerjee B, Anand M, Maurya A, Farooqui S, et al. 
Faceted titania nanocrystals doped with indium oxide nanoclusters as a superior candidate for sacrificial hydrogen evolution without any noble-metal Co catalyst under solar irradiation. ACS Applied Materials \& Interfaces. 2014;7. DOI: 10.1021/am507293b

[16] Walsh A, Woodley S. Evolutionary structure prediction and electronic properties of indium oxide nanoclusters. Physical Chemistry Chemical Physics. 2010:12-8446. DOI: 10.1039/c0cp00056f

[17] Ayesh A I, Abu Hani A, Mahmoud $\mathrm{S}$, Haik Y. Selective $\mathrm{H}_{2} \mathrm{~S}$ sensor based on $\mathrm{CuO}$ nanoparticles embedded in organic membranes. Sensors and Actuators B: Chemical. 2016:231. DOI: 10.1016/j. snb.2016.03.078

[18] Yin G, Nishikawa M, Nosaka Y, Nagarajan S, Atarashi D, Sakai E, et al. Photocatalytic carbon dioxide reduction by copper oxide nanocluster-grafted niobate nanosheets. ACS Nano. 2015: 9-2111. DOI: 10.1021/nn507429e

[19] Lomnicki S, Wu H, Osborne NS, Pruett J, M, McCarley RL, Poliakoff E, et al. Size-selective synthesis of immobilized copper oxide nanoclusters on silica. Materials Science and Engineering: B. 2010:175-136. DOI: 10.1016/j.mseb.2010.07.016

[20] Tiwari A, Nagaiah TC, Bordoloi A. Electrocatalytic activity of tungsten oxide nanoclusters grafted on mesoporous nitrogen-rich carbon material in the dioxygen reduction reaction. ChemPlusChem. 2015;80. DOI: $10.1002 /$ cplu.201500253

[21] Zhao M, Xing Huang J, Wo Ong C. Room-temperature resistive $\mathrm{H}_{2}$ sensing response of $\mathrm{Pd} / \mathrm{WO}_{3}$ nanocluster-based highly porous film. Nanotechnology. 2012:23-315503. DOI: $10.1088 / 0957-4484 / 23 / 31 / 315503$

[22] Wegner K, Piseri P, Tafreshi H, Milani P. Cluster beam deposition:
A tool for nanoscale science and technology. Journal of Physics D: Applied Physics. 2006;39:439. DOI: 10.1088/0022-3727/39/22/R02

[23] Aluri GS, Motayed A, Davydov AV, Oleshko VP, Bertness KA, Sanford $\mathrm{KA}$, et al. Highly selective GaNnanowire/ $\mathrm{TiO}_{2}$-nanocluster hybrid sensors for detection of benzene and related environment pollutants. Nanotechnology. 2011:22-295503. DOI: $10.1088 / 0957-4484 / 22 / 29 / 295503$

[24] Li X, Zhao Z. Effect of annealing on Co-doped $\mathrm{ZnO}$ thin films prepared by nanocluster-beam deposition. Journal of Superconductivity and Novel Magnetism. 2016;29:1897. DOI: 10.1007/ s10948-016-3395-4

[25] Zhao ZW, Tay BK, Chen JS, Hu J, Sun X, Tan ST. Optical properties of nanocluster-assembled $\mathrm{ZnO}$ thin films by nanocluster-beam deposition. Applied Physics Letters. 2005:87. DOI: 10.1063/1.2149170

[26] Aljawfi R, Alam M, Rahman F, Ahmad S, Shahee A, Kumar S. Impact of annealing on the structural and optical properties of $\mathrm{ZnO}$ nanoparticles and tracing the formation of clusters via DFT calculation. Arabian Journal of Chemistry. 2018. DOI: 10.1016/j. arabjc.2018.04.006

[27] Gao X. Synthesis and optical properties of $\mathrm{ZnO}$ nanocluster porous films deposited by a modified SILAR method. Applied Surface Science. 2004;229:275-281. DOI: 10.1016/ S0169-4332(04)00104-7

[28] Robbie K, Brett M. Method of depositing shadow sculpted thin films. US Patent 5. 1999:866-204

[29] Akgul G, Akgul FA, Unalan HE, Turan R. Photovoltaic performance of gallium-doped $\mathrm{ZnO}$ thin film/ Si nanowires heterojunction diodes. Philosophical Magazine. 2016:96-1093. DOI: 10.1080/14786435.2016.1154207 
[30] Agarwala DC, Chauhan RS, Kumar A, Kabiraj D, Singh F, Khan SA, et al. Synthesis and characterization of $\mathrm{ZnO}$ thin film grown by electron beam evaporation. Journal of Applied Physics. 2006:99-123105. DOI: 10.1063/1.2204333

[31] Dhar JC, Mondal A, Singh NK, Chakrabartty S, Bhattacharyya A, Chattopadhyay KK. Effect of annealing on $\mathrm{SiO}_{\mathrm{x}}-\mathrm{TiO}_{2}$ axial heterostructure nanowires and improved photodetection. Journal of Applied Physics. 2013:114-244310. DOI: 10.1063/1.4858420

[32] Zeng H, Duan G, Li Y, Yang S, Xu $\mathrm{X}$, Cai W. Blue luminescence of $\mathrm{ZnO}$ nanoparticles based on non-equilibrium processes: Defect origins and emission controls. Advanced Functional Materials. 2010:20-561. DOI: 10.1002/ adfm.200901884

[33] Raevskaya AE, Panasiuk YV, Stroyuk OL, Kuchmiy SY, Dzhagan VM, Milekhin AG, et al. Spectral and luminescent properties of $\mathrm{ZnO}-\mathrm{SiO}_{2}$ core-shell nanoparticles with sizeselected $\mathrm{ZnO}$ cores. RSC Advances. 2014;4:63393. DOI: 10.1039/c4ra07959k

[34] Rodnyi A, Khodyuk IP. Optical and luminescence properties of zinc oxide. Optics and Spectroscopy. 2012;111. DOI: 10.1134/S0030400X11120216

[35] Jeon JW, Jeon DW, Sahoo T, Kim M, Baek JH, Hoffman JL, et al. Effect of annealing temperature on optical bandgap of amorphous indium zinc oxide film. Journal of Alloys and Compounds. 2011:509-10062. DOI: 10.1016/j. jallcom.2011.08.033

[36] Wei X, Skomski R, Balasubramanian B, Sun ZJ, Sellmyer D. Magnetism of $\mathrm{TiO}$ and $\mathrm{TiO}_{2}$ clusters. Journal of Applied Physics. 2009: 105-07C517. DOI: 10.1063/1.3074509

[37] Munteanu D, Torrell M, Cunha L, Alves E, Barradas N, Cavaleiro A, et al. The influence of annealing treatments on the properties of $\mathrm{Ag}: \mathrm{TiO}_{2}$ nanocomposite films prepared by magnetron sputtering. Applied Surface Science. 2012:258-4028. DOI: 10.1016/j. apsusc.2011.12.095

[38] Song S, Kim K, Ho Jung K, Sok J, Park K. Properties of resistive switching in $\mathrm{TiO}_{2}$ nanocluster-SiO ${ }_{\mathrm{x}}(\mathrm{X}<2)$ matrix structure. Journal of Semiconductor Technology and Science. 2018:18-108. DOI: 10.5573/JSTS.2018.18.1.108

[39] Khan Abdul F, Mehmood M, Durrani S, L, Ali M, Abd Rahim N. Structural and optoelectronic properties of nanostructured $\mathrm{TiO}_{2}$ thin films with annealing. Materials Science in Semiconductor Processing. 2014:29. DOI: 10.1016/j. mssp.2014.02.009i

[40] Wang B, Qi H, Chai Y, Li M, Guo M, Pan M, et al. Alteration of titanium dioxide material properties by glancing angle deposition plus annealing treatment. Superlattices and Microstructures. 2016:90-87. DOI: 10.1016/j.spmi.2015.12.007

[41] Liu M, Qiu X, Miyauchi M, Hashimoto $\mathrm{K}$. $\mathrm{Cu}$ (II) oxide amorphous nanoclusters grafted Ti3+ self-doped TiO2: An efficient visible light photocatalyst. Chemistry of Materials. 2011:23-10. DOI: 1021/cm203025b

[42] Tadic M, Kralj S, Jagodic M, Hanzel D, Makovec D. Magnetic properties of novel superparamagnetic iron oxide nanoclusters and their peculiarity under annealing treatment. Applied Surface Science. 2014:322-255. DOI: 10.1016/j. apsusc. 2014.09.181

[43] Chong Su K, Azizan SNA, Wah C, Nguyen H, Siong Chiu W, Aspanut $Z$, et al. Structure deformation of indium oxide from nanoparticles into nanostructured polycrystalline films by in situ thermal radiation treatment. Nanoscale Research Letters. 2013:8. DOI: $10.1186 / 1556-276 X-8-428$ 
[44] Flores MM, Castanedoperez R, Torresdelgado G, Marquezmarin $\mathrm{J}$, Zelayaangel O. Influence of the annealing temperature on the properties of undoped indium oxide thin films obtained by the sol-gel method. Thin Solid Films, DOI. 2008:517-681. DOI: 10.1016/j.tsf.2008.07.036

[45] Sudha A, Sharma SL, Maity TK. Effects of annealing temperature on structural and electrical properties of indium oxide thin films prepared by thermal evaporation. Materials Letters. 2015:157. DOI: 10.1016/j.matlet.2015. 05.050

[46] Velusamy S, Vickraman P. Annealing temperature dependent on structural, optical and electrical properties of indium oxide thin films deposited by electron beam evaporation method. Current Applied Physics. 2010;10:880-885. DOI: 10.1016/j. cap.2009.10.014

[47] Priya M, Arunachalam G, Ramamurthi K, Veluswamy P, Hiroya I. Effect of $\mathrm{pH}$ and annealing temperature on the properties of tin oxide nanoparticles prepared by sol-gel method. Journal of Materials Science: Materials in Electronics. 2017:29-658. DOI: 10.1007/s10854-017-7959-2

[48] Shahrokhi M. Tuning the band gap and optical spectra of monolayer pentagraphene under in-plane biaxial strains. Optik. 2017:205-214. DOI: 10.1016/j. ijleo.2017.02.033

[49] Endrino JL, Horwat D, Anders A, Andersson J, Gago R. Impact of annealing on the conductivity of amorphous carbon films incorporating copper and gold nanoparticles deposited by pulsed dual cathodic arc. Plasma Processes and Polymers. 2009:S438-S443. DOI: 10.1002/ ppap. 200931003 



\section{Edited by Mohammed Rahman, Anish Khan, Abdullah Asiri and Inamuddin Inamuddin}

This book "Concepts of Semiconductor Photocatalysis" contains recent research on the preparation, characterization, and potential applications of the semiconductor photocatalyst. This research is promising and has received a lot of interest in the last few decades. The book covers advanced topics on the optical, physical, structural, and electro-catalysis and photo-catalysis applications. Development of new and noble efficient technology is pointing researchers toward the safe, facile, non-toxic, ecofriendly route of synthesis-to-applications, which can be used for manufacture at a large scale. This book presents an overview of the current photocatalyst fundamental theory, substantial applications, and use of the research worldwide. It is an important book for research organizations, government research-centers, academic libraries, and $R \& D$ affianced in recent research and development of doped or undoped low dimensional semiconductor photocatalysts. 